University of Rhode Island

DigitalCommons@URI

Open Access Dissertations

2001

\title{
A MECHANISTIC STUDY OF FLOW AND COMPRESSION BEHAVIOR OF PHARMACEUTICAL POWDERS
}

Yogita Desai

University of Rhode Island

Follow this and additional works at: https://digitalcommons.uri.edu/oa_diss

\section{Recommended Citation}

Desai, Yogita, "A MECHANISTIC STUDY OF FLOW AND COMPRESSION BEHAVIOR OF PHARMACEUTICAL POWDERS" (2001). Open Access Dissertations. Paper 180.

https://digitalcommons.uri.edu/oa_diss/180

This Dissertation is brought to you for free and open access by DigitalCommons@URI. It has been accepted for inclusion in Open Access Dissertations by an authorized administrator of DigitalCommons@URI. For more information, please contact digitalcommons-group@uri.edu. 


\section{DOCTOR OF PHILOSOPHY DISSERTATION \\ OF \\ YOGITA DESAI}

\section{APPROVED:}

Dissertation Committee:

Major Professor
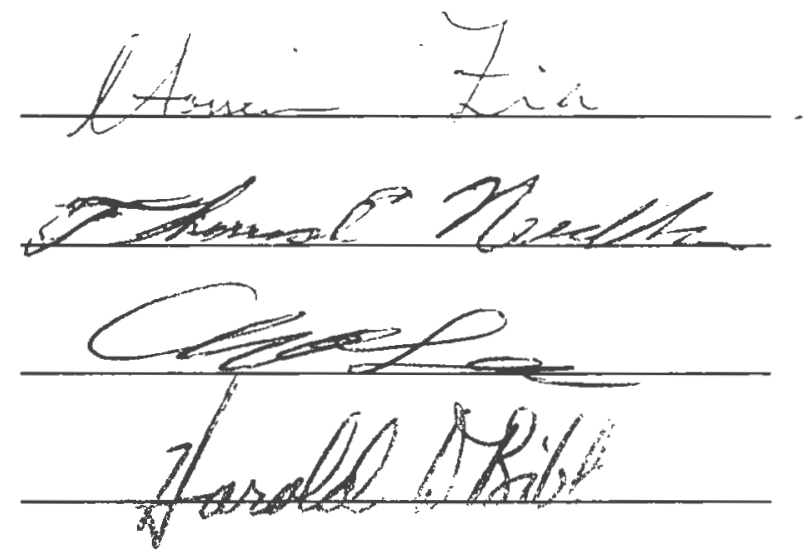

DEAN OF THE GRADUATE SCHOOL

UNIVERSITY OF RHODE ISLAND

2001 
A MECHANISTIC STUDY OF FLOW AND COMPRESSION BEHAVIOR OF PHARMACEUTICAL POWDERS

BY

YOGITA DESAI

A DISSERTATION SUBMITTED IN PARTIAL FULFILLMENT OF THE REQUIREMENTS FOR THE DEGREE OF

DOCTOR OF PHILOSOPHY

IN

PHARMACEUTICAL SCIENCES

UNIVERSITY OF RHODE ISLAND

2001 


\begin{abstract}
Majority of the drug substances are administered to patients in the form of oral solid dosage forms. The drug substance is mixed with excipients and the resulting powder blend is compressed into tablets. For a pharmaceutical powder to be compressed into uniform solid dosage forms, it is essential that the powder blend has good flow and compaction properties. The flow and compression properties of a pharmaceutical blend depend on the physicochemical properties of the individual components and their relative proportions in the mixture. Poor compressibility along with the poor flowable nature of most of the pharmaceutical mixtures poses tremendous challenges during the scale up and production stages. Vast majority of the tableting research was performed using single components though a typical tablet is a multi-component system. In this investigation, an attempt was made to study the flow and compression behaviors of multi-component mixtures containing several of the most commonly used pharmaceutical excipients. The effect of triboelectric charging during powder processing was also evaluated.

The objectives of this study include: i) to investigate the relationship between the individual components and their mixed systems; ii) to analyze and predict the flow behavior of a mixed system from individual components using an experimental design; iii) to determine the optimum conditions for a mixture to exhibit better flow behavior; iv) to investigate the compression behavior of statistically designed multi-component mixtures using an instrumented tablet press; v) to determine the effect of mixing time, mixer type and batch size on triboelectrification of powders in a high shear mixer; and vi) to compare the antistatic effect of different lubricants/glidants on electronegative and electropositive materials.
\end{abstract}


Lactose Anhydrous $(97 \% \mathrm{w} / \mathrm{w})$ blends were prepared with $3 \% \mathrm{w} / \mathrm{w}$ lubricant/glidant(s) in a planetary mixer as per simplex experimental design. The lubricants evaluated were: magnesium stearate, NF, stearic acid and colloidal silicon dioxide, NF (Cab-O-Sil M5). The relative amounts of lubricants/glidants were varied from 0 to $3 \%$ as per simplex design. One set of powder blends were prepared with a constant mix time of 3 minutes. Another set of powder blends were prepared with varying mix time until a relatively constant value for bulk density was achieved for specific blend. A total of ten powder blends of 500 grams each were prepared for each experiment. Response surface methodology was used to correlate the variation in lubricant/glidant(s) with the flow behavior. The powder blends and individual components were evaluated for bulk density, tapped density, aerated bulk density, packed bulk density, compressibility index, angle of repose, angle of spatula, angle of fall, angle of difference, cohesiveness, dispersibility, moisture content and particle size distribution. The data was analyzed using StatGraphics software and the special cubic model was fitted to generate mathematical equations. Contour plots were obtained to interpret the flow behavior of powder blends as a function of mixture composition.

The compression behavior of experimentally designed multi-component mixtures using an instrumented tablet press was studied. The mixtures comprised of anhydrous lactose, NF, microcrystalline cellulose, NF (Avicel ${ }^{\circledR}$ PH101) and pregelatinized starch, NF (Starch 1500) with individual quantities varying from 0 to $99 \% \mathrm{w} / \mathrm{w}$ based on a simplex design. Magnesium stearate, NF was added as lubricant at $1 \% \mathrm{w} / \mathrm{w}$ level. The batch size was 900 grams (equivalent to 3000 tablets). Ten experimental mixtures were prepared in a Collette Gral 10 High Shear Mixer with 3 minutes of pre-blending and 1 minute of lubricant mixing. The powder mixtures were 
evaluated for bulk and tapped densities, particle size distribution and moisture content. The powder blends were compressed using a 10-station instrumented Piccola rotary tablet press (Model: 026 B10) equipped with a compression research system (PC-30, SMI Inc.). Tablets were prepared with 12/32" standard concave tooling with compression forces of $1000 \mathrm{lbs}, 2000 \mathrm{lbs}, 3000 \mathrm{lbs}, 4000 \mathrm{lbs}, 5000 \mathrm{lbs}, 6000 \mathrm{lbs}$ and maximum achievable force. The compression force-time profiles were recorded to measure the compression force and ejection force for each compression cycle. The tablets were evaluated for hardness, weight, thickness, friability and disintegration time. The true densities of tablets and powder blends were measured using a helium pycnometer (Ultrapycnometer 1000). The compression force-time pulses for all the mixtures at each compression force were compared to investigate the effect of mixture composition on the compression behavior of powder blends. Events such as rise time, fall time, dwell time, contact time, areas and pulse widths that characterize the nature of each compression pulse were evaluated using a response surface method (StatgraphicsPlus). Tablet surface area and volume was calculated using Natoli computer program. Contour plots were generated to study the effect of formulation composition on bulk density, tablet hardness, dwell time, total area of compression force-time curve, ejection force, tablet surface area, and porosity. Heckel relationships were plotted using the compressibility model.

The effect of high shear mixing on electrical properties of pharmaceutical materials such as pregelatinized starch (Starch 1500), microcrystalline cellulose (Avicel ${ }^{\circledR}$ PH101) and cimetidine formulation (cimetidine:lactose anhydrous:Avicel ${ }^{\circledR}$ PH101:Starch 1500: lubricant $=69: 10: 10: 10: 1)$ was determined as a function of mixing time. Different lubricants/glidants such as magnesium stearate, stearic acid, 
colloidal silicon dioxide (Cab-O-Sil M5) and sodium stearyl fumarate (Pruv $\left.{ }^{\circledR}\right)$ were evaluated for their antistatic effect. The selected material(s) were screened through a 30-mesh hand screen and were mixed in a Collette Gral 10 high shear mixer for 10 minutes at a mixer arm speed of $660 \mathrm{rpm}$ and a chopper speed of $3000 \mathrm{rpm}$. Lubricant/glidant at $1 \% \mathrm{w} / \mathrm{w}$ level was added to the pre-blend and the mixing was continued for an additional 3 minutes. The electrostatic charges on powder blends were measured using the Faraday Cup connected to NanoCoulomb Electrometer after $0,5,10,11,12$ and 13 minutes of mixing. Mixer type effect was evaluated by mixing powders in Collette Gral 10 high shear mixer and Kitchen Aid Planetary Mixer and determining the electrostatic measurements. Batch sizes of $0.5 \mathrm{~kg}$ and $2.5 \mathrm{~kg}$ were evaluated to determine the batch size effect on triboelectrification during high shear mixing. The last contact surface for all electrostatic measurements was kept constant with teflon coated stainless steel surface.

From different flow parameters evaluated for lactose anhydrous blends, it can be summarized that the relationship for powder properties between the mixture and its components is non-linear. Significant differences were observed in the flow behavior of powder blends obtained with constant mixing time and those obtained with variable mixing times. Among the three variable components as per the simplex design, CabO-Sil M5 had a significant effect on the time required to achieve the constant bulk density for a specific powder blend. It was demonstrated that using the special cubic simplex design, the flow behavior of lactose blend can be optimized. For constant mix time study, the model predicted that Lactose Anhydrous would show optimum flow behavior with formulation composition of $0.25 \% \mathrm{w} / \mathrm{w}$ Magnesium Stearate, $1.48 \% \mathrm{w} / \mathrm{w}$ Stearic Acid and $1.27 \%$ w/w Cab-O-Sil M5. Thus from the response surface contour 
plots and the mathematical model equations, one can determine the composition of the flow enhancers required, mix time to achieve constant bulk density so that the final blend will display optimum flow behavior.

The statistically designed powder blends comprising Lactose Anhydrous, Avicel $^{\circledR}$ PH101, Starch 1500 and Magnesium Stearate were compressed using an instrumented tablet press. The compression force-time curves and ejection force-time curves were evaluated and critical compression parameters such as ejection force, dwell time, tablet surface area, porosity and Heckel plots were determined. The compression parameters generated in this study, provide valuable insights into how multi-component mixtures behave under pressure. The key findings can be summarized as follows: The weight variation, tablet thickness, tablet surface area and volume of tablets increased with an increase in the concentration of Starch 1500 in the mixture. As the level of Avicel ${ }^{\circledR}$ PH101 in the blend increases, so does the hardness profile for tablets. Maximum disintegration times were observed for tablets prepared from blend containing Avicel ${ }^{\circledR}$ PH101 and Lactose Anhydrous at $49.5 \%$ level. Maximum dwell time of $107 \mathrm{msec}$ was observed for 99\% Lactose Anhydrous at maximum achievable force $(\sim 8500 \mathrm{lbs})$ and a minimum dwell time of $51 \mathrm{msec}$ was observed for the same blend at $1000 \mathrm{lbs}$ of applied force. The compressibility of blends increased with an increase in the amount of Avicel ${ }^{\circledR}$ PH101 in mixture. The amount of ejection force required for tablets increased with an increase in the concentration of Anhydrous Lactose in the blend. Tablets prepared from the blend containing 49.5\% Anhydrous Lactose and 49.5\% Starch 1500 displayed maximum amount of porosity. The presence of Starch 1500 has a significant effect on tablets with high porosity values. Heckel plots were generated to elucidate the densification 
and deformation mechanism of various mixtures. Based on the shapes of the curves, the dominant component of the mixture seems to dictate the deformation mechanism. In mixtures containing the components in equal amounts, the deformation mechanism seems to be complex. The results provide critical information on compression behavior of multi-component mixtures for comparative purposes as there are hardly any published reports in this area.

When evaluated individually, cimetidine displayed electropositive charge whereas all other excipients displayed electronegative charges. Cab-O-Sil M5 was found to be the most electronegative whereas stearic acid was found to be the least electronegative among the excipients examined. Based on the results obtained in this study, when Starch 1500 was blended with 1\% lubricant/glidant in a Collette Gral 10 High Shear Mixer, the lubricants/glidants can be arranged as follows in the decreasing order of their ability to reduce the static charges produced during the blending process: magnesium stearate $>$ Pruv $^{\circledR}>$ stearic acid $>$ Cab-O-Sil M5. For Avicel ${ }^{\circledR}$ PH101 blends, the antistatic effect of the same agents can be arranged in the decreasing order as: magnesium stearate $>$ stearic acid $>$ Pruv $^{\circledR}>$ Cab-O-Sil M5. As the mixing time with lubricants/glidants increased from 1 minute to 3 minutes, the antistatic effect seems to reduce. The antistatic effect of lubricants/glidants was dependent on the electrical charge behavior of the materials studied. The mixer design and type played an important role in determining the electrostatic charges of powder blends in pharmaceutical processing. Powders blended in Collette Gral 10 High Shear Mixer produced more electrostatic charges as compared to those blended in Kitchen Aid Planetary Mixer. The mixer loading also played an important role in determining the electrostatic charges of powder blends in powder processing. The triboelectrification 
of the blend in a high shear mixer decreased with an increase in the batch size from 0.5 $\mathrm{kg}$ to $2.5 \mathrm{~kg}$. Thus by measuring static charges present on drugs/excipients during developmental stage, formulation scientist can utilize triboelectrification process to obtain powder blends that have low segregation problems.

In summary, the results indicated that by varying the mixing time and/or relative proportion and type of lubricants/flow enhancers, it is possible to achieve powder blends with markedly improved flow properties. The current findings on compression behavior of multi-component mixtures will help formulation scientists to design and develop a robust tablet dosage form that meets the desired quality attributes and is free of processing problems during scale up and production. Selection of formulation components based on their electrical behavior will enhance the development of dosage forms that have good flow and compression behavior.

With the advent of so many new polymeric materials, further studies will definitely shed more light on the complex process of compaction, since there are only a few published reports concerning multi-component mixtures are available so far. 


\section{ACKNOWLEDGEMENTS}

My heartfelt thanks to Dr. Hossein Zia, my thesis advisor, for his unerring guidance and personal and professional support to help me fulfill my goals. I am especially grateful to Dr. Thomas Needham for his constant support and encouragement. I remain indebted to my entire thesis committee including, Drs. Campbell, Lausier, Lee, Suryanarayan and Zhang for their patience and input. I am grateful to Deans Luzzi and Telang for giving me confidence to pursue my aspirations.

I would like to thank Dr. Salah U. Ahmed and Ezzeldin Hamza of Barr Laboratories, Inc. for permitting me to use the laboratory facilities at Barr. I will always cherish the support and friendship, which afforded to me at Barr by Gandha, Yan Lou, Venkatesh, Serge, Kanchan, Jaidev and numerous other peoples.

From the bottom of my heart, I would like to express my love and my gratitude to my parents, Shashikant and Yashoda, whose work ethic has tinged every nuance of my academic and professional life. Their innumerable sacrifices and unconditional understanding will always remain my source of strength.

To my angels, my husband Polireddy, and my little Priyanka, a.k.a. Nunu. Poli, you are my best friend, my truest confidant, and my harshest critic. Your honesty, your intelligence, and your compassion influence everything that I do and achieve. Thank you for your many sacrifices and helping me in so many ways. I will never be able to thank you enough and yet thank you; the two of you truly complete me.

To my younger brother, Kedar, for his love and friendship. To Tai Aaji, who could not be here to see me accomplish this milestone in my life, but who smiles down at me with a level of love and pride that only she has earned in my life. To Gangu 
Aaji, who has spent a lifetime looking after all of us. To my beloved Maushis (Aunties), I hope that in some way my work stands for the hard work and sacrifices in bringing me up.

I want to thank all the people who have afforded me so many reasons to be thankful for in my life. I thank God for blessing me with the love and support of so many special people. 
To my family 


\section{PREFACE}

This dissertation was prepared according to the University of Rhode Island "Guidelines for the Format of Theses and Dissertations" standards for Manuscript format, approved April 1, 2001. For this dissertation, three articles are combined to satisfy the requirements of the Department of Applied Pharmaceutical Sciences, College of Pharmacy, University of Rhode Island.

\section{Manuscript I Investigation of the Predictability of Flow Characteristics of Powder Mixtures}

This manuscript summarizes the trends and prediction of the flow behavior of a mixed powder system in relation to that of the individual components. These results have been presented at the 10th Annual Meeting of American Association of Pharmaceutical Scientists (AAPS) in Seattle, WA, 1996 and at the Eastern Regional Meeting of AAPS in New Brunswick, NJ, June 1997. This paper will be submitted for publication in the 'Journal of Pharmaceutical Sciences'.

\section{Manuscript II Analysis of Compression Behavior of Multi-Component Mixtures using an Instrumented Tablet Press}

This manuscript comprises of the investigation of the compression behavior of statistically designed multi-component mixtures using an instrumented tablet press. The findings of this study were presented at 12th Annual Meeting of American Association of Pharmaceutical Scientists (AAPS) held at San Francisco, CA in 1998. These findings will be submitted in two parts for publication in the 'International Journal of Pharmaceutics'. 


\section{Manuscript III Effect of Formulation Components and Manufacturing Process on the Electrostatic Behavior of Pharmaceutical Powders}

This manuscript describes a study performed to elucidate the significance of static charges generated on pharmaceutical powders during high shear mixing. These results have been presented at 12th Annual Meeting of American Association of Pharmaceutical Scientists (AAPS) held at San Francisco, CA in 1998. These results will be submitted for publication in 'Drug Development and Industrial Pharmacy'. 


\section{TABLE OF CONTENTS}

ABSTRACT

ACKNOWLEDGEMENTS viii

PREFACE $\quad$ xi

TABLE OF CONTENTS Xiii

LIST OF TABLES $\quad$ XV

LIST OF FIGURES - xix

\section{MANUSCRIPT I}

INVESTIGATION OF THE PREDICTABILITY OF FLOW

CHARACTERISTICS OF POWDER MIXTURES

Abstract ....................................................................... 2

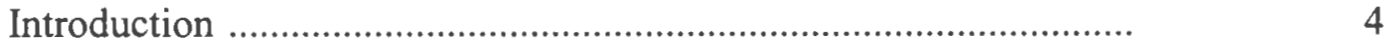

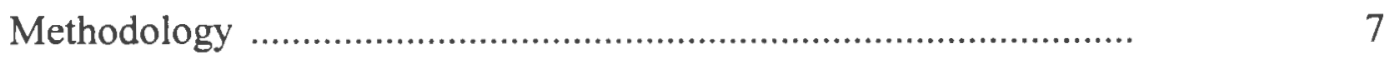

Results and Discussion ...................................................... 13

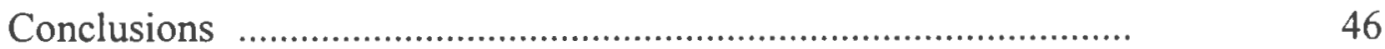

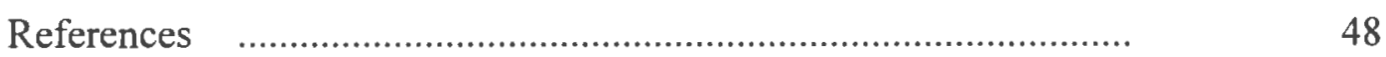

MANUSCRIPT II

ANALYSIS OF COMPRESSION BEHAVIOR OF MULTI-COMPONENT MIXTURES USING AN INSTRUMENTED TABLET PRESS

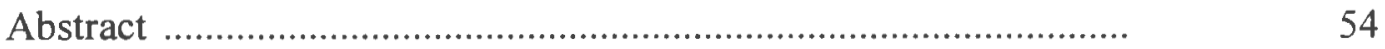

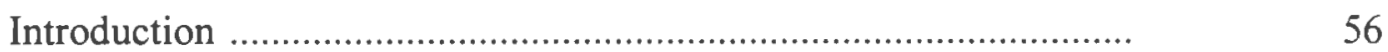

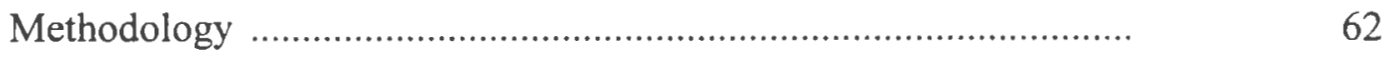


Results and Discussion

Conclusions

References

\section{MANUSCRIPT III}

EFFECT OF FORMULATION COMPONENTS AND MANUFACTURING

PROCESS ON THE ELECTROSTATIC BEHAVIOR OF

PHARMACEUTICAL POWDERS

Abstract

Introduction

Methodology 177

Results and Discussion

Conclusions

References 


\section{LIST OF TABLES}

\section{MANUSCRIPT I}

Table 1. Simplex Design for Powder Mixtures............................... 8

Table 2. Physical Properties of Individual Components............. 14

Table 3. Physical Properties of Lactose Blends with

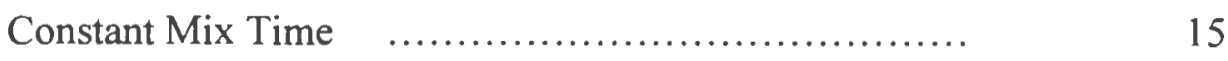

Table 4. Physical Properties of Lactose Blends with

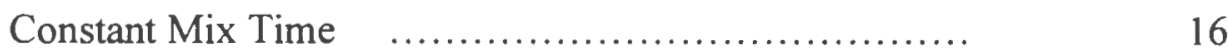

Table 5. Physical Properties of Lactose Blends with

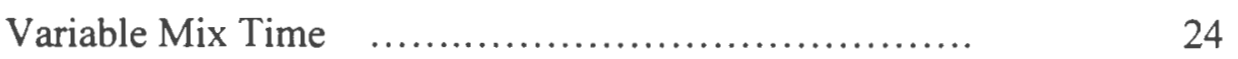

Table 6. Physical Properties of Lactose Blends with

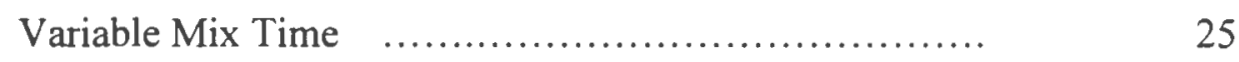

Table 7. Regression Coefficients of Special Cubic Models

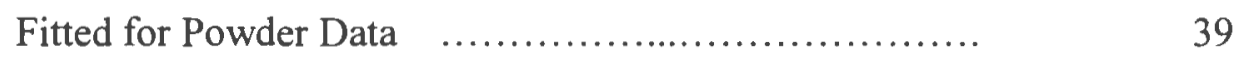

Table 8. Regression Coefficients of Special Cubic .................. 40

Models Fitted for Powder Data

Table 9. Use of Check Points for Testing Lack of

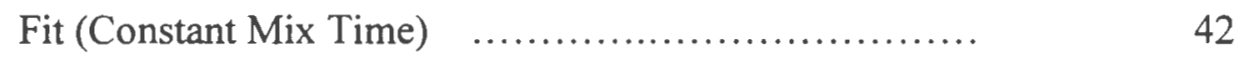

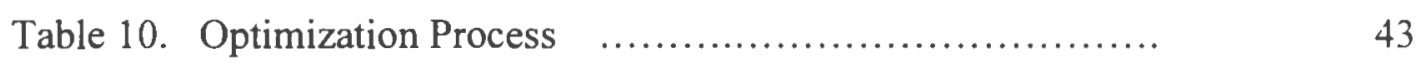

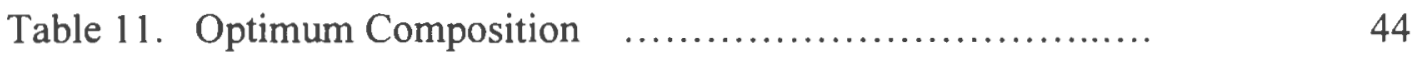




\section{MANUSCRIPT II}

Table 1. Simplex Design for Blends used for Compaction

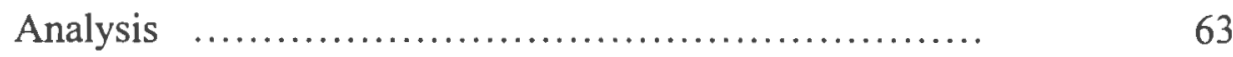

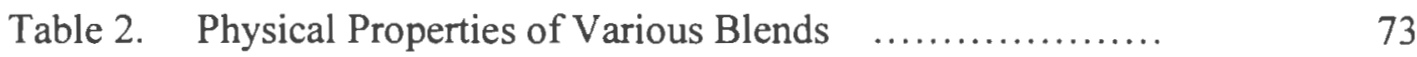

Table 3. Particle Size Distributions of Various Powder

Blends based on Sieve Analysis $\quad \ldots \ldots \ldots \ldots \ldots \ldots \ldots \ldots . \ldots \ldots$

Table 4. Physical Testing of Tablets Prepared from Blend \#1 ...... 82

Table 5. Physical Testing of Tablets Prepared from Blend \#2 ...... 83

Table 6. Physical Testing of Tablets Prepared from Blend \#3 ....... 84

Table 7. Physical Testing of Tablets Prepared from Blend \#4 ...... 85

Table 8. Physical Testing of Tablets Prepared from Blend \#5 ...... 86

Table 9. Physical Testing of Tablets Prepared from Blend \#6 ...... 87

Table 10. Physical Testing of Tablets Prepared from Blend \#7 ...... 88

Table 11. Physical Testing of Tablets Prepared from Blend \#8 ...... 89

Table 12. Physical Testing of Tablets Prepared from Blend \#9 ...... 90

Table 13. Physical Testing of Tablets Prepared from Blend \#10 ..... 91

Table 14. Summary of Upper Punch Compression and Lower

Punch Ejection Data from Force-Time Curves at 1000 lbs.

Table 15. Summary of Upper Punch Compression and Lower

Punch Ejection Data from Force-Time Curves at 2000 lbs.

Table 16. Summary of Upper Punch Compression and Lower

Punch Ejection Data from Force-Time Curves at 3000 lbs. 
Table 17. Summary of Upper Punch Compression and Lower

Punch Ejection Data from Force-Time Curves at $4000 \mathrm{lbs}$.

Table 18. Summary of Upper Punch Compression and Lower

Punch Ejection Data from Force-Time Curves at $5000 \mathrm{lbs}$.

Table 19. Summary of Upper Punch Compression and Lower

Punch Ejection Data from Force-Time Curves at $6000 \mathrm{lbs}$.

Table 20. Summary of Upper Punch Compression and Lower Punch Ejection Data from Force-Time Curves at Maximum Achievable Force

Table 21. Compression Parameters for Multi-Component

Mixtures

\section{MANUSCRIPT III}

Table 1. Electrical Behavior of Selected Pharmaceutical

Excipients

Table 2. Electrostatic Properties of Individual Pharmaceutical Materials

Table 3. Effect of Lubricant/Glidant on Triboelectrification of Starch 1500

Table 4. Effect of Lubricant/Glidant on Triboelectrification of Avicel ${ }^{\circledR}$ PH101

Table 5. Effect of Lubricant/Glidant on Triboelectrification of Cimetidine Formulation 
Table 6. Effect of Mixer Type on Triboelectrification of

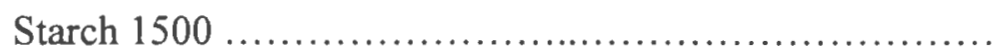

Table 7. Effect of Batch Size on Triboelectrification of

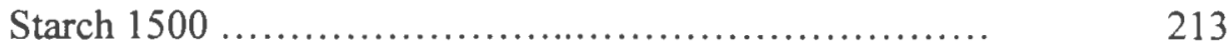




\section{LIST OF FIGURES}

\section{MANUSCRIPT I}

Figure 1. Contour Plots for Angle of Repose:

(a) Constant Mix Time (b) Variable Mix Time

Figure 2. Contour Plots for Angle of Fall:

(a) Constant Mix Time (b) Variable Mix Time

Figure 3. Contour Plots for Angle of Difference:

(a) Constant Mix Time (b) Variable Mix Time

Figure 4. Contour Plots for Angle of Spatula:

(a) Constant Mix Time (b) Variable Mix Time

Figure 5. Contour Plots for Aerated Bulk Density:

(a) Constant Mix Time (b) Variable Mix Time

Figure 6. Contour Plots for Packed Bulk Density:

(a) Constant Mix Time (b) Variable Mix Time

Figure 7. Contour Plots for Compressibility:

(a) Constant Mix Time (b) Variable Mix Time

Figure 8. Contour Plots for Cohesion:

(a) Constant Mix Time (b) Variable Mix Time

Figure 9. Contour Plots for Dispersibility:

(a) Constant Mix Time (b) Variable Mix Time

Figure 10. Contour Plots for Moisture Content:

(a) Constant Mix Time (b) Variable Mix Time 
Figure 11. Contour Plots for Mean Particle Size:

(a) Constant Mix Time (b) Variable Mix Time

Figure 12. Contour Plot for Mixing Time to obtain

Maximum Bulk Density

\section{MANUSCRIPT II}

Figure 1. Different Phases of the Compression Cycle................

Figure 2. Process Flow Chart for Preparation of Powder Blends......

Figure 3. Pulse Analysis of the Force-Time Curve ...................

Figure 4. Comparison of Bulk Densities of Powder Blends........... 74

Figure 5. Consolidation of Powder Blends as a Function of Taps....

Figure 6. Comparison of Compressibility Indices for Powder Blends

Figure 7. Geometric Mean Particle Sizes based on Sieve Analysis

for Powder Blends ......................................

Figure 8. Effect of Compression Force on Tablet Hardness ...........

Figure 9. Effect of Formulation Composition on Tablet Hardness at $4000 \mathrm{lbs}$ of Compression Force .........................

Figure 10. Effect of Compression Force on Tablet Thickness ........ 97

Figure 11. Effect of Compression Force on Tablet Friability .......... 98

Figure 12. Effect of Compression Force on Tablet Disintegration ....

Figure 13. Typical Pulse Analysis of the Compaction Force-Time 
Figure 14. Typical Pulse Analysis of the Ejection Force-Time

Curve for Blend \#1 at $4000 \mathrm{lbs} . \ldots \ldots \ldots \ldots \ldots \ldots \ldots \ldots$

Figure 15. Typical Pulse Analysis of the Compaction Force-Time

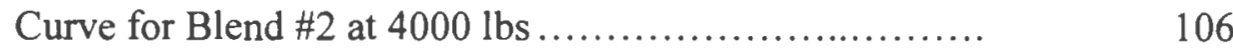

Figure 16. Typical Pulse Analysis of the Ejection Force-Time

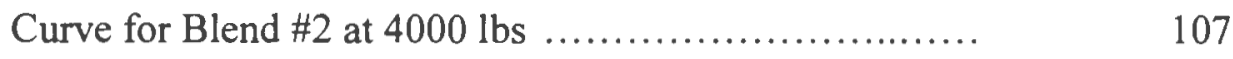

Figure 17. Typical Pulse Analysis of the Compaction Force-Time

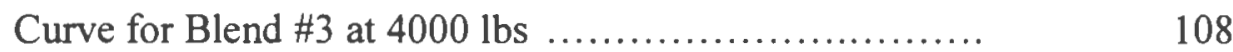

Figure 18. Typical Pulse Analysis of the Ejection Force-Time

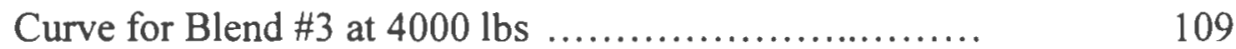

Figure 19. Typical Pulse Analysis of the Compaction Force-Time

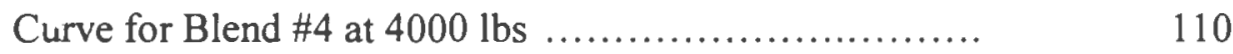

Figure 20. Typical Pulse Analysis of the Ejection Force-Time

Curve for Blend \#4 at $4000 \mathrm{lbs} \ldots \ldots \ldots \ldots \ldots \ldots \ldots \ldots \ldots \ldots \ldots \ldots . \ldots \ldots$

Figure 21. Typical Pulse Analysis of the Compaction Force-Time

Curve for Blend \#5 at $4000 \mathrm{lbs}$.......................... 112

Figure 22. Typical Pulse Analysis of the Ejection Force-Time

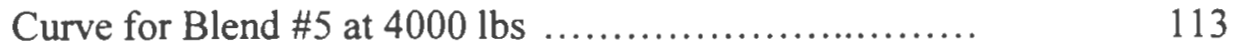

Figure 23. Typical Pulse Analysis of the Compaction Force-Time

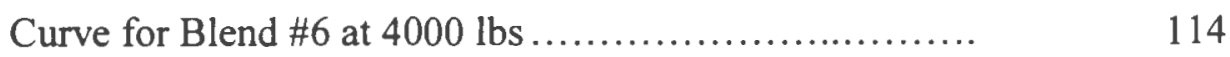

Figure 24. Typical Pulse Analysis of the Ejection Force-Time

Curve for Blend \#6 at $4000 \mathrm{lbs}$

Figure 25. Typical Pulse Analysis of the Compaction Force-Time

Curve for Blend \#7 at $4000 \mathrm{lbs}$ 
Figure 26. Typical Pulse Analysis of the Ejection Force-Time

Curve for Blend \#7 at $4000 \mathrm{lbs}$

Figure 27. Typical Pulse Analysis of the Compaction Force-Time

Curve for Blend \#8 at $4000 \mathrm{lbs}$

Figure 28. Typical Pulse Analysis of the Ejection Force-Time

Curve for Blend $\# \mathbf{8}$ at $4000 \mathrm{lbs}$

Figure 29. Typical Pulse Analysis of the Compaction Force-Time

Curve for Blend \#9 at $4000 \mathrm{lbs}$

Figure 30. Typical Pulse Analysis of the Ejection Force-Time

Curve for Blend \#9 at $4000 \mathrm{lbs}$

Figure 31. Typical Pulse Analysis of the Compaction Force-Time

Curve for Blend $\# 10$ at $4000 \mathrm{lbs}$

Figure 32. Typical Pulse Analysis of the Ejection Force-Time

Curve for Blend $\# 10$ at $4000 \mathrm{lbs}$

Figure 33. Effect of Compression Force on Dwell Time

Figure 34. Effect of Formulation Composition on Dwell

Time at $4000 \mathrm{lbs}$ of Compression Force

Figure 35. Effect of Compression Force on Total Area of

Compression Pulse

Figure 36. Effect of Compression Force on Total Area of

Ejection Pulse

Figure 37. Effect of Compression Force on Ejection Force

Figure 38. Effect of Formulation Composition on Ejection

Force at $4000 \mathrm{lbs}$ of Compression Force. 
Figure 39. Effect of Compression Force on Tablet Surface Area ......

Figure 40. Effect of Formulation Composition on Tablet Surface

Area at $4000 \mathrm{lbs}$ of Compression Force.

Figure 41. Effect of Compression Force on Tablet Volume ...........

Figure 42. Effect of Compression Force on Tablet Porosity

Figure 43. Effect of Formulation Composition on Tablet

Porosity at $4000 \mathrm{lbs}$ of Compression Force.

Figure 44. Different Types of Compression Behavior Distinguished

By the Heckel Equation

Figure 45. Heckel Plots for Statistically Designed Mixtures

\section{MANUSCRIPT III}

Figure 1. Experimental Set-Up for Measurement of Electrostatic

Charges on Pharmaceutical Powders

Figure 2. Effect of Magnesium Stearate on Triboelectrification of

Starch 1500 in Collette Gral 10 High Shear Mixer.

Figure 3. Effect of Pruv on Triboelectrification of Starch 1500 in

Collette Gral 10 High Shear Mixer

Figure 4. Effect of Stearic Acid on Triboelectrification of

Starch 1500 in Collette Gral 10 High Shear Mixer

Figure 5. Effect of Cab-O-Sil M5 on Triboelectrification of

Starch 1500 in Collette Gral 10 High Shear Mixer

Figure 6. Effect of Magnesium Stearate on Triboelectrification of

Avicel $^{\circledR}$ PH101 in Collette Gral 10 High Shear Mixer......... 
Figure 7. Effect of Pruv on Triboelectrification of Avicel ${ }^{\circledR} \mathrm{PH} 101$ in Collette Gral 10 High Shear Mixer

Figure 8. Effect of Stearic Acid on Triboelectrification of Avicel ${ }^{\circledR}$ PH101 in Collette Gral 10 High Shear Mixer.........

Figure 9 Effect of Cab-O-Sil M5 on Triboelectrification of Avicel ${ }^{\circledR}$ PH101 in Collette Gral 10 High Shear Mixer.........

Figure 10. Effect of Magnesium Stearate on Triboelectrification of Cimetidine Formulation in Collette Gral 10 High Shear Mixer

Figure 11. Effect of Cab-O-Sil M5 on Triboelectrification of Cimetidine Formulation in Collette Gral 10 High Shear Mixer

Figure 12. Effect of Mixer Type on Triboelectrification of Starch 1500

Figure 13. Effect of Batch Size on Triboelectrification of Starch 1500 in Collette Gral 10 High Shear Mixer 
MANUSCRIPT I

INVESTIGATION OF THE PREDICTABILITY OF FLOW CHARACTERISTICS OF POWDER MIXTURES 


\begin{abstract}
The flow properties of a pharmaceutical powder blend depend on the physicochemical properties of the individual components and their relative proportions in the mixture. The objective of this study is to elucidate the trends and predict the flow behavior of a mixed system in relation to the individual components. Another objective of the study is to determine the effect of mixing time on flow properties of the blends. Lactose Anhydrous $(97 \% \mathrm{w} / \mathrm{w})$ was mixed with $3 \% \mathrm{w} / \mathrm{w}$ lubricant(s) in a planetary mixer. The lubricants evaluated were: magnesium stearate, stearic acid and Cab-O-Sil M5. The relative amounts of lubricants were varied according to a special cubic simplex design with seven combinations. Two sets of experiments were conducted. One set of powder blends was prepared with a constant mix time of 3 minutes. Another set of powder blends was prepared with varying mix time until a relatively constant value for bulk density was achieved for that particular blend. An additional three experiments were conducted to validate the model. Response surface methodology was used to correlate the variation in lubricants with the flow behavior. The powder blends and individual components were evaluated for bulk density, tapped density, aerated bulk density, packed bulk density, compressibility index, angle of repose, angle of spatula, angle of fall, angle of difference, cohesiveness, dispersibility, moisture content and particle size distribution. All the powder characteristics were measured in triplicates. The data was analyzed using Statgraphics ${ }^{\circledR}$ plus software. The special cubic model was fitted to generate mathematical equations. Contour plots were obtained to interpret the flow behavior of powder blends. The flow behavior of mixed systems displayed a non-linear relationship when compared with the individual components. Mixing time
\end{abstract}


had significant effect on the flow properties of the blends that were evaluated. Among the three lubricants/flow enhancers, Cab-O-Sil M5 had the most significant effect on the mixing time required to obtain constant bulk density. Based on the statistical model, lactose anhydrous showed optimum flow behavior with $0.25 \% \mathrm{w} / \mathrm{w}$ magnesium stearate, $1.48 \% \mathrm{w} / \mathrm{w}$ stearic acid and $1.27 \% \mathrm{w} / \mathrm{w}$ Cab-O-Sil M5. The results indicated that by varying the mixing time and/or relative proportion and type of lubricants/flow enhancers, it is possible to achieve powder blends with improved flow properties.

Keywords: powder; flow; mixing time; mixtures; lubricant; simplex design; response surface; optimization; lactose anhydrous; magnesium stearate; stearic acid; silicon dioxide; Carr's indices. 


\section{INTRODUCTION}

The design and development of a successful pharmaceutical dosage form requires complete understanding of the fundamental principles involved in product development (1-3). For a pharmaceutical powder to be compressed or encapsulated into uniform solid dosage forms, it is essential that the powder blend have good flow properties. Poor flow behavior of a powder is related to the high cohesive energies associated with fine particles and causes problems in the manufacturing of a quality product $(4,5)$. Cohesive stress, which is the cohesive force per unit surface area, is smaller for the larger particles. This is the reason why fine particles are more cohesive, and increasing particle size generally improves flow. Enlargement of particle size is often done by wet granulation or slugging. The powder flow may also be improved by altering the particle shape $(6,7)$.

There are many factors which influence the behavior of powders and these include physical, mechanical and environmental factors (8). Surface energy changes and elastic deformation properties are two opposing forces that influence the particle true areas of contact. Electrostatic forces, particle size, shape and size distributions affect the flow. Environmental factors such as humidity, adsorbed impurities (air, water etc.), consolidation load and time, direction and rate of shear, and storagecontainer properties also influence the powder flow. The identification, quantification and control of these parameters is of importance during the manufacturing where the production of a uniform product is essential.

There are many published methods to determine powder flow, however due to many variables associated with powder flow, there is no universally acceptable method 
developed (9-16). Yet, well-defined experiments are essential to generate reproducible information so that accurate predictions can be made. Carr (9-11) defined a number of flow parameters, which are calculated according to a weighting system after their measurement. The flowability of a powder is evaluated using angle of repose, angle of spatula, compressibility and cohesion. The overall flowability, angle of fall, dispersibility and angle of difference, determine the floodability of a powder. Carr (911) has also provided a detailed procedure whereby indices are deduced for each floodability parameter indicative of the tendency of a powder to exhibit floodable flow.

Development of a dosage form is essentially an optimization process. For a formulator with scarce resources and time constraints, statistical experimental designs offer excellent means to obtain the best compromise within the existing constraints $(17,18)$. Thus optimization techniques have become essential tools for the formulator to develop a robust dosage form in short period of time and with fewer resources. A good design should (i) generate a satisfactory distribution of information throughout the experimental region, (ii) ensure that the fitted model predicts a value, at all points in the experimental region that is as close as possible to the true value of the response, (iii) give good detectability of model lack of fit, and (iv) provide an internal estimate of the error variance. In the current investigation, simplex design in combination with response surface methodology was utilized to understand and predict the flow behavior of mixed powders using Carr's indices. The objective was to observe the trends in the flow behavior of lactose anhydrous and predict the optimum levels of Cab-O-Sil M5. stearic acid and magnesium stearate to obtain the best possible flow. 
When two or more pharmaceutical materials are mixed together, the resultant system will exhibit flow properties, which are dependent on the nature of individual components and their proportion in the mixture. The relationship between the flow properties of the mixture and the individual components is generally considered to be linear. However, in practicality the relationship is not always linear. This study will attempt to elucidate the nature of the relationship among commonly used excipients in terms of flow properties by a systematic study of flow behavior of powder blends. Mixing time is another critical parameter that affects the blending process and will have significant impact on the flow behavior of powders.

The objectives of this study include: i) to determine a simplistic approach to improve the flow behavior of pharmaceutical powders ii) to study the relationship between the individual components and their mixed systems iii) to analyze and predict the flow behavior of a mixed system from the individual components using an experimental design (iv) to evaluate the effect of mixing time on flow properties of powder blends and v) to determine the optimum composition of lubricants/flow enhancers for a mixture to have maximum flow. 


\section{METHODOLOGY}

\section{Materials}

The materials used in this study are lactose anhydrous, NF (Sheffield Products, USA), magnesium stearate, NF (Mallinckrodt Co., USA), Colloidal Silicone Dioxide (Cab-O-Sil M5 ${ }^{\circledR}$ M5) (Cabot Corp., USA) and stearic acid, NF (Witco Corp. USA).

\section{Methods}

\section{Preparation of Powder Blends:}

Lactose anhydrous, NF $(97 \% \mathrm{w} / \mathrm{w})$ was mixed with $3 \% \mathrm{w} / \mathrm{w}$ lubricant(s) in a Kitchen Aid Planetary Mixer. Lubricants evaluated were: magnesium stearate, stearic acid and Cab-O-Sil M5 M5. The relative amounts of lubricants were varied as per the simplex design described in Table 1. A constant batch size of 500 grams was used for all the experimental runs. The validity of the design was determined by conducting three experiments at different points in the lattice model.

Constant Mixing Time: The ingredients were passed through \# 30 mesh screen separately and the screened materials were placed in a Kitchen Aid Planetary Mixer (Kitchen Aid, Inc., OH) and mixed for three minutes at $94 \mathrm{rpm}$. A total of ten powder blends were prepared with varying concentrations of flow enhancers as per the simplex design described in Table 1. A constant batch size of 500 grams was used for all the experimental runs.

Variable Mixing Time: The ingredients were passed through \# 30 mesh screen separately and the screened materials were placed in a Kitchen Aid Planetary Mixer. 
TABLE 1. Simplex Design for Powder Mixtures

\begin{tabular}{|c|c|c|c|c|}
\hline \multirow[b]{2}{*}{ RUN \# } & \multicolumn{4}{|c|}{ Percentage of Total Mixture } \\
\hline & \multirow{2}{*}{$\begin{array}{c}\begin{array}{c}\text { Constant } \\
\text { Factor }\end{array} \\
\text { Lactose } \\
\text { Anhydrous }\end{array}$} & \multicolumn{3}{|c|}{ Variable Factors } \\
\hline & & $\begin{array}{c}\text { Cab-O-Sil } \\
\left(X_{1}\right)\end{array}$ & $\begin{array}{l}\text { Stearic Acid } \\
\left(\mathrm{X}_{2}\right)\end{array}$ & $\begin{array}{c}\text { Magnesium Stearate } \\
\qquad\left(\mathbf{X}_{3}\right)\end{array}$ \\
\hline 1 & 97 & 3 & 0 & 0 \\
\hline 2 & 97 & 0 & 3 & 0 \\
\hline 3 & 97 & 0 & 0 & 3 \\
\hline 4 & 97 & 1.5 & 1.5 & 0 \\
\hline 5 & 97 & 1.5 & 0 & 1.5 \\
\hline 6 & 97 & 0 & 1.5 & 1.5 \\
\hline 7 & 97 & 1 & 1 & 1 \\
\hline $8^{*}$ & 97 & 2 & 0.5 & 0.5 \\
\hline $9 *$ & 97 & 0.5 & 2 & 0.5 \\
\hline \multirow[t]{2}{*}{$10^{*}$} & 97 & 0.5 & 0.5 & 2 \\
\hline & Total & 10 & 10 & 10 \\
\hline
\end{tabular}

* Additional runs as check points for the Simplex Design 
The contents were mixed at $94 \mathrm{rpm}$ and the bulk density of powder was monitored after every half a minute of mixing. Mixing was continued until a relatively constant value for bulk density was achieved. When a constant value for bulk density was achieved then it was considered that the blend has reached a steady state of mixing. The powder compositions as per the simplex design in Table 1 were blended until all the powders have achieved constant values for bulk density.

\section{Evaluation of Powder Blends for Flow Behavior}

The mixed powders and individual components were evaluated for powder characteristics such as bulk density, tapped density, aerated bulk density, packed bulk density, compressibility index, angle of repose, angle of spatula, angle of fall, angle of difference, cohesiveness. dispersibility, moisture cortent and particle size distribution.

Bulk and Tapped Density Determination: The weight of powder required to fill 100 $\mathrm{mL}$ of graduated cylinder was determined and from which the bulk density was calculated as the ratio of mass to volume of powder. The tapped density was calculated from a constant volume of powder achieved after a number of taps using Tap Density Tester (Van der Kamp, USA).

Flow Characterization: The flow parameters of powders such as aerated bulk density, packed bulk density, compressibility index, angle of repose, angle of spatula, angle of fall, angle of difference, cohesion, and dispersibility were determined using a Hosokawa Powder Tester (Hosokawa Micron Corporation, Japan). The Carr's indices 
determining the powder flow properties were calculated (9-11). All the measurements were made in triplicate.

Moisture Content Determination: A powder sample of 2-4 grams was placed on a Mettler Moisture Determining Balance (Model Mettler LP16, Mettler Corp., USA) and the sample was heated at $105^{\circ} \mathrm{C}$ until a constant weight was achieved. The moisture content was thus determined as the percentage of loss on drying (LOD). The measurements were made in triplicate.

Particle Size Analysis: The particle size distribution for various powders was determined using a Gilsonic Autosiever (Model GA-6A, Gilson Company Inc., OH). The sieves used for this analysis have the following opening sizes: $180 \mu \mathrm{m}, 125 \mu \mathrm{m}$, $90 \mu \mathrm{m}, 53 \mu \mathrm{m}, 45 \mu \mathrm{m}, 32 \mu \mathrm{m}$, and $20 \mu \mathrm{m}$. A sample of 5 grams of powder was placed on the top sieve and after sieving for 5 minutes, the powders retained on each sieve were weighed. The amounts of powders retained were utilized to determine the geometric mean particle size of the powder blend.

\section{Data Analysis}

A statistical design, namely "Simplex Centroid Design" was utilized in the present study (19). The points of composition in the simplex were explored in accordance with a lattice arrangement and the responses were represented by polynomials (19-22). The design is explained by an equilateral triangle. Each side of the triangle represents one of the three varying components. Each vertex of the 
triangle indicates the maximum amount of one component and the minimum amount of the other two components in the system. Any point inside the triangle corresponds to a mixture of fixed composition of three variables. Accurate mapping of responses in a lattice structure is represented by polynomial equations and contour plots. A polynomial equation correlates the measured properties (responses) with the formulation compositions (factors). Coefficients in the polynomials are simple functions of the measured responses at the lattice points. Using these polynomial equations from the data collected, the properties of the mixed systems are evaluated. The special cubic design is described by the following equation (19):

$$
\begin{aligned}
& Y=b_{1} X_{1}+b_{2} X_{2}+b_{3} X_{3}+b_{12} X_{1} X_{2}+b_{13} X_{1} X_{3}+b_{23} X_{2} X_{3}+b_{123} X_{1} X_{2} X_{3} \\
& \text { where } X_{1}=\text { Cab-O-Sil M5. } X_{2}=\text { Stearic Acid, } X_{3}=\text { Magnesium Stearate } \\
& \qquad b_{1} \ldots b_{123}=\text { Regression Coefficients }
\end{aligned}
$$

The graphical representation of a polynomial equation is the response surface or contour plot. The response variables such as flow characteristics, mean particle size and moisture content were fitted using a special cubic model. The response surface contour plots were obtained for each flow parameter as a function of varying amounts of flow enhancers. The statistical software package, "Statgraphics ${ }^{\circledR}$ plus (23) was utilized to analyze the data.

In order to determine whether the relationship between the powder properties of individual components and their mixtures was linear or not, the theoretical values for the flow properties of the mixtures were determined assuming a linear relationship 
and these values were compared with actual measured values for flow properties of mixtures. The following equation was utilized to calculate the theoretical values:

Theoretical Bulk Density of Mixture $=(0.97) \times$ BD of Lactose $+($ Proportion of Cab-O-Sil M5) x BD of Cab-O-Sil M5 + (Proportion of Stearic Acid) x BD of Stearic Acid + (Proportion of Magnesium Stearate) x BD of Magnesium Stearate

$$
\begin{aligned}
& \text { Where } \mathrm{BD}=\text { Bulk Density } \\
& \text { Proportion of each component }=0 \text { through } 0.03
\end{aligned}
$$

For all other powder properties, the same equation was utilized and Bulk Density (BD) was replaced with the respective powder characteristic and corresponding theoretical values were calculated. 


\section{RESULTS AND DISCUSSION}

The individual components of the blends were evaluated for flow properties prior to conducting the experiments as per the experimental design. The data is provided in Table 2. The powder characteristics of the blends prepared with a constant mix time are summarized in Tables 3 and 4. The powder properties of the blends prepared using variable mix times to achieve constant bulk density are provided in Tables 5 and 6 . For all parameters, the theoretical values for different blends were calculated assuming a linear relationship between the individual excipients and the mixtures. These values are summarized in Tables 3, 4, 5 and 6. The regression coefficients that would describe the polynomial equations defining the contour surfaces are summarized in Tables 7 and 8 . The summary of testing performed on lack of fit model for constant mix time is provided in Table 9. Table 10 describes the optimization process and the constraints imposed on the model. The predicted flow values for optimized formulation composition are provided in Table 11. In order to determine whether any trends existed in the flow behavior, contour plots for varying compositions of stearic acid, magnesium stearate and Cab-O-Sil M5 in lactose blends were provided in Figures 1 through 12.

One of the critical parameters that interest formulators is the flowability of the powder formulations $(14,16,24)$. The processability of these blends is markedly affected by flowability concerns, since the materials need to be moved from one place to another. For example, encapsulation and/or tabletting on high-speed machines are only possible when the powder can be fed at higher rates. 
TABLE 2. Physical Properties of Individual Components

\begin{tabular}{|l|c|c|c|c|}
\hline Response Parameter & $\begin{array}{c}\text { Lactose } \\
\text { Anhydrous }\end{array}$ & Cab-0-Sil & Stearic Acid & $\begin{array}{c}\text { Magnesium } \\
\text { Stearate }\end{array}$ \\
\hline Angle of Repose $\left(^{\circ}\right)$ & 41.0 & 14.5 & 48.5 & 18.0 \\
\hline Angle of Fall $\left(^{\circ}\right)$ & 22.4 & 23.4 & 30.1 & 18.4 \\
\hline Angle of Difference $\left(^{\circ}\right)$ & 17.5 & 18.0 & 17.0 & 17.5 \\
\hline Aerated Bulk Density $(\mathrm{g} / \mathrm{cc})$ & 0.62 & 0.04 & 0.34 & 0.12 \\
\hline Packed Bulk Density $(\mathrm{g} / \mathrm{cc})$ & 0.83 & 0.06 & 0.59 & 0.27 \\
\hline Compressibility $(\%)$ & 25.4 & 24.2 & 41.3 & 55.0 \\
\hline Cohesiveness (\%) & 37.9 & 92.3 & 63.7 & 46.4 \\
\hline Angle of Spatula $\left(^{\circ}\right)$ & 48.1 & 47.9 & 54.2 & 57.9 \\
\hline Dispersibility $(\%)$ & 6.2 & 66.8 & 15.6 & 54.1 \\
\hline Moisture Content $(\%)$ & 0.51 & 1.11 & 0.10 & 2.29 \\
\hline Flowability Index & 55.0 & 46.5 & 32.0 & 41.0 \\
\hline Floodability Index & 73.0 & 82.0 & 76.5 & 56.5 \\
\hline Bulk Density (g/cc) & 0.63 & 0.04 & 0.38 & 0.15 \\
\hline Tapped Density (g/cc) & 0.83 & 0.05 & 0.56 & 0.30 \\
\hline Particle size (microns) & 161.0 & 172.2 & 175.0 & 107.8 \\
\hline
\end{tabular}


TABLE 3. Physical Properties of Lactose Blends with Constant Mix Time

\begin{tabular}{|c|c|c|c|c|c|c|c|c|c|c|}
\hline \multirow[b]{2}{*}{ Response Parameter } & \multicolumn{2}{|c|}{ Blend\#1 } & \multicolumn{2}{|c|}{ Blend\#2 } & \multicolumn{2}{|c|}{ Blend\#3 } & \multicolumn{2}{|c|}{ Blend\#4 } & \multicolumn{2}{|c|}{ Blend\#5 } \\
\hline & Actual & Theoretical* & Actual & Theoretical* & Actual & Theoretical* $^{*}$ & Actual & Theoretical* & Actual & Theoretical $^{*}$ \\
\hline Angle of Repose $\left({ }^{\circ}\right)$ & 41.0 & 41.1 & 48.5 & 41.2 & 45.6 & 40.9 & 37.0 & 41.2 & 38.8 & 41.0 \\
\hline Angle of Fall $\left({ }^{\circ}\right)$ & 22.4 & 22.4 & 30.1 & 22.6 & 23.9 & 22.3 & 18.4 & 22.5 & 20.7 & 22.3 \\
\hline Angle of Difference $\left({ }^{\circ}\right)$ & 18.6 & 18.7 & 18.4 & 18.6 & 21.7 & 18.6 & 18.6 & 18.6 & 18.1 & 18.7 \\
\hline Aerated Bulk Density $(\mathrm{g} / \mathrm{cc})$ & 0.53 & 0.60 & 059 & 061 & 0.69 & 0.61 & 0.64 & 0.61 & 0.56 & 0.61 \\
\hline Packed Bulk Density $(\mathrm{g} / \mathrm{cc})$ & 0.77 & 0.81 & 0.80 & 0.83 & 0.84 & 0.82 & 0.81 & 0.82 & 0.80 & 0.81 \\
\hline Compressibility (\%) & 30.8 & 25.4 & 26.0 & 25.9 & 18.3 & 26.3 & 20.4 & 25.6 & 29.5 & 25.8 \\
\hline Cohesiveness (\%) & 79.4 & 39.5 & 74.8 & 38.7 & 52.4 & 38.2 & 64.3 & 39.1 & 69.5 & 38.8 \\
\hline Angle of Spatula $\left({ }^{\circ}\right)$ & 40.7 & 48.1 & 41.5 & 48.3 & 40.9 & 48.4 & 36.8 & 48.2 & 40.7 & 48.3 \\
\hline Dispersibility (\%) & 17.0 & 8.0 & 8.0 & 6.5 & 17.6 & 7.7 & 8.4 & 7.3 & 9.4 & 7.8 \\
\hline Moisture Content (\%) & 0.39 & 0.53 & 0.49 & 0.50 & 0.60 & 0.56 & 0.50 & 0.51 & 0.49 & 0.55 \\
\hline Flowability Index & 47.0 & 54.8 & 46.5 & 54.3 & 57.5 & 54.6 & 58.5 & 54.5 & 50.0 & 54.7 \\
\hline Floodability Index & 64.5 & 73.3 & 64.5 & 73.1 & 71.0 & 72.5 & 74.0 & 73.2 & 69.5 & 72.9 \\
\hline Bulk Density ( $\mathrm{g} / \mathrm{cc}$ ) & 0.53 & 063 & 0.64 & 0.65 & 066 & 0.63 & 0.59 & 0.64 & 0.59 & 0.63 \\
\hline Tapped Density (g/cc) & 0.72 & 0.84 & 0.86 & 0.86 & 0.90 & 0.85 & 0.83 & 0.85 & 0.82 & 0.84 \\
\hline Particle size (microns) & 182.8 & 161.3 & 154.7 & 161.4 & 144.6 & 159.4 & 157.1 & 161.4 & 171.4 & 160.4 \\
\hline
\end{tabular}

* Theoretical values were calculated assuming a linear relationship between the excipients and the mixtures 
TABLE 4. Physical Properties of Lactose Blends with Constant Mix Time

\begin{tabular}{|c|c|c|c|c|c|c|c|c|c|c|}
\hline \multirow[b]{2}{*}{ Response Parameter } & \multicolumn{2}{|c|}{ Blend \#6 } & \multicolumn{2}{|c|}{ Blend\#7 } & \multicolumn{2}{|c|}{ Blend\#8 } & \multicolumn{2}{|c|}{ Blend\#9 } & \multicolumn{2}{|c|}{ Blend\#10 } \\
\hline & Actual & Theoretical $^{*}$ & Actual & Theoretical* & Actual & Theoretical* $^{*}$ & Actual & Theoretical $^{*}$ & Actual & Theoretical* \\
\hline Angle of Repose $\left({ }^{\circ}\right)$ & 36.8 & 41.0 & 39.8 & 41.1 & 38.7 & 41.1 & 38.2 & 41.1 & 41.2 & 41.0 \\
\hline Angle of Fall $\left(^{\circ}\right)$ & 21.4 & 22.4 & 23.6 & 22.4 & 19.5 & 22.4 & 19.2 & 22.5 & 24.3 & 22.3 \\
\hline Angle of Difference $\left({ }^{\circ}\right)$ & 15.4 & 18.6 & 16.2 & 18.6 & 19.2 & 18.7 & 19.0 & 18.6 & 16.9 & 18.6 \\
\hline Aerated Bulk Density $(\mathrm{g} / \mathrm{cc})$ & 0.63 & 0.61 & 0.60 & 0.61 & 0.63 & 0.61 & 0.56 & 0.61 & 0.62 & $0 . \overline{61}$ \\
\hline Packed Bulk Density $(\mathrm{g} / \mathrm{cc})$ & 0.88 & 0.82 & 0.80 & 0.82 & 0.86 & 0.81 & 0.81 & 0.82 & 0.88 & 0.82 \\
\hline Compressibility (\%) & 28.7 & 26.1 & 25.6 & 25.9 & 26.4 & 25.6 & 30.8 & 25.9 & 29.9 & 26.1 \\
\hline Cohesiveness (\%) & 73.6 & 38.4 & 77.4 & 38.8 & 79.7 & 39.2 & 81.9 & 38.7 & 82.4 & 38.5 \\
\hline Angle of Spatula $\left({ }^{\circ}\right)$ & 40.7 & 48.4 & 35.3 & 48.3 & 40.5 & 48.2 & 43.7 & 48.3 & 37.0 & 48.4 \\
\hline Dispersibility (\%) & 9.3 & 7.1 & 10.3 & 7.4 & 8.7 & 7.7 & 11.8 & 6.9 & 7.0 & 7.5 \\
\hline Moisture Content (\%) & 0.49 & 0.53 & 0.59 & 0.53 & 0.60 & 0.53 & 0.60 & 0.51 & 0.60 & 0.55 \\
\hline Flowability Index & 50.0 & 54.5 & 55.0 & 54.6 & 50.5 & 54.7 & 46.0 & 54.4 & 50.0 & 54.6 \\
\hline Floodability Index & 68.0 & 72.8 & 59.5 & 73.0 & 78.5 & 73.1 & 70.3 & 73.0 & 65.0 & 72.7 \\
\hline Bulk Density ( $\mathrm{g} / \mathrm{cc}$ ) & 0.67 & 0.64 & 0.60 & 0.64 & 0.66 & 0.63 & 0.56 & 0.64 & 0.62 & 0.63 \\
\hline Tapped Density (g/cc) & 0.89 & 0.86 & 0.85 & 085 & 0.86 & 0.84 & 0.80 & 0.86 & 0.85 & 0.85 \\
\hline Particle size (microns) & 152.2 & 160.4 & 160.8 & 160.7 & 148.4 & 161.0 & 172.6 & 161.1 & 152.2 & 160.1 \\
\hline
\end{tabular}

* Theoretical values were calculated assuming a linear relationship between the excipients and mixtures 
Angle of Repose: It is defined as the angle formed when a cone of powder is poured onto a flat surface out of a bulk pile (9-11). It is a direct indication of the flowability of a material. Lower values for angle of repose indicate better flow behavior for powders. Figure 1 provides the contour plots for angle of repose, which indicates that there is a significant difference in the response surfaces for the two sets of lactose blends. When the mixing time was kept constant at 3 minutes, the increase in magnesium stearate from 0 to $3 \%$ resulted in an increase of the angle of repose from $37.5^{\circ}$ to $45^{\circ}$. The variation in amount of Cab-O-Sil M5 from 0 to $3 \%$ had a minor effect on the angle of repose as the values varied only from $37.5^{\circ}$ to $39^{\circ}$. From the contour plot, lower amounts of Cab-O-Sil M5 and magnesium stearate along with a moderate amount of stearic acid seem to provide powders that will have lower angle of repose values indicating better flow. When the mixing time was varied to obtain constant bulk density, the resulting lactose blends provided different values for angle of repose (Figure 1). None of the three variable components, in the range of 0 to $3 \%$, had any significant effect on the angle of repose.

Angle of Fall: Floodability of a material is the tendency to liquid-like flow due to natural fluidization of mass particles by air (9-11). The angle of fall describes the floodability of a material and is obtained as the new repose angle when dropping a fixed weight mechanically shocks the powder cone. The more free-flowing a material, the lower is the angle of fall. Figure 2 provides contour plots for the two sets of lactose blends. When the mixing time was constant, the powders containing a lower amount of magnesium stearate, a medium amount of stearic acid and a medium to high amount of Cab-O-Sil M5 provided the lowest values for angle of fall. 
(a) Constant Mix Time

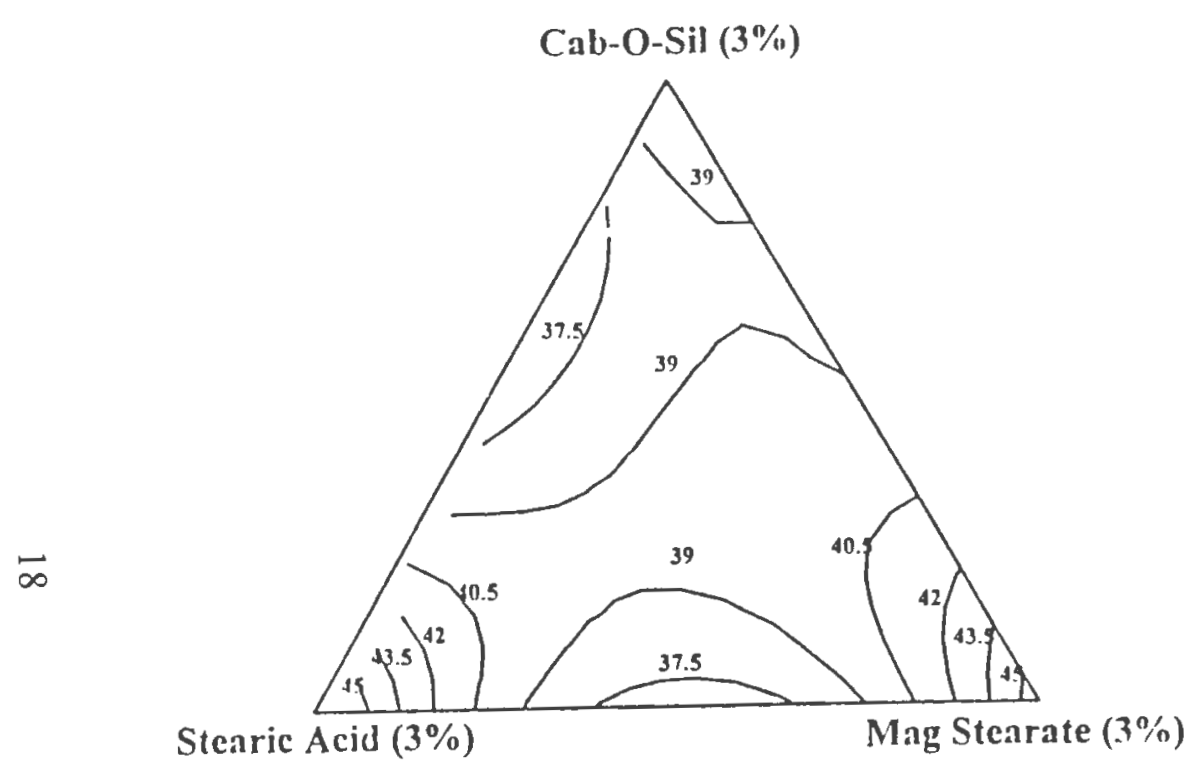

(b) Variable Mix Time

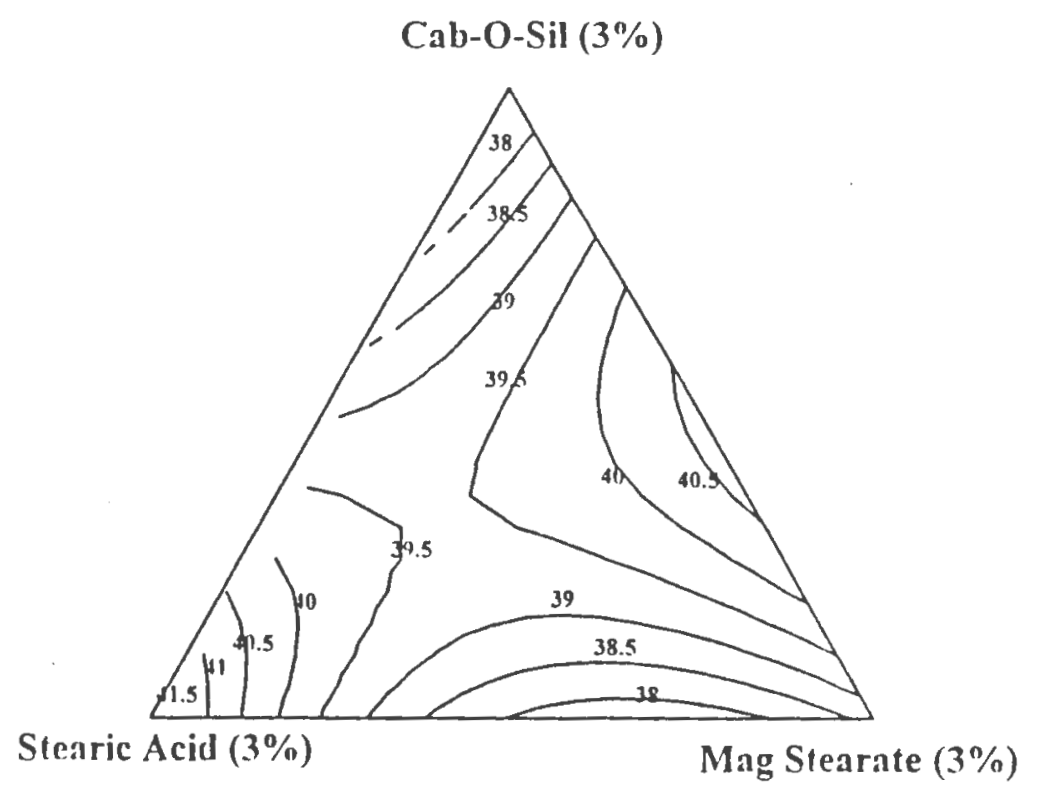

FIGURE 1. Contour Plots for Angle of Repose: (a) Constant Mix Time (b) Variable Mix Time 
(a) Constant Mix Time

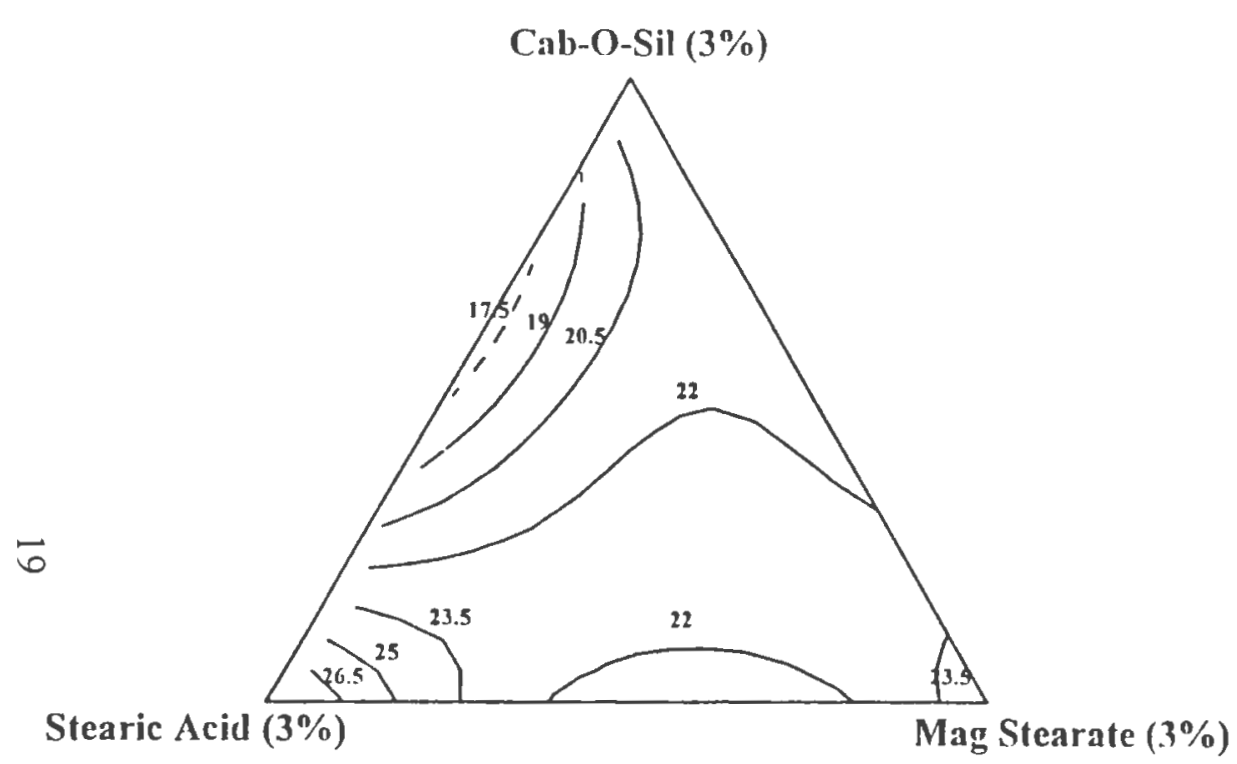

(b) Variable Mix Time

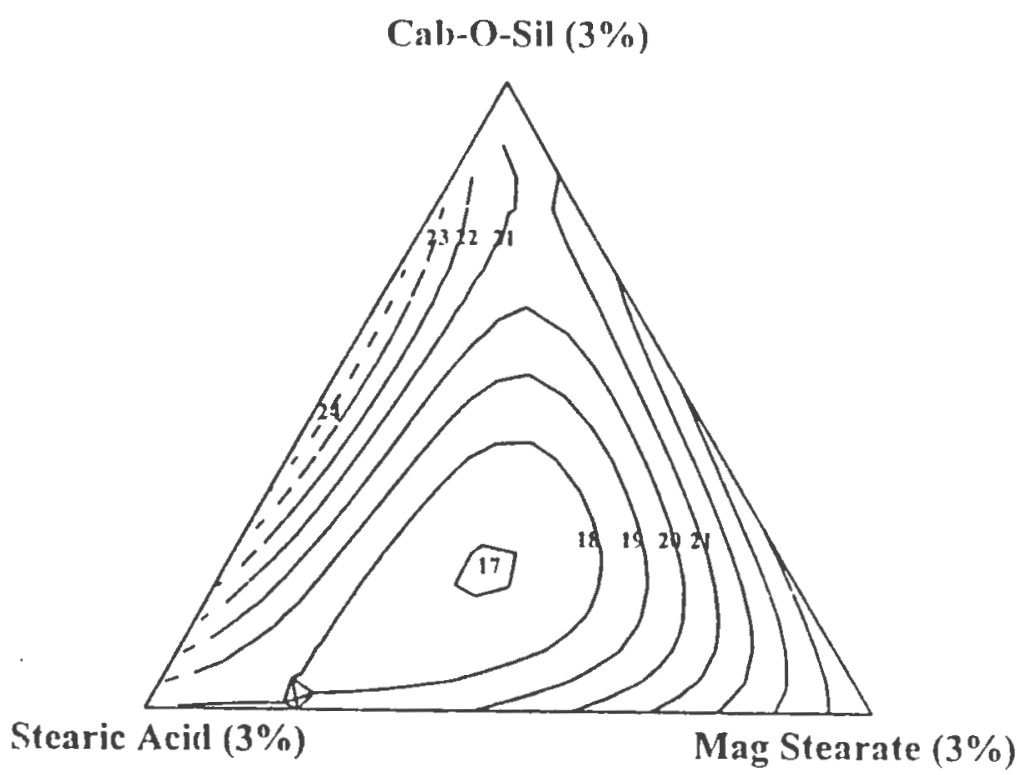

FIGURE 2. Contour Plots for Angle of Fall: (a) Constant Mix Time (b) Variable Mix Time 
When the mixing time was varied to obtain constant bulk density, a minimum value of $17^{\circ}$ was observed for angle of fall at moderate levels of all the three components that comprise the simplex design. The model predicts that at this composition, the lactose blend will have maximum floodability.

Angle of Difference: This parameter also describes the floodability of a material and is obtained as the numerical difference between the angle of fall and angle of repose. The lower the difference, the higher will be the floodable or fluidizable a material can be. As evident from the data and contour plots (Tables 3, 4, $5 \& 6$ and Figure 3) when the mixing time was constant the values for angle of difference varied from $15.8^{\circ}$ to $20.6^{\circ}$ whereas when the mixing time was varied, the values were in the range of $14^{\circ}$ to $23^{\circ}$. With a constant mix time, an increase in Cab-O-Sil M5 resulted in an increase in the angle of difference whereas increases in magnesium stearate and stearic acid had an insignificant effect. When the mix time was variable, a high value was observed for blends containing about equal amounts of stearic acid, magnesium stearate and Cab-O-Sil M5.

Angle of Spatula: It provides a measure of angle of rupture or internal friction of a material. A free flowing material will form one angle whereas a non-free flowing material will form a number of irregular angles on the blade. For free flowing materials, the value for angle of spatula is always higher than the angle of repose for a particular material (9-11). Figure 4 provides a contrast between the two sets of lactose blends. For constant mix time blends, a minimum for angle of spatula was observed for blends comprising about equal amounts of three flow enhancers. 
(a) Constant Mix Time

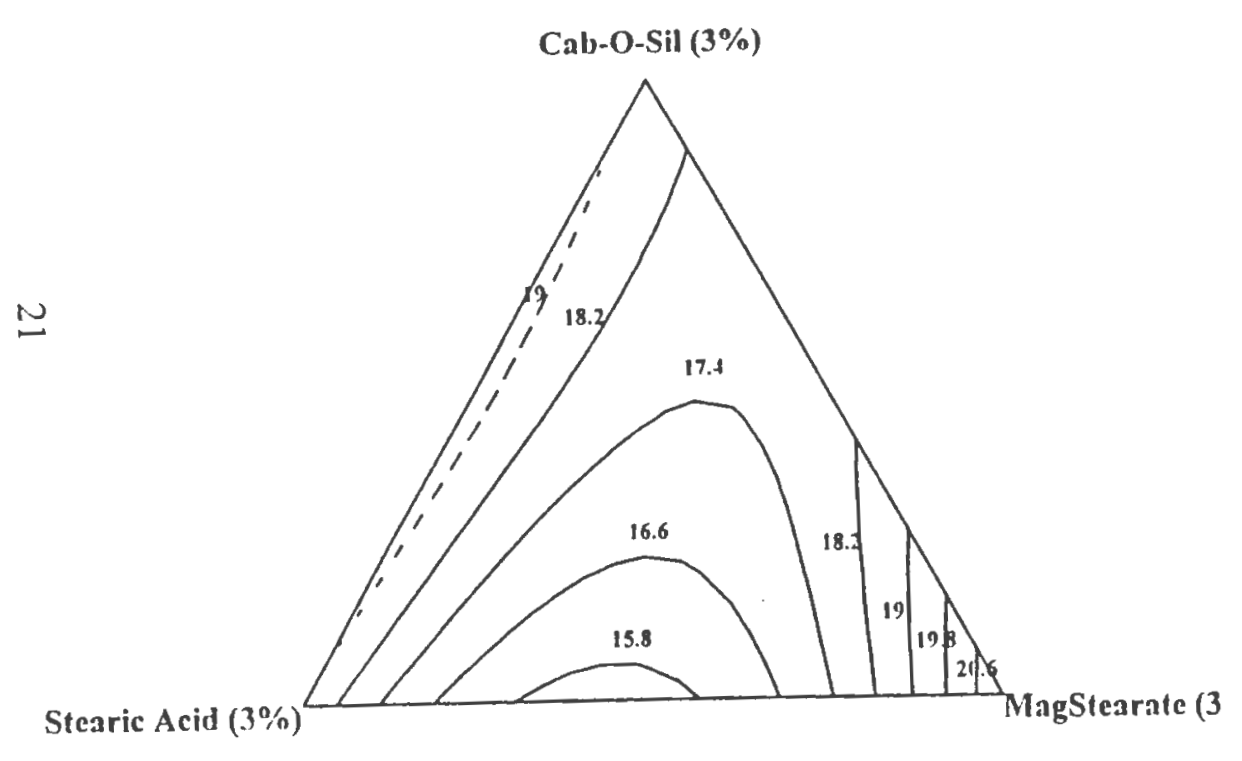

(b) Variable Mix Time

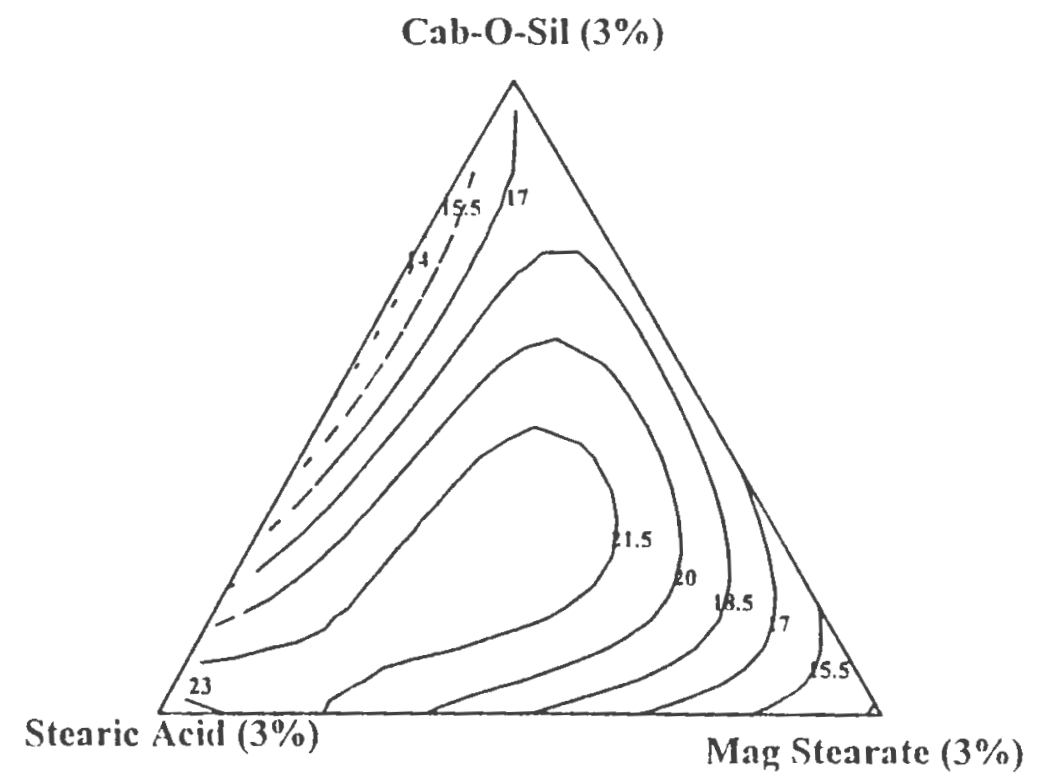

FIGURE 3. Contour Plots for Angle of Difference: (a) Constant Mix Time (b) Variable Mix Time 
(a) Constant Mix Time

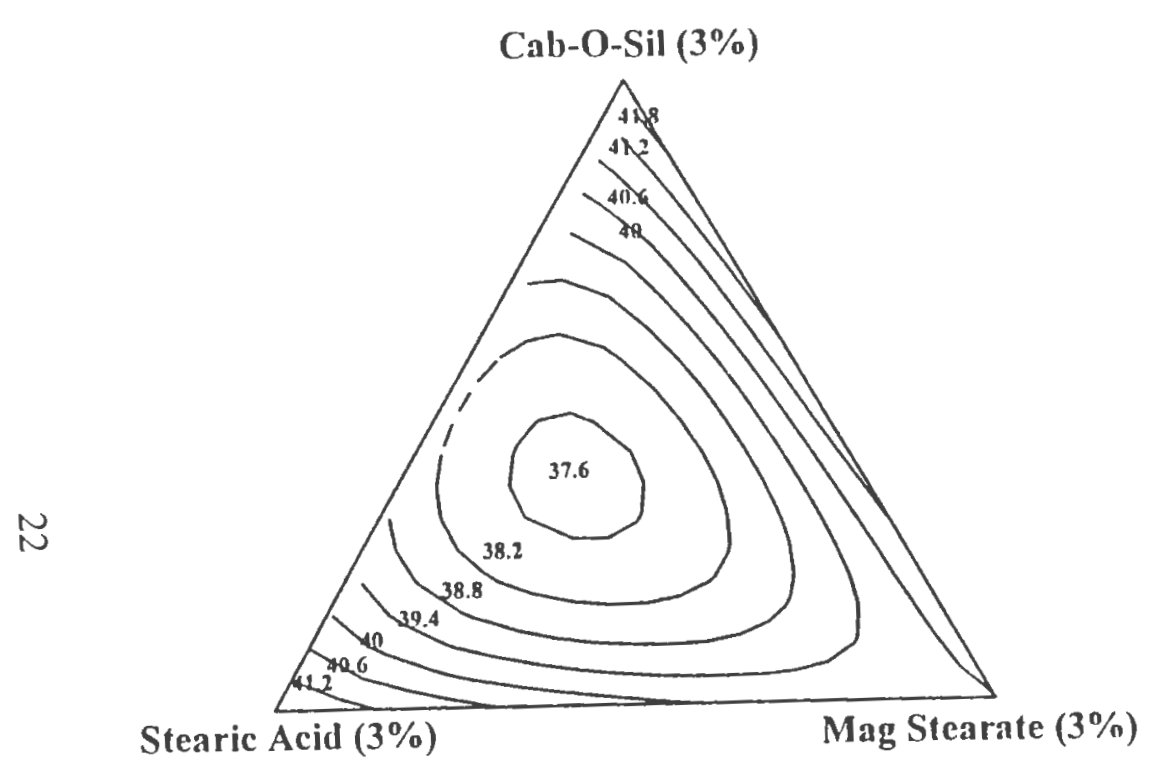

(b) Variable Mix Time

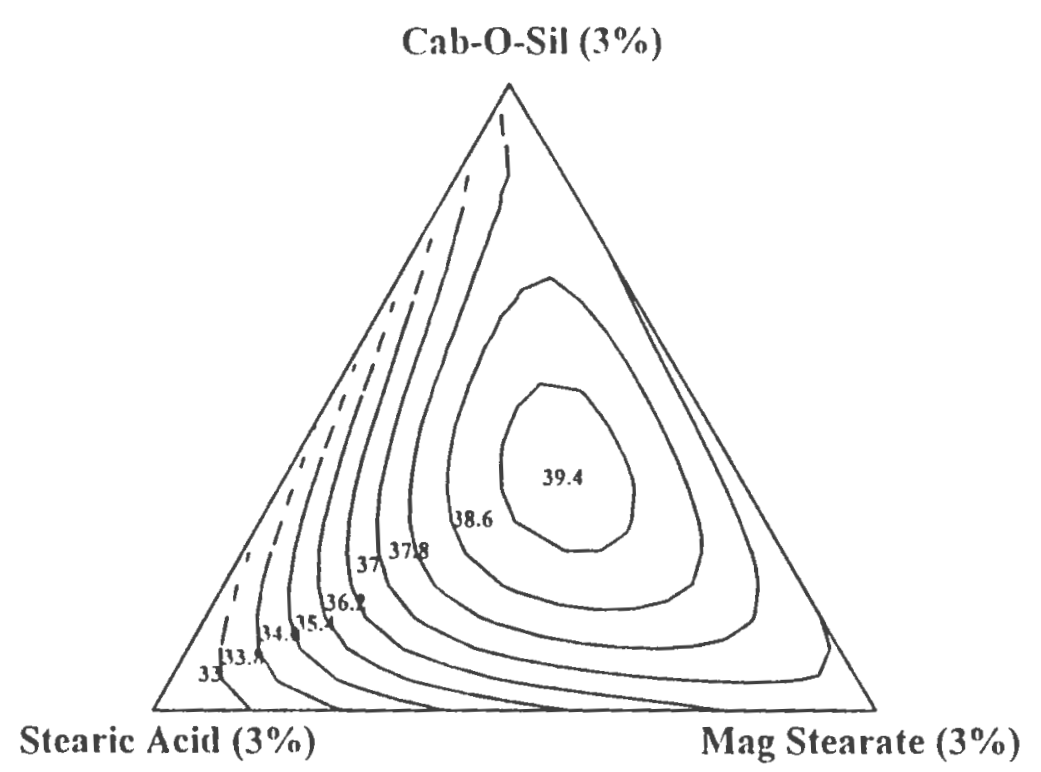

FIGURE 4. Contour Plots for Angle of Spatula: (a) Constant Mix Time (b) Variable Mix Time 
For the same composition, when the mixing time was variable, a maximum was observed in the contour plot indicating that mixing times have an effect on the values observed for angle of spatula (Figure 4).

Bulk Density \& Tapped Density: These are important micromeritic parameters in determining the flow of a powder. They are useful for determining the feed range calculations, mixer loading capacity and hopper or bin capacity $(25,40)$. Bulk density is the ratio of mass to volume. The bulk \& tapped density values for individual excipients are summarized in Table 2. In this investigation an attempt was made to determine whether the relationship between the flow properties of individual components and those of mixtures is linear or not. The theoretical values were calculated using equation described in Data Analysis section. The theoretical values for different blends were calculated assuming a linear relationship between the bulk/tapped density of excipients and that of mixtures. When the mixing time was kept constant $(3 \mathrm{~min})$ the theoretical density values were found to be higher than the actual values in some cases and for others, the values remained the same (Tables $3 \& 4$ ). When the mixing time was varied till constant bulk density was obtained for blends, all the theoretical values were found to be significantly lower than the actual values (Tables 5\&6).

Aerated Bulk Density: This is also known as loose bulk density (9-11). This gives an indication of air entrapped in the powder. From the contour plot (Figure 5) for lactose blends mixed for 3 minutes, as the amount of stearic acid was increased from $0 \%$ to $3 \%$, the aerated bulk density increased from 0.54 to $0.64 \mathrm{~g} / \mathrm{mL}$. The high values for aerated bulk density were seen when the magnesium stearate is at $3 \%$. 
TABLE 5. Physical Properties of Lactose Blends with Variable Mix Time

\begin{tabular}{|c|c|c|c|c|c|c|c|c|c|c|}
\hline \multirow[b]{2}{*}{ Response Parameter } & \multicolumn{2}{|c|}{ Blend\#1 } & \multicolumn{2}{|c|}{ Blend\#2 } & \multicolumn{2}{|c|}{ Blend\#3 } & \multicolumn{2}{|c|}{ Blend\#4 } & \multicolumn{2}{|c|}{ Blend\#5 } \\
\hline & Actual & Theoretical $^{*}$ & $\overline{\text { Actual }}$ & Theoretical ${ }^{\star}$ & Actual & Theoretical $^{*}$ & Actual & Theoretical ${ }^{*}$ & Actual & Theoretical* $^{*}$ \\
\hline Angle of Repose $\left({ }^{\circ}\right)$ & 37.4 & 41.1 & 42.2 & 41.2 & 38.4 & 40.9 & 39.3 & 41.2 & 40.5 & 41.0 \\
\hline Angle of Fall $\left(^{\circ}\right)$ & 19.7 & 22.4 & 18.3 & 22.6 & 24.8 & 22.3 & 25.1 & 22.5 & 22.9 & 22.3 \\
\hline Angle of Difference $\left({ }^{\circ}\right)$ & 17.7 & 18.7 & 24.0 & 18.6 & 13.6 & 18.6 & 14.2 & 18.6 & 17.6 & 18.7 \\
\hline Aerated Bulk Density $(\mathrm{g} / \mathrm{cc})$ & 0.64 & 0.60 & 0.66 & 0.61 & 0.70 & 0.61 & 0.64 & 0.61 & 0.61 & 0.61 \\
\hline Packed Bulk Density $(\mathrm{g} / \mathrm{cc})$ & 0.84 & 0.81 & 0.86 & 0.83 & 0.89 & 0.82 & 0.85 & 0.82 & 0.84 & 0.81 \\
\hline Compressibility (\%) & 24.2 & 25.4 & 23.2 & 25.9 & 20.8 & 26.3 & 24.3 & 25.6 & 27.8 & 25.8 \\
\hline Cohesiveness ( $\%$ ) & 76.3 & 39.5 & 72.6 & 38.7 & 76.8 & 38.2 & 75.2 & 39.1 & 80.8 & 38.8 \\
\hline Angle of Spatula $\left({ }^{\circ}\right)$ & 38.4 & 48.1 & 32.8 & 48.3 & 36.8 & 48.4 & 34.9 & 48.2 & 37.6 & 48.3 \\
\hline Dispersibility (\%) & 11.5 & 8.0 & 10.5 & 6.5 & 9.2 & 7.6 & 9.3 & 7.3 & 9.2 & 7.8 \\
\hline Moisture Content (\%) & 0.39 & 0.53 & 0.59 & 0.50 & 0.59 & 0.56 & 0.50 & 0.51 & 0.50 & 0.55 \\
\hline Flowability Index & 56 & 54.8 & 55.0 & 54.3 & 58.0 & 54.6 & 57.0 & 54.5 & 49.0 & 54.7 \\
\hline Floodability Index & 75.5 & 73.3 & 75.0 & 73.1 & 68.0 & 72.5 & 68.0 & 73.2 & 70.0 & 72.9 \\
\hline Bulk Density $(\mathrm{g} / \mathrm{cc})$ & 0.65 & 0.63 & 0.69 & 0.65 & 0.73 & 0.63 & 0.67 & 0.64 & 0.65 & 0.63 \\
\hline Tapped Density $(\mathrm{g} / \mathrm{cc})$ & 0.86 & 0.84 & 0.89 & 0.86 & 0.93 & 0.85 & 0.87 & 0.85 & 0.86 & 0.84 \\
\hline Particle size (microns) & 130.9 & 161.3 & 157.6 & 161.4 & 155.1 & 159.4 & 168.4 & 161.4 & 175.9 & 160.4 \\
\hline Mixing Time (minutes) & & 12 & & 2 & & 4.5 & & 4.5 & & 5 \\
\hline
\end{tabular}

* Theoretical values were calculated assuming a linear relationship between the excipients and mixtures 
TABLE 6. Physical Properties of Lactose Blends with Variable Mix Time

\begin{tabular}{|c|c|c|c|c|c|c|c|c|c|c|}
\hline \multirow[b]{2}{*}{ Response Parameter } & \multicolumn{2}{|c|}{ Blend\#6 } & \multicolumn{2}{|c|}{ Blend\#7 } & \multicolumn{2}{|c|}{ Blend\#8 } & \multicolumn{2}{|c|}{ Blend $\# 9$} & \multicolumn{2}{|c|}{ Blend\#10 } \\
\hline & Actual & Theoretical* & Actual & 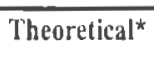 & Actual & Theoretical $^{\star}$ & Actual & Theoretical $^{*}$ & Actual & Theoretical $^{*}$ \\
\hline Angle of Repose $\left({ }^{\circ}\right)$ & 38.0 & 41.0 & 40.0 & 41.1 & 38.8 & 41.1 & 38.4 & 41.1 & 40.0 & 41.0 \\
\hline Angle of Fall $\left({ }^{\circ}\right)$ & 19.6 & 22.4 & 17.6 & 22.4 & 17.3 & 22.4 & 20.7 & 22.5 & 20.1 & 22.3 \\
\hline Angle of Difference $\left({ }^{\circ}\right)$ & 18.4 & 18.6 & 22.5 & 18.6 & 21.5 & 18.7 & 17.7 & 18.6 & 19.9 & 18.6 \\
\hline $\begin{array}{l}\text { Aerated Bulk } \\
\text { Density }(\mathrm{g} / \mathrm{cc})\end{array}$ & 0.71 & 0.61 & 0.64 & 0.61 & 0.70 & 0.61 & 0.66 & 0.61 & 0.66 & 0.61 \\
\hline Packed Bulk Density (g/cc) & 0.88 & 0.82 & 0.85 & 0.82 & 0.88 & 0.81 & 0.90 & 0.82 & 0.87 & 0.82 \\
\hline Compressibility (\%) & 20.2 & 26.1 & 25.1 & 25.9 & 20.1 & 25.6 & 26.6 & 25.9 & 24.8 & 26.1 \\
\hline Cohesiveness (\%) & 74.6 & 38.4 & 76.7 & 38.8 & 76.8 & 39.2 & 79.1 & 38.7 & 76.3 & 38.5 \\
\hline Angle of Spatula $\left({ }^{\circ}\right)$ & 35.8 & 48.4 & 42.1 & 48.3 & 32.6 & 48.2 & 37.1 & 48.3 & 37.6 & 48.4 \\
\hline Dispersibility (\%) & 11.4 & 7.1 & 9.2 & 7.4 & 7.4 & 7.7 & 8.5 & 7.0 & 8.3 & 7.5 \\
\hline Moisture Content (\%) & 0.49 & 0.53 & 0.59 & 0.53 & 0.60 & 0.53 & 0.60 & 0.51 & 0.40 & 0.55 \\
\hline Flowability Index & 58.5 & 54.5 & 52.5 & 54.6 & 58.5 & 54.7 & 51.0 & 54.4 & 55.4 & 54.6 \\
\hline Floodability Index & 73.0 & 72.8 & 63.5 & 73.0 & 77.5 & 73.1 & 74.0 & 73.0 & 77.0 & 72.7 \\
\hline Bulk Density (g/cc) & 0.72 & 0.64 & 0.66 & 0.64 & 0.71 & 0.63 & 0.71 & 0.64 & 0.68 & 0.63 \\
\hline Tapped Density $(\mathrm{g} / \mathrm{cc})$ & 0.92 & 0.86 & 0.87 & 0.85 & 0.90 & 0.84 & 0.90 & 0.86 & 0.88 & 0.85 \\
\hline Particle size (microns) & 140.6 & 160.4 & 153.0 & 160.7 & 141.4 & 161.0 & 145.7 & 161.1 & 144.7 & 160.1 \\
\hline Mixing Time (minutes) & & 4 & & 5 & & 10.5 & & 7 & & 9 \\
\hline
\end{tabular}

* Theoretical values were calculated assuming a linear relationship between the excipients and mixtures 
(a) Constant Mix Time

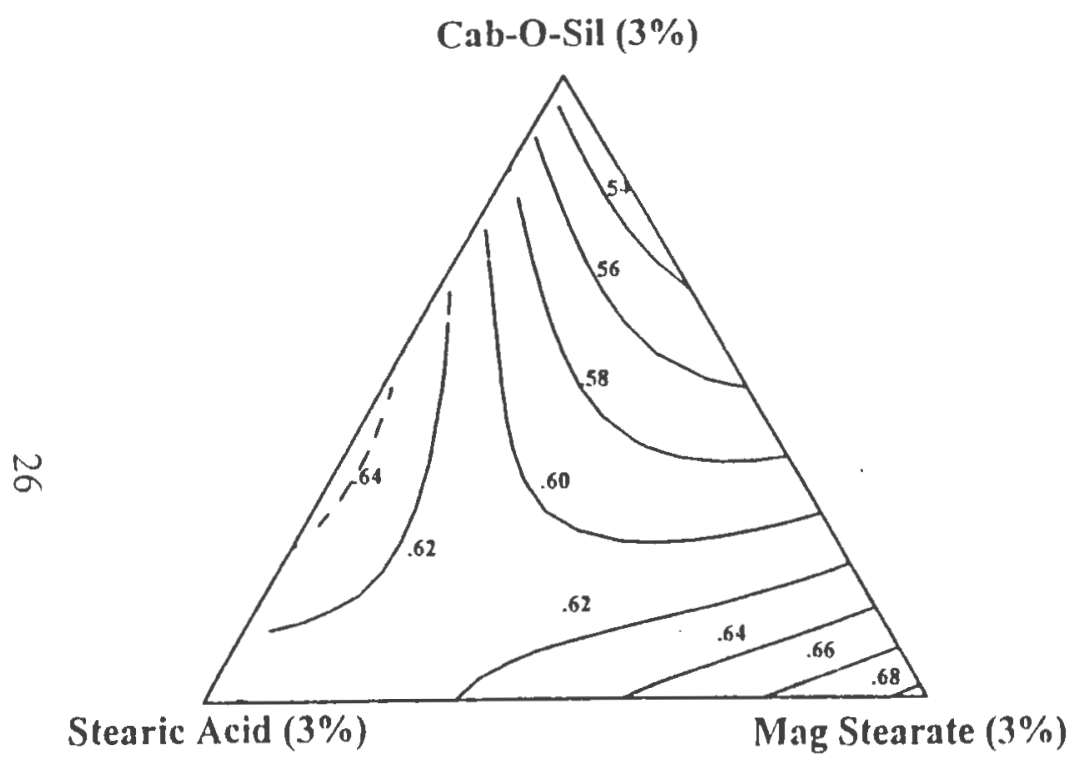

(b) Variable Mix Time

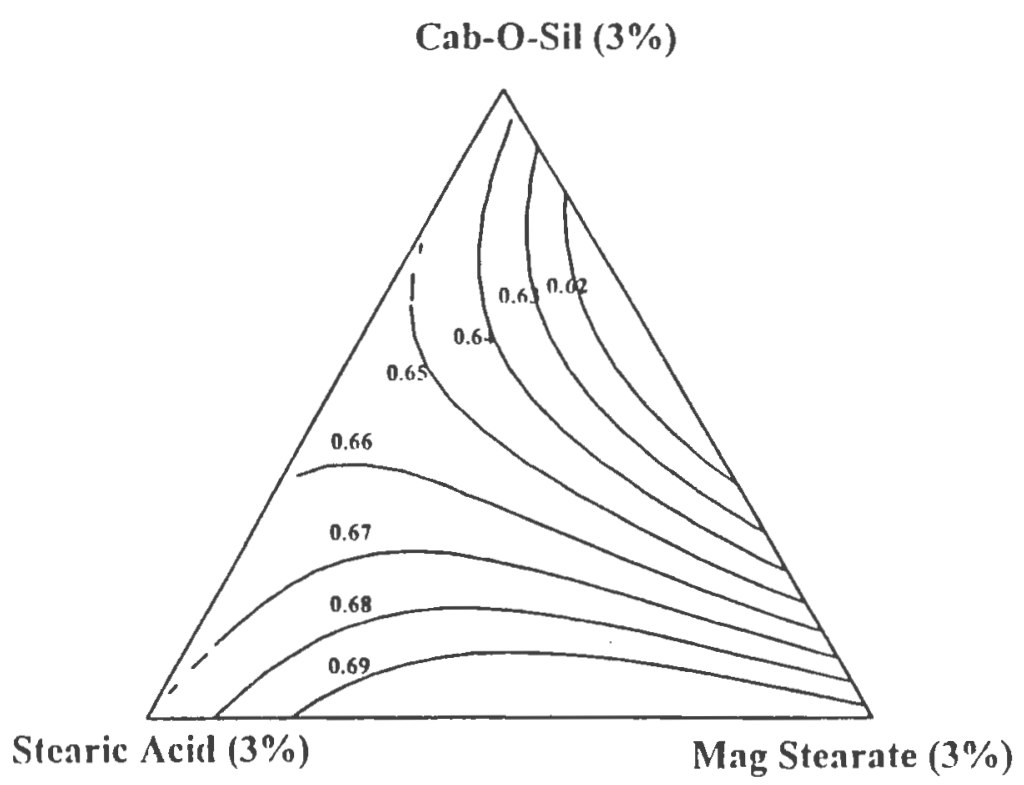

FIGURE 5. Contour Plots for Aerated Bulk Density: (a) Constant Mix Time (b) Variable Mix Time 
It is clearly evident that Cab-O-Sil M5 had inverse effect on aerated bulk density (Figure 5). When the mixing times were varied, higher values were observed at low levels of Cab-O-Sil M5 and higher levels of stearic acid and magnesium stearate (Figure 5).

Packed Bulk Density: This parameter provides useful information on the compacting strength of a material that may occur in the hopper (9-11). From the contour plot (Figure 6) for blends that were mixed for constant time, Cab-O-Sil M5 had an inverse effect on the packed bulk density whereas stearic acid and magnesium stearate had a minor effect on the density values. When the mixing times were varied, the Cab-O-Sil M5 still had the same inverse effect on bulk density (Figure 6). The packed density values increased with an increase in magnesium stearate and the amount of stearic acid in the blend had insignificant effect.

Compressibility: This is obtained from aerated and packed bulk densities and provides an excellent measure on compactibility of materials. The more compressible a material is, the less flowable it will be (9-11). Tables 2, 3, 4, 5\&6 provide the values for compressibility of various lactose blends and Figure 7 provides the trends noticed by varying the compositions of the flow enhancers from 0 to $3 \%$. When the mixing time was kept constant, magnesium stearate provided lower values for compressibility when incorporated in small amounts $(0-0.5 \%)$ or in high amounts $(\sim 3 \%)$. At moderate amounts it resulted in high values for compressibility. Stearic acid had the inverse effect on the compressibility values. When the mixing times were varied, significantly lower values for compressibility were observed. Stearic acid had the inverse effect 
(a) Constant Mix Time

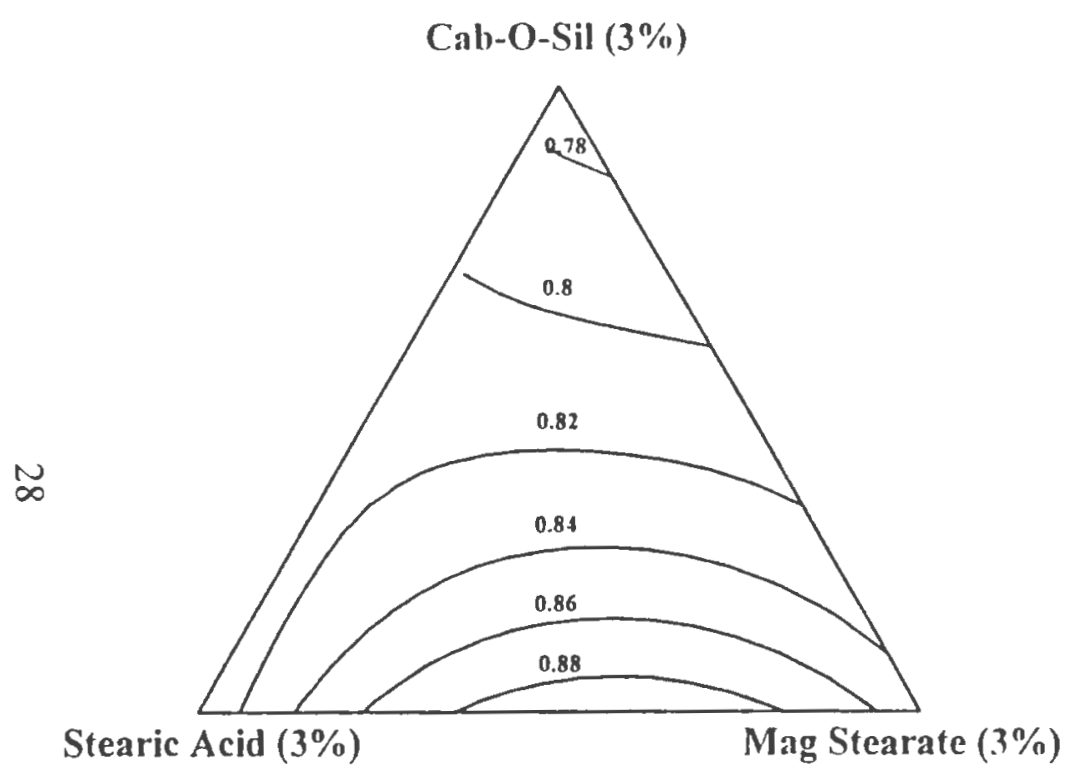

(b) Variable Mix Time

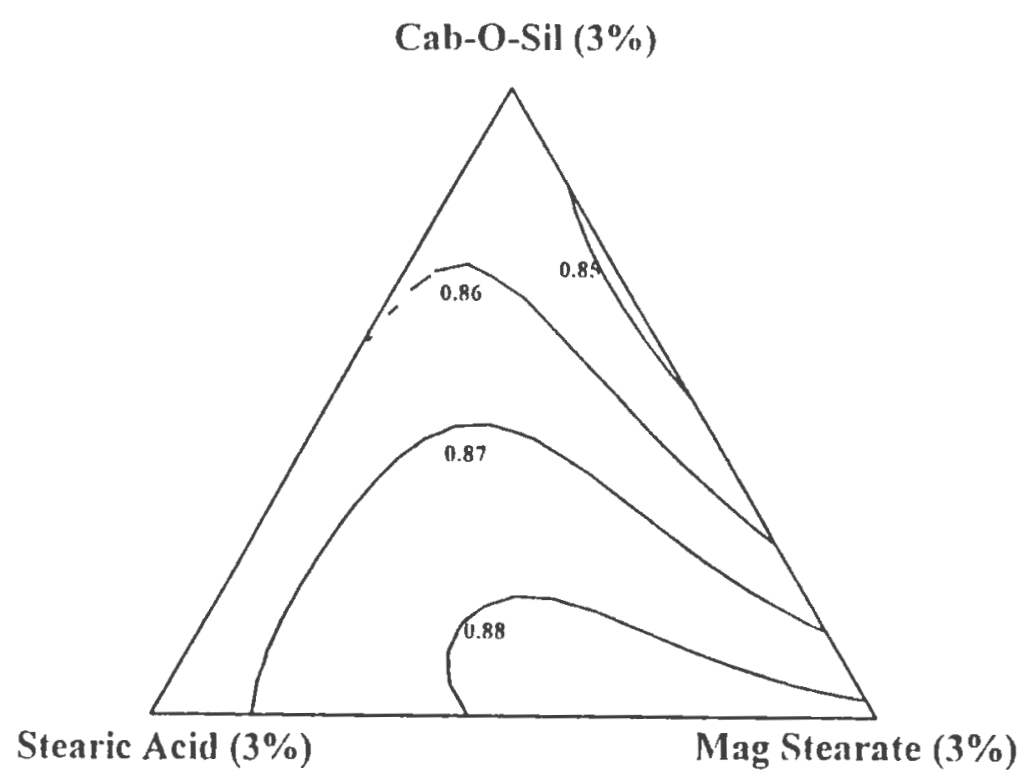

FIGURE 6. Contour Plots for Packed Bulk Density: (a) Constant Mix Time (b) Variable Mix Time 
(a) Constant Mix Time

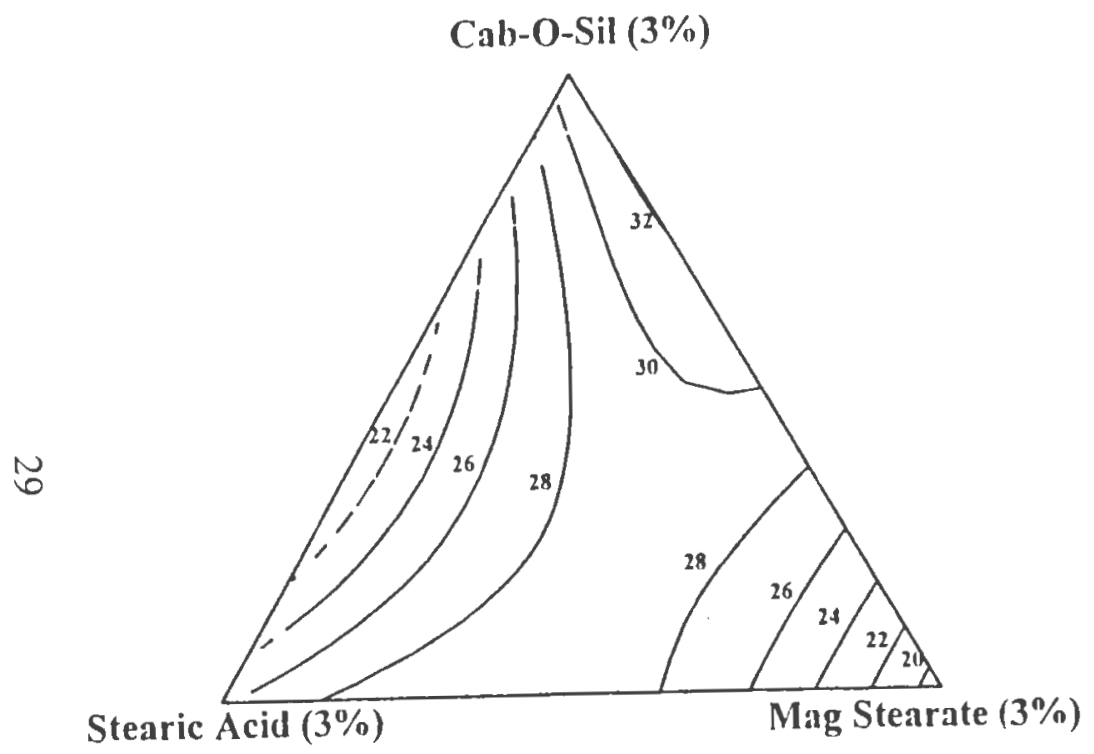

(b) Variable Mix Time

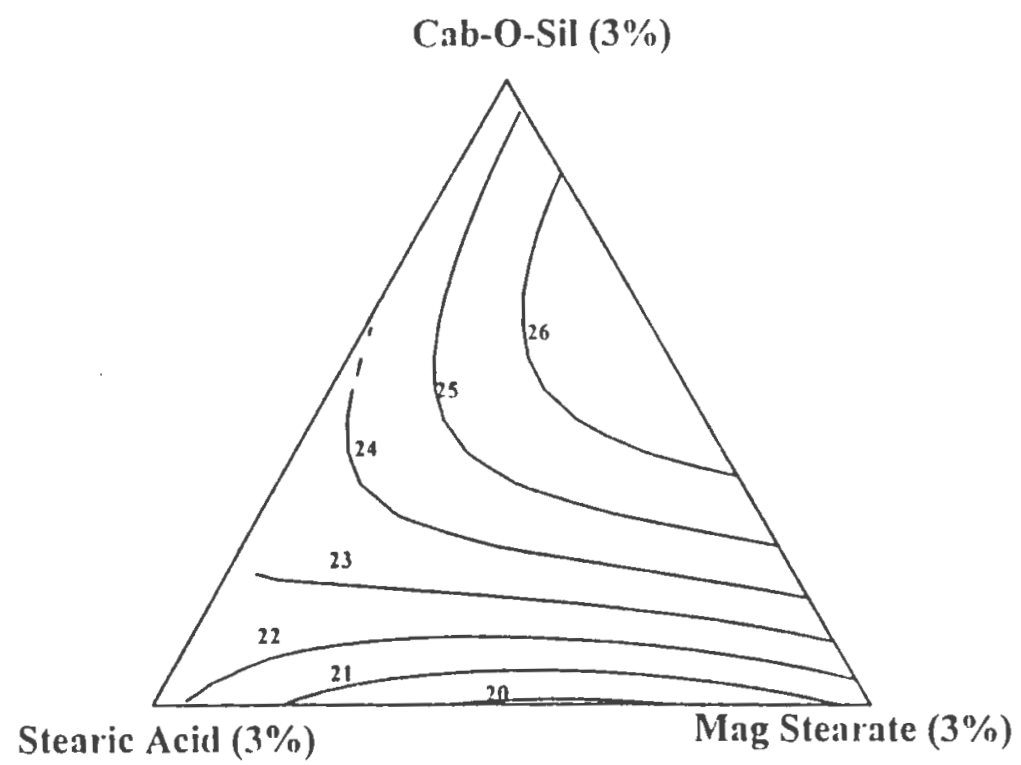

FIGURE 7. Contour Plots for Compressibility: (a) Constant Mix Time (b) Variable Mix Time 
and a significant difference in the effect of magnesium stearate on compressibility was observed when compared to the constant mix blends (Figure 7).

Cohesion: This parameter is related to the attractive forces that exist on particle surfaces $(7,9-11)$. Figure 8 provides the response surface for cohesion for lactose blends. When the mixing time was constant, a maximum value for cohesion was noticed when the components in simplex design were in about $1-2 \%$. When the mixing times were varied, stearic acid had a significant inverse effect on the cohesion values.

Dispersibility: It is a direct measure of the ability of a given powder to become fluidized or flooded (9-11). When the mixing time was constant, stearic acid had a minor effect as compared to a much larger effect when magnesium stearate and CabO-Sil M5 imparted in higher amounts (Figure 9). When the mixing time was varied a minimum was observed at about equal concentrations of the three flow enhancers.

Moisture Content: Moisture content is a critical parameter that affects the flow and compaction behavior of powder blends. Various investigators have proposed different mechanistic explanations $(26,27)$. High levels of moisture content will affect adversely with the continuous flow of blend from the hopper to the die. As the moisture content in the powder increases, so do the cohesive forces between particles thereby increasing agglomeration of particles. During the compression process, an increased amount of absorbed water can either cause a gradual change in deformability of the particles (i.e. plasticize the glassy amorphous material) or can facilitate a temporary transition of the amorphous material from a glassy to a rubbery state. 
(a) Constant Mix Time

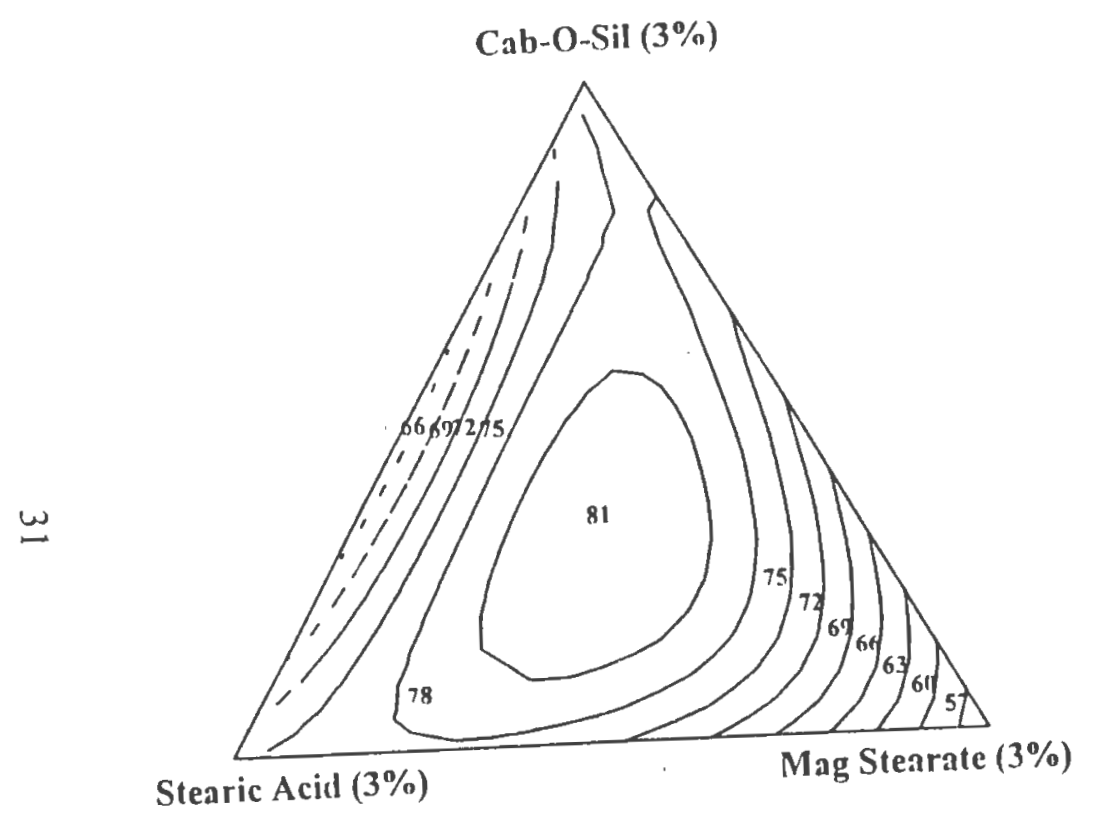

(b) Variable Mix 'Time

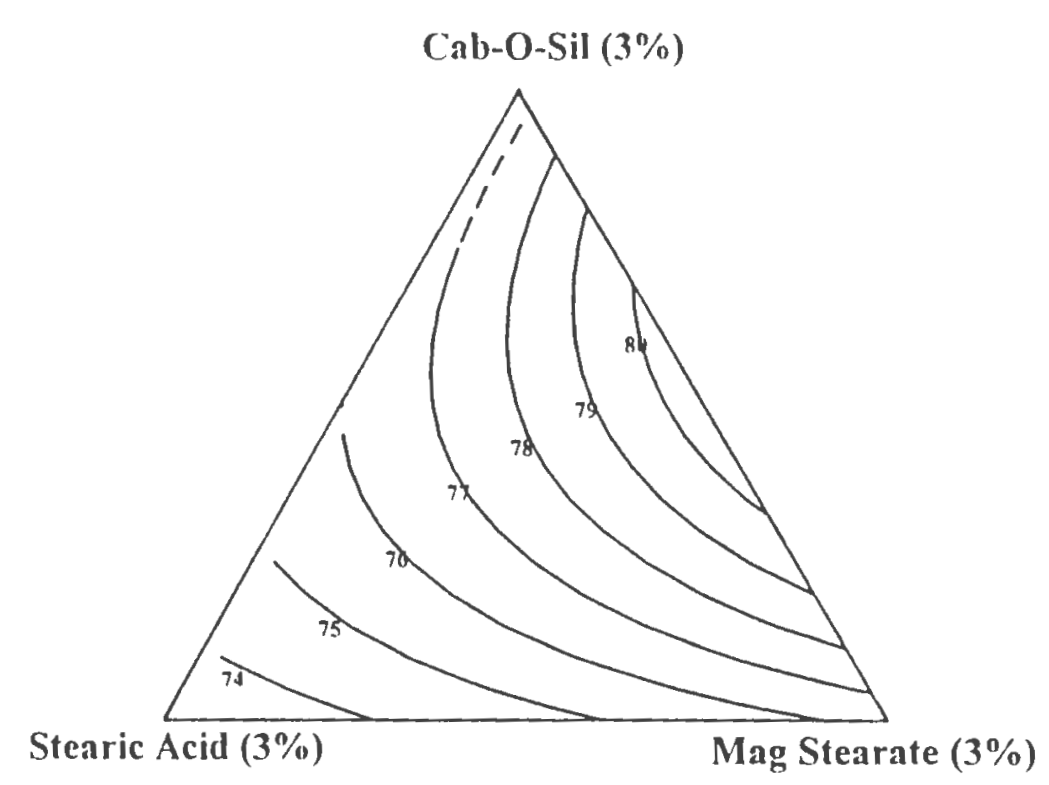

FIGURE 8. Contour Plots for Cohesion: (a) Constant Mix Time (b) Variable Mix Time 
(a) Constant Mix Time

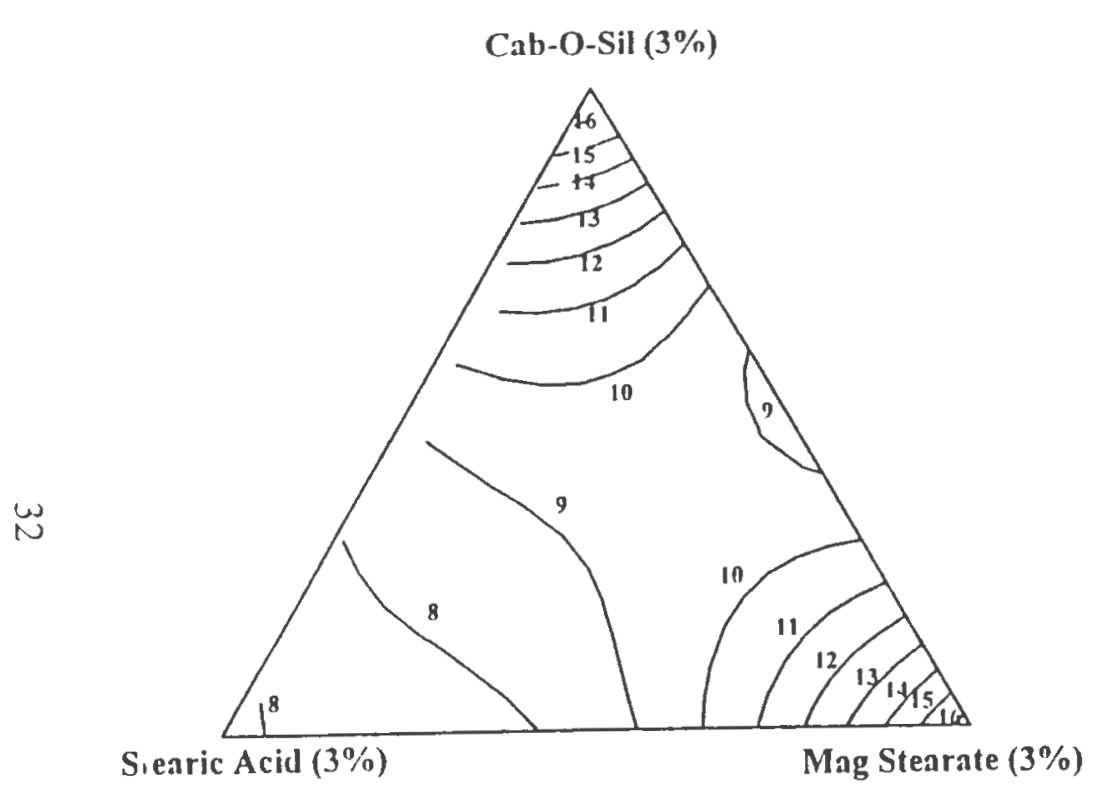

(b) Variable Mix Time

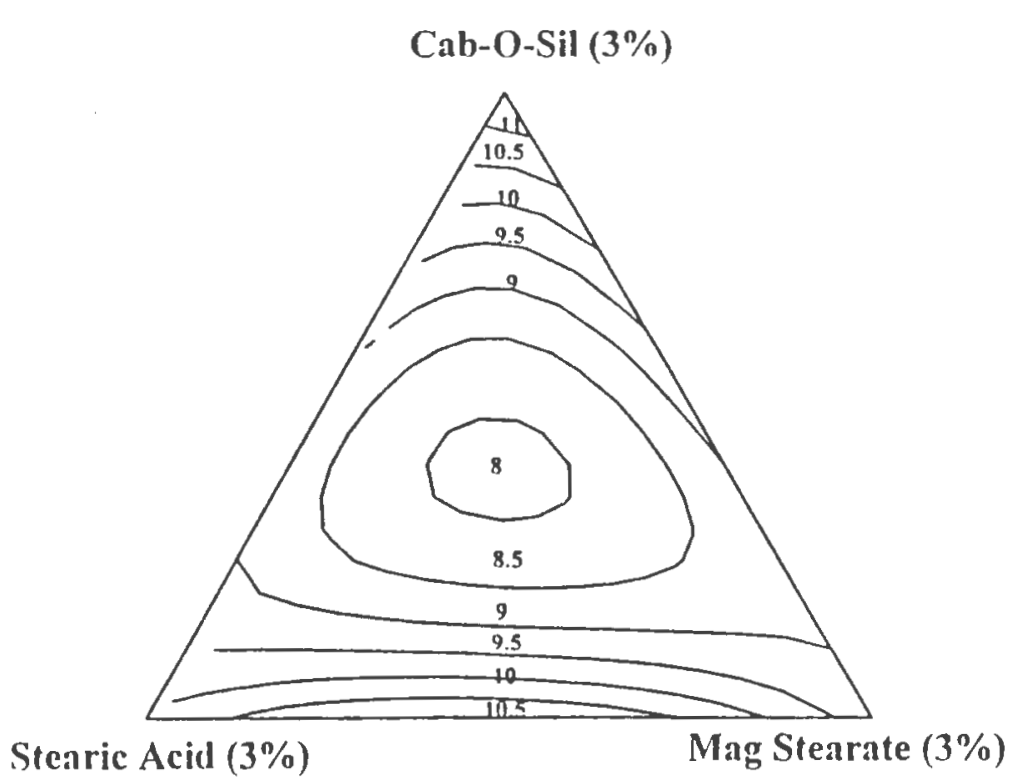

FIGURE 9. Contour PIots for Dispersibility: (a) Constant Mix Time (b) Variable Mix Time 
Moisture content also will have an adverse impact on the stability of pharmaceutical dosage forms. As the values for moisture content for various lactose blends reported in Tables 2, 3, 4, 5\&6 and indicate that there was not much significant variation in the moisture content. Figure 10 displays the effect of formulation composition on the moisture levels present in the lactose blends.

Particle Size Distribution: Particle size is a simple concept and yet a difficult one to quantitate. Feret's diameter, Martin's diameter, projected area diameter, specific area diameter, Stoke's diameter, and volume diameters are few of several measurements that have been used to quantify particle size. Reports in literature demonstrate that decreasing particle size resulted in an increased angle of repose, suggesting that the coefficient of interparticle friction increased with decreasing particle size $(4,5,7,8$, 14, 28-32). Some investigators using flow-through-an-orifice experiments reported that the flow rate increased with decreasing particle size (in contrast to angle of repose observations) until a maximum is reached; followed by a rapid decrease in flow at smaller particle size $(8,14)$. The decreased flow for small particles has been attributed to increased Van der Waals, electrostatic and surface tension forces, while the decreased flow at larger particle sizes may be partly due to the size of the orifice relative to that of the particles (4). Poor flow due to high quantity of drug present in the high dose formulations is related to the cohesive energies associated with the fine particles. Cohesive stress, which is the cohesive force per unit surface area, is smaller for the larger particles. This is the reason, why fine particles are more cohesive and increasing particle size improves flow (9-11). 
(a) Constant Mix Time

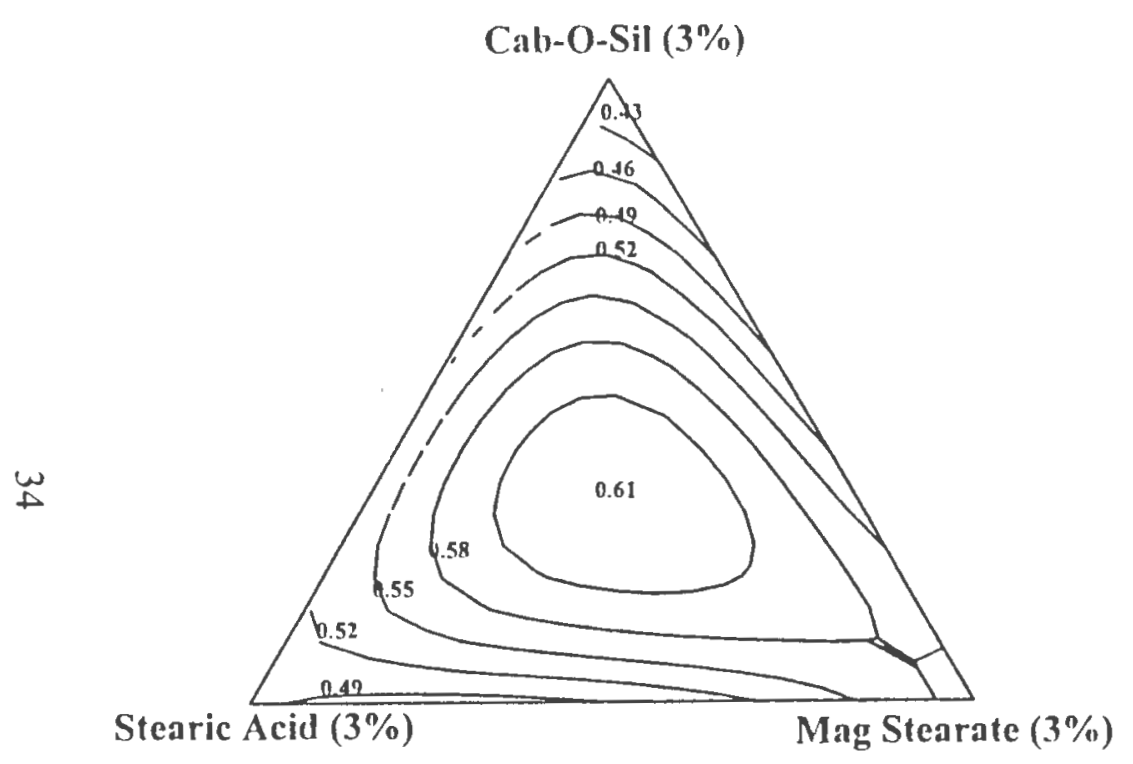

(b) Variable Mix Time

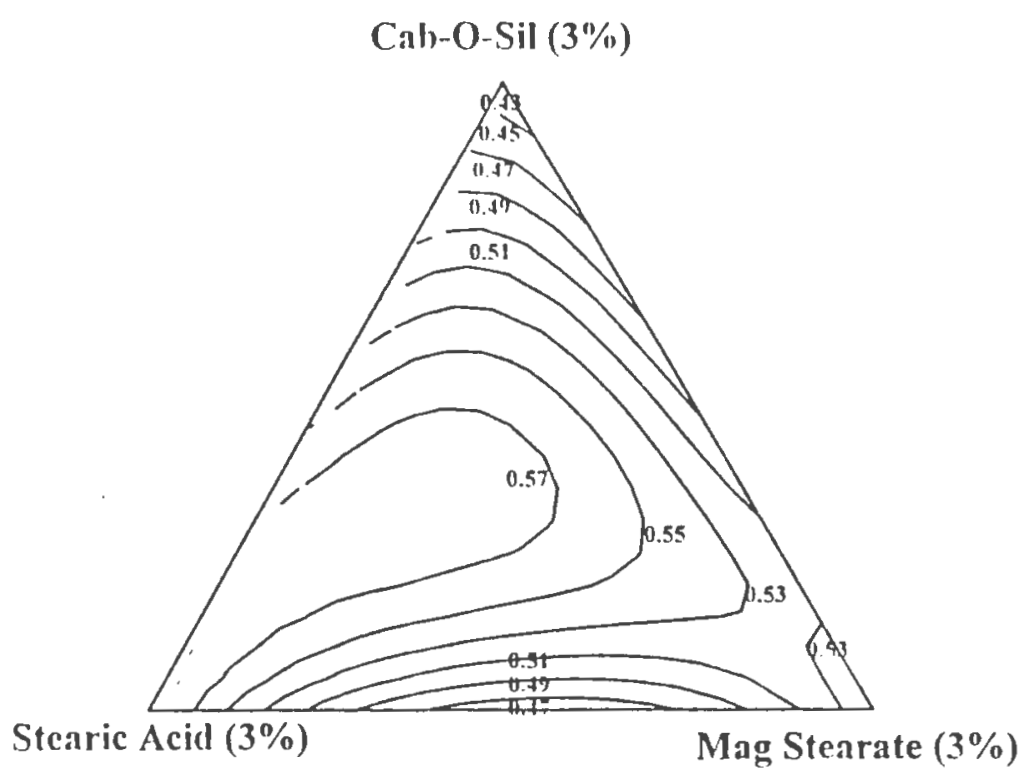

FIGURE 10. Contour Plots Moisture Content: (a) Constant Mix Time (b) Variable Mix Time 
In this study, the mean particle size for different blends was determined by sieve analysis and the data is provided in Tables 2, 3, 4, 5\&6 and Figure 11. When the mixing time was kept constant, the mean particle size values varied from 145 to 180 microns. There were minor increases in the mean particle size when the amount of Cab-O-Sil M5 was altered. These variations are probably due to the random adsorption of Cab-O-Sil M5 particles on the surface of the lactose particles (33). When the mixing times were varied, Cab-O-Sil M5 did not have any significant effect and the mean particle size remained small. In both sets of experiments, stearic acid and magnesium stearate had similar effects (Figure 11).

Mixing Time: Among all the parameters, mixing time is one critical parameter that has implications on flowability of powders and uniform distribution of drug in the powder blend. Mixing is defined as a process that results in randomization of dissimilar particles within any system (34). Mixing is a critical process that dictates the flow of pharmaceutical powders. Many investigations have been reported with the effects of physical and chemical properties of materials on powder processing (34-39). There are many parameters that affect mixing process and these include type of mixer, nature of individual components of the mixture, order of addition of components to the batch, batch size, mixing speed, mixing time etc (40-42). The effect of mixing time needs to be evaluated carefully as too much mixing time will result in demixing of powders (43-45). Longer mixing times with lubricants result in lower tablet hardness values.

From the flow data generated in this study, it is evident that significant differences in powder characteristics were noticed based on the mixing times. 
(a) Constant Mix 'lime

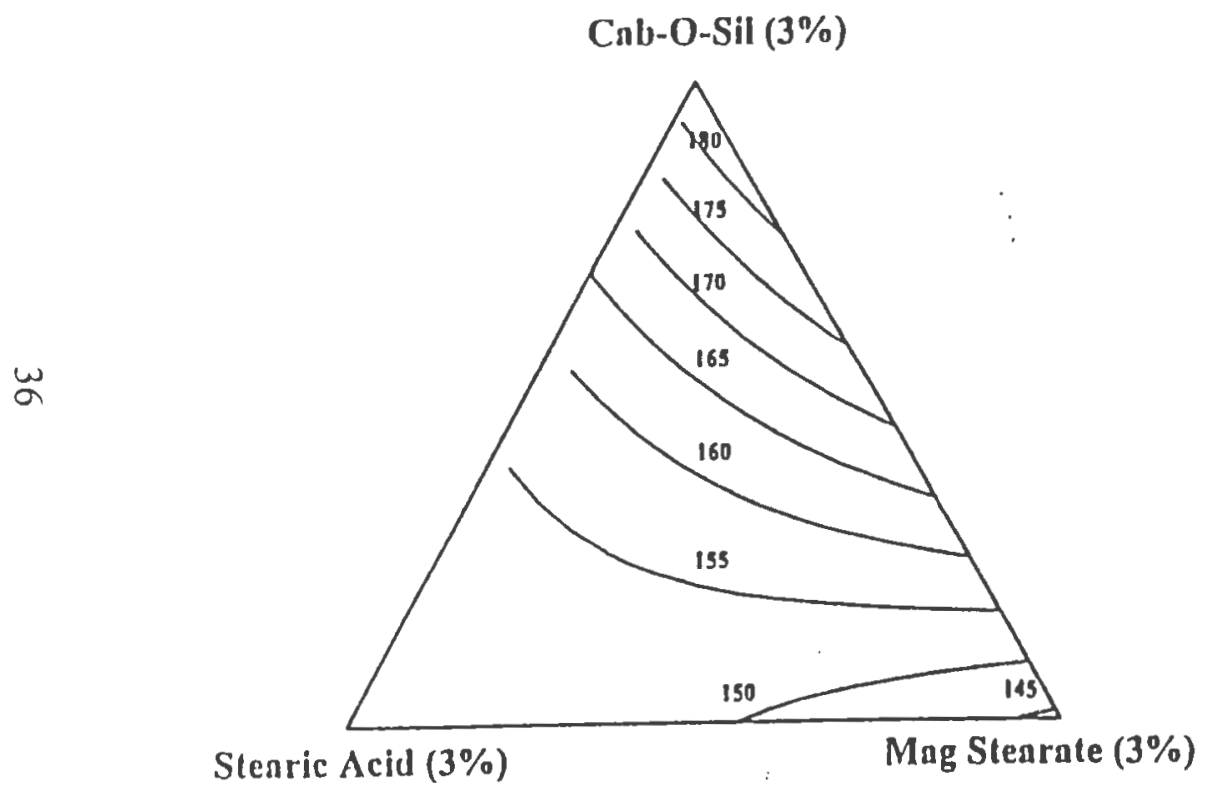

(b) Variable Mix 'lime

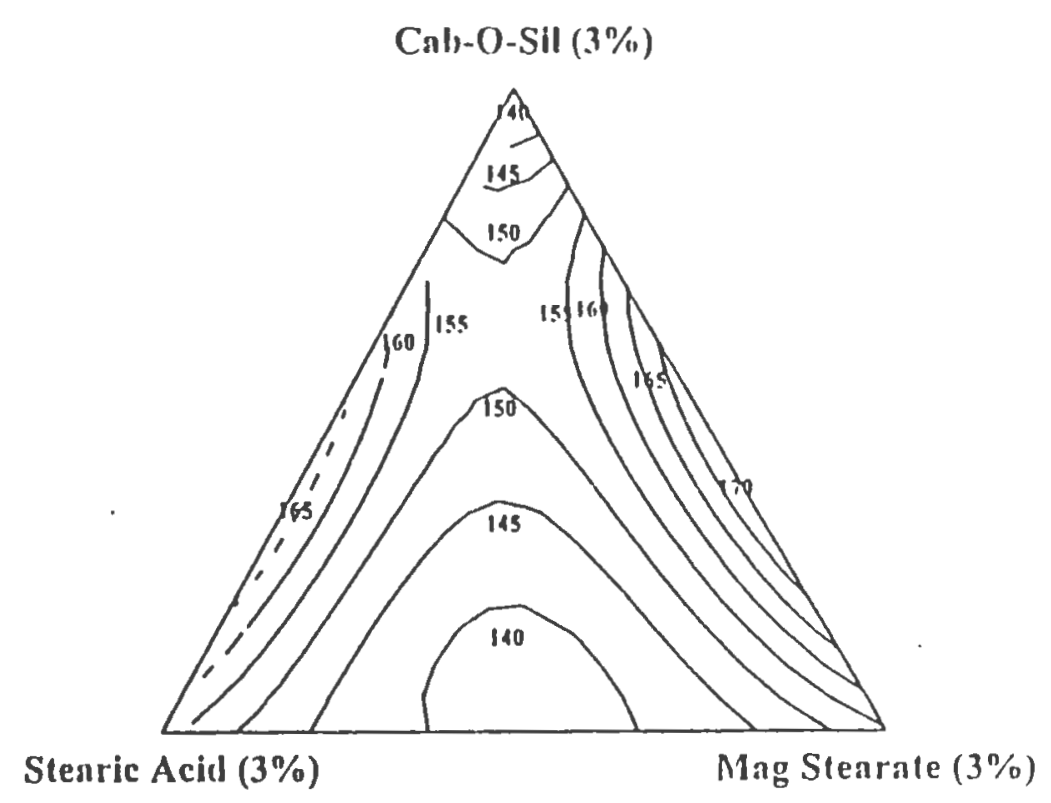

FIGURE 11. Contour Plots for Mean Particle Size: (a) Constant Mix 'Time (b) Variable Mix Tïme 
As seen from the contour plot for Mix Time (Figure 12), Cab-O-Sil M5 had a significant effect on the mixing time required to obtain a constant bulk density for lactose blend. As the amount of Cab-O-Sil M5 was increased in the formulation, the mixing time required to achieve a constant bulk density had to be increased. The high amounts of stearic acid and magnesium stearate with low amounts of Cab-O-Sil M5 seem to provide shorter mix times so as to obtain constant bulk density. Thus from the information obtained in the current investigation, the optimum mixing time to achieve a constant bulk density for a lactose blend can be determined.

From the powder data summarized in Tables $2,3,4,5$ and 6 , it is evident that there are significant differences between the actual values and theoretical values calculated from individual components assuming a linear relationship between the mixture and its components. The same can be confirmed from the response surfaces for various powder properties of the lactose blends. This supports the theory that the relationship for powder properties between the mixture and its components is more complex and not linear. Also from the data presented in this paper, one can determine the optimum composition of the flow enhancers required, optimum mix time to achieve constant bulk density so that the final blend will display optimum flow behavior.

Optimization: The regression coefficients for special cubic model fitted for powder data obtained at constant mix time ( 7 runs) and variable mix times ( 7 runs) are summarized in Table 7 and Table 8. These regression coefficients were used to generate predicted values for various powder parameters in order to check the validity 


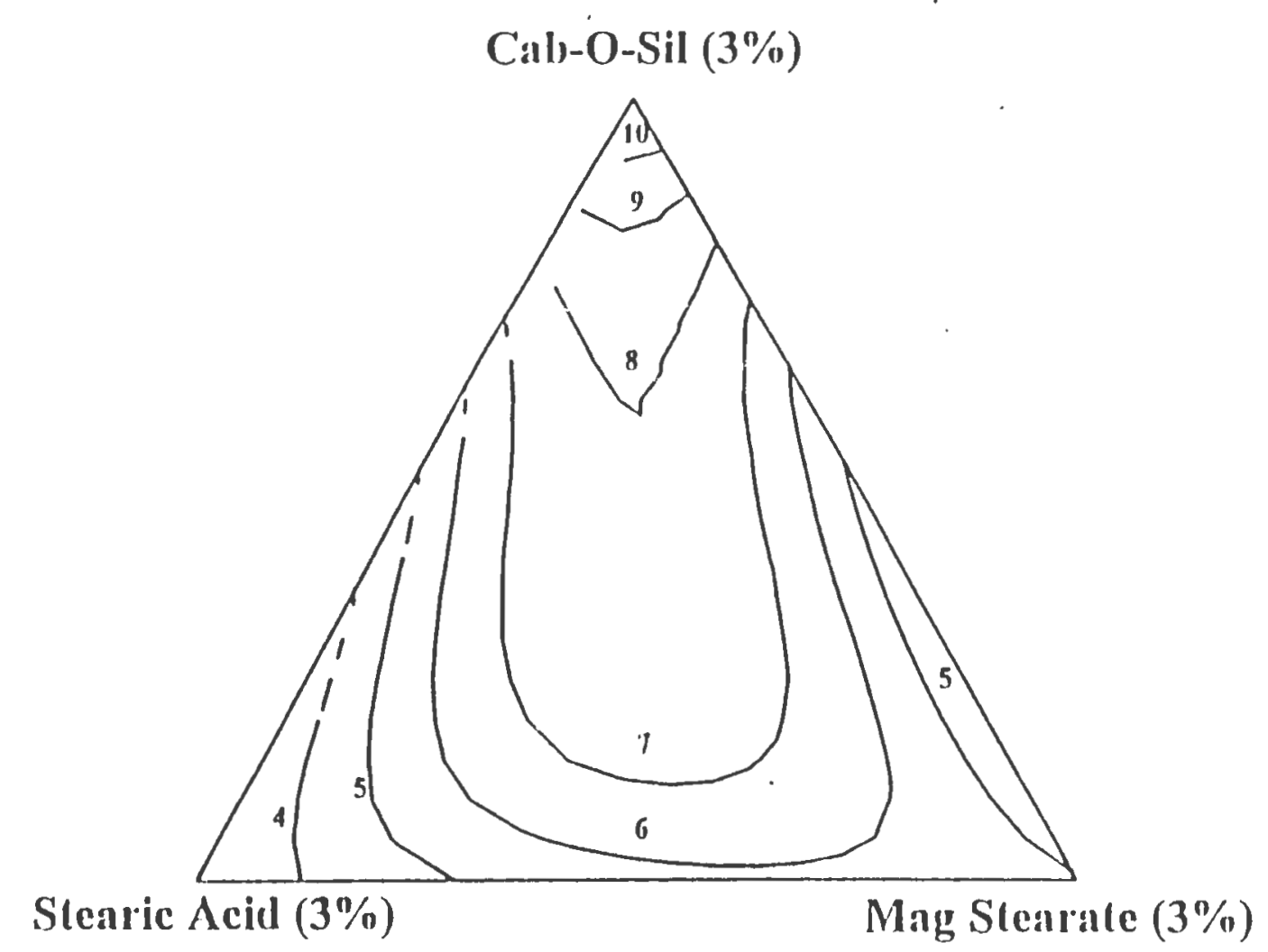

FIGURE 12. Contour Plot for Mixing Time to obtain Maximum Bulk Density 
TABLE 7. Regression Coefficients of Special Cubic Models Fitted for Powder Data

\begin{tabular}{|c|c|c|c|c|c|c|}
\hline Coefficients & \multicolumn{2}{|c|}{ B1 } & \multicolumn{2}{|c|}{$\mathbf{B 2}$} & \multicolumn{2}{|c|}{ B3 } \\
\hline Response Parameter & $\begin{array}{c}\text { Constant Mx } \\
\text { Time }\end{array}$ & $\begin{array}{c}\text { Variable } M x \\
\text { Time }\end{array}$ & $\begin{array}{c}\text { Constant Mix } \\
\text { Time }\end{array}$ & \begin{tabular}{|c|}
$\begin{array}{c}\text { Variable } \mathbf{M x} \\
\text { Tine }\end{array}$ \\
\end{tabular} & $\begin{array}{c}\text { Constant Mix } \\
\text { Time }\end{array}$ & \begin{tabular}{|c|} 
Variable $\mathrm{Mx}$ \\
Time
\end{tabular} \\
\hline Angle of Repose & 40.9 & 37.2 & 48.0 & 420 & 45.9 & 38.7 \\
\hline Angle of Fall & 221 & 19.9 & 29.2 & 17.9 & 24.6 & 24.9 \\
\hline Angle of Differenoe & 18.8 & 17.3 & 18.9 & 24.0 & 21.4 & 13.8 \\
\hline Aerated Bulk Density & 0.53 & 0.65 & 0.60 & 0.67 & 0.69 & 0.70 \\
\hline Packed Bulk Density & 0.77 & 0.86 & 0.80 & 0.86 & 0.85 & 0.88 \\
\hline Compressibility & 31.4 & 24.5 & 25.8 & 22.4 & 19.0 & 21.3 \\
\hline Cohesiveness & 79.7 & 76.5 & 74.6 & 73.1 & 54.5 & 76.3 \\
\hline Angle of Spetula & 42.0 & 38.2 & 41.8 & 32.1 & 40.0 & 36.8 \\
\hline Dispersibility & 17.4 & 11.5 & 8.4 & 10.1 & 16.5 & 9.2 \\
\hline Mbisture Content & 0.40 & 0.42 & 0.50 & 0.60 & 0.60 & 0.55 \\
\hline Flonebility Index & 67.1 & - & 0.65 & - & 69.8 & - \\
\hline Floodability Index & 0.56 & - & 0.62 & - & 0.66 & - \\
\hline Buk Density & 0.53 & - & 0.65 & - & 0.65 & - \\
\hline Tapped Density & 0.73 & - & 0.86 & - & 0.90 & - \\
\hline Partide size & 183.9 & 130.0 & 153.4 & 156.4 & 144.0 & 154.3 \\
\hline Mxing Time & - & 11.3 & - & 3.1 & - & 5.1 \\
\hline
\end{tabular}


TABLE 8. Regression Coefficients of Special Cubic Models Fitted for Powder Data

\begin{tabular}{|c|c|c|c|c|c|c|c|c|}
\hline \multirow{2}{*}{$\frac{\text { Coefficients }}{\text { Response Parameter }}$} & \multicolumn{2}{|c|}{$\mathrm{B} 12$} & \multicolumn{2}{|c|}{$\mathrm{B} 13$} & \multicolumn{2}{|c|}{$\mathrm{B23}$} & \multicolumn{2}{|c|}{ B123 } \\
\hline & $\begin{array}{l}\text { Constant } \\
\text { Mix Time }\end{array}$ & $\begin{array}{c}\text { Variable } \\
\text { Mix Time } \\
\end{array}$ & $\begin{array}{l}\text { Constant } \\
\text { Mix Time }\end{array}$ & $\begin{array}{c}\text { Váriable } \\
\text { Mix Time } \\
\end{array}$ & $\begin{array}{c}\text { Constant } \\
\text { Mix Time } \\
\end{array}$ & $\begin{array}{c}\text { Variable } \\
\text { Mix Time } \\
\end{array}$ & $\begin{array}{r}\text { Constant } \\
\text { Mix Time } \\
\end{array}$ & $\begin{array}{l}\text { Variable } \\
\text { Mix time }\end{array}$ \\
\hline Angle of Repose & -31.8 & -3.0 & -17.4 & 10.6 & -41.1 & -9.4 & 119.4 & 12.0 \\
\hline Angle of Fall & -33.8 & 24.1 & -8.6 & 2.8 & -22.8 & -8.5 & 116.4 & -154.0 \\
\hline Angle of Difference & 1.9 & -27.1 & -8.7 & $79^{\circ}$ & -18.3 & -0.9 & 3.0 & 166.0 \\
\hline Aerated Bulk Density & 0.33 & -0.01 & -0.19 & -0.25 & -0.03 & 0.09 & -0.53 & 0.17 \\
\hline Packed Bulk Density & 0.10 & 0.00 & -0.01 & -0.08 & 0.27 & 0.03 & -0.45 & 0.34 \\
\hline Compressibility & -31.7 & 1.0 & 20.2 & 15.4 & 26.7 & -7.9 & 32.7 & 31.6 \\
\hline Cohesiveness & -51.2 & 4.6 & 19.0 & 16.6 & 43.4 & -0.26 & 351 & -6.5 \\
\hline Angle of Spatula & -14.1 & -4.5 & -0.2 & -0.0 & -3.1 & 2.5 & -50.3 & 108.7 \\
\hline Dispersibility & -14.8 & -7.5 & -33.0 & -4.7 & -15.6 & 5.3 & 58.3 & -41.8 \\
\hline Moisture Content & 0.28 & 0.12 & 0.00 & 0.01 & -0.28 & 0.46 & 3.54 & 2.53 \\
\hline Flowability Index & 44.0 & - & 9.8 & - & -0.44 & - & -221.7 & - \\
\hline Floodability Index & 0.03 & - & 0.02 & - & 0.03 & - & -0.41 & - \\
\hline Bulk Density & 0.02 & - & -0.02 & - & 0.11 & - & -0.45 & - \\
\hline Tapped Density & 0.13 & - & 0.02 & - & 0.01 & - & -0.29 & - \\
\hline Partide size & -46.8 & 92.4 & 31.7 & 128.0 & 6.9 & -67.1 & -27.1 & -533.1 \\
\hline Mixing Tine & - & -9.2 & - & -13.3 & - & 6.3 & - & 86.3 \\
\hline
\end{tabular}


of the simplex design. Blend $\# 8,9$ and 10 were used as check points to determine the validity of the simplex design. The powder blends were evaluated for various flow parameters and the values thus obtained were considered actual values. Using the regression coefficients in Tables 7 and 8, and composition of Blend \#8,9,10 as per the design described in Table 1, the predicted values for flow parameters were calculated. The actual and predicted values for different flow parameters are summarized in Table 9. It is evident that the model used to fit the data was adequate as indicated by the insignificance of lack of fit and the narrower differences between the actual values and that predicted by the model (Table 9).

Optimization was performed to maximize the flow behavior of the formulation by using a constant mix time. It was accomplished by minimizing the angle of repose, angle of spatula, angle of difference, compressibility index, cohesiveness, dispersibility and floodability index and by maximizing the angle of fall, aerated bulk density, bulk density and flowability index (Table 10). Based on the results obtained from minimization and maximization processes, the following constraints were imposed on the model so that the best possible compromise can be obtained for formulation composition:

1. Cab-O-Sil M5 + Stearic Acid + Magnesium Stearate $=3.0$

2. Angle of Repose $<=38.0$

3. Compressibility Index $<=24.0$

4. Aerated Bulk Density $>=0.62$

5. Floodability Index $<=72.0$ 
TABLE 9. Use of Check Poin ts for Testing Lack of Fit (Constant Mix Time)

\begin{tabular}{|l|c|c|c|c|c|c|}
\cline { 2 - 7 } \multicolumn{1}{c|}{} & \multicolumn{2}{c|}{ Blend\#8 } & \multicolumn{2}{c|}{ Blend\#9 } & \multicolumn{2}{c|}{ Blend\#10 } \\
\hline Response & Actual & Predicted & Actual & Predicted & Actual & Predicted \\
\hline Angle of Repose $\left(^{\circ}\right)$ & 38.7 & 40.1 & 38.2 & 38.5 & 41.2 & 40.3 \\
\hline Angle of Fall $\left(^{\circ}\right)$ & 19.5 & 22.9 & 19.2 & 20.5 & 24.3 & 22.7 \\
\hline Angle of Difference $\left(^{\circ}\right)$ & 19.2 & 17.3 & 19.0 & 18.0 & 16.9 & 17.6 \\
\hline Aerated Bulk Density(g/cc) & 0.63 & 0.68 & 0.56 & 0.64 & 0.62 & 0.67 \\
\hline Packed Bulk Density(g/cc) & 0.86 & 0.84 & 0.81 & 0.80 & 0.88 & 0.85 \\
\hline Compressibility (\%) & 26.4 & 26.2 & 30.8 & 28.4 & 29.9 & 27.1 \\
\hline Cohesiveness (\%) & 79.7 & 78.3 & 81.9 & 78.8 & 82.4 & 74.1 \\
\hline Angle of Spatula ( $\left.{ }^{\circ}\right)$ & 40.5 & 38.7 & 43.7 & 39.1 & 37.0 & 39.0 \\
\hline Dispersibility (\%) & 8.7 & 8.0 & 11.8 & 11.1 & 7.0 & 10.6 \\
\hline Moisture Content (\%) & 0.60 & 0.57 & 0.60 & 0.54 & 0.60 & 0.59 \\
\hline Bulk Density (g/cc) & 0.66 & 0.63 & 0.56 & 0.56 & 0.62 & 0.63 \\
\hline Tapped Density (g/cc) & 0.86 & 0.86 & 0.80 & 0.79 & 0.85 & 0.86 \\
\hline Particle size (microns) & 148.4 & 152.9 & 172.6 & 170.2 & 152.2 & 154.7 \\
\hline \hline
\end{tabular}




\section{TABLE 10. Optimization Process}

\begin{tabular}{|c|c|c|}
\hline & MINIMIZE & MAXIMIZE \\
\hline & - Angle of Repose & - Angle of Fall \\
\hline & - Angle of Spatula & - $\quad$ Aerated Bulk Density \\
\hline & - Angle of Difference & - Bulk Density \\
\hline & - Compressibility Index & - $\quad$ Flowability Index \\
\hline & - Cohesiveness & \\
\hline$\omega$ & - Dispersibility & \\
\hline & - Floodability Index & \\
\hline
\end{tabular}




\section{TABLE 11. Optimum Composition}

\begin{tabular}{|c|}
\hline COMPOSITION \\
\hline Lactose Anhydrous $=97.0 \% \mathrm{w} / \mathrm{w}$ \\
\hline Cab-0-Sil \\
$X_{1}=1.27 \% \mathrm{w} / \mathrm{w}$ \\
\hline Stearic Acid \\
$\mathrm{X}_{2}=1.48 \% \mathrm{w} / \mathrm{w}$ \\
\hline Magnesium Stearate \\
$\mathrm{X}_{3}=0.25 \% \mathrm{w} / \mathrm{w}$ \\
\hline
\end{tabular}

\begin{tabular}{|l|c|}
\hline \multicolumn{1}{|c|}{ Response Parameter } & Predicted \\
\hline Angle of Repose $\left({ }^{\circ}\right)$ & 37.9 \\
\hline Angle of Fall $\left({ }^{\circ}\right)$ & 19.4 \\
\hline Angle of Difference $\left(^{\circ}\right)$ & 18.5 \\
\hline Aerated Bulk Density $(\mathrm{g} / \mathrm{cc})$ & 0.63 \\
\hline Packed Bulk Density(g/cc) & 0.83 \\
\hline Compressibility (\%) & 23.4 \\
\hline Cohesiveness (\%) & 72.9 \\
\hline Angle of Spatula $\left({ }^{\circ}\right)$ & 37.9 \\
\hline Dispersibility $(\%)$ & 9.0 \\
\hline Moisture Content $(\%)$ & 0.58 \\
\hline Flowability Index & 55.1 \\
\hline Floodability Index & 72.0 \\
\hline Bulk Density (g/cc) & 0.60 \\
\hline Tapped Density (g/cc) & 0.84 \\
\hline Particle size (microns) & 157.0 \\
\hline
\end{tabular}

\begin{tabular}{|c|}
\hline CONSTRAINTS \\
\hline Cab-0-Sil + Stearic Acid + Magnesium Stearate $=3.0$ \\
\hline Angle of Repose $<=38.0$ \\
\hline Compressibility Index $<=24.0$ \\
\hline Aerated Bulk Density $>=0.62$ \\
\hline Floodability Index $<=72.0$ \\
\hline
\end{tabular}


For lactose blends with constant mix time, using the above mentioned constraints, the model predicted the following composition for blend that will have optimum flow properties: Cab-O-Sil M5 $=1.27 \%$, Stearic Acid $=1.48 \%$ and Magnesium Stearate $=$ $0.25 \%$ (Table 11 ). The model also predicted the response values for various powder properties. As evident from the predicted values summarized in Table 11, the model predicted composition display optimum flow behavior. 


\section{CONCLUSIONS}

The powder properties of lactose anhydrous blends by incorporating magnesium stearate, stearic acid and $\mathrm{Cab}-\mathrm{O}-\mathrm{Sil} \mathrm{M} 5$ in varying amounts from 0 to $3 \%$ as per the simplex design were analyzed. One set of the powder blends was mixed at a constant mix time of three minutes and another set of experiments with variable mix times to achieve constant bulk density was performed. The mixed systems and individual components were evaluated for powder characteristics such as bulk density, tapped density, aerated bulk density, packed bulk density, compressibility index, angle of repose, angle of spatula, angle of fall, angle of difference, cohesiveness, dispersibility, moisture content and particle size distribution.

From the different powder parameters evaluated, it can be summarized that the relationship for powder properties between the mixture and its components is nonlinear. Significant differences were observed in the flow behavior of powder blends obtained with constant mixing time and those obtained with variable mixing times. Among the three variable components, Cab-O-Sil M5 had a significant effect on the time required to achieve constant bulk density of a powder blend.

This study demonstrated that by using simplex design, the flow behavior of lactose blend can be optimized. For constant mix time study, the model predicted that lactose anhydrous would show optimum flow behavior with $0.25 \% \mathrm{w} / \mathrm{w}$ magnesium stearate, $1.48 \%$ w/w stearic acid and $1.27 \%$ w/w Cab-O-Sil M5.

Thus from the response surface contour plots and the mathematical model equations, one can determine the optimum composition of the flow enhancers 
required, optimum mix time to achieve constant bulk density so that the final blend will display optimum flow behavior. 


\section{REFERENCES}

1. Kumar, V., Sunder, N. and Potdar, A. Critical factors in developing pharmaceutical formulations - An overview, Part I. Pharmaceutical Technology, 16: 94-102 (1992).

2. Kumar, V., Sunder, N. and Potdar, A. Critical factors in developing pharmaceutical formulations - An overview, Part II. Pharmaceutical Technology, 16: 86-92 (1992).

3. Stamm, A. Process and dosage form controls: Formulation factors. Drug Development and Industrial Pharmacy, 15: $965-974$ (1989).

4. Hartley, P. A., Parfitt, G. D., and Pollack, L. B. The role of the Van der Waals force in the agglomeration of powders containing submicron particles. Powder Technology, 42: 35-46 (1985).

5. Hiestand, E. N. Powders: Particle-particle interactions. Journal of Pharmaceutical Sciences, 55(12): 1325-1344 (1966).

6. Wong, L. W. and Pilpel, N. The effect of shape of fine particles on the formulation of ordered mixtures. Journal of Pharmacy and Pharmacology, 40: 567-568 (1988).

7. Otsuka, A., Iida, K., Danjo, K. and Sunada, H. Measurement of adhesive force between particles. III. Effect of particle shape and surface asperity. Chemical Pharmaceutical Bulletin, 36: $741-749$ (1988).

8. Amidon, G. E. Physical and mechanical property characterization of powders. In Brittain, H.G. (Ed.), Physical Characterization of Pharmaceutical Solids, Marcel Dekker, Inc., New York, 281-319 (1995). 
9. Carr, R. L. Classifying flow properties of solids. Chemical Engineering, 72: 69 (1965).

10. Carr, R. L. Evaluating flow properties of solids. Chemical Engineering, 72: 163168 (1965).

11. Carr, R. L. Particle behavior storage and flow. British Journal of Chemical Engineering, 15: 1541 (1970).

12. Buslik, D. A proposed universal homogeneity and mixing index. Powder Technology, 7: 111-116(1973).

13. Staniforth, P. T. and Berry, R. E. R. A general flowability index for powders, Powder Technology, 8: 243 (1973).

14. Amidon, G. E. and Houghton, M. E. Powder flow testing in preformulation and formulation development. Pharmaceutical Manufacturing, July, 21-31 (1985).

15. Johanson, J. R. Predicting segregation of bimodal particle mixtures using the flow properties of bulk solids. Pharmaceutical Technology, 20: 46-57 (1996).

16. Carson J. W. and Marinelli, J. Characterize bulk solids to ensure smooth flow. Chemical Engineering, April, 78-90 (1994).

17. Stetsko, G. Statistical experimental design and its application to pharmaceutical development problems. Drug Development and Industrial Pharmacy, 12: 1109$1123(1986)$.

18. Schwartz, J. B. and O'Connor, R. E. Optimization techniques in pharmaceutical formulation and processing. In Banker, G.S. and Rhodes, C.T. (Eds.), Modern Pharmaceutics, $3^{\text {rd }}$ Edition, Marcel Dekker, Inc., New York, 727-772 (1996). 
19. Scheffe, H. The simplex-centroid design for experiments with mixtures. Journal of Royal Statistical Society, B25: 235-263 (1963).

20. Scheffe, H. Experiments with mixtures. Journal of Royal Statistical Society, B20: 344-360 (1958).

21. Gorman, J. W. and Hinman, J. E. Simplex lattice designs for multicomponent systems. Technometrics, 4: 463-487 (1962).

22. Spendley, W., Hext, G. R. and Hinsworth, F. R. Sequential application of simplex designs in optimization and evolutionary operation. Technometrics, 4: 441-461 (1962).

23. Statgraphics ${ }^{\circledR}$ Plus for Windows, Version 2.0, Manugistics, Inc., Rockville, Maryland, USA.

24. Sheskey, P. J. and Dasbach, T. P. Evaluation of various polymers as dry binders in the preparation of an immediate release tablet formulation by roller compaction. Pharmaceutical Technology, 19: 98-112 (1995).

25. Zuurman, G. K. Bolhuis and H. Vromans. Effect of binder on the relationship between bulk density and compactibility of lactose granulations. International Journal of Pharmaceutics, 119: 65-69 (1995).

26. Shotton, E. J. and Harb, N. The effect of humidity and temperature on the cohesion of powders. Journal of Pharmacy and Pharmacology, 18: 175-178 (1966).

27. Amidon, G. E and Houghton, M. E. The effect of moisture on the mechanical and powder flow properties of microcrystalline cellulose. Pharmaceutical Research, 12: 923-929 (1995). 
28. Johnson, M. C. R. The effect of particle size upon mixture homogeneity. Pharmaceutica Acta Helvetiae, 50 (3): 60-63 (1975).

29. Williams, J. C. and Khan, M. I. The mixing and segregation of particulate solids of different particle size. The Chemical Engineer, January, 19-25 (1973).

30. Chowhan, Z. T. Segregation of particulate solids-Part I. Pharmaceutical Technology, 19: 56-70 (1995).

31. Chowhan, Z. T. Segregation of particulate solids-Part II Pharmaceutical Technology, 19: 80-94 (1995).

32. Vachon, M. G. and Chulia, D. The use of particle characteristics to elucidate mix homogeneity in binary powder blends. Drug Development and Industrial Pharmacy, 24(10): 961-971 (1998).

33. Sindel, U., Schweiger, A. and Zimmermann, I. Determination of the optimum mixing time for a mixture of lactose and colloidal silicon dioxide. Journal of Pharmaceutical Sciences, 87 (4): 524-526 (1998).

34. Cooke, M. H., Stephens, D. J. and Bridgwater, J. Powder mixing- A literature survey. Powder Technology, 15: 1-20 (1976).

35. Hersey, J. A., Cook, P., Smyth, M., Bishop, E. A. and Clarke, E. A. Homogeneity of multicomponent powder mixtures. Journal of Pharmaceutical Sciences, 63(3): 408-411 (1974).

36. Staniforth, J. N. The effect of frictional charges on flow properties of direct compression tableting excipients. International Journal of Pharmaceutics, 11: 109-117 (1982). 
37. Chowhan, Z. T. and Chi, L. Drug-excipient interactions resulting from powder mixing III: Solid state properties and their effect on drug dissolution. Journal of Pharmaceutical Sciences, 75(6): 534-541 (1986).

38. Velasco, M. V., Munoz-Ruiz, A., Monedero, M. C. and Jimenez-Castellanos, M. R. Study of flowability of powders. Effect of the addition of lubricants. Drug Development and Industrial Pharmacy, 21(20): 2385-2391 (1995).

39. de Villiers, M. M. Description of the kinetics of the deagglomeration of drug particle agglomerates during powder mixing. International Journal of Pharmaceutics, 151:1-6 (1997).

40. Fuller, W. O. Mixing up a batch: Batch mixer types and selection tips. Powder and Bulk Engineering, January, 48-66 (1998).

41. Waters, A. J. Solving flow problems: How to select a bin retrofit. Powder and Bulk Engineering, November, 45-55 (1997).

42. Abouzied, A. Z. M. and Fuerstenau, D. W. Effect of mixing aids on the transport behavior of particulate solids. Powder Technology, 23: 261-271 (1979).

43. Johansson, M. E. Investigations of mixing time dependence of the lubricating properties of granular and powdered magnesium stearate. Acta Pharmaceutica Suec 22: 343-350 (1985).

44. Ragnarsson, G., Holzer, A. W., and Sjogren, J. The influence of mixing time and colloidal silica on the lubricating properties of magnesium stearate. International Journal of Pharmaceutics, 3: 127-131 (1979).

45. Khan, K. A., Musikabhumma, P. and Rubinstein, M. H. The effect of mixing time of magnesium stearate on the tabletting properties of dried microcrystalline cellulose. Pharmaceutica Acta Helvetiae, 58: 109-111 (1983). 
MANUSCRIPT II

ANALYSIS OF COMPRESSION BEHAVIOR OF MULTI-COMPONENT MIXTURES USING AN INSTRUMENTED TABLET PRESS 


\begin{abstract}
Purpose. To investigate the compression behavior of experimentally designed multicomponent mixtures using an instrumented tablet press. Methods. The mixtures comprised of Anhydrous Lactose, NF, Microcrystalline Cellulose, NF (Avicel PH101) and Pregelatinized Starch, NF (Starch 1500) with individual quantities varying from 0 to $99 \% \mathrm{w} / \mathrm{w}$ based on a simplex design. Magnesium Stearate, NF was added as lubricant at $1 \% \mathrm{w} / \mathrm{w}$ level. The batch size was 900 grams (equivalent to 3000 tablets). Ten experimental mixtures were prepared in a Collette Gral 10 High Shear Mixer with 3 minutes of pre-blending and 1 minute of lubricant mixing. The mixtures were evaluated for bulk and tapped densities, particle size distribution and moisture content. The mixtures were compressed using a 10-station instrumented rotary tablet press (Piccola 026 B10) equipped with a compression research system (PC-30, SMI Inc.) and 12/32" standard concave tooling at $1000 \mathrm{lbs}, 2000 \mathrm{lbs}, 3000 \mathrm{lbs}, 4000 \mathrm{lbs}, 5000$ lbs, $6000 \mathrm{lbs}$ and maximum achievable force. The compression force-time profiles were recorded to measure the de-aeration force, compression force and ejection force for each compression cycle. The tablets were evaluated for hardness, weight, thickness, friability and disintegration time. The true densities of tablets and mixtures were measured using a helium pycnometer (Ultrapycnometer 1000). Results. The compression force-time pulses for all the mixtures at each compressional force were compared to investigate the effect of mixture composition on the compression behavior of mixtures. Events such as rise time, fall time, dwell time, contact time, areas and pulse widths that characterize nature of each compression pulse were evaluated using a response surface methodology (StatgraphicsPlus). Heckel
\end{abstract}


relationships were plotted using the compressibility model. Conclusions. The results indicate that the compression behavior of multi-component mixtures as a function of component proportion provides critical information, which mimics the realistic formulation conditions. Such information, during the developmental stage will be useful to formulators to design a robust tablet formulation that will minimize problems during scale-up and production environment.

Key Words: multi-component mixtures; simplex design; contour plot; pharmaceutical excipients; flow; compression; instrumented tablet press; heckle plots; compression force-time curve; anhydrous lactose; microcrystalline cellulose; pregelatinized starch; magnesium stearate. 


\section{INTRODUCTION}

Interest and popularity of tablet dosage forms has brought increasing attention on the compression of pharmaceutical mixtures. The advantages of tablets are: 1) low manufacturing cost, 2) reduced liability to tampering, 3) less variation in dosage and 4) improved patient compliance as compared to other dosage forms. Tablets can be made either from granulations or powder blends. Since wet or dry granulation involves additional processing steps such as drying, milling, slugging or roller compaction, direct compression seems to be the method of choice for tablet manufacturing. However, poor compressibility along with the poor flowable nature of most of the pharmaceutical mixtures poses tremendous challenges during the scaleup and production stages. In this investigation, the compression behaviors of mixtures containing, several of the most commonly used excipients have been evaluated.

There are many ongoing investigations that focus on characterizing the compression behavior of pharmaceutical materials (1-9). Compression behavior of pharmaceutical blends is determined by factors such as individual excipients, type of tablet press, tooling, press speed, feed rate etc. Compression force-time profiles are used to characterize the compaction behavior of formulations with respect to their elastic and plastic properties. The compression force-time profile is a fingerprint for a formulation and can be useful in choosing excipients for direct compression and binders for granulation.

Powders consolidate under a compressive force by a variety of mechanisms, ranging from particle fragmentation to plastic and elastic deformation (9-14). Particle

fracture can be regarded as a virtually instantaneous process, while irreversible 
deformation resulting from plastic flow or viscoelasticity is comparatively slow, and greater consolidation may be achieved by applying force for a longer time. There are numerous reports in literature describing attempts to characterize compression forcetime profiles from single punch as well as from rotary tablet presses. The consolidation time can be defined as the time to reach the maximum force, the dwell time as the time at the maximum displacement of the punches and contact time as the time for compression and decompression. Parameters that characterize the shape of the compression force-time curves were developed by several authors $(5,9-14,17)$.

A typical compression event can be classified into three parts. The first one is the compression phase, when punches are penetrating into the die caused by the movement of their head curvature in contact with the pressure rollers. The second phase is the dwell time, when no vertical punch movements occur while the flat punch tops are moving over the compression rollers. In the third phase, the relaxation phase, the punch heads are leaving the pressure rollers. Figure 1 depicts the different phases of the compression event on a rotary tablet machine. Though tablets have been a choice of dosage form over other delivery systems and have been in practice for more than a century, yet remarkably little is known of the relationships involved in the behavior of powders and powder mixtures during compression. Most of the work published so far dealt with mainly single substances or binary mixtures. But in reality, a typical tablet dosage form is a multi-component system. The compression characteristics of multi-component mixtures were rarely investigated (9). Since the formation of a strong and coherent tablet depends on the process of powder consolidation, knowledge of the compression behavior of multi-component mixtures is 
essential for formulation scientists to optimize formulation composition. The instrumented tablet machines are considered to be very useful tools to evaluate the compaction behavior of pharmaceutical materials that make up the formulations. Usually, these materials differ in physical and chemical properties thereby making the compaction of multi-component mixtures more challenging.

Compression profiles may act as formulation 'finger-prints' and aid in troubleshooting. In spite of extensive research in tableting area, the basic questions still seem to be open. Is it possible to obtain some basic parameters from the forcetime curve in order to predict compression characteristics of different types of materials? How well can the most important mechanical properties of tablets are estimated from force-time curves? And, is it possible to predict the compression behavior of materials in high speed rotary machines used in production on the basis of compression data obtained from varying types of laboratory tablet machines?

The assessment of the compaction performances of the formulation ingredients is an important aspect of tablet product design and development. However, there is no standard compaction test method required by the pharmacopeias. Therefore data obtained from two or more compaction studies are not comparable, since because of the inconsistent techniques employed, the equipment (i.e. type of press and tooling), the parameters monitored (i.e. compaction speed, applied force, and punch displacement), or methods used to manipulate the compaction data (i.e. Heckel equation, work of compaction) vary widely in these studies (6). 


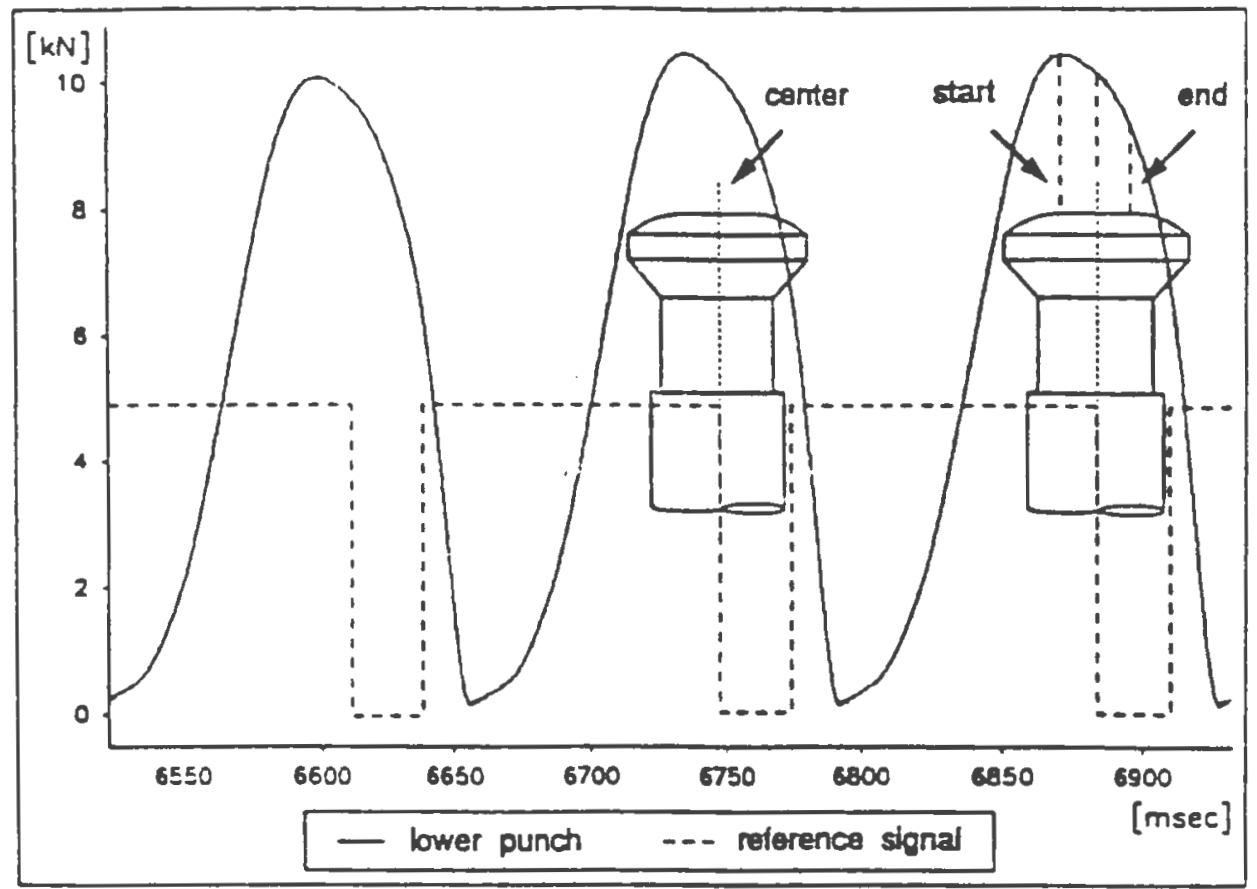

Figure 1. Different Phases of the Compression Cycle (14)

1) Compression: punch head moving against pressure roller

2) Dwell time: maximum deformation takes place

3) Relaxation: punch head leaving pressure roller 
Recently, Celik and Okutgen (15) optimized the parameters of tablet weight, lubrication, equipment, tooling, punch displacement profile, pressure range, as well as other pre-, during, and postcompaction parameters in their compaction studies, and proposed a standard compaction functionality 'tabletability' testing method capable of comparing the relative tabletability features of different materials and different lots of the same material with high sensitivity. Applying this test method, the authors generated 'compaction finger-prints' for a number of commonly used tableting excipients in order to establish a compaction data bank that can eventually be utilized as an informative reference source in tablet formulation studies.

A recent survey by Shangraw and Demarest (16) revealed a number of interesting facts about solid-dosage formulation design and development: lactose and microcrystalline cellulose are the most preferred fillers-binders and tradition is still a very important reason for the preference.

At present there are hardly any reports available in literature on behavior of multi-component mixtures during compression. But in reality, a typical tablet dosage form contains drug, filler, binder, disintegrant and lubricant. Most of the tableting research was done with individual components. The objective of this investigation was to evaluate the compression behavior of powder blends consisting of commonly used pharmaceutical excipients, namely, Anhydrous Lactose, NF, Microcrystalline Cellulose, NF (Avicel ${ }^{\circledast}$ PH101), Pregelatinized Starch, NF $\left(\right.$ Starch $^{\circledast 1500)}$ ) and Magnesium Stearate, NF. A simplex design was utilized to determine the effect of individual components comprising the mixtures on tablet properties. Compression 
parameters were determined from compression force-time pulse. Such information shall, help to develop a robust tablet formulation that will minimize problems during scale-up and production conditions. 


\section{METHODOLOGY}

\section{MATERIALS}

The materials used in this study were Anhydrous Lactose, NF (Sheffield Products, USA), Microcrystalline Cellulose, NF (Avicel ${ }^{\circledR}$ PH101) (FMC Inc, USA), Pregelatinized Starch, NF (Starch ${ }^{\circledR}$ 1500) (Colorcon Inc., USA) and Magnesium Stearate, NF (Mallinckrodt Co., USA).

\section{METHODS}

Preparation of Powder Blends: The powder blends were prepared using commonly used pharmaceutical excipients, namely, Anhydrous Lactose, NF, Microcrystalline Cellulose, NF (Avicel ${ }^{\circledR}$ PH101) and Pregclatinized Starch, NF (Starch ${ }^{\circledR}$ 1500) as per the simplex design described in Table 1. The quantities of the excipients were varied from 0 to $99 \% \mathrm{w} / \mathrm{w}$ as per the experimental design. The batch size for each blend was kept constant at 900 grams (equivalent to 3000 tablets). Magnesium Stearate, NF, at $1 \% \mathrm{w} / \mathrm{w}$ level, was added as lubricant. A total of ten blends were prepared as per the process described in Figure 2. The ingredients were passed through a \#30 mesh hand screen separately and the screened materials were placed in a Collette Gral 10 High Shear Mixer. The mixing was performed for three minutes at low speed (430 rpm) with chopper OFF. The lubricant was passed through a \#30 mesh hand screen and was mixed with the pre-blend for 1 minute at the same mixer settings. Each powder blend containing composition as per the simplex experimental design (Table 1) was prepared in a similar fashion. 
Table 1. Simplex Design for Blends used for Compression Analysis

\begin{tabular}{|c||c|c|c|c||}
\hline \multicolumn{1}{|c||}{} & \multicolumn{3}{|c||}{ Percentage of Each Ingredient in The Formulation (\%w/w) } \\
\hline \multirow{3}{*}{ Blend \# } & $\begin{array}{c}\text { Constant } \\
\text { Factor }\end{array}$ & \multicolumn{4}{c||}{ Variable Factors } \\
\cline { 2 - 5 } & $\begin{array}{c}\text { Magnesium } \\
\text { Stearate, NF }\end{array}$ & $\begin{array}{c}\text { Lactose } \\
\text { Anhydrous, NF } \\
\left(\mathrm{X}_{1}\right)\end{array}$ & $\begin{array}{c}\text { Microcrystalline } \\
\text { Cellulose, NF } \\
\text { Avicel }^{\circledR} \text { PH101) } \\
\left(\mathrm{X}_{2}\right)\end{array}$ & $\begin{array}{c}\text { Pregelatinized } \\
\text { Starch, NF } \\
\left.\text { Starch }^{\circledR} 1500\right) \\
\left(\mathrm{X}_{3}\right)\end{array}$ \\
\hline 1 & 1 & 99 & 0 & 0 \\
\hline 2 & 1 & 0 & 99 & 0 \\
\hline 3 & 1 & 0 & 0 & 99 \\
\hline 4 & 1 & 49.5 & 49.5 & 0 \\
\hline 5 & 1 & 49.5 & 0 & 49.5 \\
\hline 6 & 1 & 0 & 49.5 & 49.5 \\
\hline 7 & 1 & 33 & 33 & 33 \\
\hline $8^{*}$ & 1 & 66 & 16.5 & 16.5 \\
\hline $9^{*}$ & 1 & 16.5 & 66 & 16.5 \\
\hline $10^{*}$ & 1 & 16.5 & 16.5 & 66 \\
\hline Total & 1 & & 99 & \\
\hline
\end{tabular}

* Additional runs as check points for the Simplex Design 


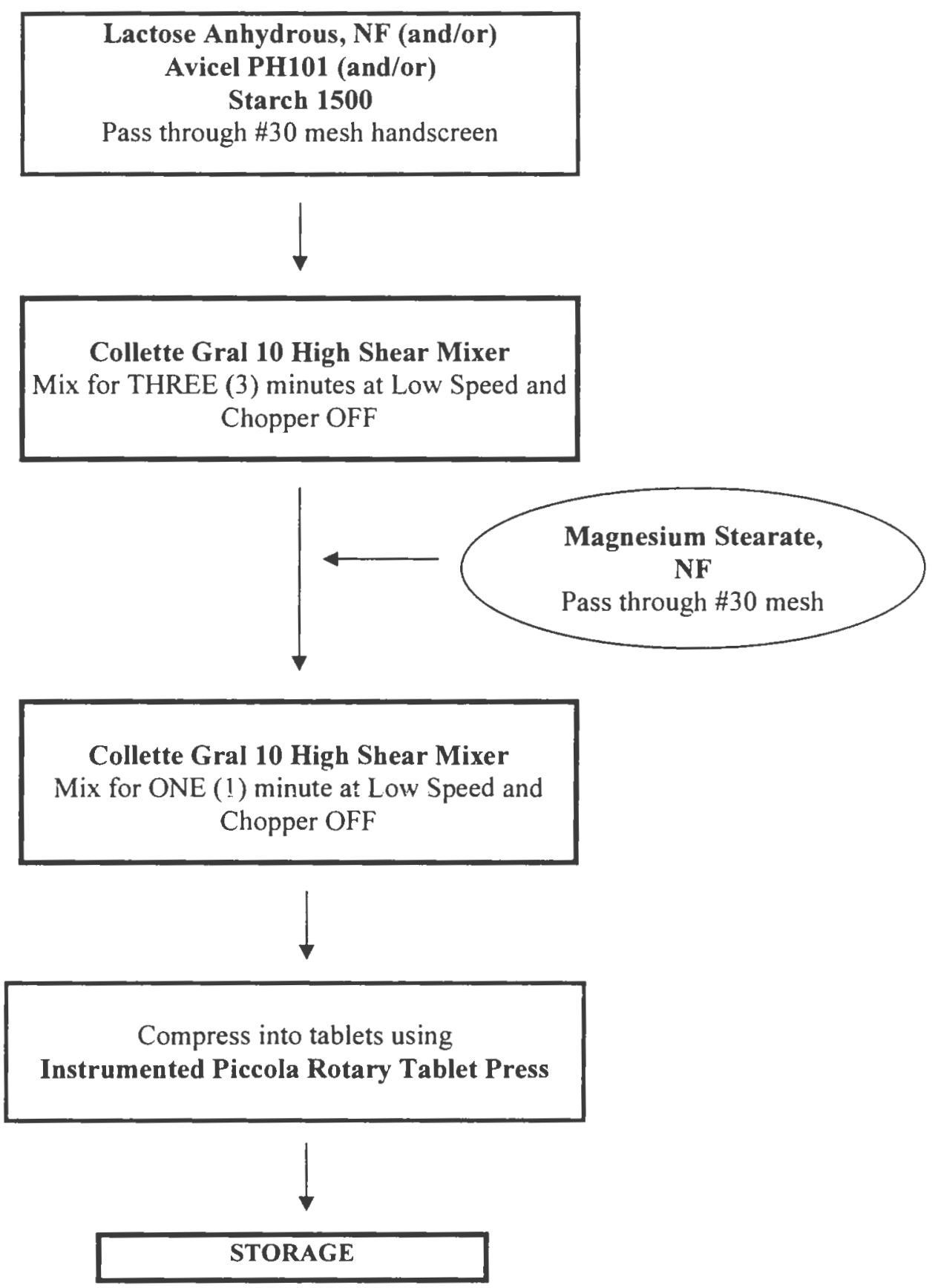

Figure 2. Process Flow Chart for Preparation of Powder Blends 


\section{Characterization of Powder Blends:}

The powder mixtures were evaluated for bulk density, tap density, compressibility index, moisture content, particle size distribution and true density.

Bulk and Tap Density Determination: The weight of powder required to fill a 100 $\mathrm{mL}$ graduated cylinder was determined and from which the bulk density was calculated as the ratio of mass per volume of the powder. The tap density of the powder was calculated after 100, 250, 500 and 1000 taps using Vander Kamp Tap Density Tester (Van Kel Industries, Inc., USA). Mean values of three density measurements were determined. From these measurements, Hausner Number and Compressibility Index values were calculated.

The Hausner Number was determined using the equation:

$$
\text { Hausner Number }=(\text { Tapped Density/Bulk Density })
$$

The Compressibility Index was determined using the following equation:

$$
\begin{aligned}
\text { Compressibility Index }(\%) & =\{(\text { Initial Volume-Final Volume }) / \text { Final Volume }\} \times 100 \\
& =\{(\text { Tap Density-Bulk Density }) / \text { Tap Density }\} \times 100
\end{aligned}
$$

Moisture Content Determination: A powder sample of 2-4 grams was placed on a Mettler Moisture Determining Balance (Model Mettler LP16, Mettler Corp., USA) and the sample was heated at $105^{\circ} \mathrm{C}$ until a constant weight was achieved. The moisture content was thus determined as the percentage of loss on drying (LOD). Mean values of three measurements were determined. 
Particle Size Analysis: The particle size distribution for various powders was determined using a Gilsonic Autosiever (Model GA-6A, Gilson Company Inc., Ohio). The sieves used for this analysis have the following opening sizes: $180 \mu \mathrm{m}, 125 \mu \mathrm{m}$, $90 \mu \mathrm{m}, 53 \mu \mathrm{m}, 45 \mu \mathrm{m}, 32 \mu \mathrm{m}$, and $20 \mu \mathrm{m}$. A sample of 5 grams of powder was placed on the top sieve and after sieving for 5 minutes, the powders retained on each sieve were weighed. The amounts of powders retained were utilized to determine the geometric mean particle size of the powder blend.

\section{Preparation of Tablets:}

A ten-station instrumented rotary tablet press (Model: Piccola 026 B10, Piccola Industria, Riva S.A., Buenos Aires, Argentina) was utilized to compress blends into tablets. Only five out of ten stations were utilized for compression of powders. A tablet weight of $300 \mathrm{mg}$ and 12/32 inch standard concave tooling were used. A paddle feeder was utilized to feed the powder into the die stations. The powder blends were compressed at $\sim 1000$ lbs., 2000 lbs., 3000 lbs., 4000 lbs., 5000 lbs., 6000 lbs. and at maximum achievable force on the tablet press. All blends were compressed at a press speed of $15 \mathrm{rpm}$.

Compression Data Collection: The compression force-time profiles at different compressional forces were obtained using an instrumented Piccola Rotary Tablet Press. The Piccola Rotary Tablet Press was equipped with strain gauge based transducers to measure the de-aeration force, compression force and ejection force for the compression cycle. Five stations were utilized to obtain data during compression 
of various formulations as per the experimental design described in Table 1. A Compression Research System (PC-30, SMI Inc.) was utilized to gather and analyze data during compression process. The software allows collecting data in four modes: Scope, Tooling, Status and Repetitive Sample. In Scope mode, detailed information about an individual pulse can be obtained. Events such as rise and fall time, dwell time, contact time, area under the curve, and pulse width characterize the signature of the pulse. A typical pulse diagram was shown in Figure 3. Pulse signatures are a function of the physical characteristics of the tablet press, turret speed, and the properties of the formulation. Therefore for the same press running at a constant speed, different formulations can be directly compared for evaluation. Tooling mode provides very useful information during compression and can be used to evaluate the performance of each station. The variation in data in this mode can be directly related to the flow behavior of the powders. Status mode is used to statistically analyze large quantities of data resulting from extended time runs. This mode can be used to determine whether a process is in control or not. Repetitive Sample mode is used to acquire data that will later be cross-plotted. This mode is used typically to determine the effect of applied force on the tablet hardness.

\section{Characterization of Tablets:}

Weight, Thickness \& Hardness: The tablets produced for all the blends at various compressional forces were evaluated for weight variation, thickness and hardness using Dr. Schleuniger Pharmatron Tablet tester (Model: 6D, Dr. K. Schleuniger, Geneva, Switzerland). For each parameter, mean value of 10 tablets was determined. 


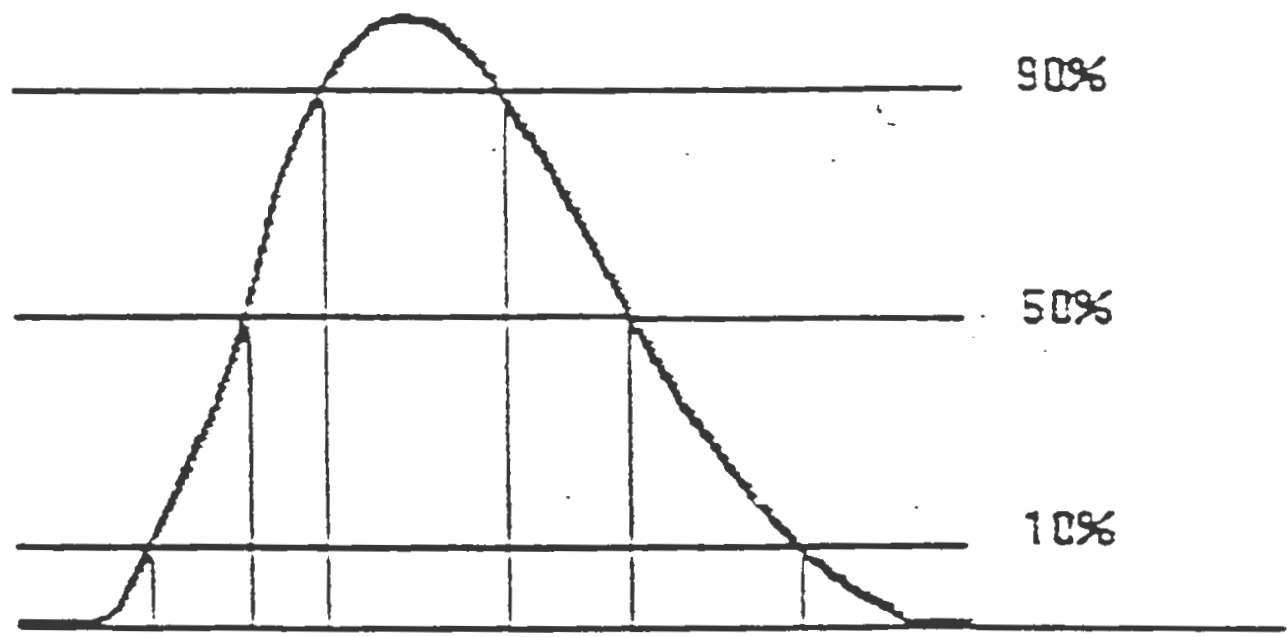

$\longrightarrow$ Rise time

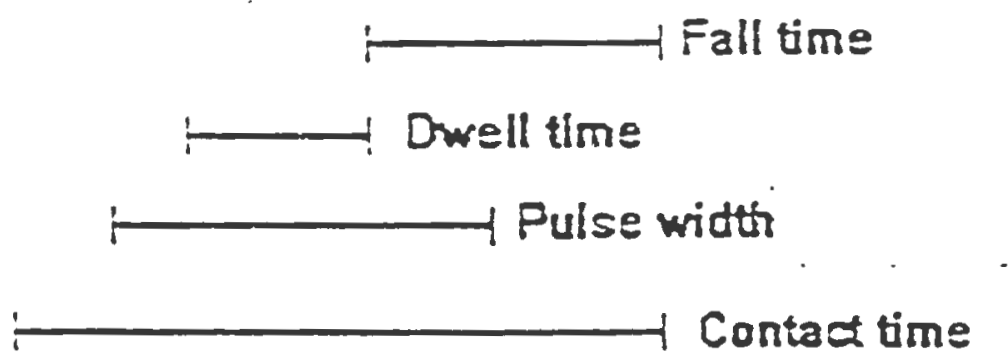

Figure 3. Pulse Analysis of the Force-Time Curve 
Disintegration Testing: The disintegration test as per the USP method was performed utilizing Hanson Research Disintegration Test Apparatus (Model: QC-21, Chatsworth, CA, USA) at 30 cycles per minute and distilled water as medium at $37 \pm 0.5^{\circ} \mathrm{C}$. The mean disintegration time for six tablets at each experimental condition was determined.

True Density Determination: The true density of tablets and final blends was measured using a helium pycnometer (Ultrapycnometer 1000, Quantachrome Corp., Fairfield, NJ, USA). Mean values of 5 readings were calculated for both the powder blends and tablets prepared from various compositions.

Tablet Volume and Surface Area Determination: The tablet volume and surface area were calculated from the mean values of tablet weight and tablet thickness and tooling dimensions utilizing a Natoli computer program.

\section{Data Analysis:}

Porosity is a function of the voids in a powder column and measurement of porosity changes as a function of the compression pressure is a method widely used in describing the compaction processes of powders. For porosity measurements, the dimensions and weight of a powder column (i.e. apparent density) and particle density (referred to often as true density) of the solid material should be known. The porosity, $C$, can be expressed by the equation:

$$
\epsilon=1-\left(\rho_{A} / \rho_{T}\right)
$$


Where $\rho_{\mathrm{A}}$ is the apparent density of powder column and $\rho_{\mathrm{T}}$ is the particle density of the compressed material. The value of $\rho_{A} / \rho_{T}$, also referred as $D$, is regarded as the relative density or the packing fraction, which describes the solid fraction of a porous powder column. A value for the applied pressure, $\mathrm{P}$, while loading a powder column under pressure is a function of the compression force, $\mathrm{F}$, and the punch tip area, $\mathrm{A}$ :

$$
P=F / A
$$

The compression force and porosity data were analyzed using the Heckel compressibility model (17), one form of which is:

$$
\operatorname{Ln}(1 / 1-\mathrm{D})=K \mathrm{P}+A
$$

Where $D$ is the relative density, (1-D) represents the pore fraction, $P$ is the applied pressure, and $K$ and $A$ are constants. A plot of $\ln (1 / 1-\mathrm{D})$ vs $\mathrm{P}$ is known as a Heckel plot. The constants $\mathrm{K}$ and $\mathrm{A}$ are the slope and intercept, respectively, calculated from the linear portion of the Heckel plot. Typically at lower pressures, the plot is curved whereas at higher pressures, the plot is linear. The reciprocal of the slope of the linear region $(\mathrm{K})$ is termed the mean yield pressure. The intercept, $\mathrm{A}$, is related to the initial packing density of the powder. The initial curved region of the Heckel plot is attributed to particle rearrangement and its extent can be quantified using the relationship:

$$
D_{b}=D_{a}-D_{o}
$$

Where $D_{b}$ is the increase in relative density due to particle rearrangement, $D_{a}=1-e^{-A}$ is the extrapolated relative density from the intercept (A) of the linear portion of the Heckel plot, and $D_{0}$ is the initial relative density. 
A statistical design, namely "Simplex-Centroid Design" was utilized in the present study (18). The points of composition in the simplex were explored in accordance with a lattice arrangement and the responses were represented by polynomials (18-20). The special cubic design is described by the following equation (18):

$$
\begin{aligned}
& Y=b_{1} X_{1}+b_{2} X_{2}+b_{3} X_{3}+b_{12} X_{1} X_{2}+b_{13} X_{1} X_{3}+b_{23} X_{2} X_{3}+b_{123} X_{1} X_{2} X_{3} \\
& \text { where } X_{1}=\text { Lactose Anhydrous, } X_{2}=\text { Avicel PH101, } X_{3}=\text { Starch } 1500 \\
& \qquad b_{1} \ldots b_{123}=\text { Regression Coefficients }
\end{aligned}
$$

The graphical representation of a polynomial equation is the response surface or contour plot. The response variables such as tablet hardness, dwell time, tablet surface area, porosity etc. were fitted using a special cubic model. The response surface contour plots were obtained for each parameter as a function of varying amounts of lactose anhydrous, Avicel ${ }^{\circledast}$ PH101 and Starch ${ }^{\circledast}$ 1500. The statistical software packages Statgraphics ${ }^{\circledast}$ Plus (21) and Design-Expert ${ }^{\circledast}$ (22) were utilized to analyze the data. 


\section{RESULTS \& DISCUSSION}

\section{Physical Characteristics of Powder Blends:}

The powder mixtures containing Lactose Anhydrous, NF, Microcrystalline Cellulose, NF (Avicel ${ }^{\circledR}$ PH101), Pregelatinized Starch, NF (Starch ${ }^{\circledR}$ 1500) and Magnesium Stearate, NF in various proportions as per the simplex design described in Table 1, were prepared and evaluated for blend characteristics such as bulk density, tapped density, true density, Hausner Number, compressibility index, moisture content and particle size distribution. The results are summarized in Tables 2-3 and Figures 4-7.

Most of the active pharmaceutical ingredients have low bulk density and this is due to entrapment of large amounts of air between particles. At high speeds, this entrapped air causes capping of tablets and reduces tablet strength. For filling the die cavities, high bulk density is advantageous. Hence an objective of formulation design process is to increase the bulk density of the final blend to minimize the air entrapment and offset the effect of high compression speeds. Figure 4 describes the change of bulk density of mixtures as a function of component proportion. Among the three excipients, Starch ${ }^{\circledast} 1500$ had the highest bulk density $(0.7277 \mathrm{gm} / \mathrm{cc})$ followed by Lactose Anhydrous, NF $(0.6717 \mathrm{gm} / \mathrm{cc})$ and Avicel ${ }^{\circledR} \mathrm{PH} 101$ (0.4014 gm/cc). Among all the mixtures, the binary mixture containing Starch ${ }^{\circledR} 1500$ and Lactose Anhydrous, NF in 1:1 ratio (Blend\#5) had the highest bulk density $(0.7786 \mathrm{gm} / \mathrm{cc})$ whereas Avicel $^{\circledR}$ PH101 (Blend\#2) had the lowest bulk density $(0.4014 \mathrm{gm} / \mathrm{cc})$. Figure 5 demonstrates the effect of tapping process on the bulk density of mixtures. As can be seen from Figure 5, 250-500 taps were sufficient to obtain plateau conditions for all the mixtures, which indicate that the mixtures are free flowing $(23,24)$. 
Table 2. Physical Properties of Various Blends

\begin{tabular}{|l|c|c|c|c|c|c|c|c|c|c|}
\hline \multicolumn{1}{|c|}{$\begin{array}{c}\text { Physical } \\
\text { Property }\end{array}$} & $\begin{array}{c}\text { Blend } \\
\# 1\end{array}$ & $\begin{array}{c}\text { Blend } \\
\# 2\end{array}$ & $\begin{array}{c}\text { Blend } \\
\# 3\end{array}$ & $\begin{array}{c}\text { Blend } \\
\# 4\end{array}$ & $\begin{array}{c}\text { Blend } \\
\# 5\end{array}$ & $\begin{array}{c}\text { Blend } \\
\# 6\end{array}$ & $\begin{array}{c}\text { Blend } \\
\# 7\end{array}$ & $\begin{array}{c}\text { Blend } \\
\# 8\end{array}$ & $\begin{array}{c}\text { Blend } \\
\# 9\end{array}$ & $\begin{array}{c}\text { Blend } \\
\# 10\end{array}$ \\
\hline $\begin{array}{l}\text { Bulk Density } \\
\text { (g/cc) }\end{array}$ & 0.6717 & 0.4014 & 0.7277 & 0.5498 & 0.7786 & 0.5284 & 0.6183 & 0.6965 & 0.4866 & 0.6728 \\
\hline $\begin{array}{l}\text { Tapped Density } \\
\text { (g/cc) }\end{array}$ & 0.9016 & 0.5614 & 0.9968 & 0.7331 & 1.0110 & 0.7238 & 0.8135 & 0.893 & 0.6666 & 0.8971 \\
\hline $\begin{array}{l}\text { Hausner } \\
\text { Number }\end{array}$ & 1.34 & 1.40 & 1.37 & 1.33 & 1.30 & 1.37 & 1.32 & 1.28 & 1.37 & 1.33 \\
\hline $\begin{array}{l}\text { Compressibility } \\
\text { (\%) }\end{array}$ & 25 & 29 & 27 & 25 & 23 & 27 & 24 & 22 & 27 & 25 \\
\hline $\begin{array}{l}\text { Mean Particle } \\
\text { Size ( } \mu \text { m) }\end{array}$ & 161 & 111 & 99 & 133 & 117 & 85 & 107 & 94 & 122 & 94 \\
\hline $\begin{array}{l}\text { Moisture } \\
\text { Content (\%) }\end{array}$ & 0.60 & 5.12 & 4.06 & 2.42 & 2.01 & 4.71 & 3.13 & 1.92 & 4.22 & 3.36 \\
\hline $\begin{array}{l}\text { True Density } \\
\text { (g/cc) }\end{array}$ & 1.5767 & 1.6188 & 1.5190 & 1.6136 & 1.5623 & 1.5772 & 1.5719 & 1.5712 & 1.5966 & 1.5540 \\
\hline
\end{tabular}




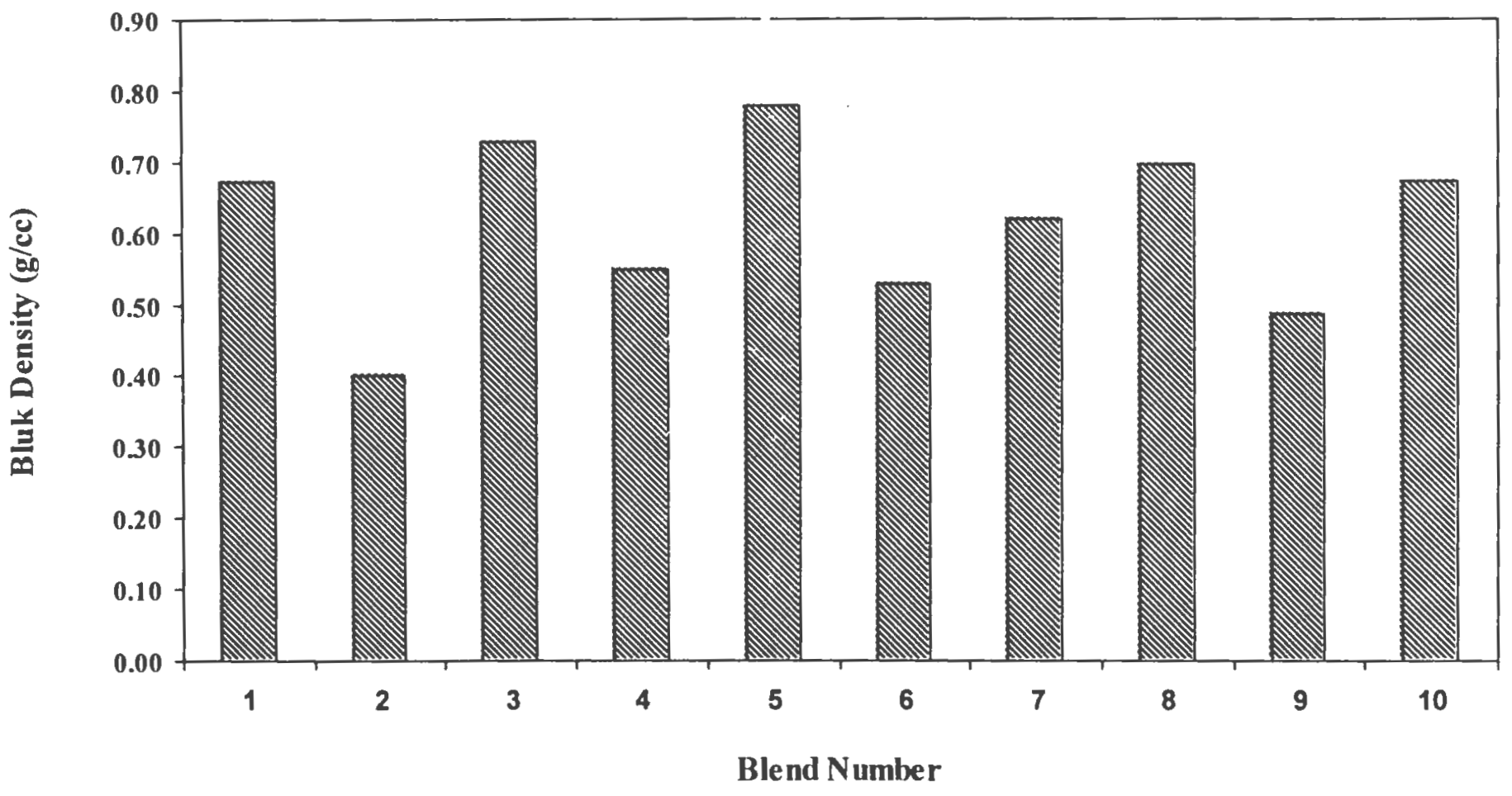

Figure 4. Comparison of Bulk Densities of Powder Blends 


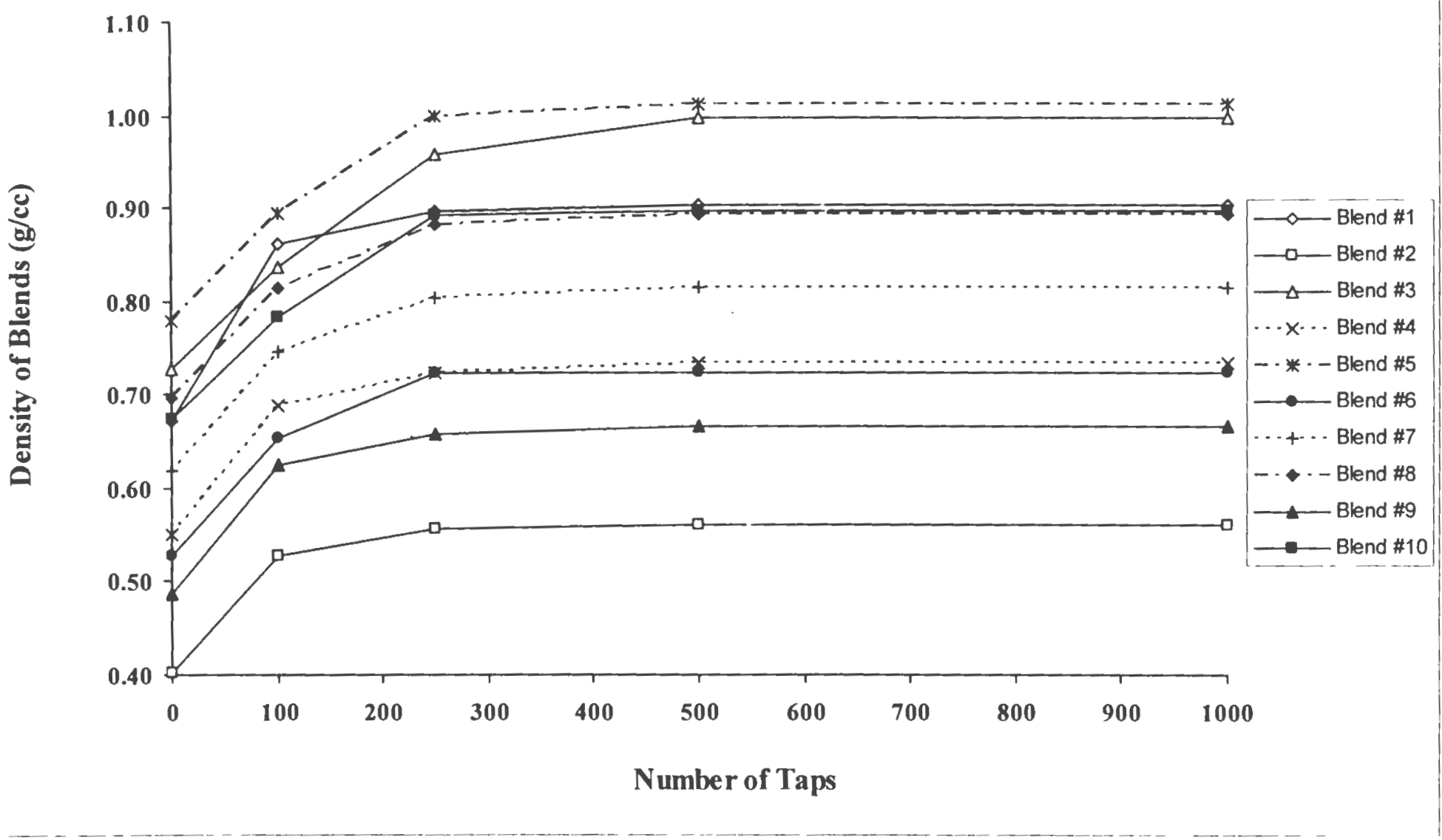

Figure 5. Consolidation of Powder Blends as a Function of Taps 
For poor flowing materials, a large number of taps will be required. Carr $(23,24)$ proposed the 'Compressibility Index' as a simple and fast method for predicting powder flow characteristics. It is used as an indirect measure of bulk density, size and shape, surface area, moisture content and cohesiveness of materials. It is also a measure of the likelihood of arch formation and the ease with which arches will fail. Table 2 provides the compressibility index values for all blends used in this study. As Figure 6 indicates, the compressibility index value varies with the composition of the mixtures with a maximum value of 28.5 (Blend \#2) observed for the $99 \%$ Avicel ${ }^{\circledR}$ PH101 and a minimum value of 22.0 observed for the mixture containing $66 \%$ Lactose Anhydrous, NF, 16.5\% Avicel ${ }^{\circledR} \mathrm{PH} 101$ and $16.5 \% \operatorname{Starch}^{\circledR} 1500$.

Hausner Number is another parameter used to assess the flowability of pharmaceutical powders. As data from Table 2 indicates that the Hausner Number values varied from 1.28 to 1.40. Lower the values for Hausner Number, the better will be the powder flow. Among the ten blends prepared in this study, Blend $\# 2$ containing $99 \%$ Avicel ${ }^{\circledast}$ PH101 displayed the highest value and the lowest value was observed for blend containing $66 \%$ Lactose Anhydrous, NF, $16.5 \%$ Avicel $^{\circledR}$ PH101 and $16.5 \%$ $\operatorname{Starch}^{\circledR} 1500$ (Blend \#8).

Particle size information may be the most critical physical parameter that not only determines the dissolution behavior of drugs but also has a significant impact on the manufacturability of a formulation. Mixtures with fine particles provide better compression but will cause flow problems at higher speeds of production. Large variations in the particle size distribution of excipients that makeup the final blend 


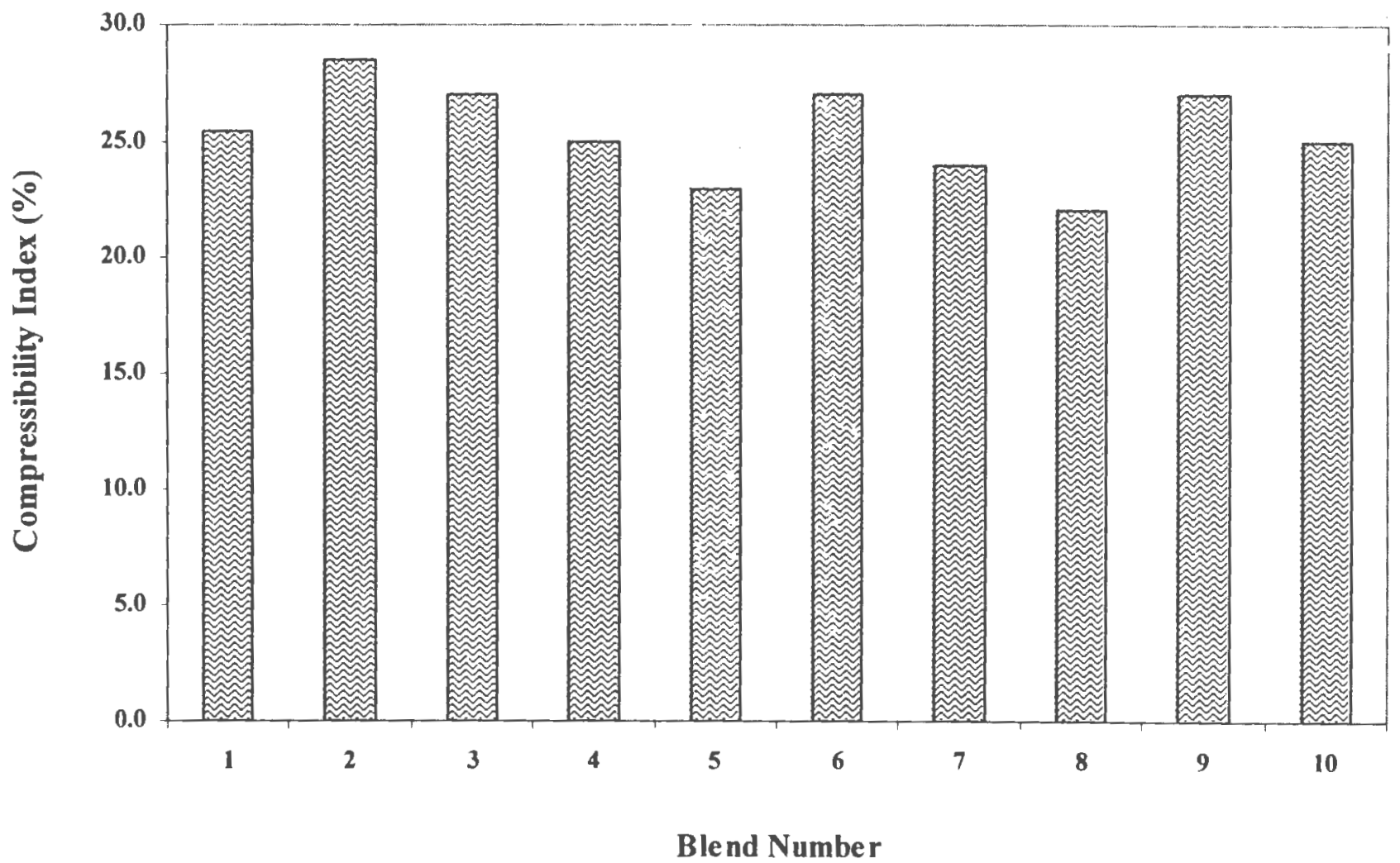

Figure 6. Comparison of Compressibility Indices for Powder Blends 
cause segregation during processing thereby resulting in content uniformity problems (25-31). Thus for tableting purposes, a narrow particle size range is desirable. The particle size distributions of all mixtures in the current study are summarized in Table 3. Based on the sieve analysis data, the geometric mean particle size was calculated and plotted as function of mixture components (Figure 6). The mixture containing 49.5\% Avicel ${ }^{\circledR}$ PH101 and 49.5\% Starch $^{\circledast} 1500$ (Blend\#6) had the lowest geometric mean particle size of $85 \mu \mathrm{m}$ whereas the $99 \%$ Lactose Anhydrous, NF mixture (Blend\#1) had the highest geometric mean particle size of $161 \mu \mathrm{m}$.

Moisture content is a critical parameter that affects the flow and compaction behavior of powder blends (32-34). Various investigators have proposed different mechanistic explanations. High levels of moisture content will affect adversely with the continuous flow of blend from the hopper to the die. During the compression process, an increased amount of absorbed water can either cause a gradual change in deformability of the particles (i.e. plasticize the glassy amorphous material) or can facilitate a temporary transition of the amorphous material from a glassy to a rubbery state. Concerning the binding process, improved particle deformability or a glassrubber transition can affect either type of bonds formed between the particles or the area of bonding formed between the particles during compression. As the values for moisture content for various mixtures reported in Table 2 indicates that Blend\#1 has the lowest moisture content $(0.60 \%)$ whereas the Blend\#2 has the highest moisture content $(5.12 \%)$. 
Table 3. Particle Size Distributions of Various Powder Blends based on Sieve Analysis

\begin{tabular}{|c|c|c|c|c|c|c|c|c|c|c|}
\hline \multirow{2}{*}{$\begin{array}{c}\text { Screen Size } \\
(\mu \mathrm{m}) \\
\end{array}$} & \multicolumn{10}{|c|}{$\%$ Retained } \\
\hline & Blend\#1 & Blend\#2 & Blend\#3 & Blend\#4 & Blend\#5 & Blend\#6 & Blend\#7 & Blend\#8 & Blend\#9 & Blend\#10 \\
\hline 180 & 59.5 & 16.5 & 11.2 & 41.9 & 21.4 & 4.6 & 14.4 & 23.1 & 27.9 & 9.5 \\
\hline 125 & 13.1 & 19.3 & 16.6 & 10.6 & 15.8 & 12.8 & 14.8 & 8.7 & 23.3 & 13.3 \\
\hline 90 & 16.1 & 27.8 & 22.4 & 17.0 & 30.7 & 23.6 & 33.9 & 17.3 & 8.4 & 22.6 \\
\hline 53 & 6.9 & 14.1 & 23.6 & 13.8 & 16.6 & 25.9 & 16.6 & 5.8 & 21.5 & 27.6 \\
\hline 45 & 2.2 & 9.9 & 12.8 & 5.2 & 4.0 & 8.4 & 6.8 & 2.4 & 8.6 & 12.1 \\
\hline 32 & 1.2 & 6.8 & 5.0 & 5.0 & 4.0 & 9.0 & 4.8 & 1.9 & 4.0 & 5.6 \\
\hline 20 & 0.6 & 3.4 & 5.8 & 4.2 & 3.8 & 8.8 & 4.0 & 39.3 & 4.2 & 4.6 \\
\hline 0 & 0.4 & 2.2 & 2.8 & 2.4 & 3.6 & 6.8 & 4.6 & 1.5 & 2.2 & 4.6 \\
\hline $\begin{array}{c}\text { Mean Particle } \\
\text { Size (microns) }\end{array}$ & 161 & 111 & 99 & 133 & 117 & 85 & 107 & 94 & 122 & 94 \\
\hline
\end{tabular}




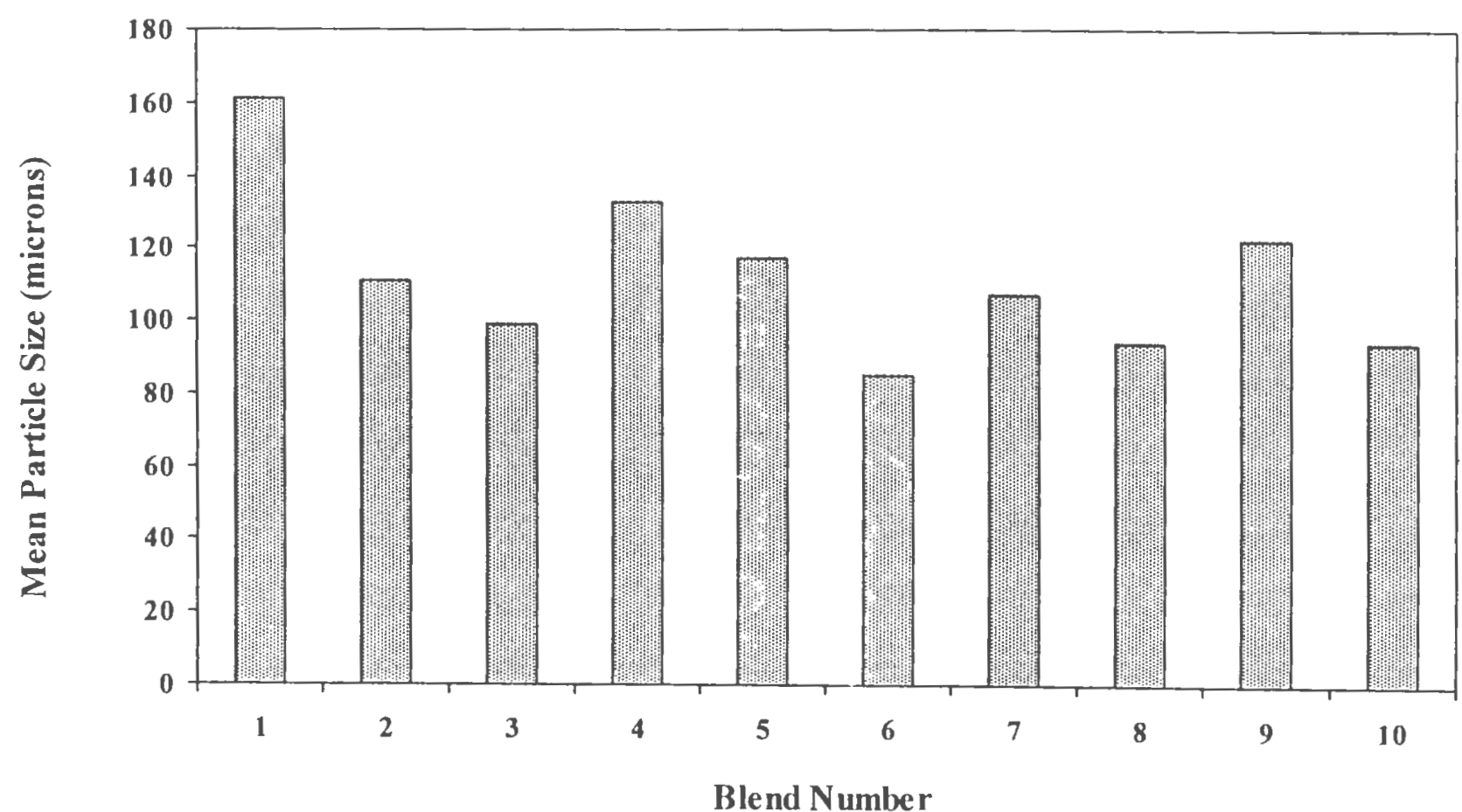

Figure 7. Geometric Mean Particle Sizes Based on Sieve Analysis for Powder Blends 
The true densities for all the mixtures were determined used helium pycnometer. Table 2 provides the summary of these results. The true density values varied from $1.5190 \mathrm{~g} / \mathrm{cc}$ for blend\#3 (99\% $\left.\mathrm{Starch}^{\circledR} 1500\right)$ through $1.6188 \mathrm{~g} / \mathrm{cc}$ for blend\#2 (99\% Avicel ${ }^{\circledR}$ PH101). These vaiues were used in determining the tablet porosity values in order to analyze the densification behavior of various experimental blends.

Characterization of Tablets: Tablets prepared from the blends at varying levels of compression force (1000 lbs, $2000 \mathrm{lbs}, 3000 \mathrm{lbs}, 4000 \mathrm{lbs}, 5000 \mathrm{lbs}, 6000 \mathrm{lbs}$ and maximum achievable force on the tableting machine were characterized for weight variation, thickness, hardness, friability loss and disintegration time. The results are summarized in Tables 4 to 13 . The tablet weights measured during the study indicated that all blends produced tablets with consistent weights and the weight variations are within the acceptable range. Maximum variability in tablet weight was observed for the blend containing $99 \%$ of $\operatorname{Starch}^{\circledR} 1500$ (Blend\#3) and minimum variability was observed for tablets prepared using Blend\#4 which contains Lactose Anhydrous, NF and Avicel ${ }^{\circledR} \mathrm{PH} 101$ at $49.5 \%$ level. The tablet weight is considered to be dependent upon the die fill, compression speed, feeding mechanism and nature of blend $(31,35$, 36). The tablet weight variation observed in the present study may be attributed to the differences in the flow properties of the blends and also due to the poor binding properties of the components that make up the tablets. 
Table 4. Physical Testing of Tablets Prepared from Blend\#1

Composition: 99\% Lactose Anhydrous+1\% Magnesium Stearate

\begin{tabular}{|c|c|c|c|c|c|c|c|c|}
\hline \multirow{2}{*}{\multicolumn{2}{|c|}{ Test Parameters }} & \multicolumn{7}{|c|}{ Compressional Force (lbs) } \\
\hline & & $1000 \mathrm{lbs}$ & $2000 \mathrm{lbs}$ & 3000 lbs & $4000 \mathrm{lbs}$ & $5000 \mathrm{lbs}$ & $6000 \mathrm{lbs}$ & Max (lbs) \\
\hline $\begin{array}{l}\text { Weight (mg) } \\
n=10\end{array}$ & $\begin{array}{c}\text { Mean } \\
\text { S.D } \\
\text { \%RSD } \\
\text { Min } \\
\text { Max } \\
\end{array}$ & $\begin{array}{c}303 \\
1.9 \\
0.6 \\
300 \\
305 \\
\end{array}$ & $\begin{array}{c}300 \\
1.6 \\
0.5 \\
298 \\
302 \\
\end{array}$ & $\begin{array}{c}299 \\
2.5 \\
0.8 \\
296 \\
303 \\
\end{array}$ & $\begin{array}{l}304 \\
1.7 \\
0.6 \\
301 \\
307 \\
\end{array}$ & $\begin{array}{c}303 \\
3.4 \\
1.1 \\
299 \\
308 \\
\end{array}$ & $\begin{array}{c}303 \\
2.4 \\
0.8 \\
300 \\
306 \\
\end{array}$ & $\begin{array}{c}303 \\
2.0 \\
0.6 \\
301 \\
307 \\
\end{array}$ \\
\hline $\begin{array}{l}\text { Hardness }(\mathrm{Kp}) \\
\mathrm{n}=10\end{array}$ & $\begin{array}{c}\text { Mean } \\
\text { S.D } \\
\% \text { RSD } \\
\text { Min } \\
\text { Max }\end{array}$ & $\begin{array}{c}1.9 \\
0.27 \\
14.0 \\
1.6 \\
2.3 \\
\end{array}$ & $\begin{array}{c}5.2 \\
0.50 \\
9.5 \\
4.2 \\
5.8 \\
\end{array}$ & $\begin{array}{c}9.2 \\
0.73 \\
7.8 \\
8.4 \\
11.0 \\
\end{array}$ & $\begin{array}{c}12.2 \\
0.39 \\
3.2 \\
11.7 \\
12.7 \\
\end{array}$ & $\begin{array}{l}15.0 \\
1.62 \\
10.8 \\
12.2 \\
16.9\end{array}$ & $\begin{array}{c}17.3 \\
1.28 \\
7.4 \\
15.5 \\
19.5 \\
\end{array}$ & $\begin{array}{l}14.2 \\
3.41 \\
24.0 \\
11.4 \\
20.5 \\
\end{array}$ \\
\hline $\begin{array}{l}\text { Loss of } \\
\text { Friability (\%) }\end{array}$ & - & 2.79 & 0.92 & 0.32 & 0.30 & 0.12 & 0.13 & 0.21 \\
\hline $\begin{array}{l}\text { Disintegration } \\
\text { Time (min), } n=6\end{array}$ & $\begin{array}{c}\text { Mean } \\
\text { S.D } \\
\text { \%RSD }\end{array}$ & $\begin{array}{c}2.63 \\
0.14 \\
5.5\end{array}$ & $\begin{array}{l}5.96 \\
0.80 \\
13.4 \\
\end{array}$ & $\begin{array}{c}7.03 \\
0.14 \\
2.0 \\
\end{array}$ & $\begin{array}{c}7.06 \\
0.33 \\
4.7\end{array}$ & $\begin{array}{c}7.16 \\
0.16 \\
2.2\end{array}$ & $\begin{array}{c}7.09 \\
0.15 \\
2.1\end{array}$ & $\begin{array}{c}7.24 \\
0.06 \\
0.8\end{array}$ \\
\hline
\end{tabular}


Table 5. Physical Testing of Tablets Prepared from Blend\#2

Composition: 99\% Avicel PH101+1\% Magnesium Stearate

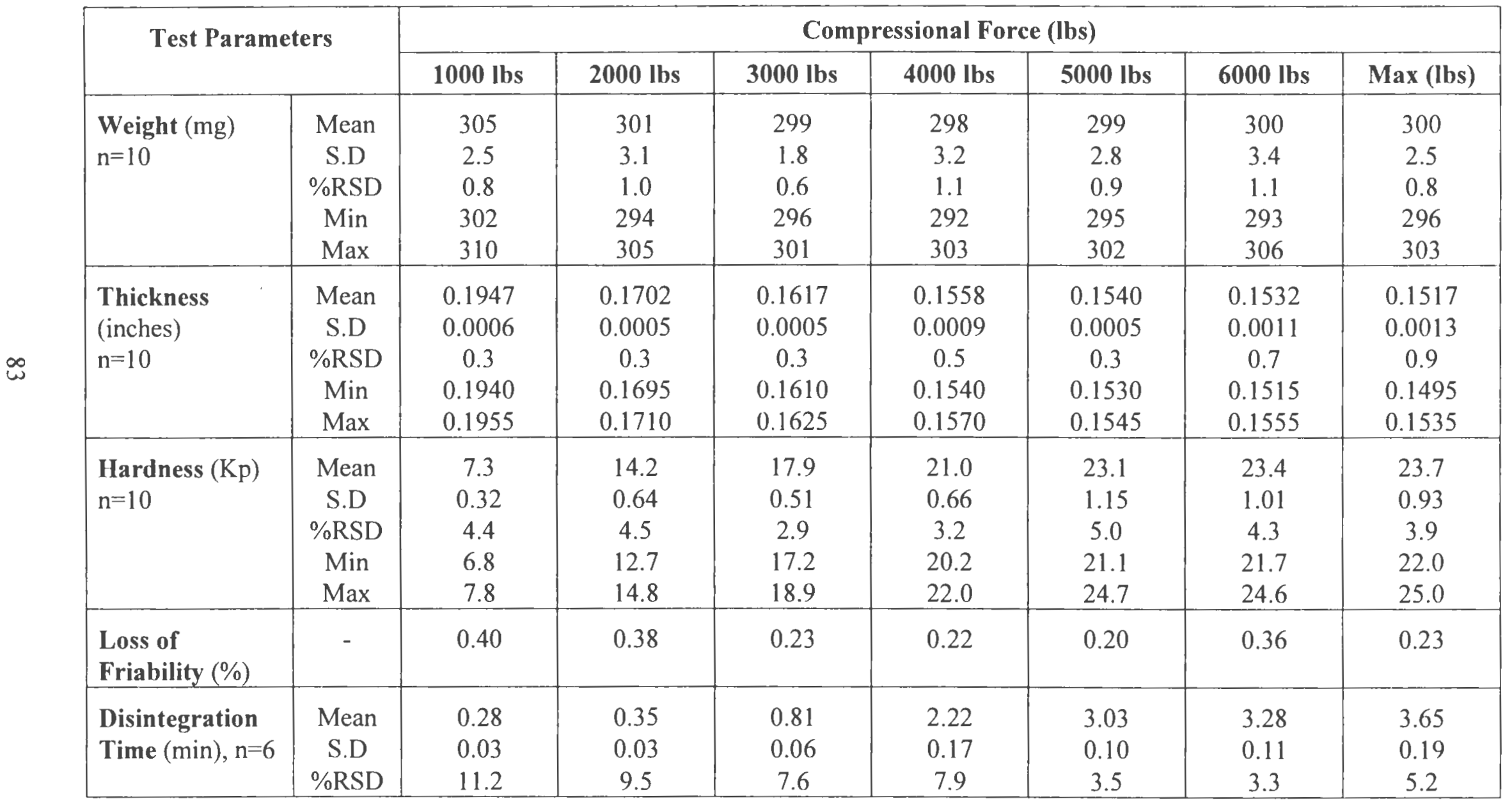


Table 6. Physical Testing of Tablets Prepared from Blend \#3

Composition: $99 \%$ Starch $1500+1 \%$ Magnesium Stearate

\begin{tabular}{|c|c|c|c|c|}
\hline \multicolumn{2}{|c|}{ Test Parameters } & \multicolumn{3}{|c|}{ Compressional Force (lbs) } \\
\hline & & \multirow{2}{*}{$\begin{array}{c}4000 \text { lbs } \\
287 \\
4.5 \\
1.6 \\
278 \\
293 \\
\end{array}$} & \multirow{2}{*}{$\begin{array}{c}6000 \text { lbs } \\
293 \\
7.1 \\
2.4 \\
284 \\
308 \\
\end{array}$} & \multirow{2}{*}{$\begin{array}{c}\text { Max (lbs) } \\
296 \\
6.0 \\
2.0 \\
287 \\
307 \\
\end{array}$} \\
\hline $\begin{array}{l}\text { Weight (mg) } \\
n=10\end{array}$ & $\begin{array}{c}\text { Mean } \\
\text { S.D } \\
\% \text { RSD } \\
\text { Min } \\
\text { Max } \\
\end{array}$ & & & \\
\hline $\begin{array}{l}\text { Thickness } \\
\text { (inches) } \\
n=10\end{array}$ & $\begin{array}{l}\text { Mean } \\
\text { S.D } \\
\text { \%RSD } \\
\text { Min } \\
\text { Max } \\
\end{array}$ & $\begin{array}{c}0.1645 \\
0.0029 \\
1.8 \\
0.1605 \\
0.1695 \\
\end{array}$ & $\begin{array}{c}0.1648 \\
0.0034 \\
2.1 \\
0.1610 \\
0.1700 \\
\end{array}$ & $\begin{array}{c}0.1679 \\
0.0030 \\
1.8 \\
0.1630 \\
0.1725 \\
\end{array}$ \\
\hline $\begin{array}{l}\text { Hardness }(K p) \\
n=10\end{array}$ & $\begin{array}{c}\text { Mean } \\
\text { S.D } \\
\% \text { RSD } \\
\text { Min } \\
\text { Max }\end{array}$ & $\begin{array}{l}0.0 \\
0.0 \\
0.0 \\
0.0 \\
0.0\end{array}$ & $\begin{array}{l}0.0 \\
0.0 \\
0.0 \\
0.0 \\
0.0\end{array}$ & $\begin{array}{c}0.3 \\
0.07 \\
20.5 \\
0.2 \\
0.4 \\
\end{array}$ \\
\hline $\begin{array}{l}\text { Loss of } \\
\text { Friability (\%) }\end{array}$ & . & 100 & 100 & 100 \\
\hline $\begin{array}{l}\text { Disintegration } \\
\text { Time (min), } n=6\end{array}$ & $\begin{array}{c}\text { Mean } \\
\text { S.D } \\
\% \text { RSD }\end{array}$ & $\begin{array}{l}0.91 \\
0.12 \\
13.2\end{array}$ & $\begin{array}{c}2.39 \\
0.18 \\
7.6\end{array}$ & $\begin{array}{c}2.88 \\
0.27 \\
9.2\end{array}$ \\
\hline
\end{tabular}


Table 7. Physical Testing of Tablets Prepared from Blend\#4

Composition: 49.5\% Lactose Anhydrous + 49.5\% Avicel PH101 + 1\% Magnesium Stearate

\begin{tabular}{|c|c|c|c|c|c|c|}
\hline & & \multicolumn{5}{|c|}{ Compression Force (lb) } \\
\hline \multicolumn{2}{|c|}{ Test Parameters } & $1000 \mathrm{lbs}$ & $2000 \mathrm{lbs}$ & 4000 lbs & $6000 \mathrm{lbs}$ & Max (lbs) \\
\hline $\begin{array}{l}\text { Weight (mg) } \\
\qquad n=10\end{array}$ & $\begin{array}{c}\text { Mean } \\
\text { S.D } \\
\text { \%RSD } \\
\text { Min } \\
\text { Max } \\
\end{array}$ & $\begin{array}{l}300 \\
2.1 \\
0.7 \\
296 \\
304 \\
\end{array}$ & $\begin{array}{l}301 \\
1.5 \\
0.5 \\
298 \\
302 \\
\end{array}$ & $\begin{array}{c}299 \\
1.3 \\
0.4 \\
298 \\
302 \\
\end{array}$ & $\begin{array}{c}301 \\
2.1 \\
0.7 \\
298 \\
305 \\
\end{array}$ & $\begin{array}{c}302 \\
2.2 \\
0.7 \\
299 \\
305 \\
\end{array}$ \\
\hline $\begin{array}{c}\text { Thickness } \\
\text { (inches) } \\
n=10\end{array}$ & $\begin{array}{l}\text { Mean } \\
\text { S.D } \\
\text { RSD } \\
\text { Min } \\
\text { Max } \\
\end{array}$ & $\begin{array}{c}0.1913 \\
0.0006 \\
0.3 \\
0.1905 \\
0.1925 \\
\end{array}$ & $\begin{array}{c}0.1710 \\
0.0005 \\
0.3 \\
0.1700 \\
0.1715 \\
\end{array}$ & $\begin{array}{c}0.1576 \\
0.0008 \\
0.5 \\
0.1570 \\
0.1590 \\
\end{array}$ & $\begin{array}{c}0.1526 \\
0.0004 \\
0.3 \\
0.1520 \\
0.1530 \\
\end{array}$ & $\begin{array}{c}0.1507 \\
0.0008 \\
0.5 \\
0.1495 \\
0.1520 \\
\end{array}$ \\
\hline $\begin{array}{c}\text { Hardness } \\
\qquad \begin{array}{c}(\mathrm{Kp}) \\
\mathrm{n}=10\end{array}\end{array}$ & $\begin{array}{l}\text { Mean } \\
\text { S.D } \\
\text { RSD } \\
\text { Min } \\
\text { Max } \\
\end{array}$ & $\begin{array}{c}2.6 \\
0.15 \\
5.7 \\
2.3 \\
2.8 \\
\end{array}$ & $\begin{array}{c}7.8 \\
0.39 \\
4.9 \\
7.4 \\
8.6 \\
\end{array}$ & $\begin{array}{c}16.0 \\
0.52 \\
3.3 \\
15.0 \\
16.8 \\
\end{array}$ & $\begin{array}{c}19.9 \\
0.98 \\
4.9 \\
18.0 \\
21.0\end{array}$ & $\begin{array}{c}22.6 \\
0.91 \\
4.0 \\
20.6 \\
24.0 \\
\end{array}$ \\
\hline $\begin{array}{c}\text { Loss of Friability } \\
(\%)\end{array}$ & - & 0.91 & 0.35 & 0.25 & 0.23 & 0.20 \\
\hline $\begin{array}{l}\text { Disintegration } \\
\text { Time (min), } n=6\end{array}$ & $\begin{array}{l}\text { Mean } \\
\text { S.D. } \\
\text { RSD }\end{array}$ & $\begin{array}{l}0.19 \\
0.04 \\
20.8\end{array}$ & $\begin{array}{l}0.36 \\
0.04 \\
12.2\end{array}$ & $\begin{array}{l}9.45 \\
0.47 \\
4.9\end{array}$ & $\begin{array}{c}19.48 \\
0.54 \\
2.8\end{array}$ & $\begin{array}{c}33.13 \\
1.36 \\
4.1\end{array}$ \\
\hline
\end{tabular}


Table 8. Physical Testing of Tablets Prepared from Blend\#5

Composition: $49.5 \%$ Lactose Anhydrous + 49.5\% Starch $1500+1 \%$ Magnesium Stearate

\begin{tabular}{|c|c|c|c|c|c|c|c|}
\hline \multirow{2}{*}{\multicolumn{2}{|c|}{ Test Parameters }} & \multicolumn{6}{|c|}{ Compressional Force (lbs) } \\
\hline & & $2000 \mathrm{lbs}$ & 3000 lbs & $4000 \mathrm{lbs}$ & $5000 \mathrm{lbs}$ & $6000 \mathrm{lbs}$ & Max (lbs) \\
\hline $\begin{array}{l}\text { Weight (mg) } \\
n=10\end{array}$ & $\begin{array}{c}\text { Mean } \\
\text { S.D } \\
\% \text { RSD } \\
\text { Min } \\
\text { Max }\end{array}$ & $\begin{array}{c}300 \\
3.1 \\
1.0 \\
297 \\
305 \\
\end{array}$ & $\begin{array}{c}299 \\
1.3 \\
0.4 \\
297 \\
301 \\
\end{array}$ & $\begin{array}{c}301 \\
1.7 \\
0.6 \\
299 \\
304 \\
\end{array}$ & $\begin{array}{c}301 \\
2.0 \\
0.7 \\
299 \\
306 \\
\end{array}$ & $\begin{array}{c}301 \\
1.3 \\
0.4 \\
300 \\
304 \\
\end{array}$ & $\begin{array}{c}300 \\
2.2 \\
0.7 \\
297 \\
303 \\
\end{array}$ \\
\hline $\begin{array}{l}\text { Thickness } \\
\text { (inches) } \\
n=10\end{array}$ & $\begin{array}{c}\text { Mean } \\
\text { S.D } \\
\% \text { RSD } \\
\text { Min } \\
\text { Max } \\
\end{array}$ & $\begin{array}{c}0.1768 \\
0.0014 \\
0.8 \\
0.1755 \\
0.1800 \\
\end{array}$ & $\begin{array}{c}0.1719 \\
0.0005 \\
0.3 \\
0.1715 \\
0.1730 \\
\end{array}$ & $\begin{array}{c}0.1697 \\
0.6062 \\
0.4 \\
0.1685 \\
0.1710 \\
\end{array}$ & $\begin{array}{c}0.1667 \\
0.0006 \\
0.4 \\
0.1660 \\
0.1680 \\
\end{array}$ & $\begin{array}{c}0.1660 \\
0.0008 \\
0.5 \\
0.1650 \\
0.1675 \\
\end{array}$ & $\begin{array}{c}0.1636 \\
0.0011 \\
0.7 \\
0.1625 \\
0.1660 \\
\end{array}$ \\
\hline $\begin{array}{l}\text { Hardness }(\mathrm{Kp}) \\
\mathrm{n}=10\end{array}$ & $\begin{array}{c}\text { Mean } \\
\text { S.D } \\
\% \text { RSD } \\
\text { Min } \\
\text { Max }\end{array}$ & $\begin{array}{c}0.4 \\
0.05 \\
13.6 \\
0.3 \\
0.4 \\
\end{array}$ & $\begin{array}{c}0.8 \\
0.11 \\
14.4 \\
0.6 \\
0.9 \\
\end{array}$ & $\begin{array}{c}1.2 \\
0.09 \\
7.4 \\
1.1 \\
1.4 \\
\end{array}$ & $\begin{array}{c}1.8 \\
0.11 \\
5.8 \\
1.6 \\
2.0 \\
\end{array}$ & $\begin{array}{c}2.2 \\
0.13 \\
6.1 \\
2.0 \\
2.4 \\
\end{array}$ & $\begin{array}{c}2.9 \\
0.10 \\
3.4 \\
2.7 \\
3.0 \\
\end{array}$ \\
\hline $\begin{array}{l}\text { Loss of } \\
\text { Friability (\%) }\end{array}$ & - & 100 & 42.03 & 4.53 & 2.29 & 2.20 & 1.59 \\
\hline $\begin{array}{l}\text { Disintegration } \\
\text { Time }(\min ), n=6\end{array}$ & $\begin{array}{c}\text { Mean } \\
\text { S.D } \\
\text { \%RSD }\end{array}$ & $\begin{array}{c}1.29 \\
0.09 \\
6.9\end{array}$ & $\begin{array}{c}4.48 \\
0.35 \\
7.7 \\
\end{array}$ & $\begin{array}{c}5.80 \\
0.55 \\
9.4\end{array}$ & $\begin{array}{c}8.32 \\
0.33 \\
3.9 \\
\end{array}$ & $\begin{array}{c}8.32 \\
0.33 \\
3.9 \\
\end{array}$ & $\begin{array}{c}9.70 \\
0.42 \\
4.4 \\
\end{array}$ \\
\hline
\end{tabular}


Table 9. Physical Testing of Tablets Prepared from Blend\#6

Composition: $49.5 \%$ Avicel PH101 $+49.5 \%$ Starch $1500+1 \%$ Magnesium Stearate

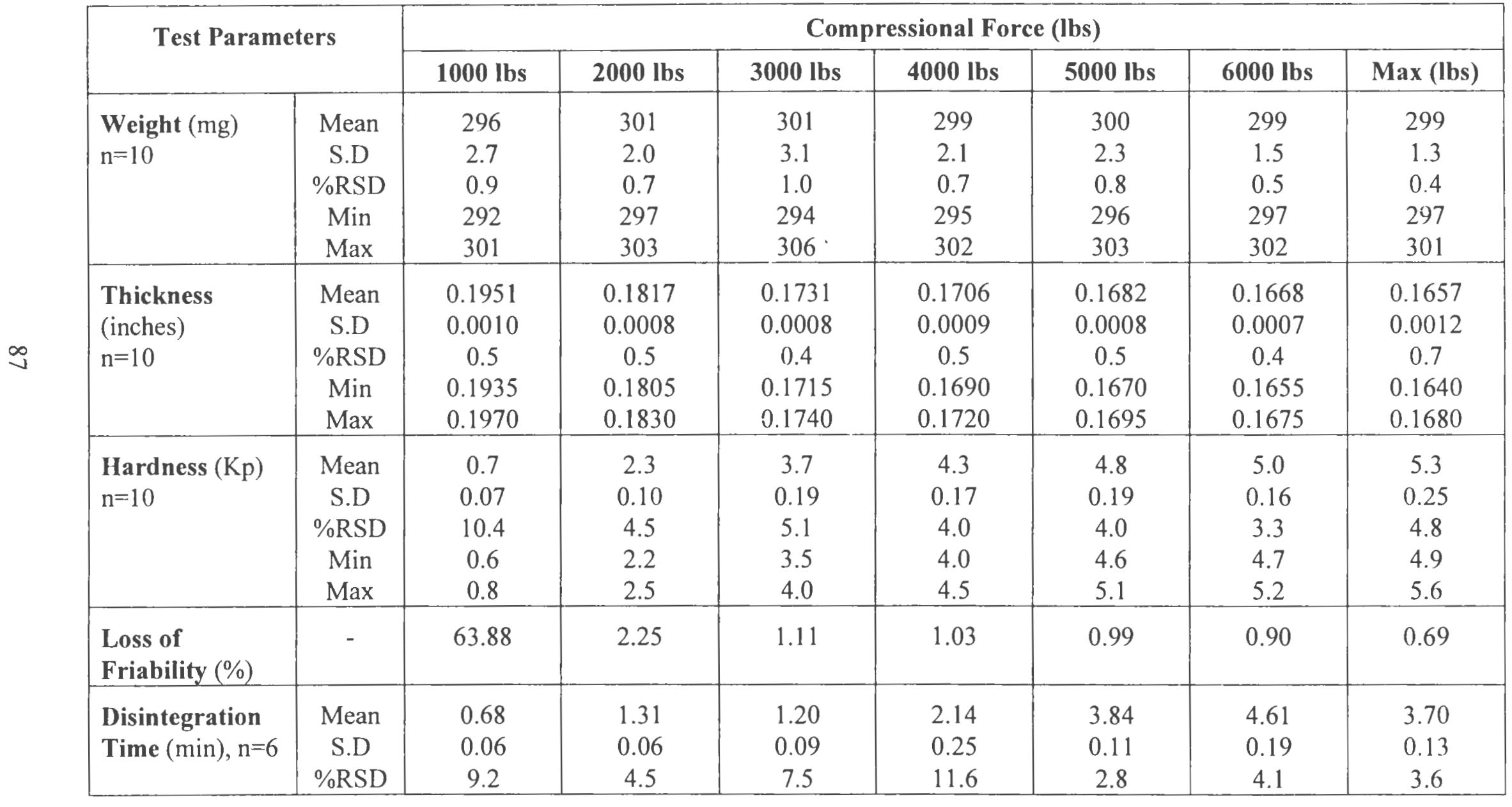


Table 10. Physical Testing of Tablets Prepared from Blend\#7

Composition: $33 \%$ Lactose Anhydrous $+33 \%$ Avicel PH101 + 33\% Starch $1500+1 \%$ Magnesium Stearate

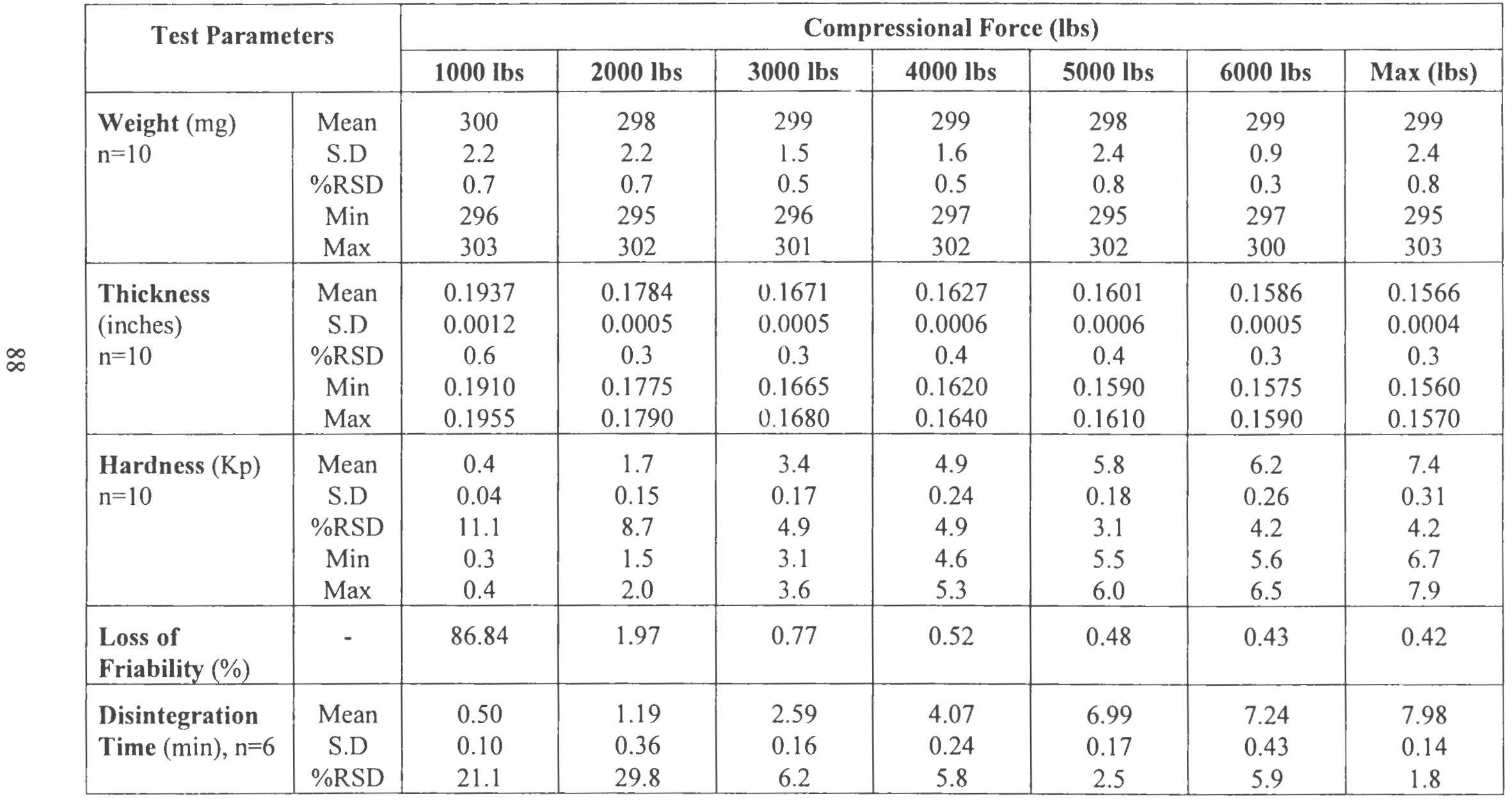


Table 11. Physical Testing of Tablets Prepared from Blend \#8

Composition: $66 \%$ Lactose Anhydrous $+16.5 \%$ Avicel PH101 + 16.5\% Starch $1500+1 \%$ Magnesium Stearate

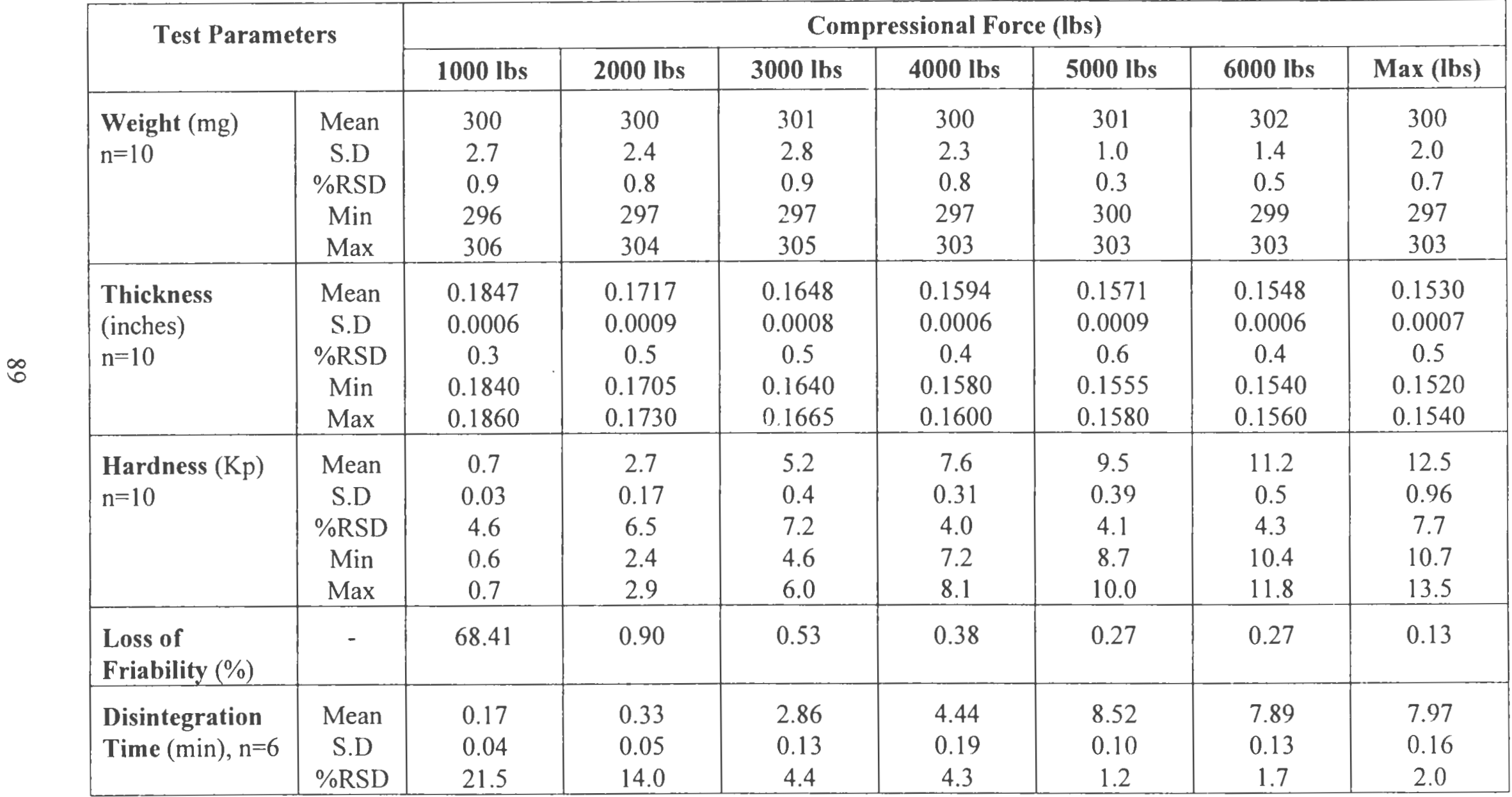


Table 12. Physical Testing of Tablets Prepared from Blend\#9

Composition: $16.5 \%$ Lactose Anhydrous $+66 \%$ Avicel PH101 + 16.5\% Starch $1500+1 \%$ Magnesium Stearate

\begin{tabular}{|c|c|c|c|c|c|c|c|c|}
\hline \multicolumn{2}{|c|}{ Test Parameters } & \multicolumn{7}{|c|}{ Compressional Force (lbs) } \\
\hline & & 1000 lbs & 2000 lbs & 3000 lbs & $4000 \mathrm{lbs}$ & $5000 \mathrm{lbs}$ & $6000 \mathrm{lbs}$ & Max (lbs) \\
\hline $\begin{array}{l}\text { Weight (mg) } \\
n=10\end{array}$ & $\begin{array}{l}\text { Mean } \\
\text { S.D } \\
\% \text { RSD } \\
\text { Min } \\
\text { Max }\end{array}$ & $\begin{array}{c}299 \\
2.7 \\
0.9 \\
294 \\
303 \\
\end{array}$ & $\begin{array}{c}300 \\
1.9 \\
0.6 \\
296 \\
303 \\
\end{array}$ & $\begin{array}{c}300 \\
2.7 \\
0.9 \\
296 \\
303 \\
\end{array}$ & $\begin{array}{c}302 \\
1.8 \\
0.6 \\
298 \\
304 \\
\end{array}$ & $\begin{array}{l}302 \\
2.1 \\
0.7 \\
299 \\
304 \\
\end{array}$ & $\begin{array}{c}300 \\
2.4 \\
0.8 \\
296 \\
304 \\
\end{array}$ & $\begin{array}{c}302 \\
2.3 \\
0.8 \\
297 \\
305\end{array}$ \\
\hline $\begin{array}{l}\text { Thickness } \\
\text { (inches) } \\
n=10\end{array}$ & $\begin{array}{c}\text { Mean } \\
\text { S.D } \\
\% \text { RSD } \\
\text { Min } \\
\text { Max }\end{array}$ & $\begin{array}{c}0.1952 \\
0.0005 \\
0.3 \\
0.1945 \\
0.1960 \\
\end{array}$ & $\begin{array}{c}0.1727 \\
0.0006 \\
0.4 \\
0.1715 \\
0.1740 \\
\end{array}$ & $\begin{array}{c}0.1628 \\
0.0007 \\
0.4 \\
0.1620 \\
0.1640 \\
\end{array}$ & $\begin{array}{c}0.1586 \\
0.0008 \\
0.5 \\
0.1575 \\
0.1600 \\
\end{array}$ & $\begin{array}{c}0.1563 \\
0.0006 \\
0.4 \\
0.1555 \\
0.1575 \\
\end{array}$ & $\begin{array}{c}0.1548 \\
0.0007 \\
0.4 \\
0.1530 \\
0.1555 \\
\end{array}$ & $\begin{array}{c}0.1539 \\
0.0006 \\
0.4 \\
0.1530 \\
0.1545 \\
\end{array}$ \\
\hline $\begin{array}{l}\text { Hardness }(\mathrm{Kp}) \\
\mathrm{n}=10\end{array}$ & $\begin{array}{c}\text { Mean } \\
\text { S.D } \\
\% \text { RSD } \\
\text { Min } \\
\text { Max }\end{array}$ & $\begin{array}{c}2.2 \\
0.14 \\
6.7 \\
2.0 \\
2.4 \\
\end{array}$ & $\begin{array}{l}6.2 \\
0.4 \\
7.2 \\
5.6 \\
7.0 \\
\end{array}$ & $\begin{array}{c}10.1 \\
0.42 \\
4.2 \\
9.3 \\
10.7 \\
\end{array}$ & $\begin{array}{c}11.6 \\
0.29 \\
2.5 \\
11.3 \\
12.1 \\
\end{array}$ & $\begin{array}{c}13.1 \\
0.54 \\
4.1 \\
12.2 \\
14.0 \\
\end{array}$ & $\begin{array}{c}13.8 \\
0.6 \\
4.0 \\
12.7 \\
14.5 \\
\end{array}$ & $\begin{array}{c}15.6 \\
0.63 \\
4.0 \\
14.6 \\
16.4 \\
\end{array}$ \\
\hline $\begin{array}{l}\text { Loss of } \\
\text { Friability (\%) }\end{array}$ & - & 1.48 & 0.56 & 0.43 & 0.33 & 0.33 & 0.31 & 0.28 \\
\hline $\begin{array}{l}\text { Disintegration } \\
\text { Time }(\min ), n=6\end{array}$ & $\begin{array}{c}\text { Mean } \\
\text { S.D } \\
\% \text { RSD }\end{array}$ & $\begin{array}{l}0.23 \\
0.08 \\
33.8 \\
\end{array}$ & $\begin{array}{c}0.50 \\
0.05 \\
9.6 \\
\end{array}$ & $\begin{array}{c}3.91 \\
0.08 \\
2.0 \\
\end{array}$ & $\begin{array}{c}5.05 \\
0.20 \\
3.9\end{array}$ & $\begin{array}{c}8.92 \\
0.14 \\
1.6\end{array}$ & $\begin{array}{c}10.89 \\
0.13 \\
1.2\end{array}$ & $\begin{array}{c}12.63 \\
0.14 \\
1.1\end{array}$ \\
\hline
\end{tabular}


Table 13. Physical Testing of Tablets Prepared from Blend\#10

Composition: $16.5 \%$ Lactose Anhydrous $+16.5 \%$ Avicel PH101 + 66\% Starch $1500+1 \%$ Magnesium Stearate

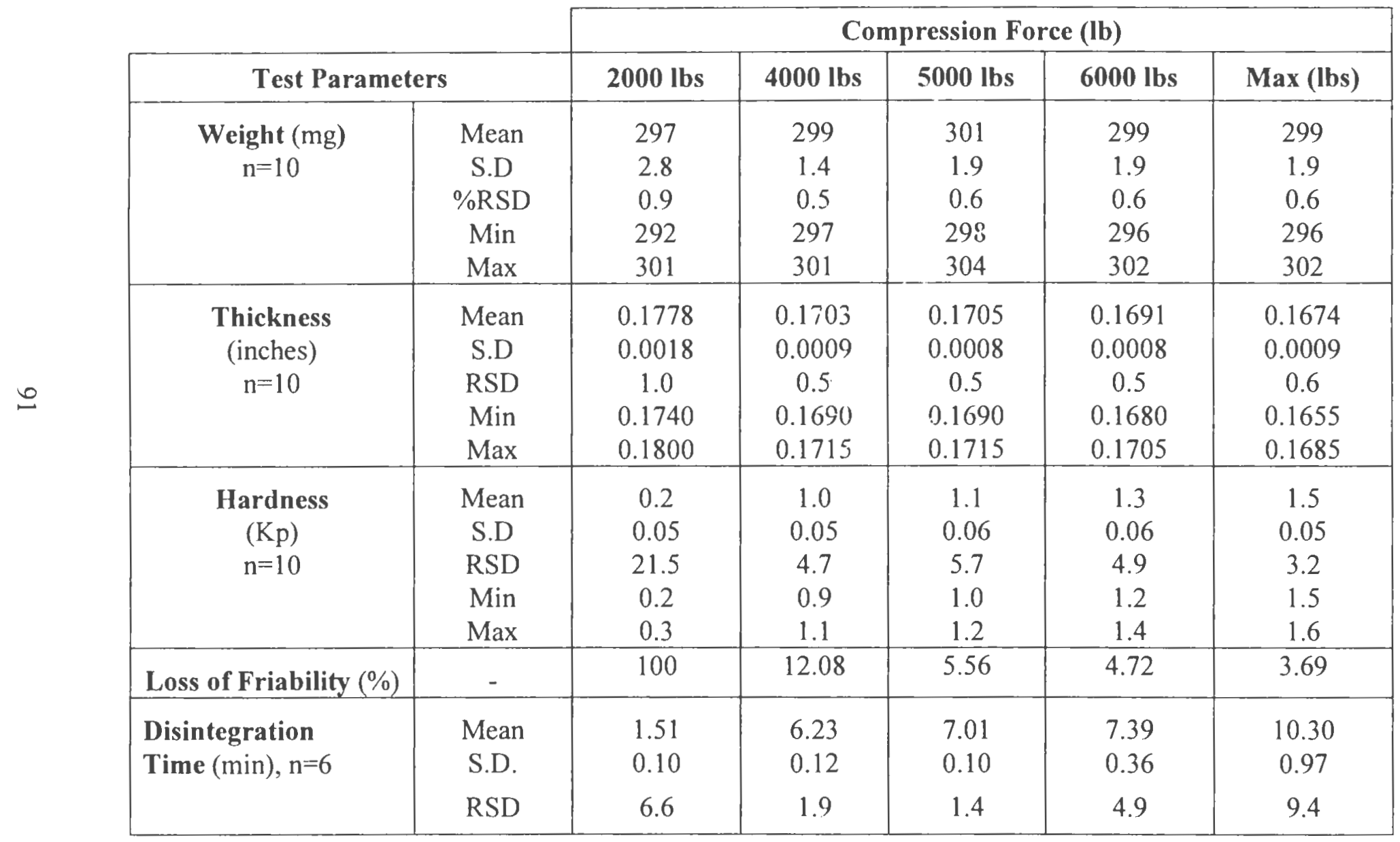


There are few parameters that are of importance in judging the quality of tablets produced from pharmaceutical mixtures. The first of these is hardness. Tablets require certain strength to withstand the mechanical shocks of handling during manufacturing, packaging, shipping, dispensing and consumption. Hardness is critical to those products that may cause bioavailability problems and to those that are sensitive to altered dissolution profiles that may be attributed to the compressive force applied. Hardness values also act as an in-process control so that the compression process is robust and validatable. Hardness can be defined, as the force required to break a tablet in a diametric compression test. It is sometimes referred to as tablet crushing strength. Generally, a high compression load is required to obtain a hard tablet, which has the disadvantage of producing high stress on the tableting machines and punches. It is therefore desirable to produce satisfactorily hard tablets at the lowest possible compression load. The hardness of a tablet, like its thickness, is a function of die fill and compression force. At a constant die fill, the hardness increases and thickness decreases as additional compression force is applied. This relationship holds up to a maximum value for hardness and a minimum value for thickness; beyond which increase in pressure causes the tablet to laminate or cap. At a constant compression force (fixed distance between upper and lower punches), hardness increases with increasing die fills and decreases with lower die fills. Aging affects the hardness of tablets of certain formulations (8-9). Lubricants may also reduce the tablet hardness when they are used in high concentrations or mixed for longer periods of time (37-42). Similarly large sized tablets display higher values of hardness as compared to the small sized tablets. The tablet tooling also makes an 
impact on the hardness of the tablet. For a given formulation, a flat-faced tool provides harder tablets than a deep cup tool. For optimum hardness, round tooling is preferred to the caplet or oval shaped tooling. In the current study all mixtures were compressed with 12/32" standard concave tooling at target weight of $300 \mathrm{mg}$. Tables 4 to 13 provide a summary of tablet hardness and thickness values for all the blends at varying levels of compression force. Figure 8 shows the effect of applied compression force on tablet hardness as a function of varying composition in the blends. The Avicel ${ }^{\circledR}$ PH101 mixture (Blend\#2) provided the highest tablet hardness values (7.323.7 Kp) as compared to all other mixtures. Starch $^{\circledR} 1500$ (Blend\#3) provided the lowest tablet hardness values $(0-0.3 \mathrm{Kp})$. The lactose anhydrous (Blend\#1) provided an intermediate hardness profile $(1.9-14.2 \mathrm{Kp})$ when compared to Avicel ${ }^{\circledR} \mathrm{PH} 101$ and Starch $^{(} 1500$. It is well documented that Avicel displays excellent compressibility behavior whereas Starch 1500 shows poor bonding characteristics (8). And also the presence of magnesium stearate in the formulation adversely affects the tablet hardness for $\operatorname{Starch}^{\circledR} 1500$ blends. Magnesium stearate is known to have strong negative effects on the binding properties of excipients, due to the formation of lubricant film on the particle surface. These observations are in consistent with the findings by other investigators $(8,37-42)$. Figure 9 displays the effect of formulation composition on tablet hardness at $4000 \mathrm{lbs}$ of applied force. It is evident from the graph that as the amount of Avicel ${ }^{\circledR}$ PH101 is increased in the mixture, hardness values increased proportionally with the highest hardness of $21 \mathrm{Kp}$ being observed when the mixture had $99 \%$ of Avicel ${ }^{\circledR}$ PH101. This could be attributed to the high amount of moisture content present in the blend $(5.12 \%)(32)$. 


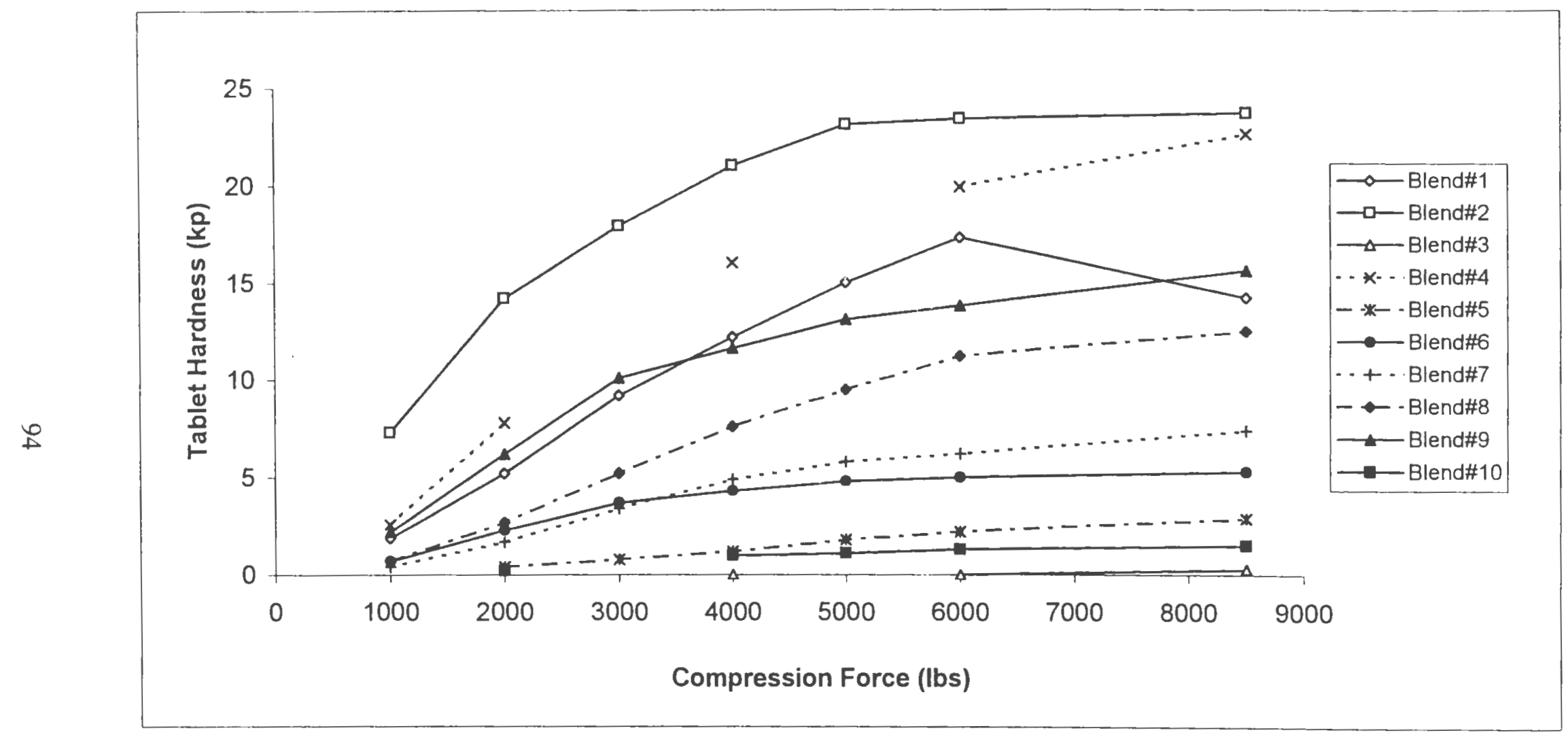

Figure 8. Effect of Compression Force on Tablet Hardness 


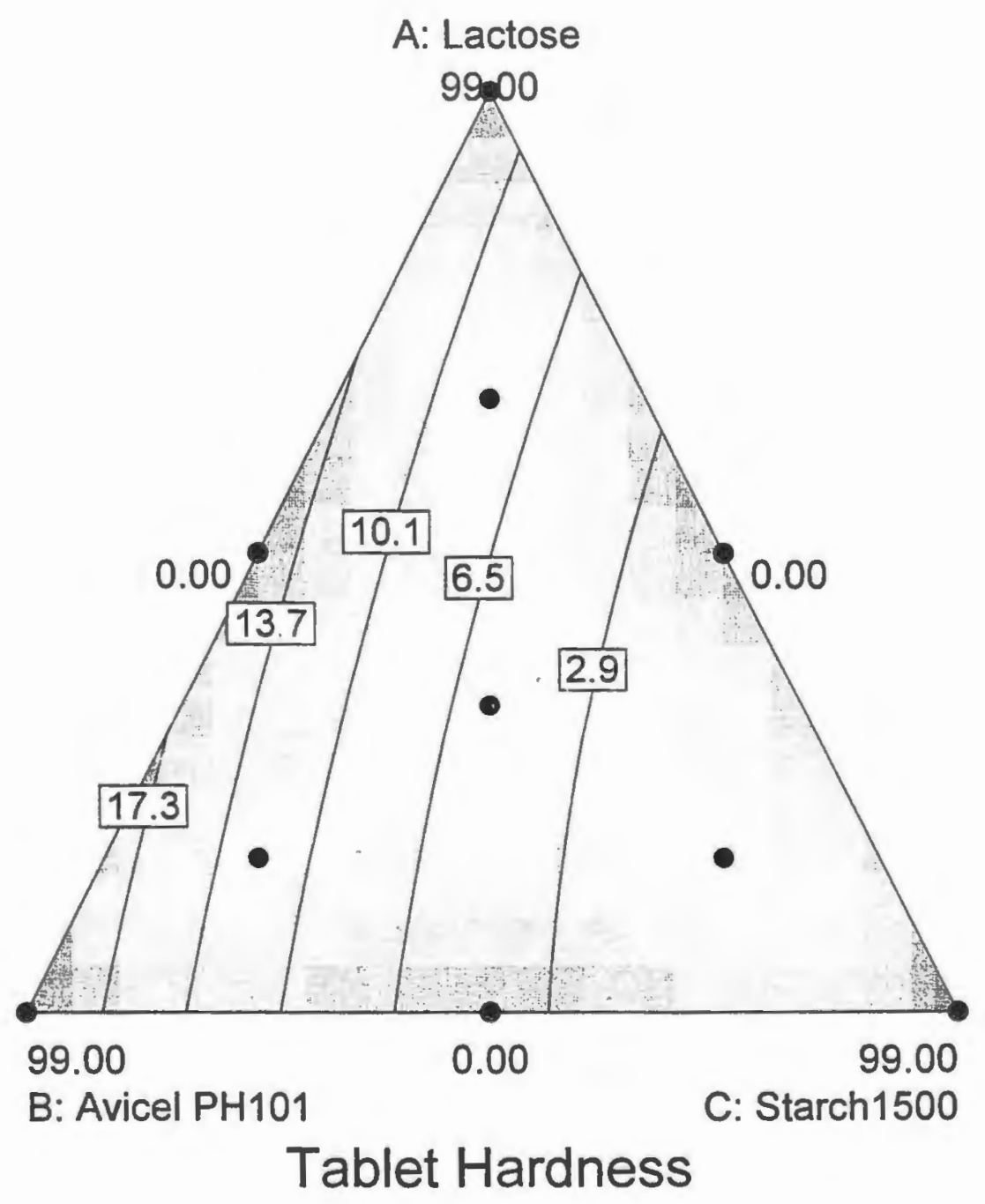

Figure 9. Effect of Formulation Composition on Tablet Hardness at $\mathbf{4 0 0 0}$ Ibs of Compression Force 
The effect of compression force on tablet thickness is described in Figure 10 and Tables 4 to 13. Tablet thickness is dependent on the nature of blend, die fill and compression force $(31,35,36,43)$. The higher the applied force, the lower will be the thickness. However the thickness value will reach a constant at which the pore volume in the tablet is minimum or zero and beyond which application of more force does not reduce tablet thickness. Among the three excipients, Starch ${ }^{\circledast} 1500$ tends to impart more thickness $\left(0.1645^{\prime \prime}-0.1679^{\prime \prime}\right)$ to the tablet followed by Avicel ${ }^{\circledR}$ PH101 $\left(0.1947^{\prime \prime}-0.1517^{\prime \prime}\right)$ and Lactose Anhydrous $\left(0.1785^{\prime \prime}-1568^{\prime \prime}\right)$. Among all the blends, the binary mixture of Avicel ${ }^{\circledast}$ PH101 and Starch $^{\circledR} 1500$ (Blend\#6) provided the thickest tablets throughout the range of applied forces tested.

Another important characteristic in measuring the strength of a tablet is tablet friability which should be as iow as possible. Tablets that tend to powder, chip, and fragment may cause problems during manufacturing, coating, packaging and transportation also adds to tablet weight variation or content uniformity problems. Friability generally increases as compression load decreases; thus a material that forms adequately cohesive tablets at a low compression load will also provide acceptably low friability. Figure 11 and Tables 4 to 13 shows the effect of compression force on the friability loss for tablets made from the tested blends. Tablets containing Starch ${ }^{\circledR} 1500$ (Blend\#3) displayed the maximum friability loss indicating that $\operatorname{Starch}^{\circledR} 1500$ provided poor binding strength. Tablets containing Avicel ${ }^{\circledR}$ PH101 (Blend\#2) showed the least friability loss indicating that it provided an excellent binding mechanism for particles to be held as coherent tablets. As Figure 11 indicates friability loss is inversely proportional to the applied compression forces. The increase in friability loss at lower 


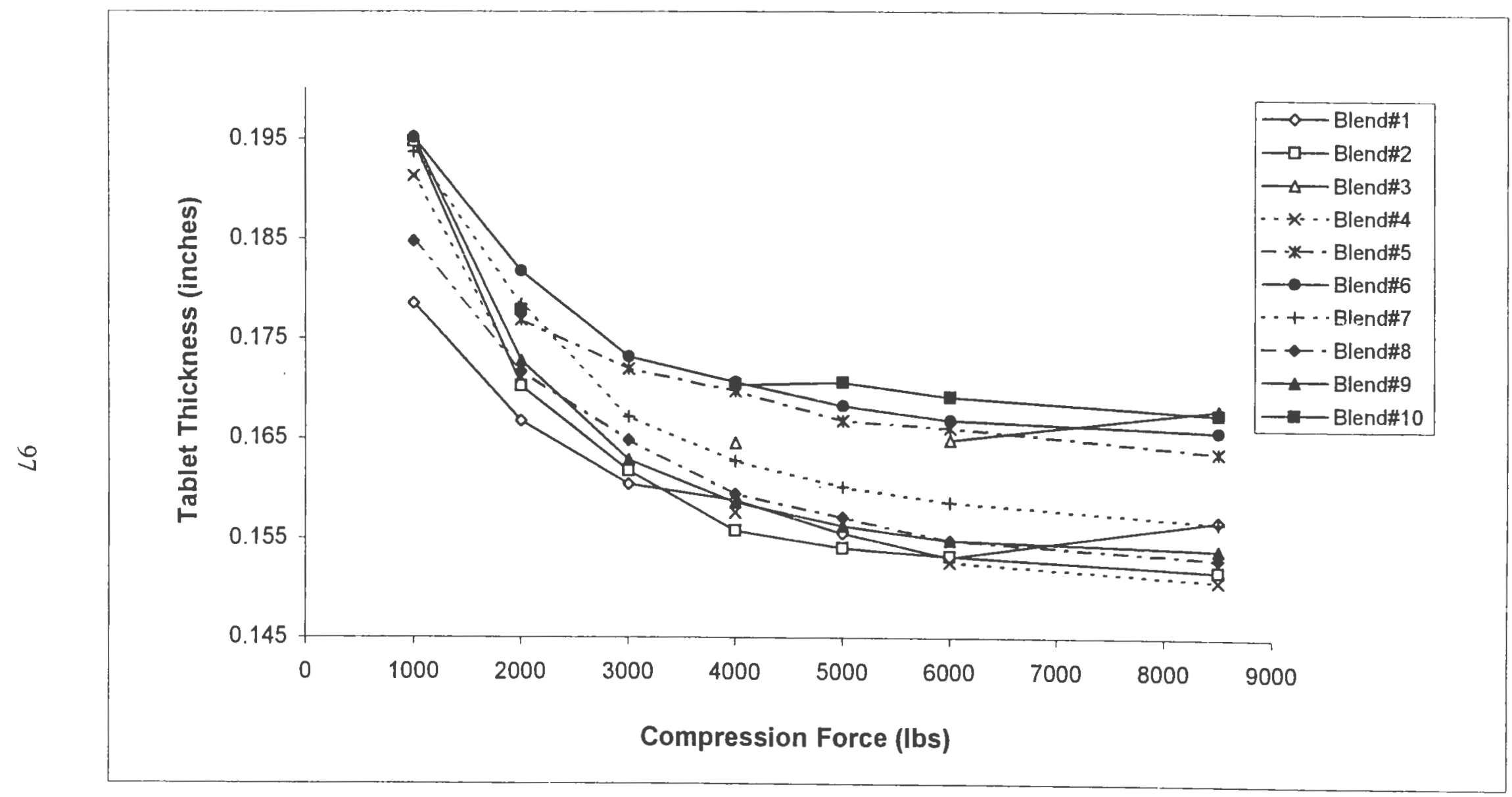

Figure 10. Effect of Compression Force on Tablet Thickness 


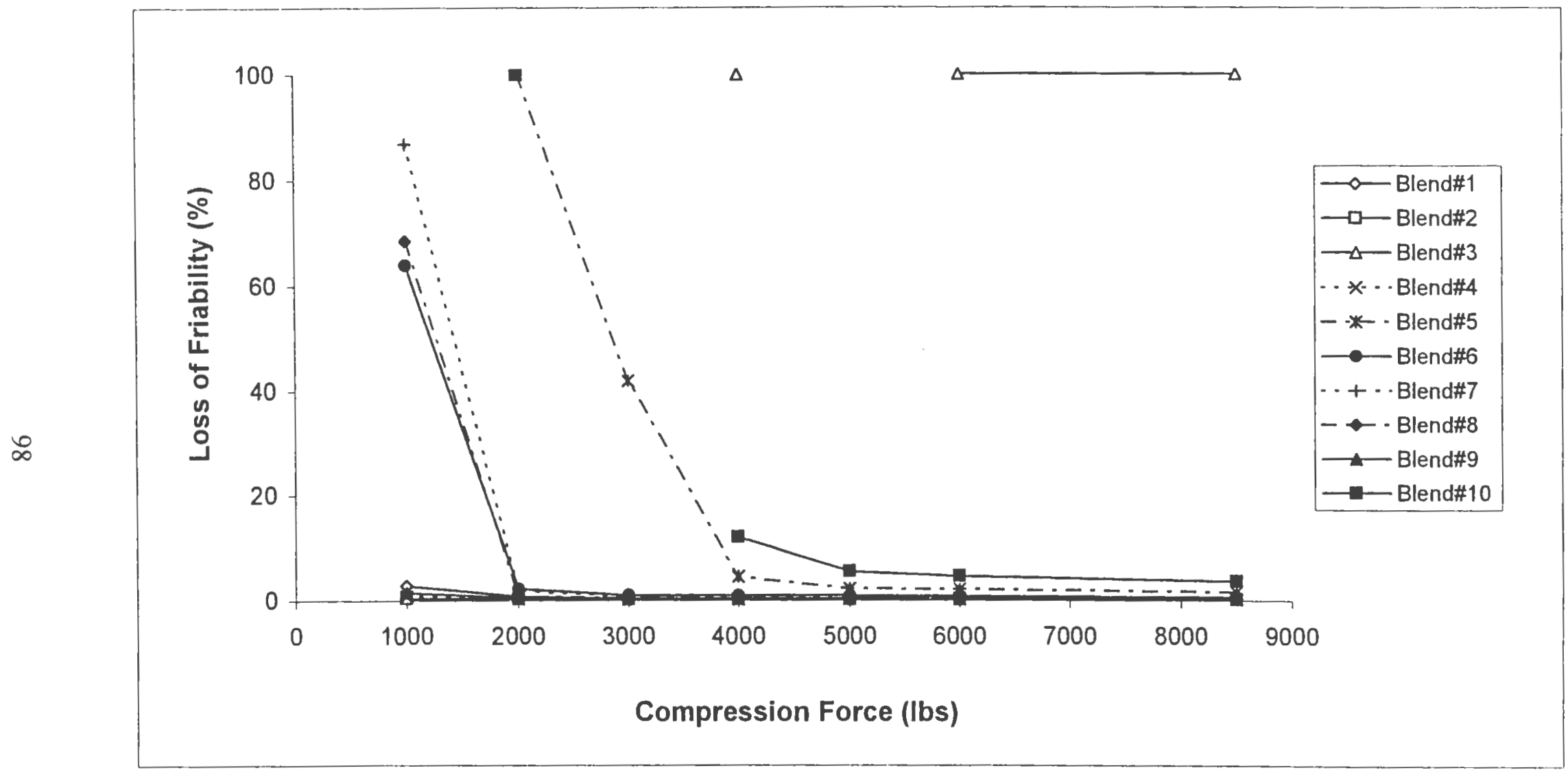

Figure 11. Effect of Compression Force on Tablet Friability 
compression load is more drastic than that observed at medium or higher forces. As other investigators reported, friability loss is a characteristic of blend composition at a constant applied force and is critical for further processing steps such as coating etc (44-51).

Figure 12 and Tables 4 to 13 indicate the effect of compression force on the disintegration time of the various blend compositions. The three major excipients in this study have an affinity to pick up water in the following order: $\operatorname{Starch}^{\circledR} 1500>$ Avicel $^{(2}$ PH101 $>$ Lactose Anhydrous. Disintegration time defined as the time required for tablets to break into primary particles before dissolution, is dependent upon mixture composition. applied force, tooling design, tablet weight, hardness etc $(8,44-52$,$) . The higher the applied force, the harder will be the tablet and the longer$ the disintegration time. In the current study, testing was performed as per the USP disintegration test. As Figure 10 indicates there was an increase in disintegration time for all the blends when compression force was increased from $1000 \mathrm{lbs}$ to maximum achievable force ( $~ 8500 \mathrm{lbs})$. Maximum disintegration times were observed for Blend \#4 that contains $49.5 \%$ of Avicel ${ }^{\circledR}$ PH101 and $49.5 \%$ Lactose Anhydrous. Disintegration time generally provides a good indication of how long a tablet will take to break into particles and then go into solution. It thus provides useful information for predicting the in-vivo performance. Dissolution testing in multiple media coupled with disintegration test results will be valuable to formulation scientists in order to obtain successful formulations. 


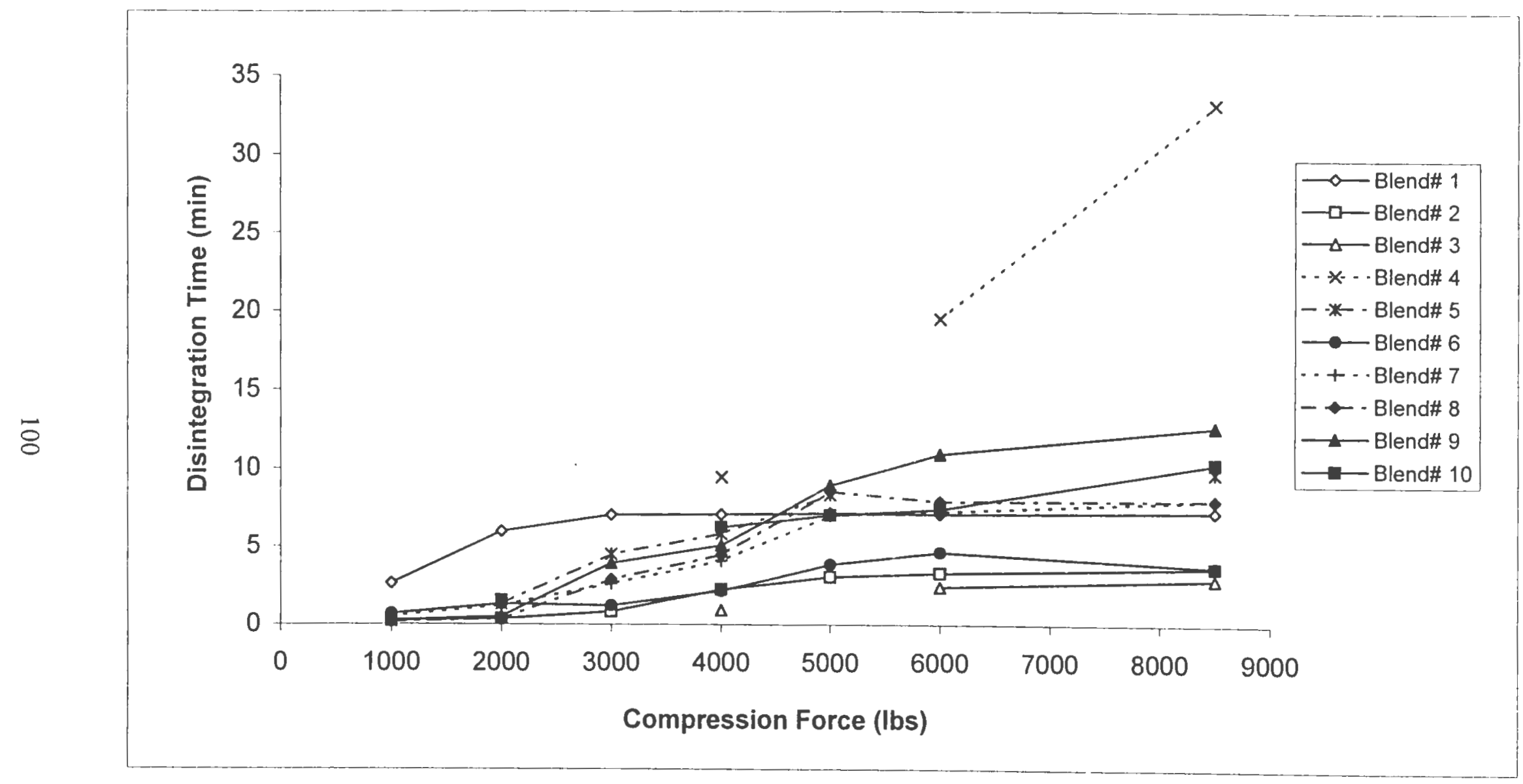

Figure 12. Effect of Compression Force on Tablet Disintegration 


\section{Analysis of Compression Behavior of Mixtures using Force-Time Profiles:}

The process of consolidation involves a reduction in the porosity of a powder bed. At low pressures, this occurs by rearrangement of the particles, but at the pressures used in the tableting process, two mechanisms, fragmentation and deformation achieve porosity reduction. Most materials will consolidate using a combination of both these mechanisms, but in practice one of the mechanisms will dominate the other $(9,12,17,53)$. It has been suggested that the more deformation contributes to the consolidation mechanism of a solid, the more likely is that substance to show time-dependent compressional properties.

Compression work describes the total amount of mechanical energy needed to compress a loose powder column into a dense tablet. Three components can be differentiated in this work: energy to overcome friction, energy consumption in the expansion of the tablet after maximum compression and finally energy used in bonding and formation of strong bonds (44-53).

Many parameters influence the powder compaction process (9). Some of these include stress intensity, speed and application time of the stress, die dimensions, and the mechanical properties of the powder. Particle size distribution, shape, crystalline state, interfacial properties, and viscoelastic properties of a powder mixture affect the mechanical properties of the compacts. Materials that undergo fragmentation show little change in yield pressure when punch velocity is increased. Such materials do not show much variation in their behavior when the punch speed or press is changed. 
Changes in tablet strength brought about by increasing punch speed are fundamentally due to increased tablet porosity $(31,35,36)$.

It has been hypothesized that interparticulate bonds are formed during the dwell time, and that the ultimate strength of a tablet depends on these interparticulate bonds. Thus claims have been made that the longer the dwell time, the better the quality of tablet, but there is no evidence that the formation of interparticulate bonds is time-dependent $(53,54)$. It should be noted that the radius of the pressure roll has no effect on the duration of the dwell time.

In the case of compressed powders, the particle surface is the most dynamic component of structural relaxation, where relaxation is a function of the attractive forces between individual powder particles.

The energy consumption during compression of powders can be classified into the following stages: i) for arriving at the closest possible proximity of the particles, ii) by friction between the particles, iii) by friction with the die wall, iv) by plastic deformation and $v$ ) by elastic deformation.

In the current study, compression force-time data was collected using an instrumented rotary tablet press for all the ten mixtures prepared as per the simplex design described in Table 1. The compression force applied was varied from $1000 \mathrm{lbs}$ to maximum achievable force $(1000 \mathrm{lbs}, 2000 \mathrm{lbs}, 3000 \mathrm{lbs}, 4000 \mathrm{lbs}, 5000 \mathrm{lbs}, 6000$ lbs and maximum achievable force) on the tablet machine. From each upper punch compaction force-time pulse, parameters such as rise time $(10 \%$ to $90 \%$ of peak value), fall time ( $90 \%$ to $10 \%$ of peak value), pulse width ( $50 \%$ to $50 \%$ of peak value), dwell time ( $90 \%$ to $90 \%$ of peak value), contact time (10\% to $10 \%$ of peak value), 
force at $10 \%$, force at $50 \%$, force at $90 \%$, maximum force, area to peak, area from peak and total area were determined. Similarly, from each lower punch ejection forcetime pulse, parameters such as rise time ( $10 \%$ to $90 \%$ of peak value), fall time ( $90 \%$ to $10 \%$ of peak value), pulse width (50\% to $50 \%$ of peak value), dwell time ( $90 \%$ to $90 \%$ of peak value), contact time ( $10 \%$ to $10 \%$ of peak value), force at $10 \%$, force at $50 \%$, force at $90 \%$, maximum force, area to peak, area from peak and total area were calculated. Figures $13,15,17,19,21,23,25,27,29$ and 31 provide the representative pulse analysis of various parameters from compaction force-time curves at an applied compression force of $4000 \mathrm{lbs}$ for Blend\#1 to \#10 respectively. Similarly, Figures 14 , $16,18,20,22,24,26,28,30$ and 32 provide the representative pulse analysis of various parameters from ejection force-time curves at an applied compression force of $4000 \mathrm{lbs}$ for Blend\#1 to \#10 respectively. The upper punch compression data obtained for all the ten blends with varying proportions of Avicel ${ }^{\circledR}$ PH101, Lactose Anhydrous, NF and Starch ${ }^{\circledR} 1500$ at compression forces of $1000 \mathrm{lbs}, 2000 \mathrm{lbs}, 3000 \mathrm{lbs}, 4000 \mathrm{lbs}$, $5000 \mathrm{lbs}, 6000 \mathrm{lbs}$ and maximum achievable forces on the tableting machine are summarized in Tables 14, 15, 16, 17, 18, 19 and 20, respectively. At the same compression forces, the lower punch ejection data generated for the ten blends are summarized in Tables $14,15,16,17,18,19$ and 20 , respectively.

The compression event can be divided into the compression and decompression phase. On rotary tablet press there is dwell time because the punches do not move actively in a vertical direction when they are with their plane punch head area under the compression rollers. At the beginning of the compression event the upper punch is hitting against the compression roller. After reaching its lowest position 


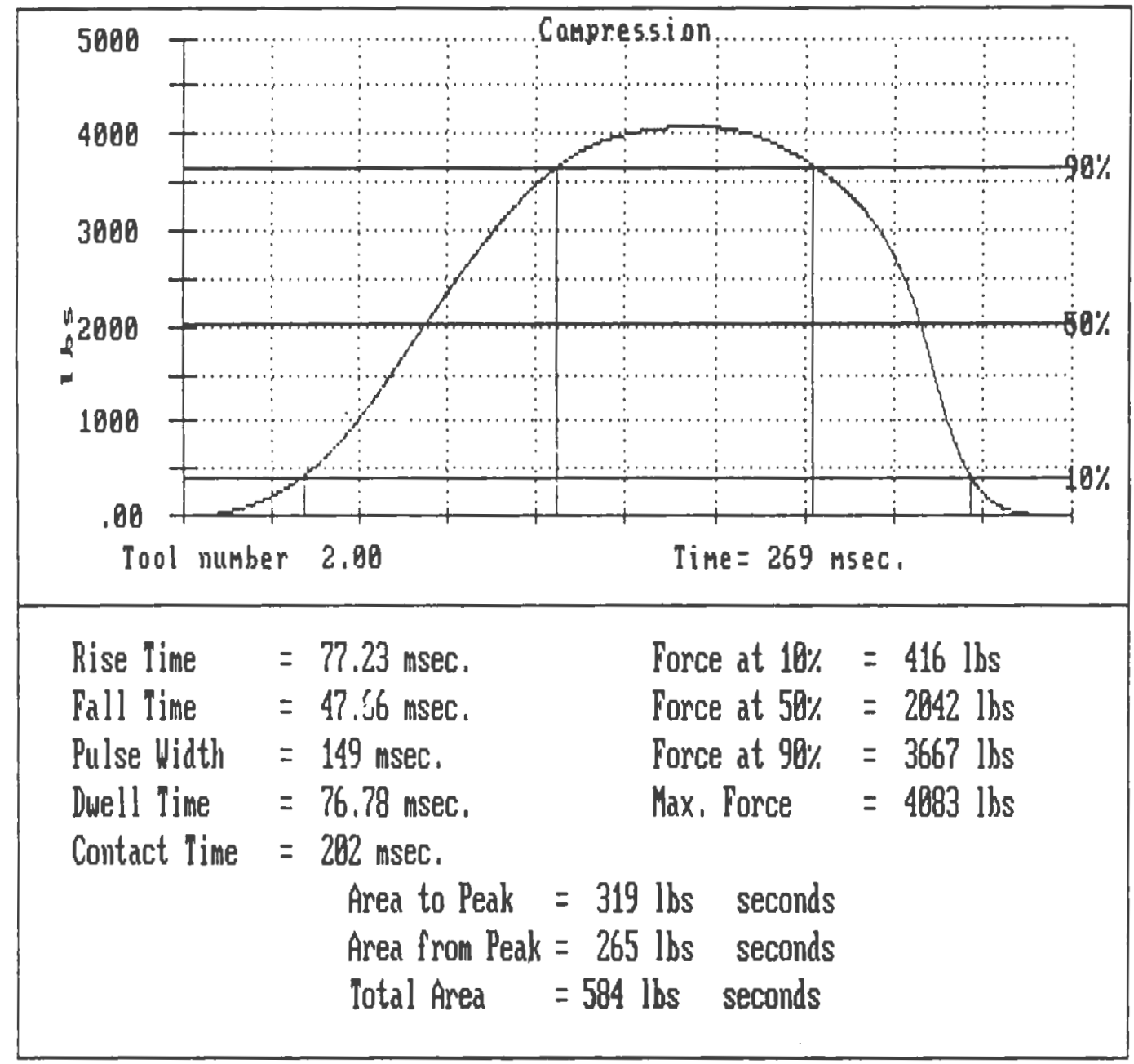

Figure 13. Typical Pulse Analysis of the Compaction Force-Time Curve for Blend\#1 at $4000 \mathrm{lbs}$ 


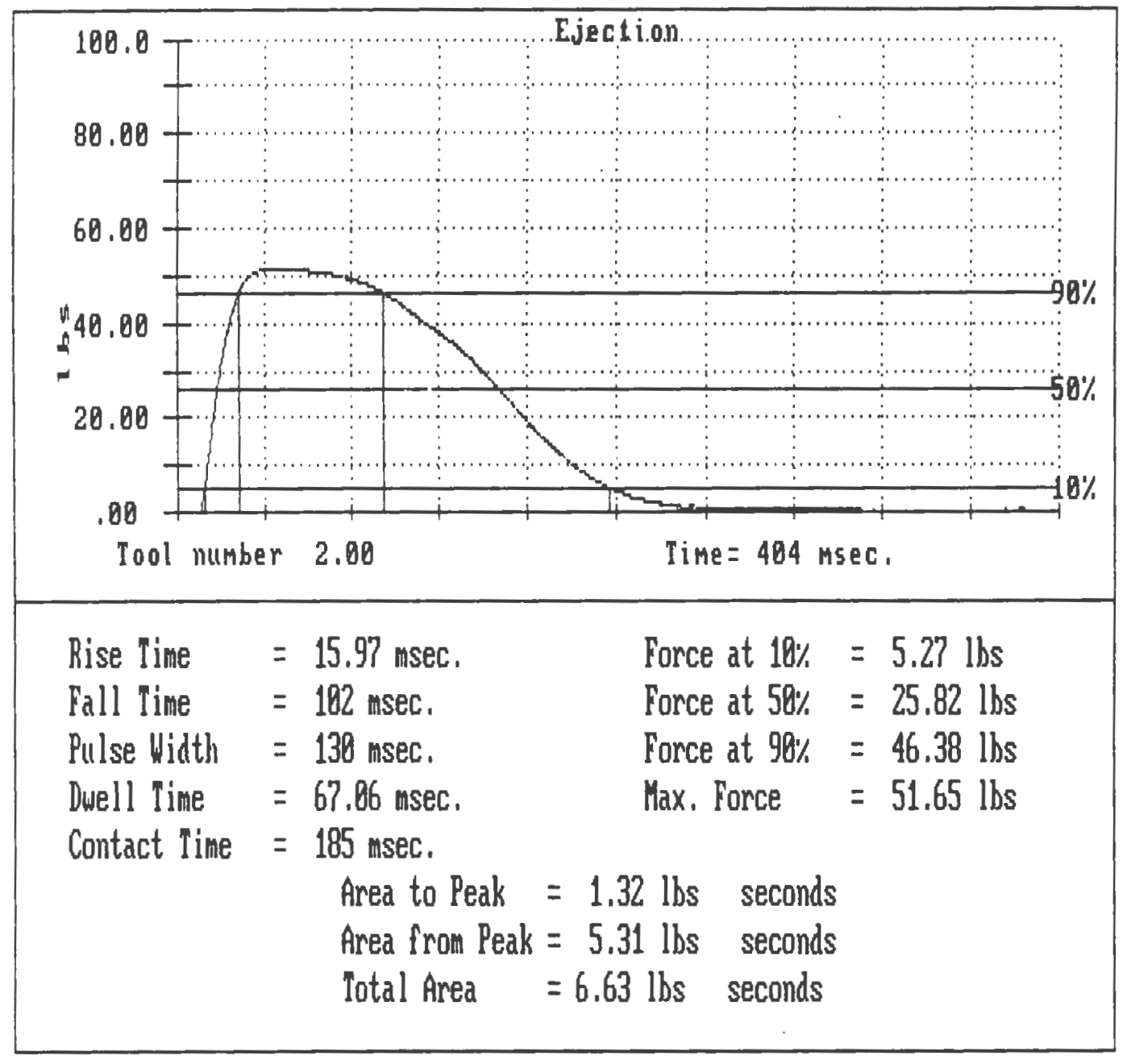

Figure 14. Typical Pulse Analysis of the Ejection Force-Time Curve for Blend\#1 at 4000 lbs 


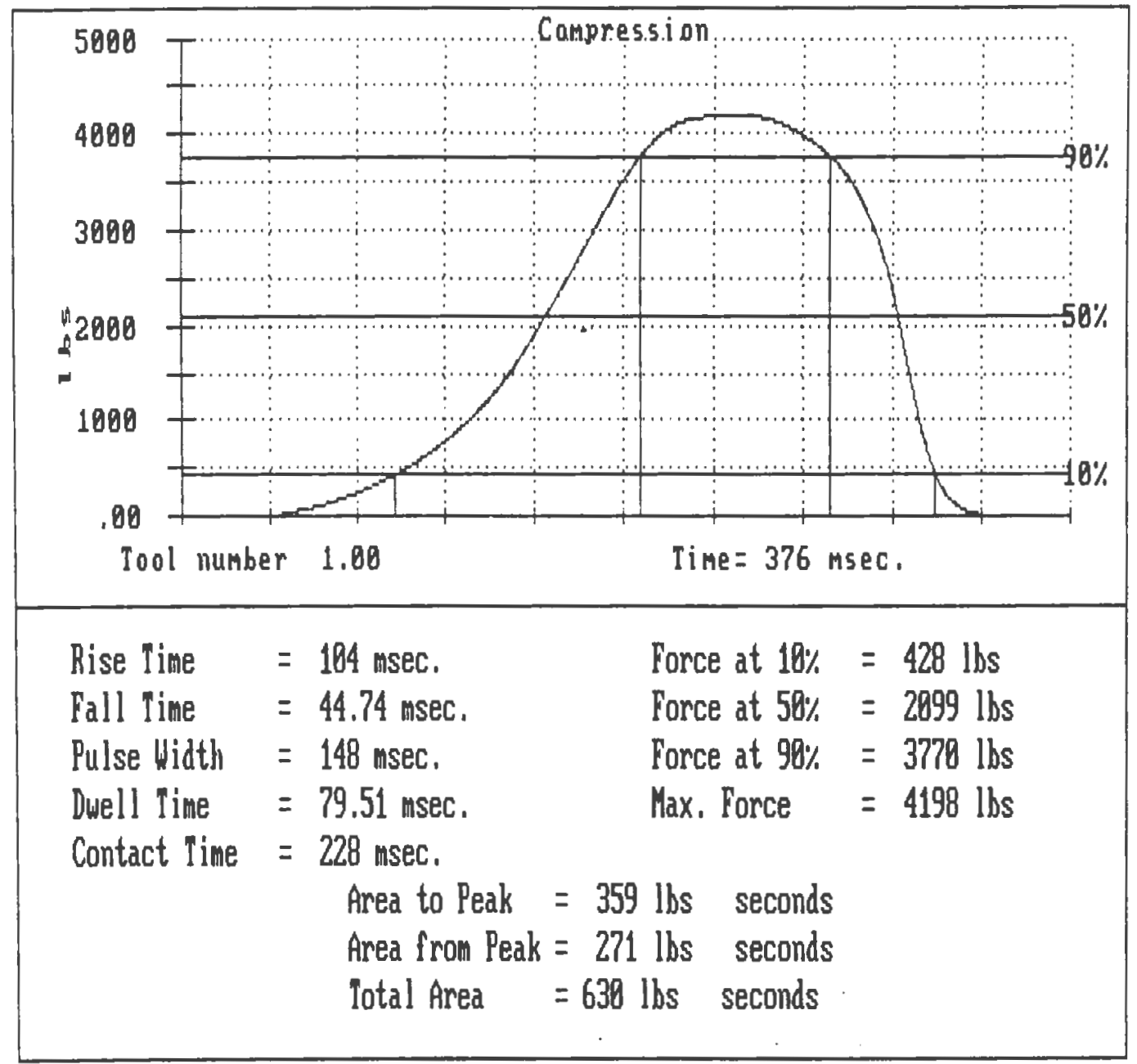

Figure 15. Typical Pulse Analysis of the Compaction Force-Time Curve for Blend\#2 at 4000 lbs 


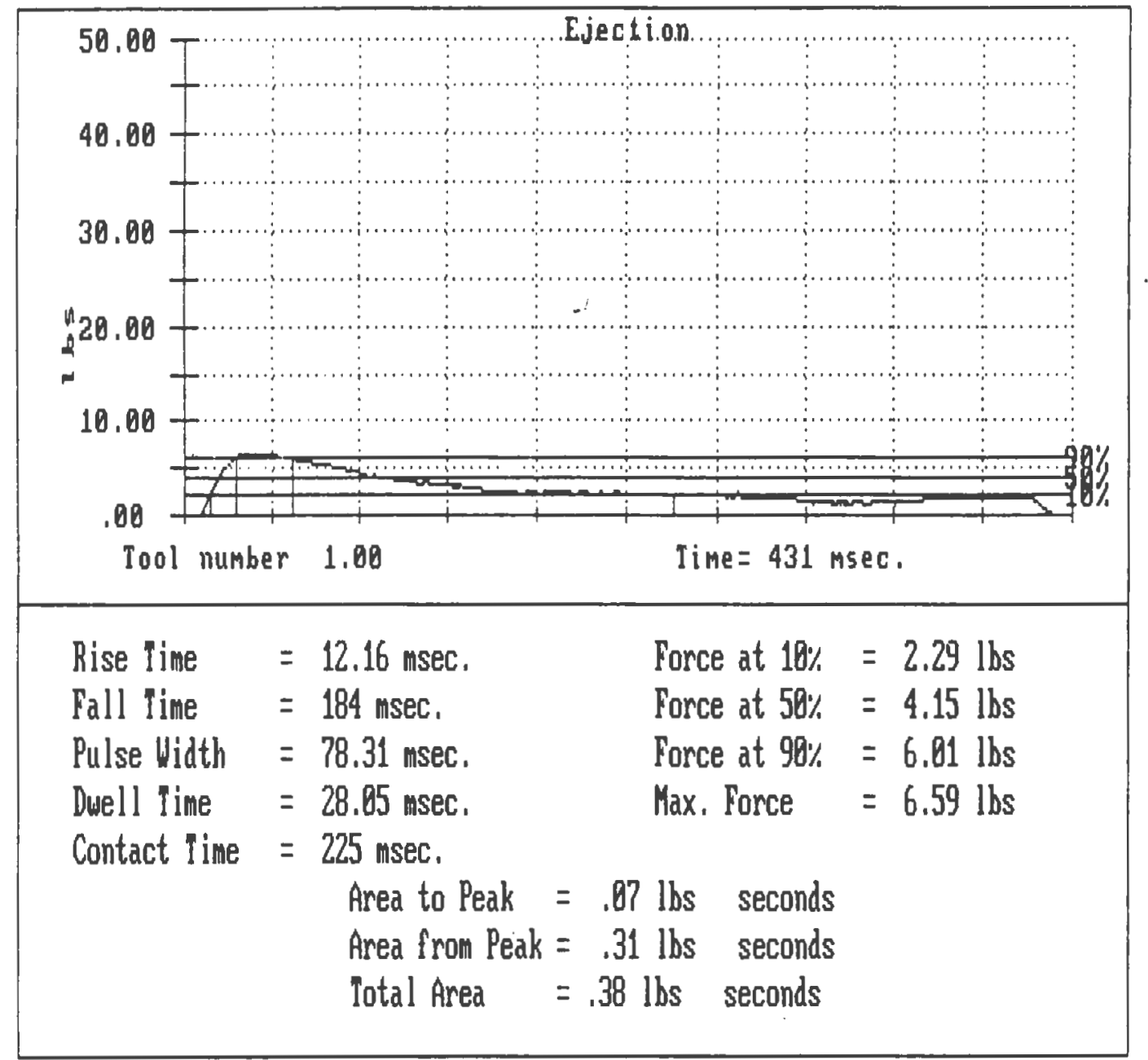

Figure 16. Typical Pulse Analysis of the Ejection Force-Time Curve for Blend\#2 at 4000 lbs 


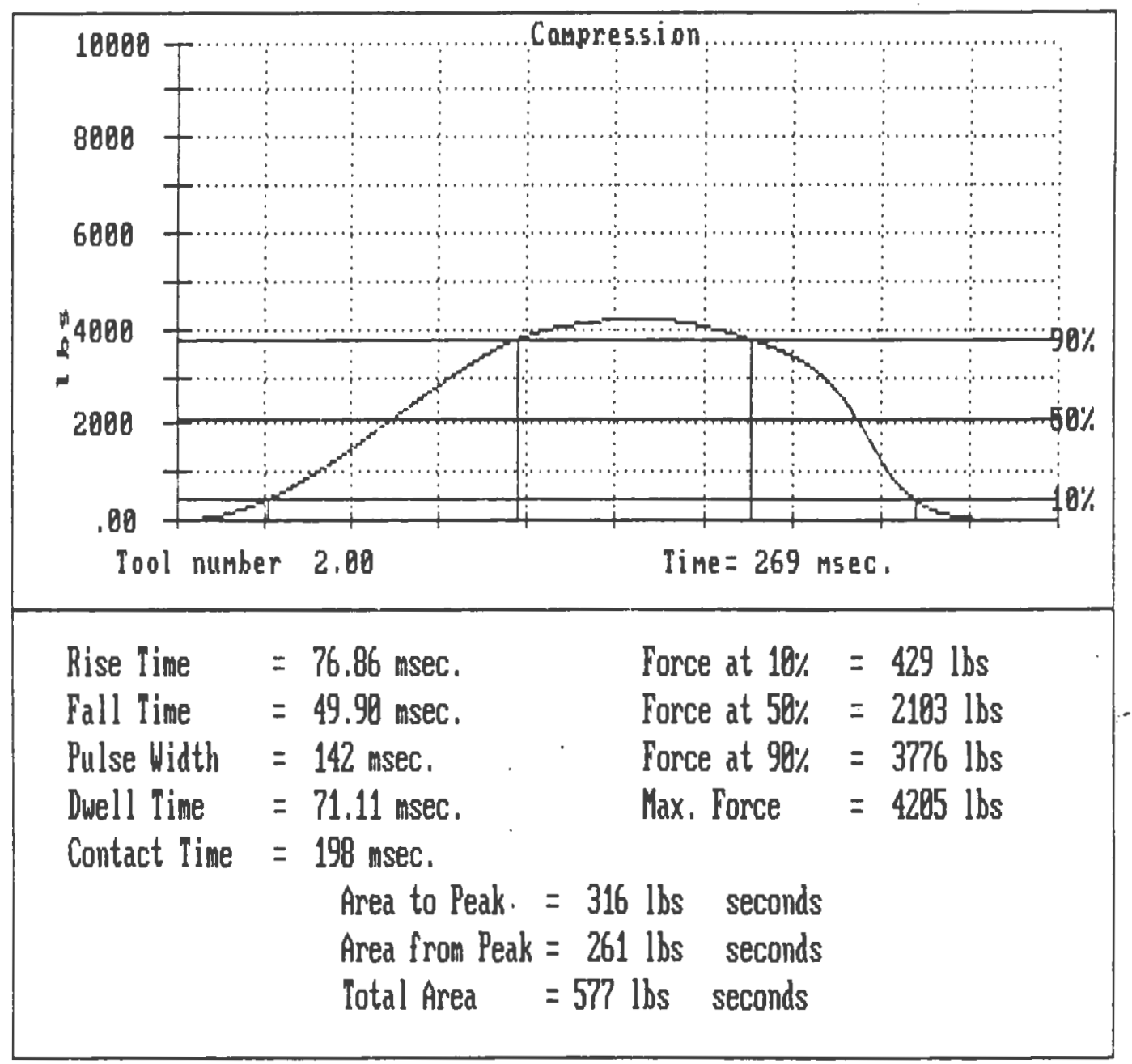

Figure 17. Typical Pulse Analysis of the Compaction Force-Time Curve for Blend\#3 at 4000 lbs 


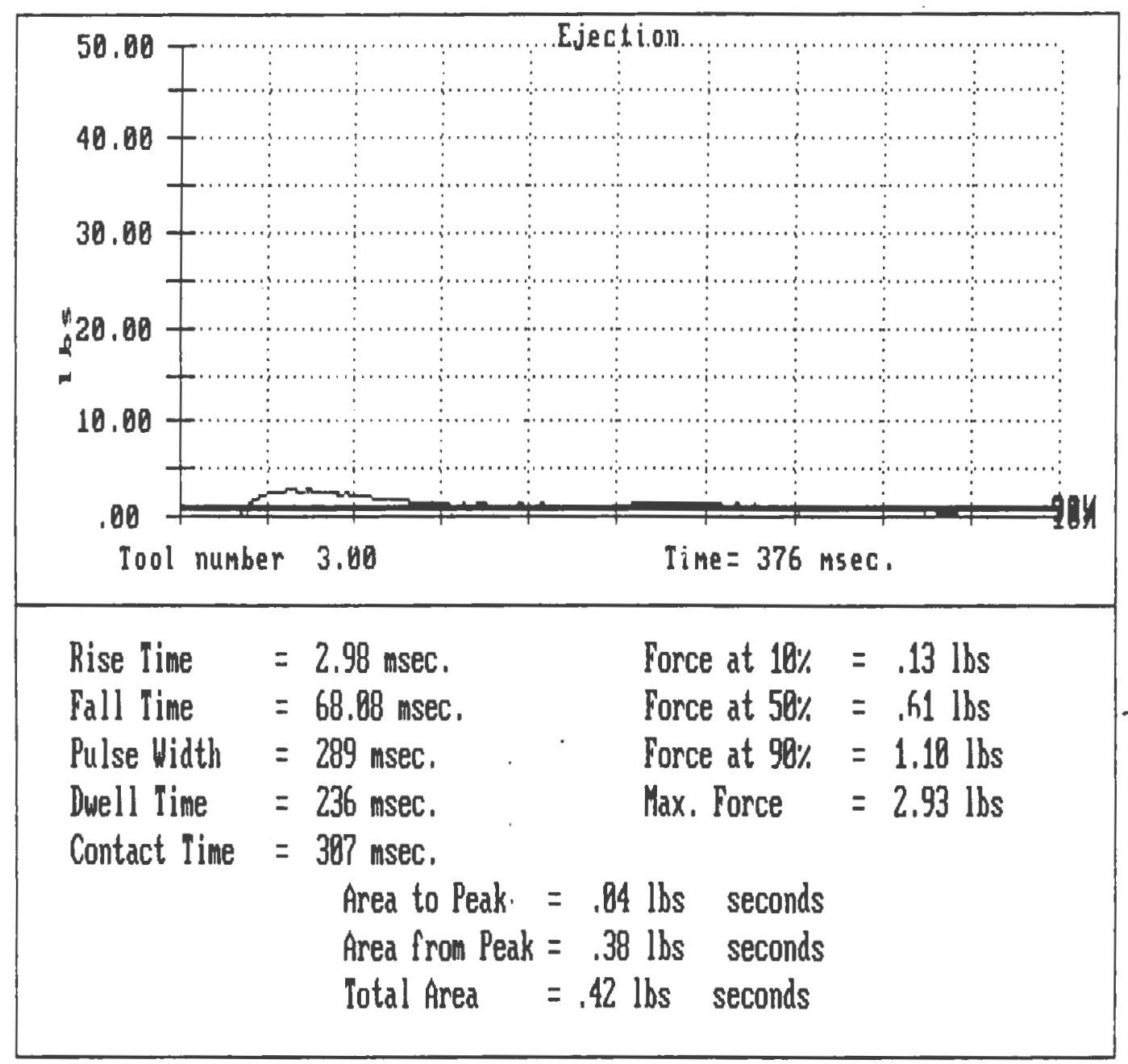

Figure 18. Typical Pulse Analysis of the Ejection Force-Time Curve for Blend\#3 at $\mathbf{4 0 0 0} \mathrm{lbs}$ 


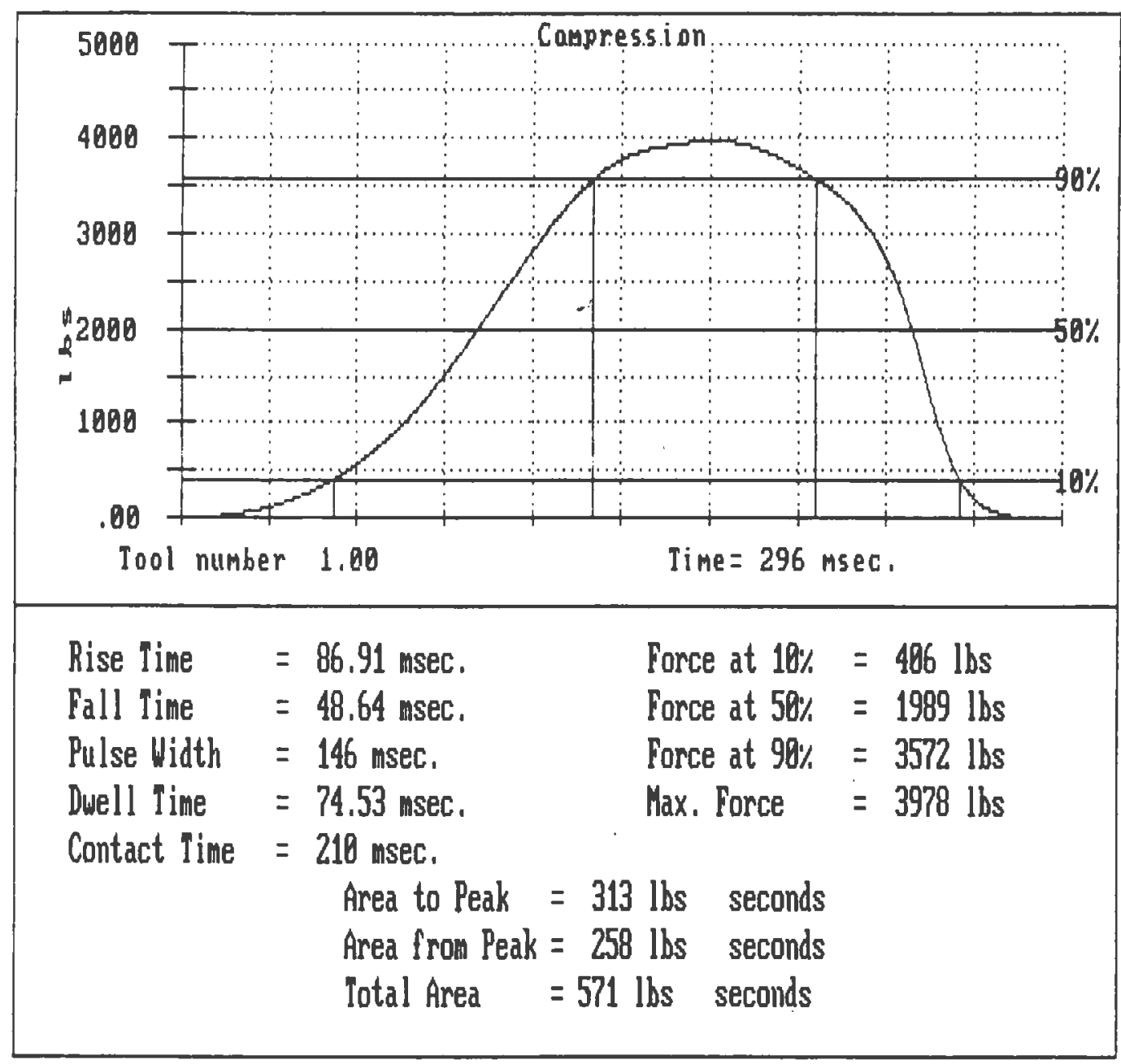

Figure 19. Typical Pulse Analysis of the Compaction Force-Time Curve for Blend\#4 at $\mathbf{4 0 0 0}$ lbs 


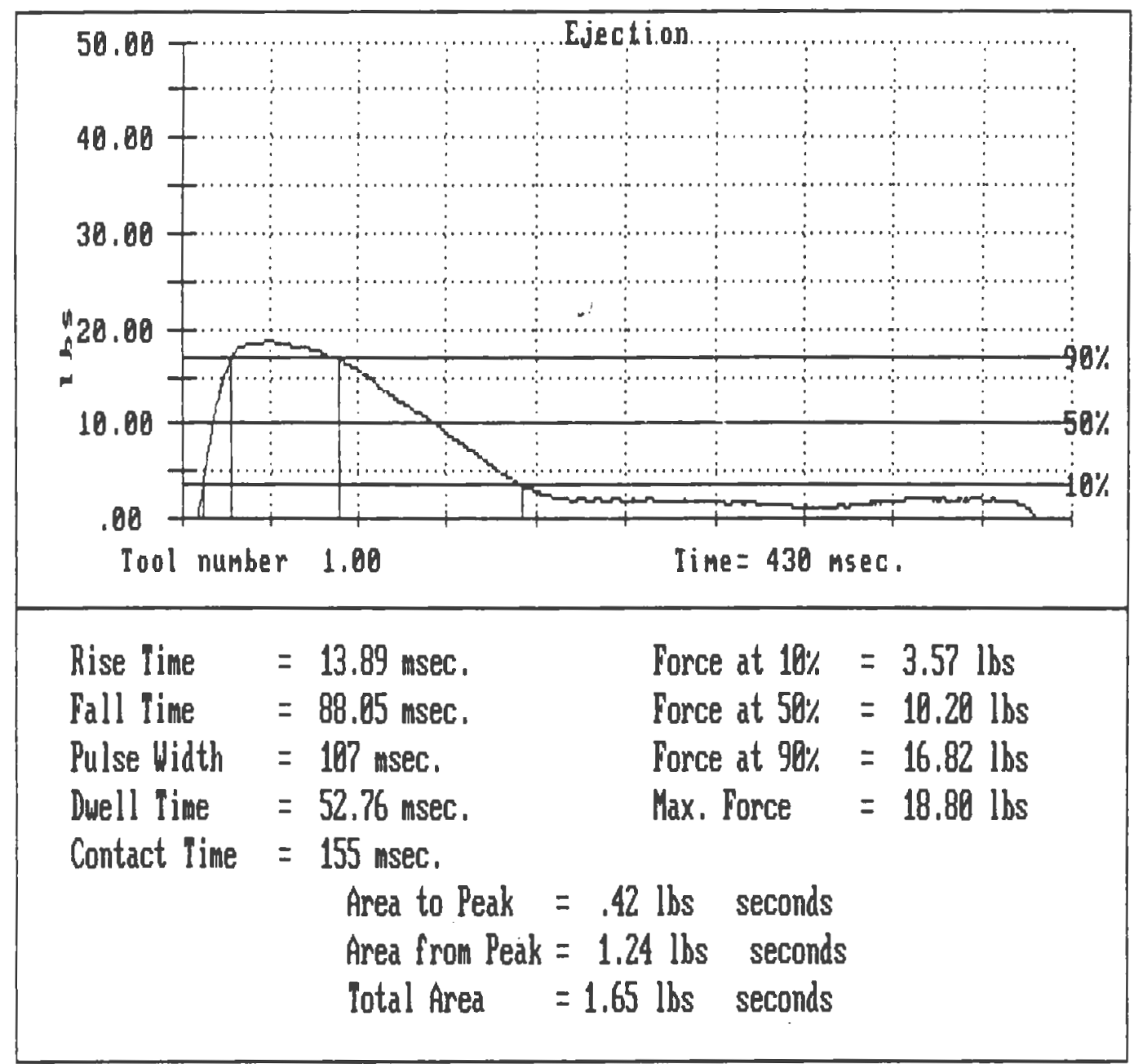

Figure 20. Typical Pulse Analysis of the Ejection Force-Time Curve for Blend\#4 at $4000 \mathrm{lbs}$ 


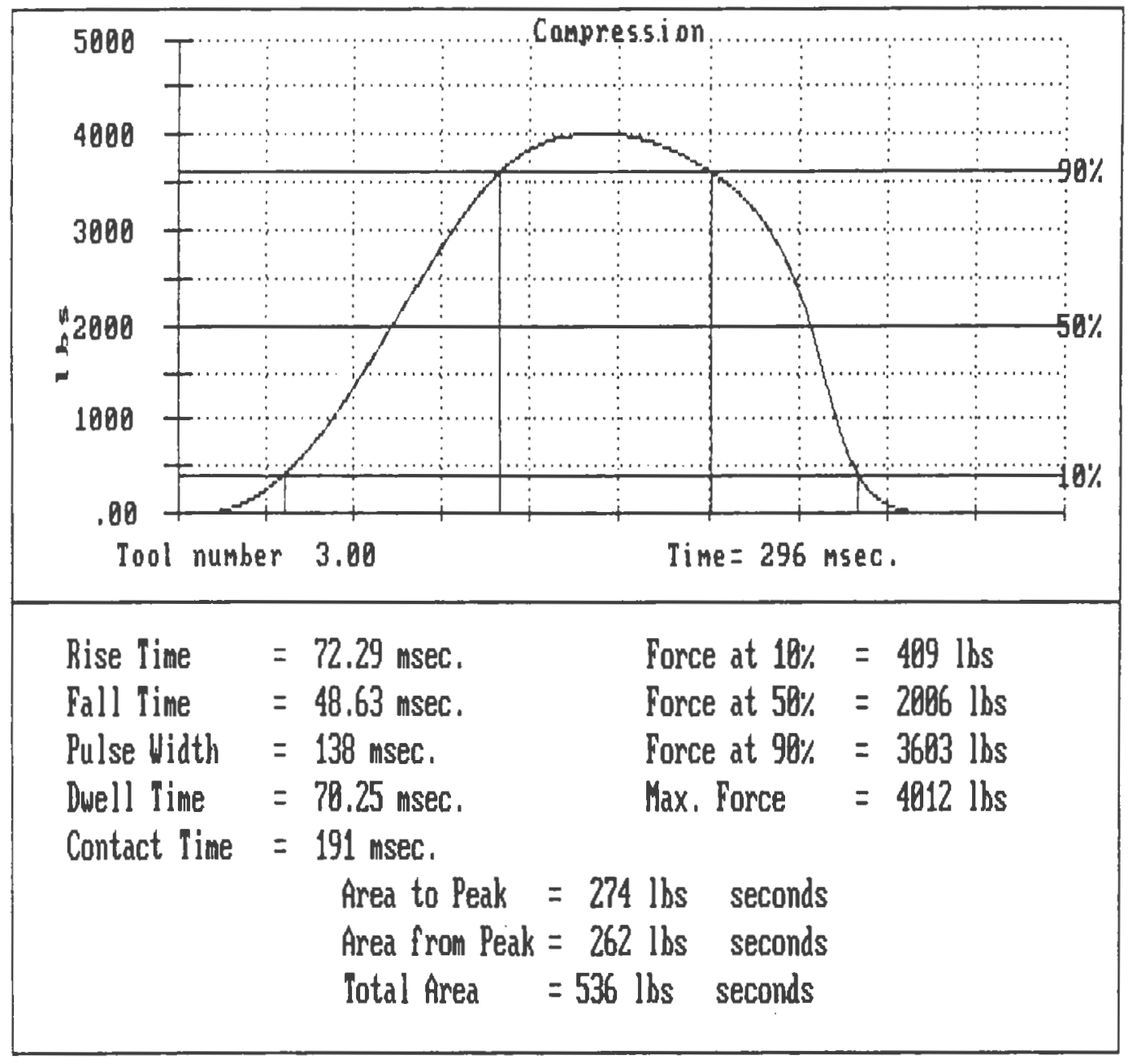

Figure 21. Typical Pulse Analysis of the Compaction Force-Time Curve for Blend\#5 at $\mathbf{4 0 0 0}$ lbs 


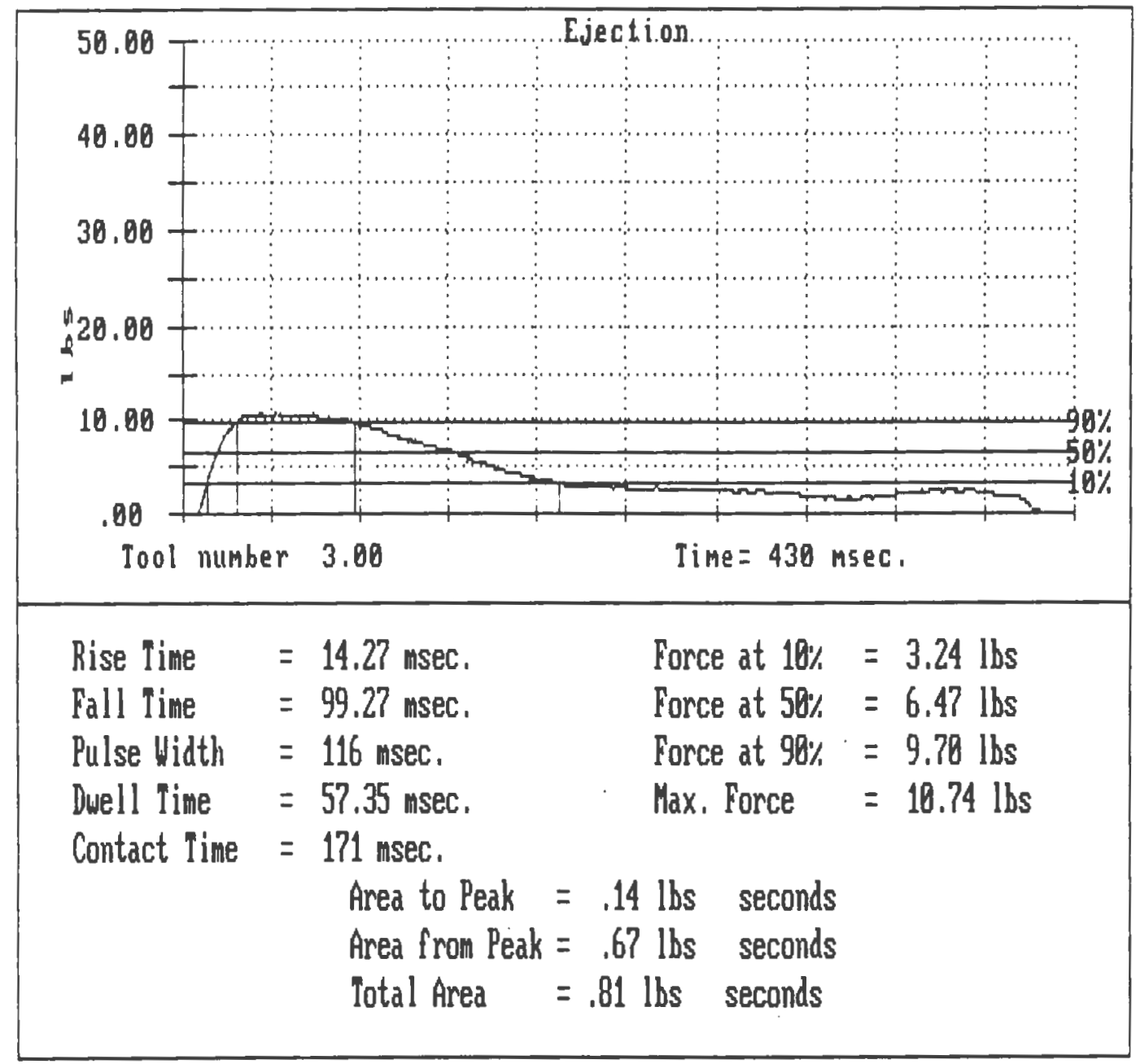

Figure 22. Typical Pulse Analysis of the Ejection Force-Time Curve for Blend\#5 at 4000 lbs 


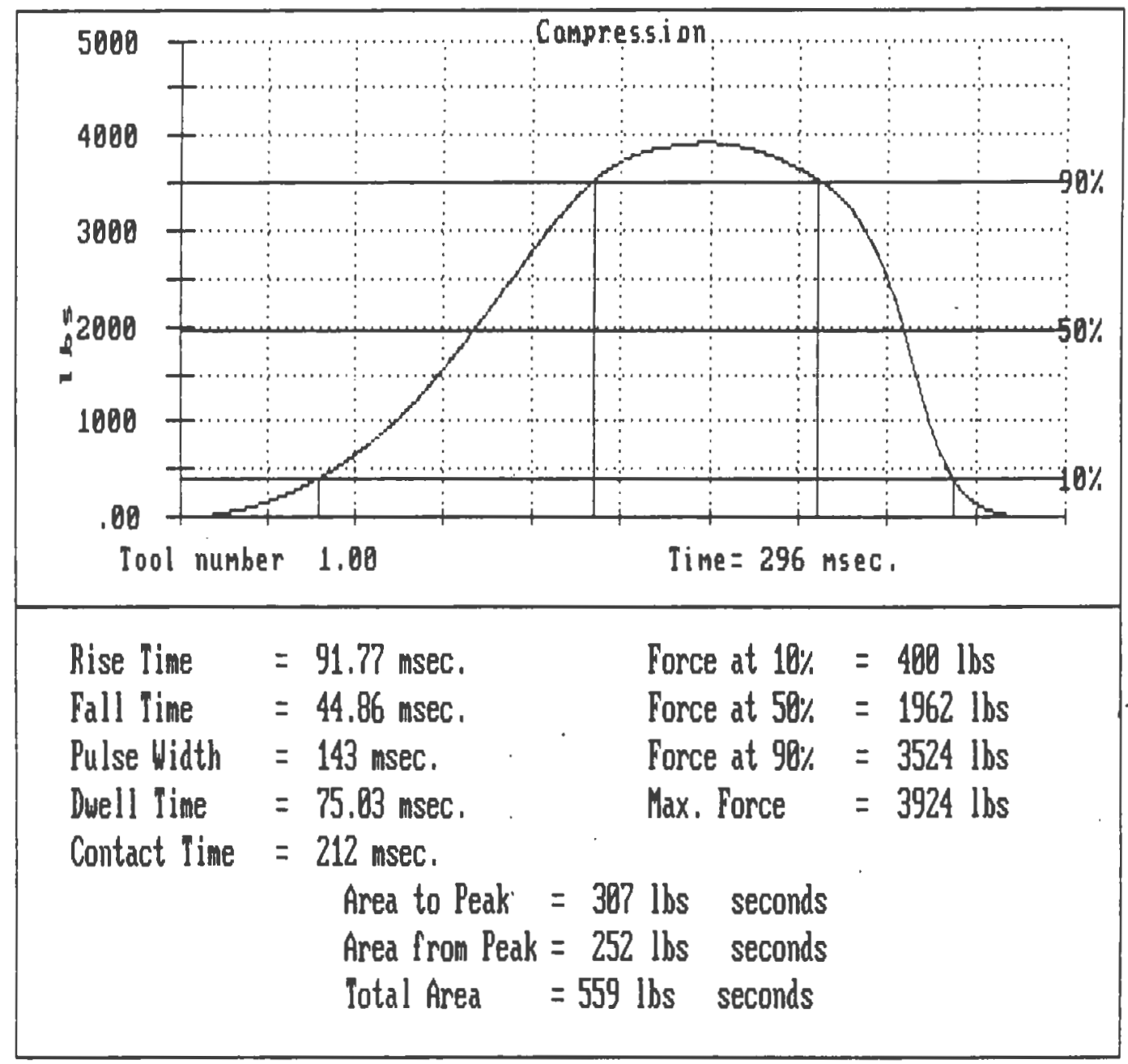

Figure 23. Typical Pulse Analysis of the Compaction Force-Time Curve for Blend\#6 at $4000 \mathrm{lbs}$ 


\begin{tabular}{|l}
50.00 \\
$40.00-100$
\end{tabular}

Figure 24. Typical Pulse Analysis of the Ejection Force-Time Curve for Blend\#6 at $4000 \mathrm{lbs}$ 


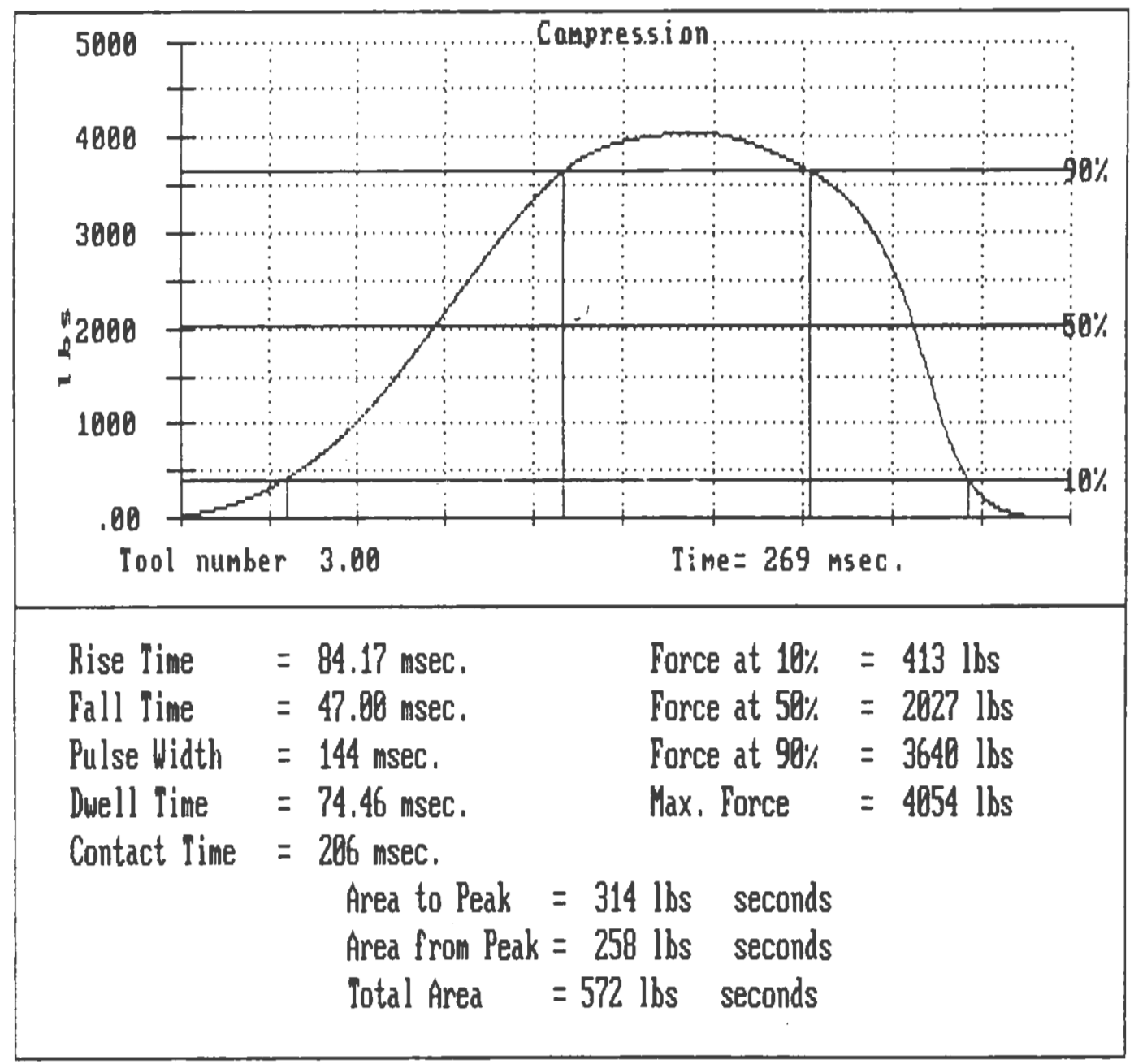

Figure 25. Typical Pulse Analysis of the Compaction Force-Time Curve for Blend\#7 at $4000 \mathrm{lbs}$ 


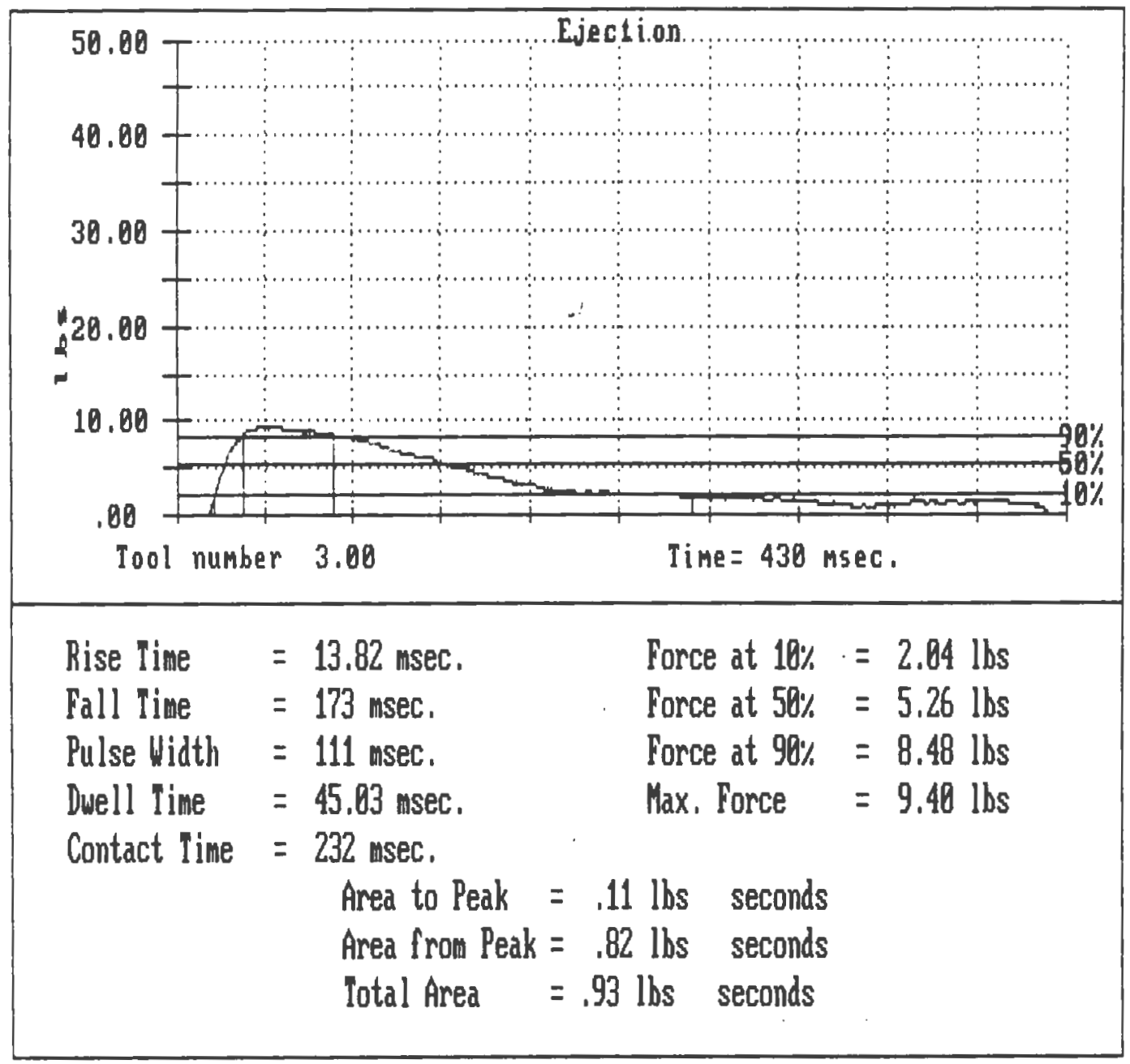

Figure 26. Typical Pulse Analysis of the Ejection Force-Time Curve for Blend\#7 at $4000 \mathrm{lbs}$ 


\begin{tabular}{|c|c|c|c|}
\hline 5000 & &
\end{tabular}

Figure 27. Typical Pulse Analysis of the Compaction Force-Time Curve for Blend\#8 at 4000 lbs 


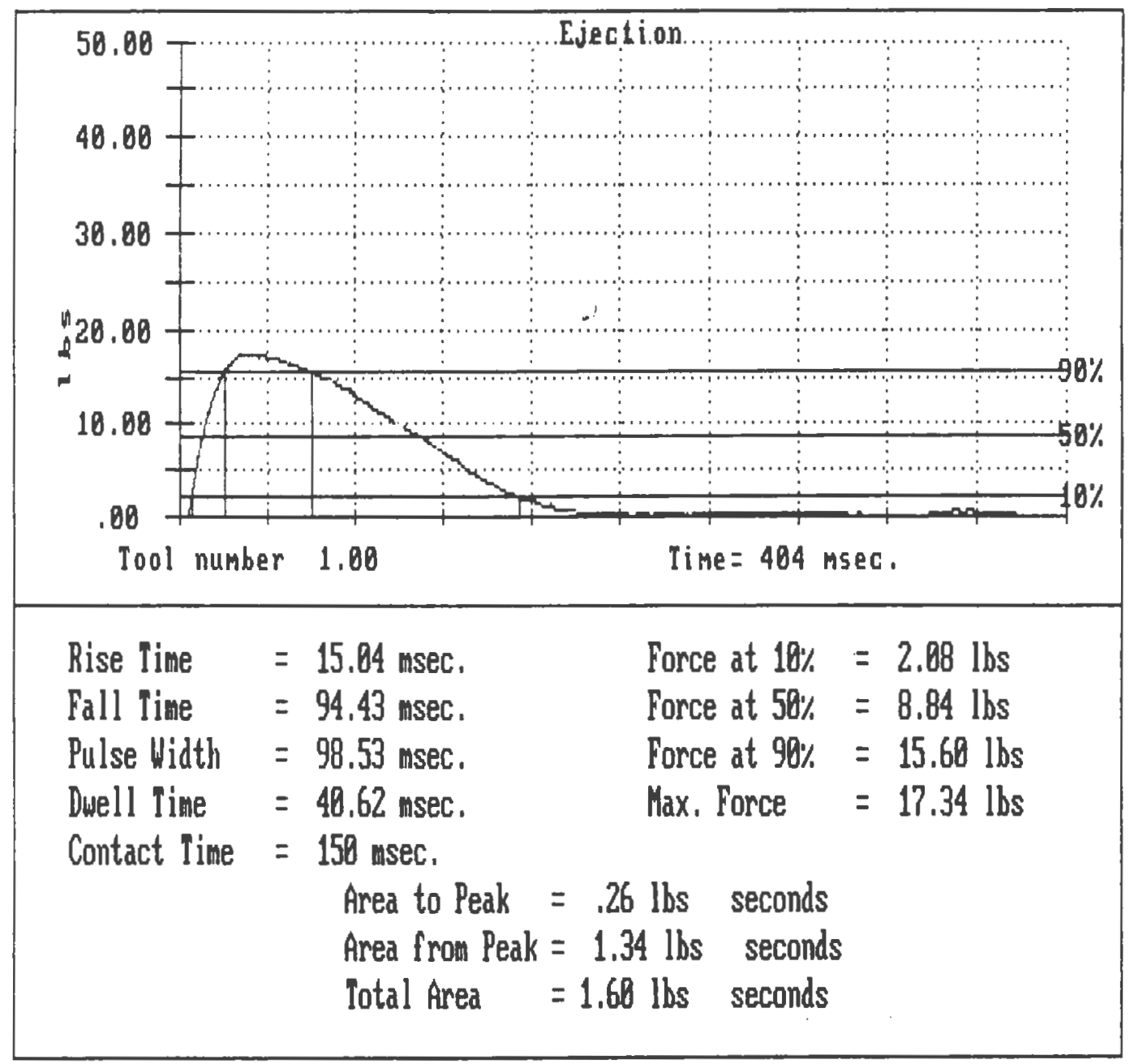

Figure 28. Typical Pulse Analysis of the Ejection Force-Time Curve for Blend\#8 at $4000 \mathrm{lbs}$ 


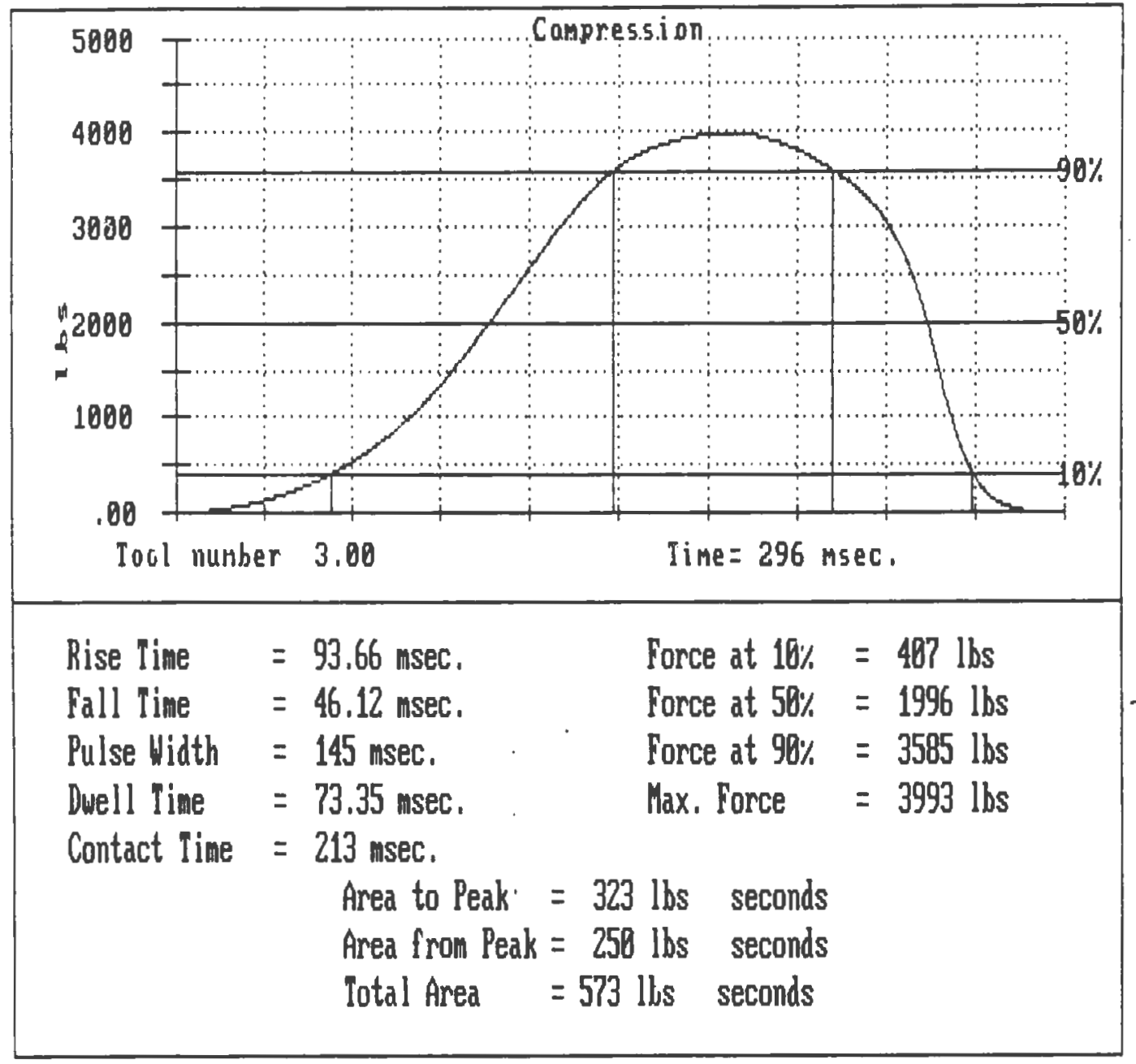

Figure 29. Typical Pulse Analysis of the Compaction Force-Time Curve for Blend\#9 at 4000 lbs 


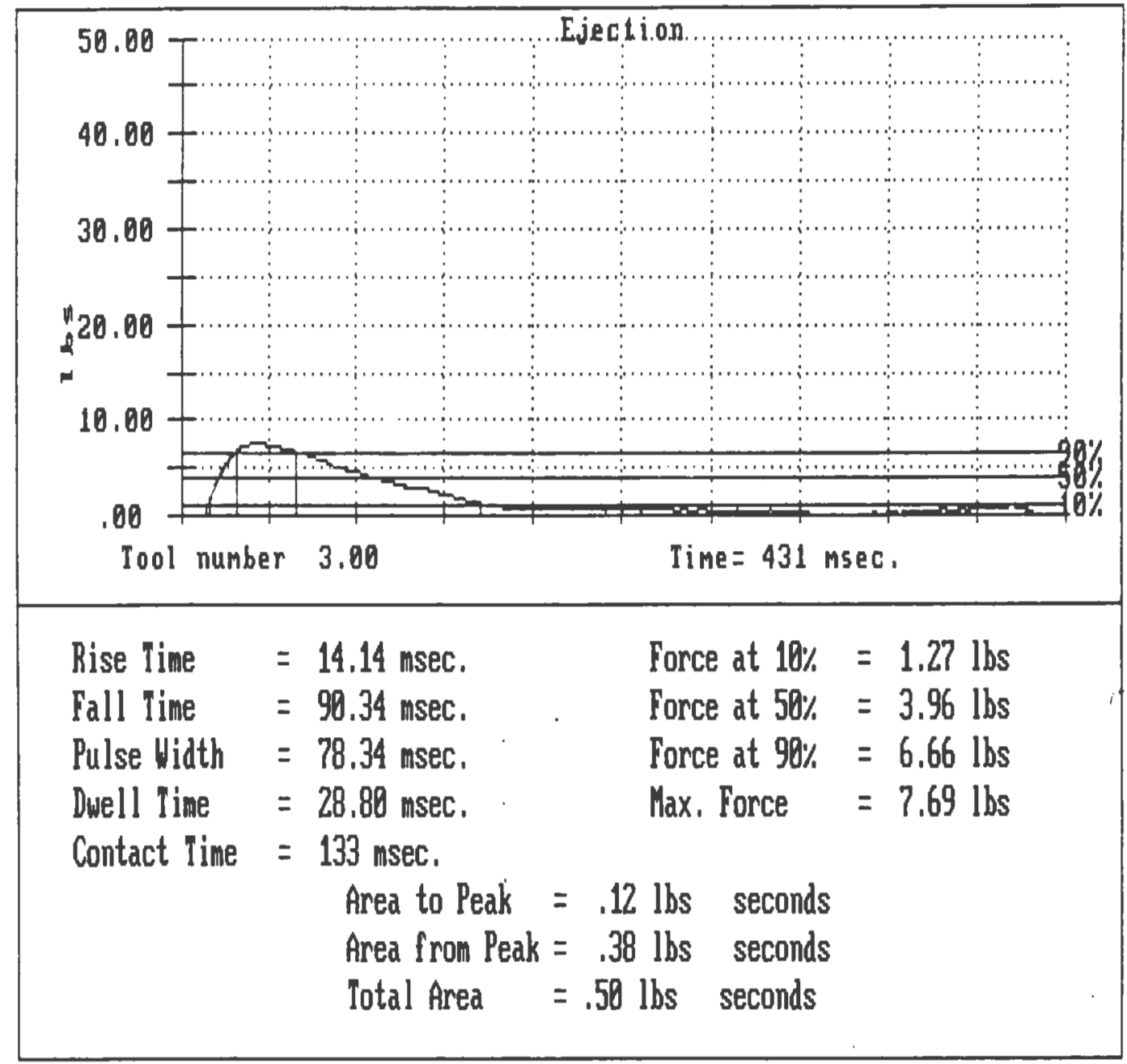

Figure 30. Typical Pulse Analysis of the Ejection Force-Time Curve for Blend\#9 at $4000 \mathrm{lbs}$ 


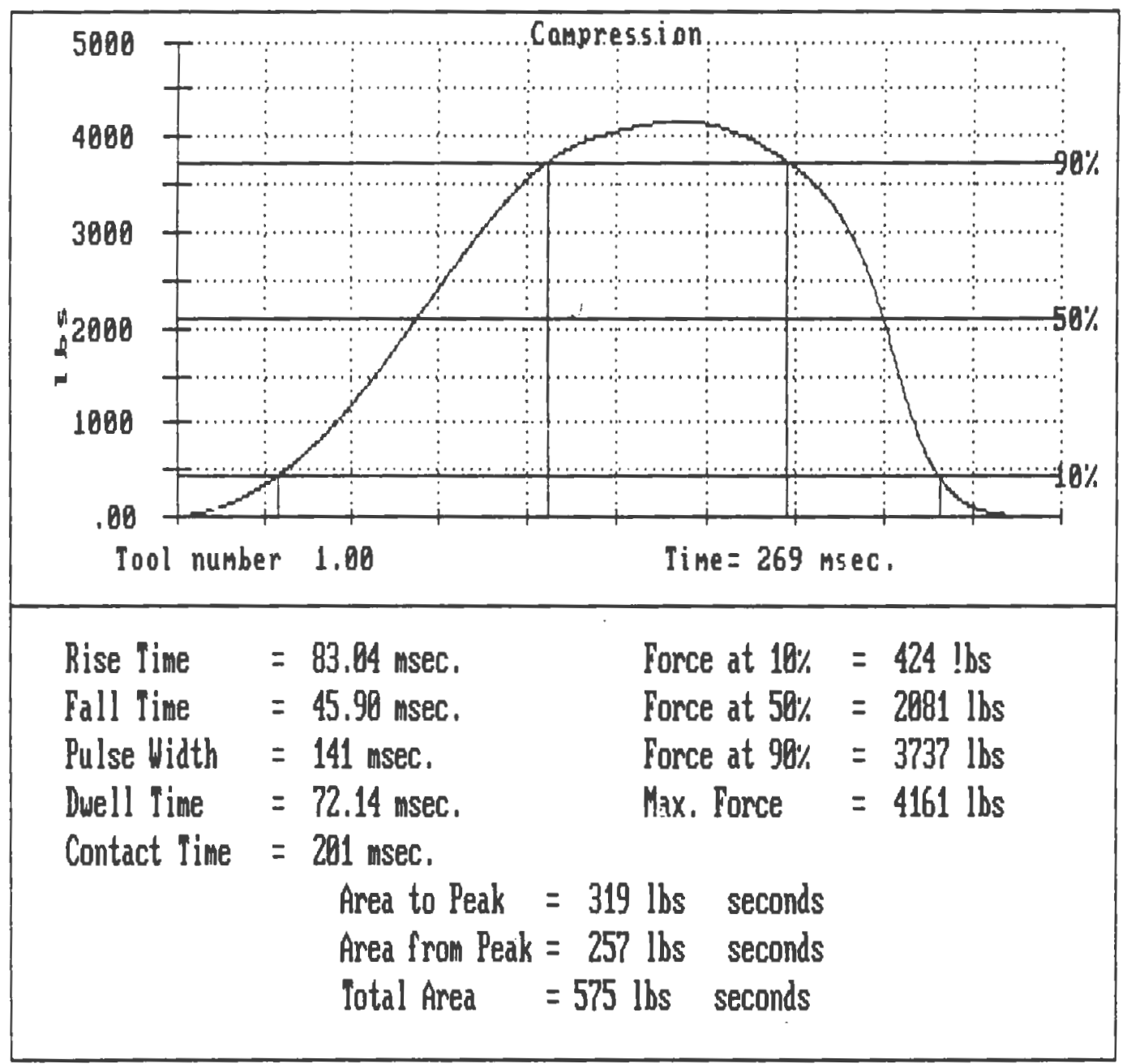

Figure 31. Typical Pulse Analysis of the Compaction Force-Time Curve for Blend\#10 at 4000 lbs 


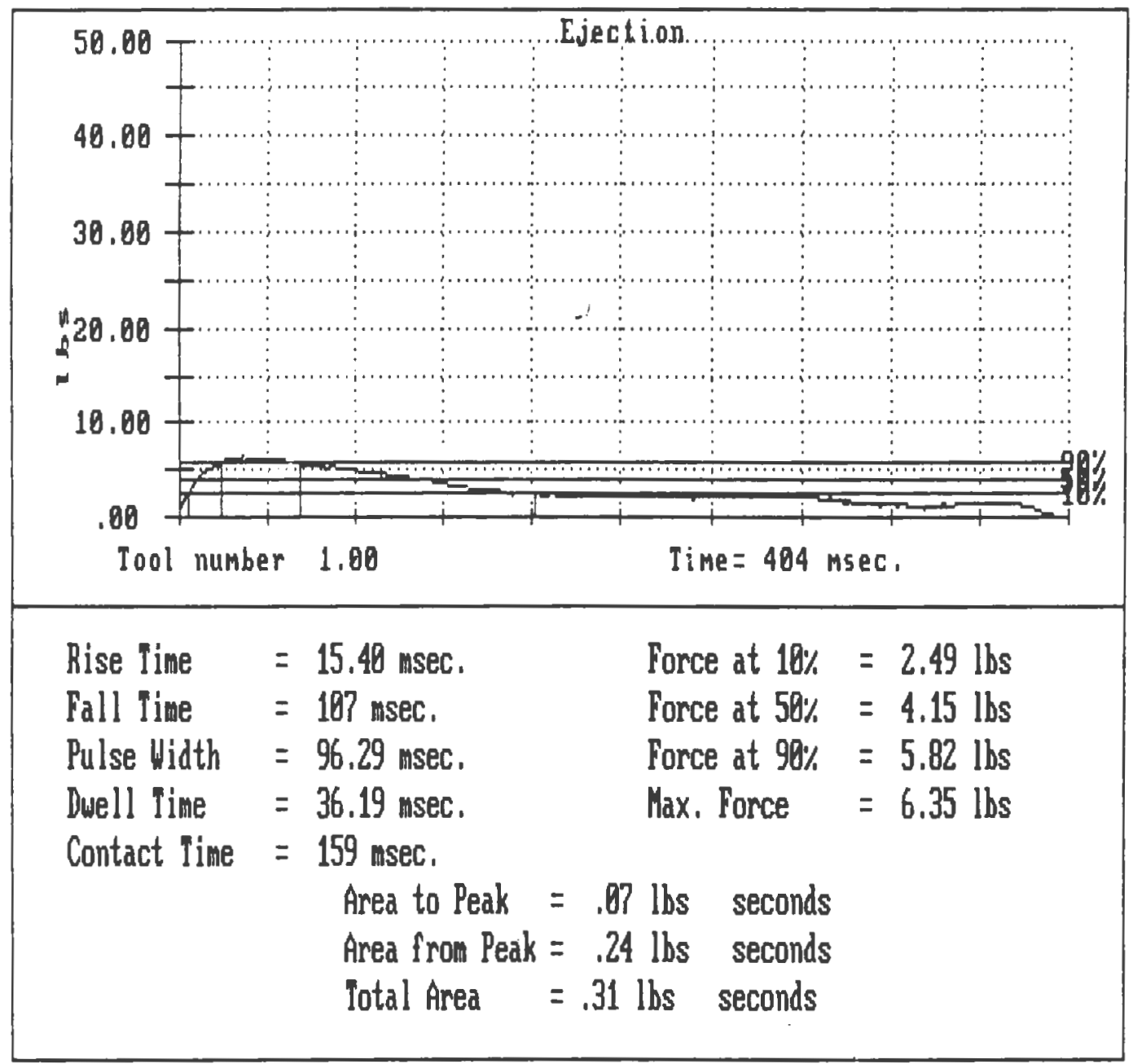

Figure 32. Typical Pulse Analysis of the Ejection Force-Time Curve for Blend\#10 at $4000 \mathrm{lbs}$ 
Table 14. Summary of Upper Punch Compression and Lower Punch Ejection Data from Force-Time Curves at 1000 lbs

\begin{tabular}{|c|c|c|c|c|c|c|c|}
\hline & \multicolumn{7}{|c|}{ Upper Punch Compression Data at 1000 lbs [Mean (SD)], $n=5$} \\
\hline & Blend \#1 & Blend $\# \mathbf{2}$ & Blend \#4 & Blend $\# 6$ & Blend $\# 7$ & Blend $\# 8$ & Blend \#9 \\
\hline Rise Time(msec) & $56.1(0.4)$ & $94.0(0.8)$ & $71.7(1.7)$ & $74.5(1.0)$ & $63.7(0.4)$ & $58.1(0.5)$ & $75.1(2.1)$ \\
\hline Fall Time(msec) & $49.5(1.3)$ & $67.1(14.0)$ & $58.6(8.1)$ & $57.4(1.7)$ & $61.6(7.5)$ & $55.3(5.3)$ & $64.5(10.5)$ \\
\hline Pulse Width(msec) & $128.7(2.5)$ & $154.3(0.6)$ & $136.9(3.1)$ & $142.0(3.0)$ & $133.0(2.0)$ & $128.1(2.1)$ & $142.8(3.7)$ \\
\hline Dwell Time(msec) & $51.3(29.7)$ & $65.3(13.6)$ & $62.7(8.1)$ & $68.8(4.0)$ & $59.9(7.9)$ & $61.3(6.3)$ & $62.8(14.2)$ \\
\hline Contact Time(msec) & $174.7(2.5)$ & $226.3(0.6)$ & $193(2.6)$ & $201(2.0)$ & $185.2(1.5)$ & $175.6(1.4)$ & $202.2(2.4)$ \\
\hline Max Force(lb.) & $986.7(31.7)$ & $1056.0(37.4)$ & $965.1(21.1)$ & $1107.3(19.5)$ & $1009.0(22.2)$ & $1019.3(28.8)$ & $939.0(24.5)$ \\
\hline Area to peak (lb msec) & $47.3(0.8)$ & $69.0(3.8)$ & $52.3(4.5)$ & $64.5(4.6)$ & $51.9(3.1)$ & $47.0(3.5)$ & $51.1(1.7)$ \\
\hline Area from peak(lb msec) & $75.4(5.8)$ & $88.9(2.7)$ & $74.7(6.5)$ & $87.5(4.8)$ & $76.2(4.3)$ & $77.1(5.0)$ & $76.1(2.2)$ \\
\hline \multirow[t]{3}{*}{ Total area(lb msec) } & $122.7(6.0)$ & $158.0(6.0)$ & $126.9(4.8)$ & $152.3(5.5)$ & $128.0(3.4)$ & $124.1(4.3)$ & $127.4(3.8)$ \\
\hline & \multicolumn{7}{|c|}{ Lower Punch Ejection Data at 1000 lbs [Mean (SD)], $n=5$} \\
\hline & Blend \#1 & Blend \#2 & Blend H4 & Blend $\# 6$ & Blend \#7 & Biend $\# \mathbf{8}$ & Blend \#9 \\
\hline Rise Time $(\mathrm{msec})$ & $12.1(1.5)$ & $11.8(2.3)$ & $8.2(3.0)$ & $8.2(5.0)$ & $1.0(0.01)$ & $0.9(0.4)$ & $11.2(0.5)$ \\
\hline Fall Time(msec) & $237.5(193)$ & $221.2(182.2)$ & $248.7(153.0)$ & $168.5(77.1)$ & $75.8(93.6)$ & $54.8(85.5)$ & $101.5(0.7)$ \\
\hline Pulse Width(msec) & $97(22.6)$ & $75.7(9.1)$ & $93.1(5.7)$ & $242.2(228.8)$ & $254.0(166.9)$ & $330.5(103.9)$ & $83.0(15.9)$ \\
\hline Dwell Time(msec) & $32.1(2.5)$ & $29.2(1.8)$ & $43.2(13.0)$ & $117.5(130.9)$ & $246.0(168.3)$ & $299.3(149.7)$ & $29.0(10.3)$ \\
\hline Contact Time(msec) & $325(157.7)$ & $261.5(186)$ & $305.6(105.6)$ & $293.5(202.9)$ & $323(75)$ & $355(64.8)$ & $142.0(9.9)$ \\
\hline Max Force(lb.) & $11.3(0.6)$ & $8.1(0.4)$ & $6.2(1.3)$ & $5.4(0.9)$ & $5.1(0.9)$ & $4.4(1.2)$ & $5.7(0.4)$ \\
\hline Area to peak (lb msec) & $0.2(0.1)$ & $0.1(0.0)$ & $0.03(0.0)$ & $0.05(0.06)$ & $0.04(0.03)$ & $0.02(0.01)$ & $0.35(0.0)$ \\
\hline Area from peak(lb msec) & $1.2(0.7)$ & $0.3(0.1)$ & $0.4(0.1)$ & $0.7(0.8)$ & $0.13(0.1)$ & $0.14(0.1)$ & $0.3(0.0)$ \\
\hline Total area(lb msec) & $1.4(0.7)$ & $0.4(0.1)$ & $0.4(0.1)$ & $0.8(0.9)$ & $0.17(0.1)$ & $0.16(0.1)$ & $0.3(0.0)$ \\
\hline
\end{tabular}


Table 15. Summary of Upper Punch Compression and Lower Punch Ejection Data from Force-Time Curves at 2000 Ibs

\begin{tabular}{|c|c|c|c|c|c|c|c|c|c|}
\hline & \multicolumn{9}{|c|}{ Upper Punch Compression Data at 2000 lbs [Mean (SD)], n=5 } \\
\hline & Blend \#1 & Blend $\# \mathbf{2}$ & Blend \#4 & Blend $\# 5$ & Blend \#6 & Blend \#7 & Blend \#8 & Blend \#9 & Blend $\# 10$ \\
\hline Rise Time(msec) & $62.1(1.1)$ & $100.8(2.1)$ & $77.4(1.5)$ & $58.9(1.0)$ & $79.2(0.7)$ & $71.7(1.1)$ & $64.9(0.9)$ & $85(1.3)$ & $66(0.7)$ \\
\hline Fall Time(msec) & $53.0(3.3)$ & $55.4(2.3)$ & $45.5(17.7)$ & $54.8(4.3)$ & $59.4(5.0)$ & $55.3(4.4)$ & $54.9(0.2)$ & $56.3(2.6)$ & $56.6(2.7)$ \\
\hline Dwell Time(msec) & $72.4(5.2)$ & $73(5.5)$ & $62.6(3.2)$ & $66.9(4.6)$ & $68.4(6.4)$ & $70.3(4.1)$ & $67(2.3)$ & $70(1.6)$ & $68(3.3)$ \\
\hline Contact Time(msec) & $187.3(2.3)$ & $229.3(1.5)$ & $200.5(0.7)$ & $183.3(1.5)$ & $207.2(2.8)$ & $197.2(1.5)$ & $186.7(2.1)$ & $211.3(1.5)$ & $190.7(1.7)$ \\
\hline Area from peak(lb msec) & $154.3(17.6)$ & $172(9.5)$ & $154.5(3.5)$ & $156.7(9.3)$ & $160.5(6.5)$ & $153.8(19.7)$ & $153.3(2.5)$ & $164(4.7)$ & $157.2(3.2)$ \\
\hline Total area $(\mathrm{lb} \mathrm{msec})$ & $270.3(5.1)$ & $318.7(12.4)$ & $267.5(9.2)$ & $263.3(10.0)$ & $279.5(10.9)$ & $273.8(8.4)$ & $253.7(8.5)$ & $286.5(6)$ & $268.2(8.7)$ \\
\hline
\end{tabular}

\begin{tabular}{|l|c|c|c|c|c|c|c|c|c|}
\cline { 2 - 10 } \multicolumn{1}{c|}{} & \multicolumn{9}{c|}{ Lower Punch Ejection Data at 2000 Ibs [Mean (SD)], $\mathbf{n}=\mathbf{5}$} \\
\cline { 2 - 11 } \multicolumn{1}{c|}{} & Blend \#1 & Blend \#2 & Blend \#4 & Blend \#5 & Blend \#6 & Blend \#7 & Blend \#8 & Blend \#9 & Blend \#10 \\
\hline Rise Time(msec) & $13.8(0.8)$ & $10.9(0.5)$ & $13.9(0.0)$ & $14.8(0.0)$ & $3.2(3.1)$ & $11.7(0.7)$ & $10.6(1.7)$ & $11.7(0.0)$ & $11.7(1.7)$ \\
\hline Fall Time(msec) & $118(1.0)$ & $229.9(205.2)$ & $95.3(0.0)$ & $323(0.0)$ & $161.7(116.4)$ & $218.6(183)$ & $74.5(33.3)$ & $105.5(26.2)$ & $177.7(133.9)$ \\
\hline Pulse Width(msec) & $104.5(11.2)$ & $72.1(8.8)$ & $87(8.6)$ & $157(0.0)$ & $252.4(140.6)$ & $104.8(27.2)$ & $64.9(31.4)$ & $77.1(0.2)$ & $105.3(4.5)$ \\
\hline Dwell Time(msec) & $41.1(11.0)$ & $29.7(6.2)$ & $37.9(0.0)$ & $56.4(0.0)$ & $179.7(80.4)$ & $44.6(11)$ & $24.2(9.0)$ & $51.9(26.2)$ & $39.5(6.3)$ \\
\hline Contact Time(msec) & $172.3(11.8)$ & $270.5(211.4)$ & $147(0.0)$ & $396(1.4)$ & $344.8(101.9)$ & $275(195.2)$ & $109(43.8)$ & $163.5(44.5)$ & $229(134.3)$ \\
\hline Max Force(lb.) & $24.1(1.5)$ & $8.1(0.4)$ & $11.2(2.8)$ & $7.2(1.6)$ & $5.0(1.0)$ & $7.5(0.7)$ & $7.7(1.1)$ & $6(1.1)$ & $4.7(0.7)$ \\
\hline Area to peak $(\mathrm{lb} \mathrm{msec)}$ & $0.4(0.1)$ & $0.1(0.0)$ & $0.2(0.0)$ & $0.1(0.06)$ & $0.06(0.04)$ & $0.12(0.06)$ & $0.08(0.04)$ & $0.1(0.0)$ & $0.04(0.0)$ \\
\hline Area from peak(lb msec) & $2.2(0.3)$ & $0.3(0.1)$ & $0.7(0.0)$ & $1.1(0.06)$ & $0.4(0.4)$ & $0.8(0.6)$ & $0.3(0.27)$ & $0.3(0.2)$ & $0.2(0.1)$ \\
\hline Total area(lb msec) & $2.5(0.3)$ & $0.3(0.1)$ & $0.9(0.0)$ & $1.2(0.6)$ & $0.5(0.5)$ & $0.9(0.7)$ & $0.38(0.31)$ & $0.3(0.2)$ & $0.2(0.1)$ \\
\hline
\end{tabular}


Table 16. Summary of Upper Punch Compression and Lower Punch Ejection Data from Force-Time Curves at 3000 lbs

\begin{tabular}{|c|c|c|c|c|c|c|c|}
\hline & \multicolumn{7}{|c|}{ Upper Punch Compression Data at 3000 lbs [Mean (SD)], $n=5$} \\
\hline & Blend \#1 & Blend \#2 & Blend \#5 & Blend \#6 & Blend \#7 & Blend \#8 & Blend \#9 \\
\hline Rise Time $(\mathrm{msec})$ & $68.7(1.2)$ & $103.3(2.1)$ & $66.3(1.3)$ & $86.6(1.3)$ & $78.6(1.0)$ & $61.5(26.4)$ & $90.0(2.5)$ \\
\hline Fall Time(msec) & $51.4(0.4)$ & $50(0.6)$ & $50.2(1.8)$ & $51.3(3.0)$ & $49.6(1.7)$ & $49.8(3.2)$ & $50.7(3.4)$ \\
\hline Pulse Width(msec) & $144(0.0)$ & $149.7(2.1)$ & $136.8(1.8)$ & $143.2(2.1)$ & $141.8(2.3)$ & $147.4(21.1)$ & $144.7(1.6)$ \\
\hline Dwell Time(msec) & $76.1(0.5)$ & $76.2(3.7)$ & $70.3(2)$ & $71.8(3.2)$ & $73.7(2.70$ & $85.5(34.2)$ & $73.4(1.3)$ \\
\hline Contact Time(msec) & $196(1.4)$ & $229.7(2.1)$ & $186.7(1.8)$ & $209.3(2.0)$ & $201.8(1.6)$ & $196.9(6.9)$ & $214.0(2.4)$ \\
\hline Max Force(lb.) & $3109.5(43.1)$ & $2966.3(79.7)$ & $3122.6(60.1)$ & $3102.3(91.1)$ & $3060.5(52.3)$ & $2928.3(59.5)$ & $3136.3(183.7)$ \\
\hline Area to peak (lb msec) & $215(14.1)$ & $253(5.6)$ & $203.5(14.7)$ & $229.3(21.4)$ & $210.2(17.5)$ & $198.6(21.4)$ & $240.7(29.3)$ \\
\hline Area from peak(lb msec) & $229.5(3.5)$ & $193.7(13.3)$ & $208.4(11.9)$ & $20.9(12.1)$ & $215.5(13.6)$ & $200.9(19.1)$ & $209.5(16.9)$ \\
\hline Total area(lb msec) & $445.5(10.6)$ & $446.7(18.2)$ & $411.8(10.6)$ & $438.3(14.5)$ & $425.7(11.1)$ & $399.6(10.0)$ & $450.3(28.0)$ \\
\hline
\end{tabular}

\begin{tabular}{|l|c|c|c|c|c|c|c|}
\cline { 2 - 9 } \multicolumn{1}{c|}{} & \multicolumn{9}{c|}{ Lower Punch Ejection Data at 3000 lbs [Mean (SD)], $\mathbf{n}=5$} \\
\cline { 2 - 9 } \multicolumn{1}{c|}{} & Blend $\# \mathbf{1}$ & Blend \#2 & Blend \#5 & Blend \#6 & Blend \#7 & Blend \#8 & Blend \#9 \\
\hline Rise Time(msec) & $14(1.6)$ & $4.3(5.9)$ & $14.5(0.9)$ & $5.6(5.2)$ & $14.1(1.2)$ & $12.0(1.6)$ & $11.21(1.8)$ \\
\hline Fall Time(msec) & $82.2(25.9)$ & $80.3(46.9)$ & $103.6(7.7)$ & $116.2(35.8)$ & $104.5(10.8)$ & $70.0(27.6)$ & $93.0(5.3)$ \\
\hline Pulse Width(msec) & $85.7(43.1)$ & $197(179.7)$ & $105.1(4.7)$ & $271(136)$ & $118.5(39.5)$ & $66.9(35.1)$ & $70.1(26.2)$ \\
\hline Dwell Time(msec) & $39.4(23.8)$ & $179.5(194.7)$ & $40.2(9.1)$ & $208.4(137.4)$ & $71.6(44.5)$ & $28.1(17.9)$ & $33.9(15.0)$ \\
\hline Contact Time(msec) & $135.7(51.3)$ & $263.7(156.8)$ & $158(2.2)$ & $308.4(128.9)$ & $227.7(122)$ & $110.1(45.9)$ & $123.0(28.4)$ \\
\hline Max Force(lb.) & $26.7(15.4)$ & $7.2(0.3)$ & $9.5(0.3)$ & $4.6(1.0)$ & $7.6(1.2)$ & $11.9(1.3)$ & $6.9(1.5)$ \\
\hline Area to peak $(\mathrm{lb} \mathrm{msec)}$ & $4.8(8.5)$ & $0.04(0.0)$ & $0.11(0.04)$ & $0.02(0.01)$ & $0.09(0.05)$ & $0.1(0.1)$ & $0.07(0.03)$ \\
\hline Area from peak(lb msec) & $9.3(14.8)$ & $0.2(0.1)$ & $0.55(0.04)$ & $0.22(0.18)$ & $0.3(0.23)$ & $0.6(0.3)$ & $0.28(0.14)$ \\
\hline Total area(lb msec) & $10.6(16.3)$ & $0.3(0.1)$ & $0.66(0.06)$ & $0.23(0.19)$ & $0.4(0.27)$ & $0.7(0.4)$ & $0.35(0.15)$ \\
\hline
\end{tabular}


Table 17. Summary of Upper Punch Compression and Lower Punch Ejection Data from Force-Time Curves at 4000 lbs

\begin{tabular}{|c|c|c|c|c|c|c|c|c|c|c|}
\hline & \multicolumn{10}{|c|}{ Upper Punch Compression Data at 4000 lbs [Mean (SD)], $n=5$} \\
\hline & Blend \#1 & Blend \#2 & Blend \#3 & Blend \#4 & Biend \#5 & Blend \#6 & Blend \#7 & Blend \#8 & Blend \#9 & Blend \#10 \\
\hline Rise Time(msec) & $75.8(1.3)$ & $104.6(2.5)$ & $74.6(3.4)$ & $87.1(0.7)$ & $72.2(1.6)$ & $91.2(1.3)$ & $85.3(1.2)$ & $78.4(1.2)$ & $93.1(0.9)$ & $81.3(1.2)$ \\
\hline Fall Time(msec) & $48.9(3.5)$ & $49.3(4.6)$ & $42.6(12.1)$ & $47.2(2.9)$ & $48.7(0.7)$ & $46.4(1.8)$ & $46.0(2.5)$ & $46.2(2.4)$ & $46.3(0.2)$ & $47.5(2.0)$ \\
\hline Pulse Width(msec) & $149.7(0.6)$ & $149.0(1.4)$ & $135.8(6.6)$ & $143(2.6)$ & $139.7(1.5)$ & $141.6(0.9)$ & $143.2(1.8)$ & $142.2(2.3)$ & $142.7(2.5)$ & $138.8(1.8)$ \\
\hline Dwell Time(msec) & $78.7(2.7)$ & $75.6(2.4)$ & $70.1(1.50$ & $72.7(2.1)$ & $70.2(1.8)$ & $72.1(2.0)$ & $72.5(1.2)$ & $74.5(1.6)$ & $72.3(1.1)$ & $70.6(1.5)$ \\
\hline Contact Time(msec) & $203.7(2.1)$ & $229.4(5.9)$ & $187.2(13.0)$ & $207(26)$ & $191.3(0.6)$ & $209.8(1.3)$ & $204.5(1.9)$ & $198.8(2.2)$ & $211.7(2.3)$ & $199.3(1.5)$ \\
\hline Max Force(lb.) & $4042.3(66.2)$ & $4051.4(135.9)$ & 4099.5(86.3) & $3970.7(43.5)$ & $3945.3(87.7)$ & $3857.2(68.7)$ & 4099.3(68.2) & $4182.2(76.4)$ & $3928.7(58.7)$ & $4195.7(67.3)$ \\
\hline Area to peak ( $(\mathrm{lb} \mathrm{msec})$ & $305.3(14.6)$ & $340.6(15.0)$ & $296.2(14.7)$ & $313.7(17)$ & $275.0(7.5)$ & $300.6(10.6)$ & $323.67(7.1)$ & $311.5(14.7)$ & $310.7(11.0)$ & $311.0(9.6)$ \\
\hline Area from peak(lb msec) & $278.3(20.6)$ & $265.6(5.3)$ & $242.5(23.5)$ & $245.3(14.2)$ & $254.7(6.4)$ & $241.4(10.8)$ & $249.3(14.4)$ & $268.3(12.0)$ & $246.3(5.5)$ & $260.2(11.5)$ \\
\hline Total area(lb msec) & $583.7(8.5)$ & $605.8(17.6)$ & $538.8(34.5)$ & $558.7(13.1)$ & $529.7(8.5)$ & $541.8(12.6)$ & $572.8(13.9)$ & $579.3(14.4)$ & $557.0(15.50$ & $571.2(11.2)$ \\
\hline
\end{tabular}

\begin{tabular}{|c|c|c|c|c|c|c|c|c|c|c|}
\hline & \multicolumn{10}{|c|}{ Lower Punch Ejection Data at 4000 lbs [Mean (SD)], $n=5$} \\
\hline & Blend \#1 & Blend \#2 & Blend \#3 & Blend \#4 & Blend \#5 & Blend \#6 & Blend \#7 & Blend \#B & Blend \#9 & Blend \#10 \\
\hline Rise Time(msec) & $15.1(1.3)$ & $5.5(4.9)$ & $6.0(4.2)$ & $12.1(1.7)$ & $15.8(1.3)$ & $2.7(2.6)$ & $13.9(2.0)$ & $13.8(2.2)$ & $8.4(7.1)$ & $15.0(1.4)$ \\
\hline Fall Time(msec) & $91.8(25.8)$ & $176.0(93.0)$ & $42.6(36.1)$ & $45.1(1.1)$ & $147.8(75.7)$ & $126.1(44.1)$ & $109.7(44.1)$ & $71.4(28.4)$ & $79.6(27.0)$ & $97.9(17.5)$ \\
\hline Dwell Time(msec) & $44.6(23.4)$ & $163.1(145.0)$ & $331.0(82.3)$ & $15.6(1.9)$ & $45.0(11.1)$ & $243.7(30.8)$ & $40.4(16.3)$ & $41.7(30.9)$ & $55.9(59.4)$ & $40.8(13.1)$ \\
\hline Contact Time(msec) & $151.5(48.0)$ & $344.8(112.7)$ & $363.7(51.6)$ & $71.9(3.8)$ & $208.3(73.5)$ & $305.3(153.1)$ & $162.5(55.0)$ & $148.0(83.9)$ & $143.8(75.3)$ & $154.0(6.2)$ \\
\hline Max Force(lb.) & $50.5(3.0)$ & $5.4(1.3)$ & $3.4(0.4)$ & $15.9(2.7)$ & $10.6(0.1)$ & $4.4(1.3)$ & $8.6(1.0)$ & $16.6(1.6)$ & $6.4(1.20$ & $5.6(0.9)$ \\
\hline Area from peak(lb msec) & $4.0(1.8)$ & $0.4(0.3)$ & $0.6(0.3)$ & $0.6(0.5)$ & $0.81(0.21)$ & $0.5(0.5)$ & $0.46(0.3)$ & $0.9(0.5)$ & $0.2(0.1)$ & $0.1(0.1)$ \\
\hline Total area(lb msec) & $5.1(2.2)$ & $0.5(0.3)$ & $0.7(0.40$ & $0.9(0.7)$ & $1.0(0.28)$ & $0.54(0.59)$ & $0.6(0.3)$ & $1.1(0.6)$ & $0.3(0.2)$ & $0.2(0.1)$ \\
\hline
\end{tabular}


Table 18. Summary of Upper Punch Compression and Lower Punch Ejection Data from Force-Time Curves at 5000 lbs

\begin{tabular}{|c|c|c|c|c|c|c|c|c|}
\hline & \multicolumn{8}{|c|}{ Upper Punch Compression Data at 5000 lbs [Mean (SD)], $n=5$} \\
\hline & Blend \#1 & Blend \#2 & Blend \#5 & Blend \#6 & Blend \#7 & Blend \#8 & Blend \#9 & Blend \#10 \\
\hline Rise Time $(\mathrm{msec})$ & $75.4(1.9)$ & $106.7(2.1)$ & $82.6(1.2)$ & $94.8(0.5)$ & $92.0(1.7)$ & $84.5(0.7)$ & $102.0(1.4)$ & $88.7(1.2)$ \\
\hline Fall Time(msec) & $45.8(1.3)$ & $48.6(1.1)$ & $45.3(1.1)$ & $44.8(1.2)$ & $44.1(1.7)$ & $44.7(1.4)$ & $42.4(0.2)$ & $45.1(0.8)$ \\
\hline Dwell Time(msec) & $77.4(1.5)$ & $75.4(3.5)$ & $72.0(1.4)$ & $73.2(1.6)$ & $72.7(2.1)$ & $73.8(0.7)$ & $74.2(1.0)$ & $71.8(1.5)$ \\
\hline Contact Time(msec) & $198.5(2.3)$ & $230.7(4.0)$ & $199.7(2.1)$ & $213.0(1.0)$ & $209.0(1.0)$ & $202.7(1.1)$ & $219.0(0.0)$ & $205.3(1.2)$ \\
\hline Area from peak(lb msec) & $321.8(29.9)$ & $299.3(11.7)$ & $317.3(12.5)$ & $2890(4.6)$ & $289.3(13.6)$ & $301.7(9.9)$ & $302.0(5.7)$ & $301.5(9.8)$ \\
\hline Total area(lb msec) & $681.2(40.8)$ & $699.3(30.5)$ & $704.0(23.1)$ & $660.7(13.6)$ & $697.3(14.6)$ & $679.3(14.5)$ & $737.5(29.0)$ & $692.5(19.1)$ \\
\hline
\end{tabular}

\begin{tabular}{|l|c|c|c|c|c|c|c|c|}
\cline { 2 - 9 } \multicolumn{1}{c|}{} & \multicolumn{8}{c|}{ Lower Punch Ejection Data at 5000 lbs [Mean (SD)], $\mathbf{n}=\mathbf{5}$} \\
\cline { 2 - 10 } \multicolumn{1}{c|}{} & Blend \#1 & Blend \#2 & Blend \#5 & Blend \#6 & Blend \#7 & Blend \#8 & Blend \#9 & Blend \#10 \\
\hline Rise Time(msec) & $16.4(1.8)$ & $1.4(0.9)$ & $13.9(2.3)$ & $4.5(1.9)$ & $7.7(7.2)$ & $15.2(2.9)$ & $14.8(0.0)$ & $7.8(7.2)$ \\
\hline Fall Time(msec) & $89.4(21.9)$ & $67.7(93.8)$ & $119.2(28.0)$ & $130.5(6.4)$ & $193.8(93.4)$ & $72.7(38.4)$ & $121.4(40.5)$ & $127.4(47.2)$ \\
\hline Pulse Width(msec) & $104.9(30.5)$ & $371.5(99.7)$ & $77.0(46.7)$ & $353.0(72.1)$ & $191.6(100.3)$ & $63.5(30.5)$ & $94.8(21.5)$ & $240.2(131.3)$ \\
\hline Dwell Time(msec) & $46.9(18.5)$ & $348.5(130.8)$ & $35.0(26.2)$ & $273.0(2.8)$ & $65.0(23.2)$ & $31.5(13.6)$ & $43.7(21.9)$ & $163.9(104.5)$ \\
\hline Contact Time(msec) & $152.6(38.3)$ & $417.5(36.1)$ & $168.0(1.4)$ & $408.0(5.7)$ & $266.5(106.7)$ & $95.7(51.8)$ & $173.0(52.3)$ & $298.6(135.3)$ \\
\hline Max Force(lb.) & $63.2(6.4)$ & $3.9(0.0)$ & $11.2(2.0)$ & $4.6(0.9)$ & $8.9(1.3)$ & $19.3(2.0)$ & $6.8(1.7)$ & $5.3(1.0)$ \\
\hline Area to peak $(\mathrm{lb} \mathrm{msec)}$ & $1.5(0.5)$ & $0.04(0.0)$ & $0.21(0.13)$ & $0.07(0.03)$ & $0.13(0.05)$ & $0.3(0.1)$ & $0.1(0.0)$ & $0.1(0.0)$ \\
\hline Area from peak(lb msec) & $5.1(1.7)$ & $0.2(0.2)$ & $0.7(0.23)$ & $0.8(0.38)$ & $0.59(0.19)$ & $0.9(0.6)$ & $0.3(0.2)$ & $0.4(0.2)$ \\
\hline Total area(lb msec) & $6.5(2.1)$ & $0.2(0.3)$ & $0.9(0.37)$ & $0.87(0.42)$ & $0.72(0.19)$ & $1.3(0.6)$ & $0.4(0.3)$ & $0.5(0.2)$ \\
\hline
\end{tabular}


Table 19. Summary of Upper Punch Compression and Lower Punch Ejection Data from Force-Time Curves at 6000 lbs

\begin{tabular}{|c|c|c|c|c|c|c|c|c|c|}
\hline & \multicolumn{9}{|c|}{ Upper Punch Compression Data at 6000 lbs [Mean (SD)], $n=5$} \\
\hline & Blend \#1 & Blend \#2 & Blend \#3 & Blend \#4 & Blend \#6 & Blend \#7 & Blend \#8 & Blend \#9 & Blend \#10 \\
\hline Fall Time(msec) & $48.8(1.2)$ & $47.5(2.5)$ & $50.6(4.6)$ & $47.0(1.5)$ & $47.9(1.6)$ & $47.0(0.2)$ & $46.7(1.1)$ & $46.6(1.1)$ & $48.2(1.2)$ \\
\hline Dwell Time(msec) & $80.4(2.0)$ & $78.5(2.0)$ & $71.9(2.0)$ & $76.1(2.2)$ & $73.2(1.8)$ & $76.4(0.7)$ & $76.9(2.5)$ & $75.5(1.8)$ & $73.6(1.8)$ \\
\hline Contact Time(msec) & $215.7(1.2)$ & $237.8(3.4)$ & $213.8(1.8)$ & $224.8(1.9)$ & $2234(1.1)$ & $218.0(1.0)$ & $215.7(1.5)$ & $226.7(0.5)$ & $215.5(1.4)$ \\
\hline Max Force(lb.) & $6245.0(104.9)$ & 6105.3(98.0) & $6576.4(113.1)$ & 6111.0(163.9) & $6233.8(127.5)$ & $5885.3(159.0)$ & $6132.3(133.9)$ & $6244.5(148.1)$ & $6191.3(109.2)$ \\
\hline Total area(lb msec) & $925.0(22.3)$ & $939.5(29.0)$ & $923.2(27.4)$ & $900.5(34.8)$ & $899.0(20.7)$ & $848.0(27.7)$ & $889.5(32.2)$ & $916.5(26.3)$ & $877.0(26.4)$ \\
\hline
\end{tabular}

\begin{tabular}{|l|c|c|c|c|c|c|c|c|c|}
\cline { 2 - 9 } \multicolumn{1}{c|}{} & \multicolumn{8}{c|}{ Lower Punch Ejection Data at 6000 lbs |Mean (SD)], $\mathbf{n = 5}$} \\
\cline { 2 - 10 } \multicolumn{1}{c|}{} & Blend \#1 & Blend \#2 & Blend \#3 & Blend \#4 & Blend \#6 & Blend \#7 & Blend \#8 & Blend \#9 & Biend \#10 \\
\hline Rise Time(msec) & $16.8(1.7)$ & $2.0(1.3)$ & 1.57 & $12.9(0.8)$ & 16.3 & $13.5(0.1)$ & $14.4(1.2)$ & $12.6(2.1)$ & $11.4(8.5)$ \\
\hline Fall Time(msec) & $85.5(18.6)$ & $12.5(0.6)$ & 68.6 & $63.4(19.3)$ & 99.1 & $267.0(91.9)$ & $71.6(17.5)$ & $130.8(102.6)$ & $123.9(112.3)$ \\
\hline Pulse Width(msec) & $106.7(42.1)$ & $404.0(13.7)$ & 193 & $71.0(46.1)$ & 81.3 & $93.4(53.2)$ & $87.1(40.6)$ & $74.8(31.4)$ & $183.8(117.9)$ \\
\hline Dwell Time(msec) & $51.8(29.3)$ & $352.3(83.2)$ & 190 & $35.3(29.9)$ & 29.3 & $44.3(30.7)$ & $43.9(26.5)$ & $29.4(13.1)$ & $124.9(114.1)$ \\
\hline Contact Time(msec) & $154.3(44.6)$ & $408.7(15.6)$ & 260 & $111.5(48.9)$ & 145 & $324.5(122.3)$ & $129.7(44.0)$ & $172.8(116.2)$ & $259.8(124.2)$ \\
\hline Max Force(lb.) & $78.8(12.2)$ & $5.0(1.3)$ & 4.5 & $20.1(3.6)$ & 5.2 & $9.6(2.2)$ & $22.1(2.6)$ & $7.4(1.4)$ & $5.9(0.9)$ \\
\hline Area to peak $(\mathrm{lb} \mathrm{msec)}$ & $2.4(1.4)$ & $0.1(0.0)$ & 0.04 & $0.3(0.1)$ & 0.03 & $0.16(0.06)$ & $0.46(0.19)$ & $0.1(0.0)$ & $0.08(0.05)$ \\
\hline Area from peak(lb msec) & $6.1(2.8)$ & $0.5(0.4)$ & 0.1 & $1.1(0.8)$ & 0.15 & $1.0(0.69)$ & $1.46(0.73)$ & $0.4(0.3)$ & $0.45(0.43)$ \\
\hline Total area(lb msec) & $8.5(4.0)$ & $0.5(0.4)$ & 0.2 & $1.4(0.9)$ & 0.19 & $1.2(0.76)$ & $1.92(0.89)$ & $0.5(0.3)$ & $0.53(0.46)$ \\
\hline
\end{tabular}


Table 20. Summary of Upper Punch Compression and Lower Punch Ejection Data from Force-Time Curves at Maximum Achicvable Force

\begin{tabular}{|c|c|c|c|c|c|c|c|c|c|c|}
\hline & \multicolumn{10}{|c|}{ Upper Punch Compression Data at Maximum Achievable Force, [Mean (SD)], $n=5$} \\
\hline & Blend \#1 & Blend \#2 & Blend \#3 & Blend \#4 & Blend $\# 5$ & Blend \#6 & Blend \#7 & Blend \#8 & Blend \#9 & Blend \#10 \\
\hline Rise Time(msec) & $117.7(0.6)$ & $119.3(3.2)$ & 113 & $116.0(3.6)$ & $105.3(2.1)$ & $114.4(1.7)$ & $110.8(4.2)$ & 102.1(1.9) & $116.3(2.5)$ & $108.8(1.5)$ \\
\hline Fall Time(msec) & $46.5(0.1)$ & $48.8(3.7)$ & 47.3 & $50.0(0.8)$ & $48.5(1.4)$ & $51.5(1.9)$ & $49.9(1.7)$ & $47.3(1.5)$ & $50.1(1.5)$ & $51.0(1.1)$ \\
\hline Pulse Width(msec) & $194.0(7.5)$ & $159.7(7.3)$ & 162 & $171.3(4.7)$ & $162.3(4.5)$ & $161.8(2.8)$ & $165.2(2.5)$ & $157.2(3.2)$ & $163.0(2.9)$ & $159.5(4.0)$ \\
\hline Dwell Time(msec) & $107.3(7.1)$ & $82.2(4.2)$ & 81 & $88.8(2.2)$ & $85.5(3.1)$ & $83.2(1.6)$ & $86.3(2.3)$ & $83.1(2.3)$ & $83.7(2.8)$ & $82.5(2.7)$ \\
\hline Contact Time (msec) & $271.0(7.0)$ & $250.5(9.3)$ & 241 & $254.7(4.5)$ & $239.3(4.4)$ & $249.4(2.6)$ & $247.2(2.8)$ & $232.2(2.1)$ & $250.0(2.2)$ & $242.2(3.1)$ \\
\hline Max Force(lb.) & $8190.7(109.2)$ & $7455.0(224.5)$ & 8808 & $8593.3(49.2)$ & $8395.2(118.1)$ & $8977.4(102.2)$ & $8551.8(129.6)$ & $7744.0(104.5)$ & $8588.8(162.0)$ & $8678.3(157.8)$ \\
\hline Area to peak (lb msec) & $1034.3(49.0)$ & $751.3(50.7)$ & 896 & $946.7(39.3)$ & $852.3(36.5)$ & $934.2(21.5)$ & $901.2(40.8)$ & $743(17.3)$ & $895.3(36.8)$ & $863.2(40.6)$ \\
\hline Area from peak(lb msec) & $523.7(28.0)$ & $462.8(23.0)$ & 521 & $530.0(7.5)$ & $502.8(18.9)$ & $538.0(16.3)$ & $517.7(10.7)$ & $472.5(22.0)$ & $523.8(16.7)$ & $530.5(16.1)$ \\
\hline Total area(lb msec) & $1558.0(76.9)$ & $1214.2(70.1)$ & 1418 & $1476.3(44.1)$ & $1355.3(48.3)$ & $1472.0(30.1)$ & $1418.7(37.7)$ & $1215.3(38.5)$ & $1419.0(47.1)$ & $1393.8(55.4)$ \\
\hline
\end{tabular}

\begin{tabular}{|l|c|c|c|c|c|c|c|c|c|c|}
\cline { 2 - 11 } \multicolumn{1}{c|}{} & \multicolumn{9}{c|}{ Lower Punch Ejection Data at Maximum Achievable Force, [Mean (SD)], $\mathrm{n}=5$} \\
\cline { 2 - 12 } \multicolumn{1}{c|}{} & Blend \#1 & Blend \#2 & Blend \#3 & Blend \#4 & Blend \#5 & Blend \#6 & Blend \#7 & Blend \#8 & Blend \#9 & Blend \#10 \\
\hline Rise Time(msec) & $17.5(2.1)$ & $9.5(10.6)$ & 7.4 & $16.0(3.5)$ & $16.7(2.0)$ & $11.9(2.5)$ & $13.6(1.9)$ & $16.3(3.7)$ & $13.7(3.2)$ & $12.2(6.4)$ \\
\hline Fall Time(msec) & $88.2(15.4)$ & $107.7(84.8)$ & 0.3 & $93.2(35.2)$ & $145.0(55.7)$ & $86.1(5.8)$ & $150.0(60.9)$ & $73.3(23.4)$ & $120.9(40.4)$ & $124.7(66.5)$ \\
\hline Pulse Width(msec) & $116.1(44.1)$ & $176.9(96.3)$ & 77.5 & $100.8(39.4)$ & $128.0(16.2)$ & $88.7(21.1)$ & $104.7(30.2)$ & $92.3(40.3)$ & $83.9(23.8)$ & $150.4(92.6)$ \\
\hline Dwell Time(msec) & $59.9(31.2)$ & $149.6(81.7)$ & 73.5 & $38.0(12.3)$ & $61.2(15.1)$ & $46.8(11.7)$ & $48.2(15.2)$ & $42.9(26.1)$ & $33.0(10.2)$ & $84.1(79.0)$ \\
\hline Contact Time(msec) & $165.7(46.7)$ & $261.0(118.3)$ & 81.2 & $147.0(49.0)$ & $222.8(68.2)$ & $145.0(19.5)$ & $211.8(61.8)$ & $132.6(46.9)$ & $167.6(41.3)$ & $221.1(104.1)$ \\
\hline Max Force(lb.) & $98.8(14.3)$ & $5.3(1.2)$ & 3.2 & $26.7(4.7)$ & $14.6(0.6)$ & $4.3(0.7)$ & $11.1(1.7)$ & $25.3(4.3)$ & $8.5(1.4)$ & $5.9(1.2)$ \\
\hline Area to peak $(\mathrm{lb} \mathrm{msec)}$ & $2.6(0.8)$ & $0.0(0.0)$ & 0.08 & $0.6(0.2)$ & $0.4(0.0)$ & $0.02(0.02)$ & $0.23(0.06)$ & $0.54(0.16)$ & $0.1(0.1)$ & $0.1(0.0)$ \\
\hline Area from peak(lb msec) & $8.9(4.5)$ & $0.2(0.2)$ & 0.14 & $2.1(1.2)$ & $1.5(0.5)$ & $0.06(0.04)$ & $0.91(0.37)$ & $1.77(1.1)$ & $0.5(0.2)$ & $0.4(0.3)$ \\
\hline Total area(lb msec) & $11.5(5.4)$ & $0.2(0.2)$ & 0.21 & $2.7(1.4)$ & $1.9(0.5)$ & $0.07(0.05)$ & $1.1(0.43)$ & $2.31(1.25)$ & $0.6(0.2)$ & $0.5(0.3)$ \\
\hline
\end{tabular}


the dwell time starts. Decompression occurs when the punch rises again. The duration of dwell time is dependent on the diameter of the plane surface of the punch head and the speed of the machine $(31,35,36)$. Many believe that interparticulate bonds are formed during dwell time, and the ultimate strength of tablet depends on these interparticulate bonds $(53,54)$. Thus the longer the dwell time, harder will be the tablet formed. In the current study, the tablet tooling and tablet machine speed were kept constant for all the mixtures, since the purpose was to determine the effect of formulation composition on the compaction behavior of multi-component mixtures. In order to determine the effect of compression force on dwell time, the dwell times obtained for each compression cycle were plotted in Figure 33 and the data is summarized in Tables $14,15,16,17,18,19$ and 20 at varying compression forces for Blend $\# 1,2,3,4,5,6,7,8,9$ and 10, respectively. The highest dwell time of $107 \mathrm{msec}$ was observed for $99 \%$ lactose anhydrous mixture (Blend\#1) at maximum achievable force and the minimum dwell time of $51 \mathrm{msec}$ was observed for the same blend at $1000 \mathrm{lbs}$ of applied force. The dwell times for all other mixtures relatively remained between 60 and $80 \mathrm{msec}$. Dwell time increased with an increase in applied force for any given blend. Figure 34 illustrates the effect of formulation composition on dwell time at $4000 \mathrm{lbs}$ of applied force. As the contour plot indicates, the higher the amount of lactose anhydrous and Avicel ${ }^{\circledR} \mathrm{PH} 101$, the longer is the dwell time. Since during dwell time, the interparticulate bond formation takes place, the comparison of dwell times in correlation with tablet hardness for various multi-component mixtures will provide critical information in understanding the compression behavior of pharmaceutical mixtures $(9-14,17,52-54)$. 


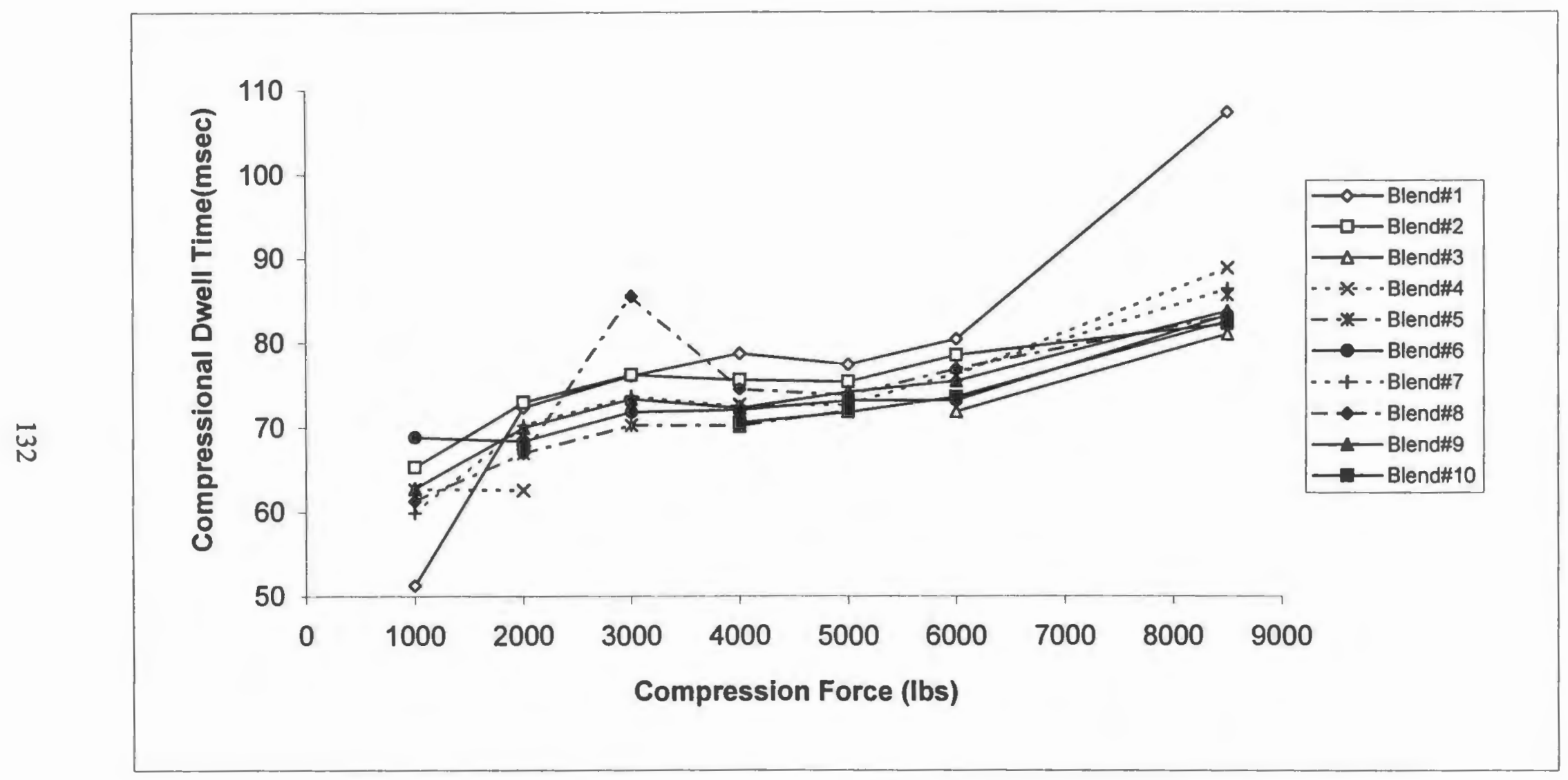

Figure 33. Effect of Compression Force on Dwell Time 


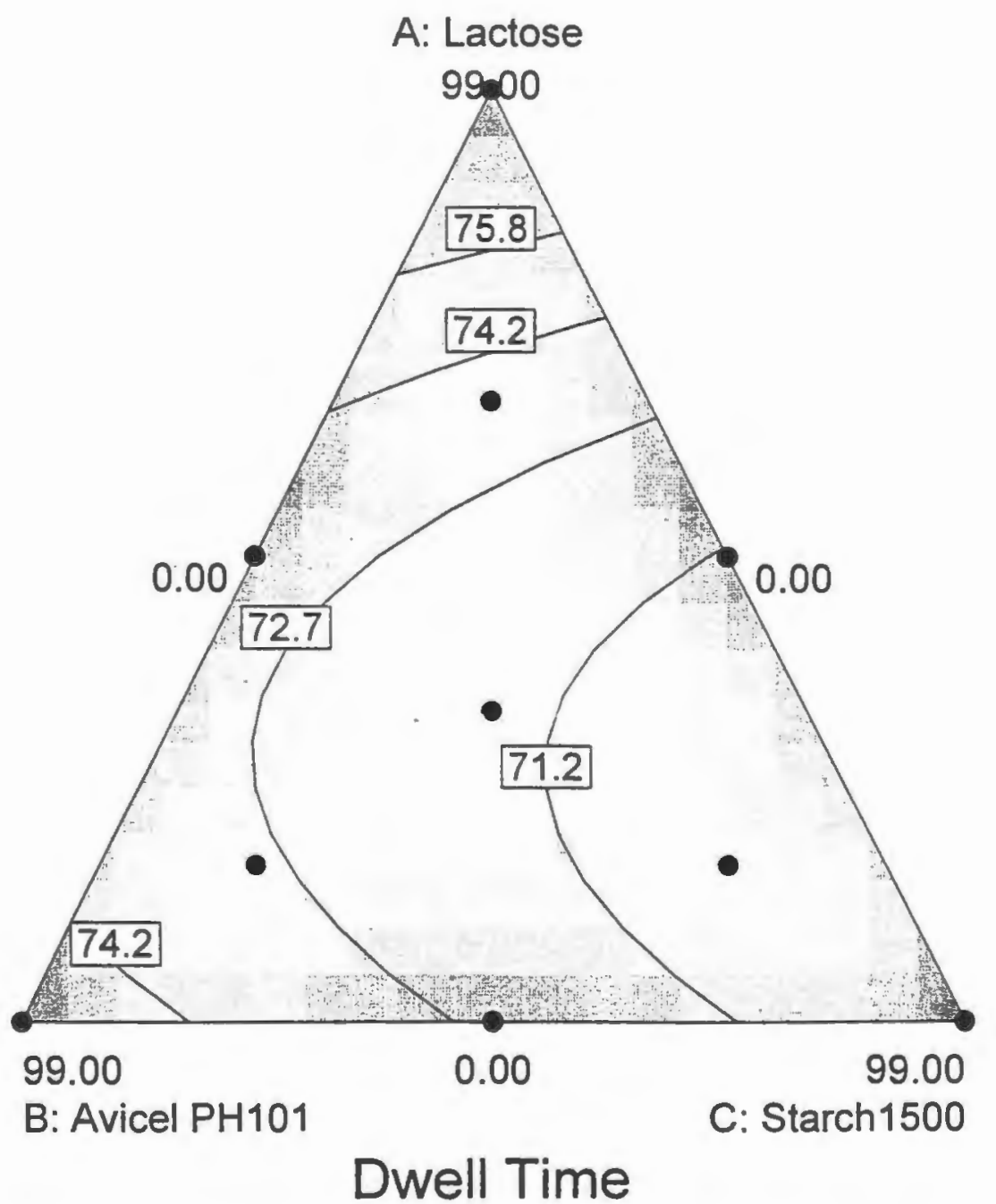

Figure 34. Effect of Formulation Composition on Dwell Time at 4000 Ibs of Compression Force 
Figure 35 describes the effect of applied force on the total area of compactionforce time pulse. The total area of the compression pulse denotes the total amount of work done for the compression process as a function of applied pressure. For 10 powder blends studied, the highest total area was observed for $99 \%$ Avicel ${ }^{\circledR}$ PH101 blend. Overall, the total amount of work involved increased with the applied force and this in turn resulted in harder tablets. It is apparent for all blends that the total work involved in the compression process increased with the applied pressure following a linear relationship. The higher the work input involved during the compaction of powder, the stronger the tablet is expected to be formed due to the larger amount of energy utilized in the formation of bonds. As the compression forces are increased, the contact areas between particles are also increased. Plastic materials will permanently deform and create extensive areas of true contact between particles whereas elastic materials will store energy elastically under compression. During decompression, the stored elastic energy may disrupt and separate the true contact areas that were established by compression forces resulting in poor bonding $(9-14,52-$ $61)$.

Figure 36 illustrates the effect of compression force on the total area of ejection pulse. In the current study, compression force or force applied was varied from 1000 lbs to maximum achievable force on the tabieting machine. The parameters generated during ejection cycle were recorded and analyzed. As the ejection force-time data summarized in Tables 14,15, 16, 17, 18, 19, and 20 and Figure 36 indicate for varying formulation compositions, the highest amount of work was needed to eject tablets 


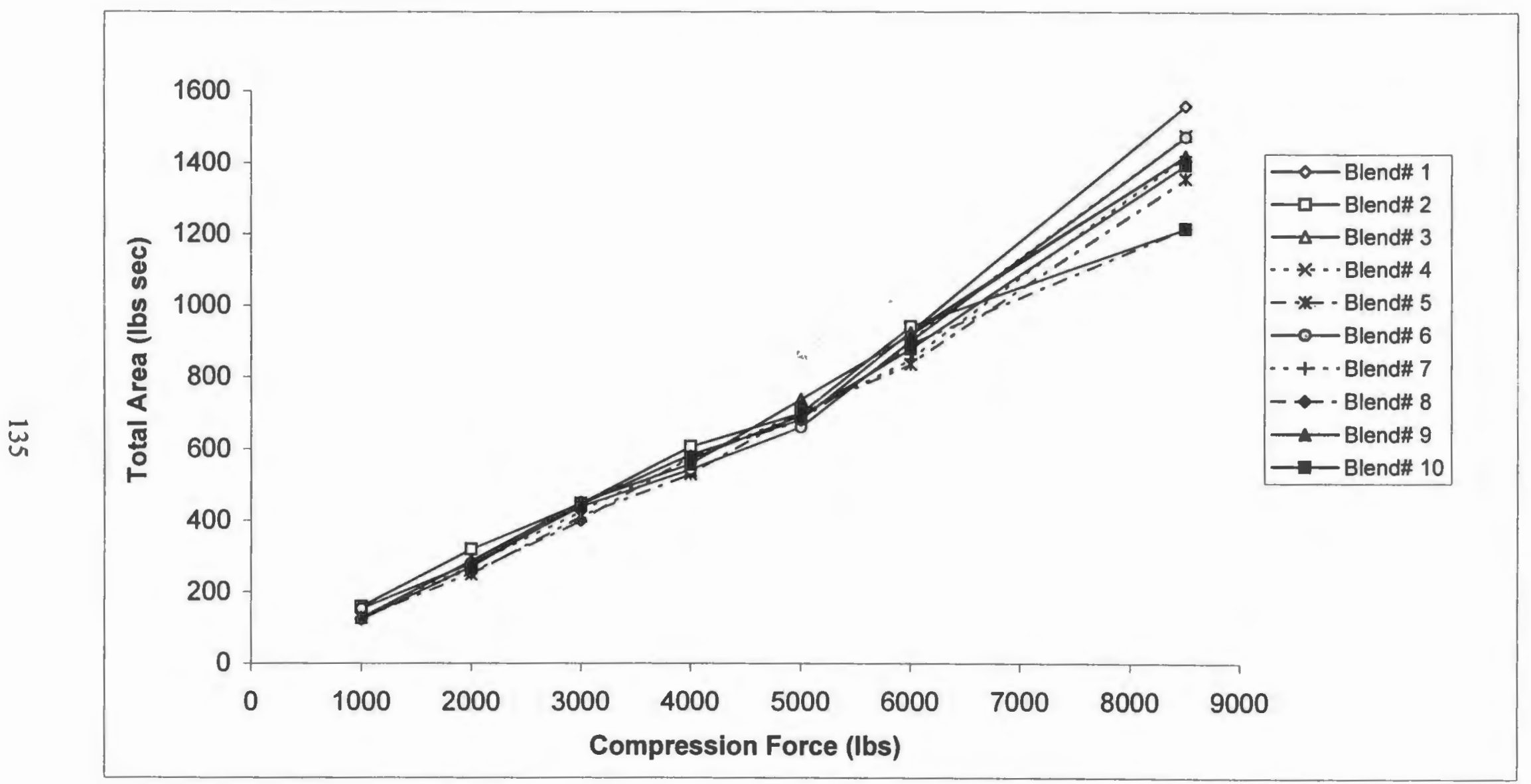

Figure 35. Effect of Compression Force on Total Area of Compression Pulse 


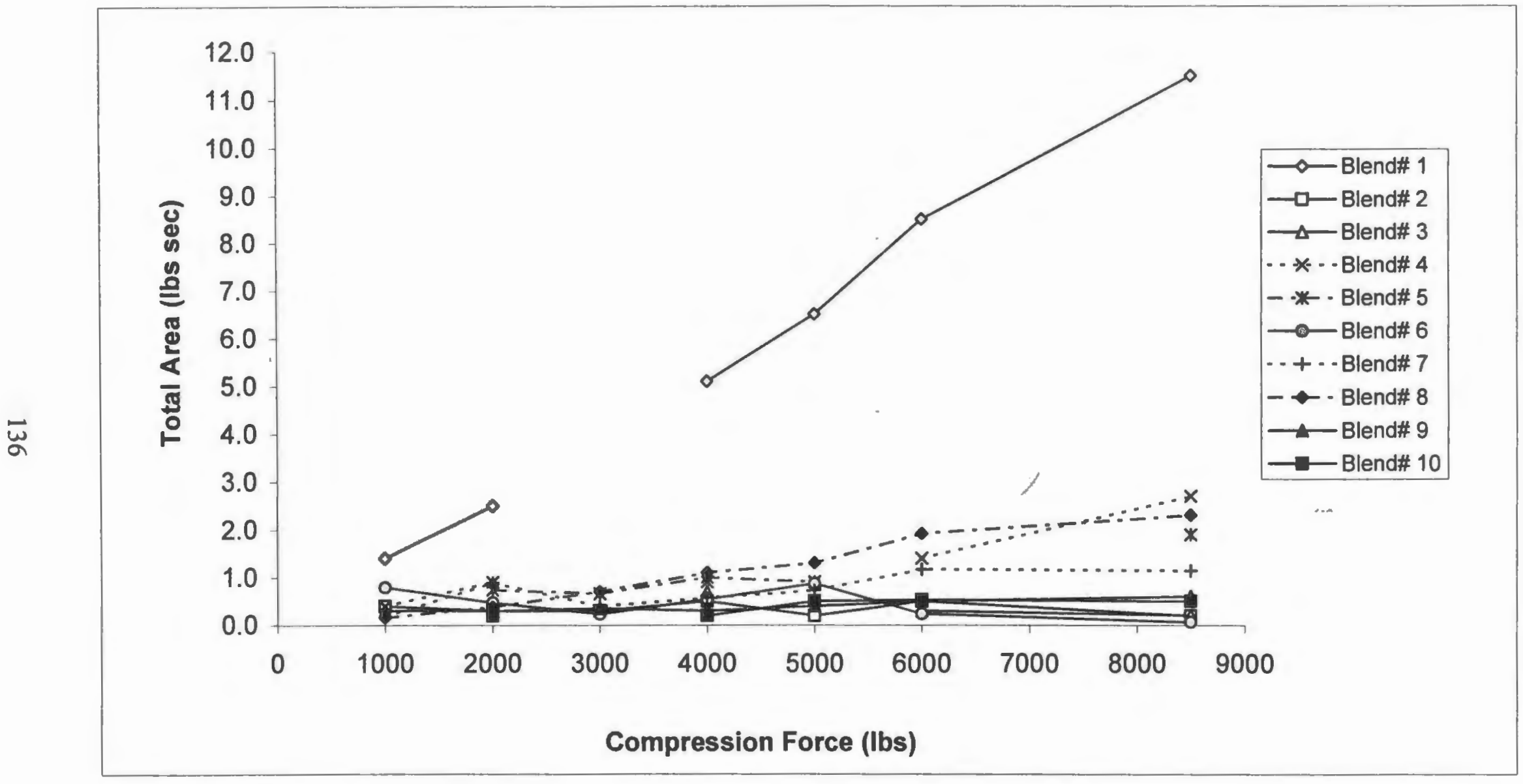

Figure 36. Effect of Compression Force on Total Area of Ejection Pulse 
prepared from 99\% lactose anhydrous blends. In Figure 37, the ejection forces required during tableting of different blends were plotted as a function of applied compression force. The lactose blends demonstrated tiat significantly higher amounts of ejection force was needed to eject tablets as compared to other formulation compositions. The highest amount of ejection force $(98.8 \mathrm{lbs})$ was required for tablets using $99 \%$ lactose anhydrous blend (blend\#1) at an applied compression force of 8191 lbs (Table 20). Figure 38 provides the effect of formulation composition on ejection force at an applied force of $4000 \mathrm{lbs}$. As the percentage of lactose anhydrous increases in the formulation, the force required to eject tablets increases. Significantly lower amounts of forces were required to eject tablets prepared from Avicel ${ }^{\circledR}$ PH101 and $\operatorname{Starch}^{\circledR} 1500$ blends.

Another parameter of interest is the tablet's specific volume. The patient's compliance improves with smaller size tablets. Smaller size tablets which have low tablet volumes will be possible only with either use of lower quantity of material or use of material that has very high compressibility value. The particle characteristics of the starting materials and changes that take place during the process of compaction determine the volume reduction (60). Figure 39 and Table 21 provide the reduction of surface area as a function of the compressional force for various powder mixtures. For all the blends, plateau values for tablet surface area were reached when compression force was approximately 4000-5000 lbs. Figure 40 displays the effect of formulation composition on tablet surface area at a compression force of $4000 \mathrm{lbs}$. As the graph indicates, increase in the concentration of Avicel ${ }^{\circledR}$ PH101 in tablet composition 


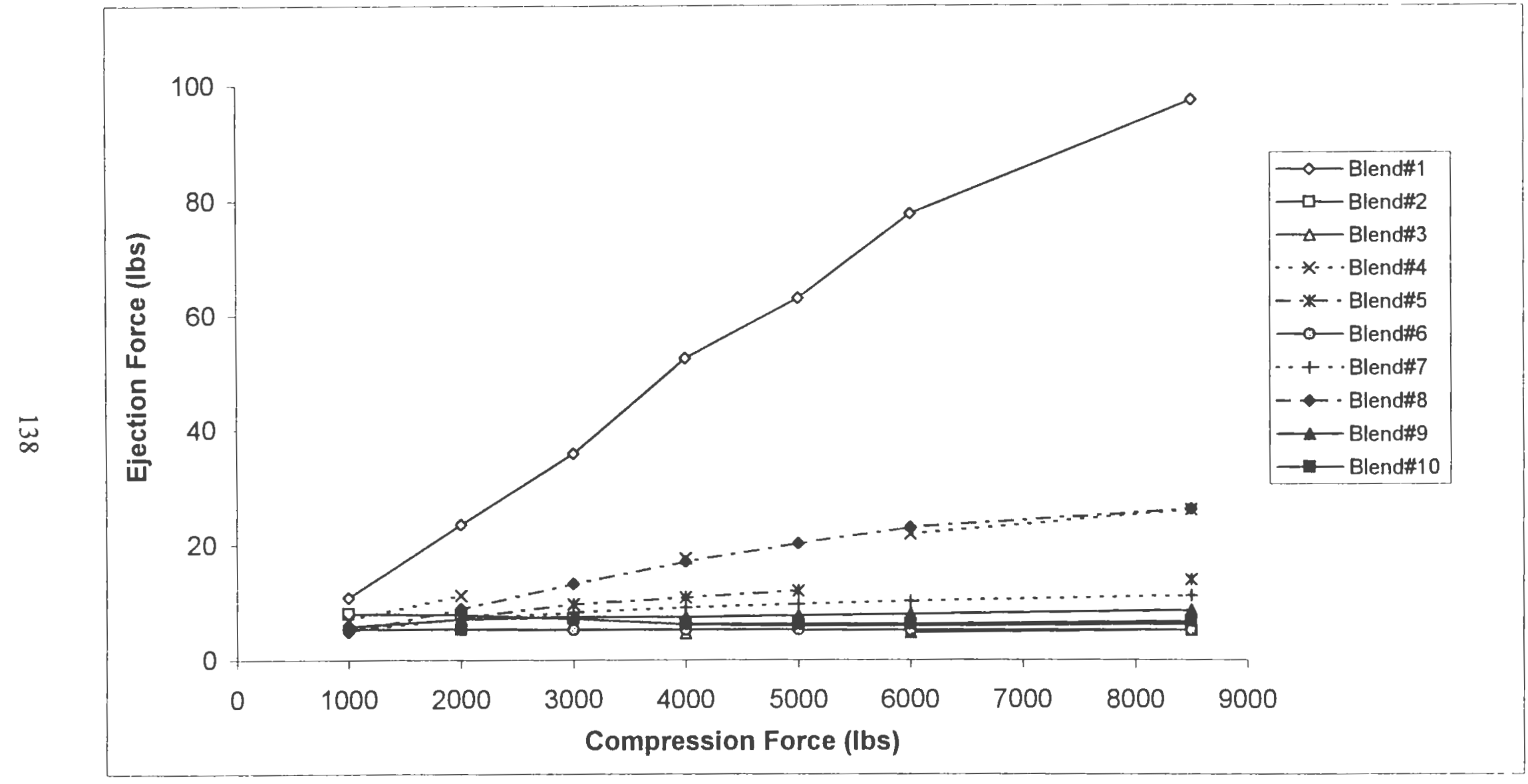

Figure 37. Effect of Compression Force on Ejection Force 


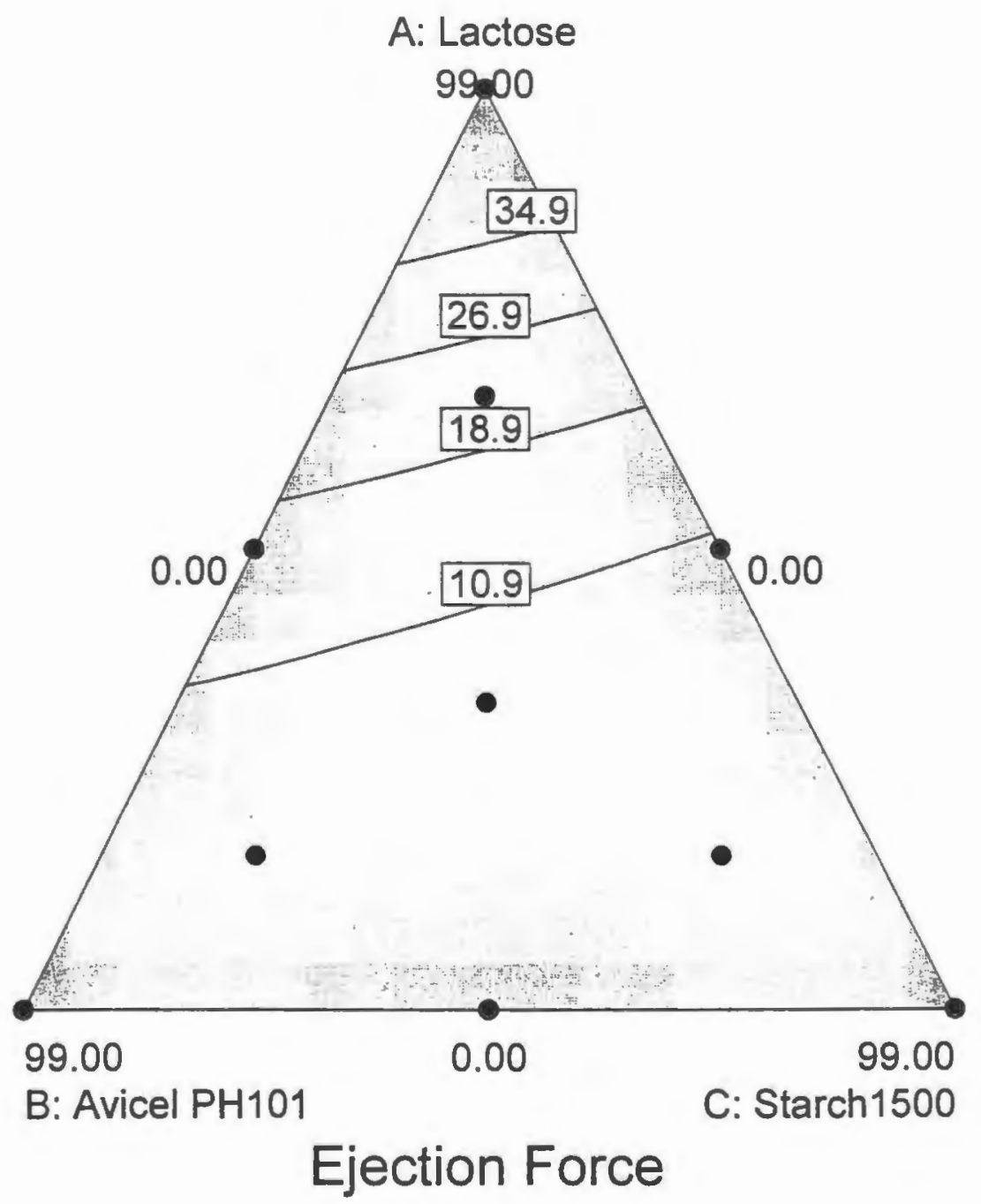

Figure 38. Effect of Formulation Composition on Ejection Force at 4000 Ibs of Compression Force 
Table 21. Compression Parameters For Multi-Component Mixtures

\begin{tabular}{|c|c|c|c|c|c|c|c|c|c|c|c|}
\hline & & Blend "hI & Blend $H_{2}$ & Blend H3 & Blend $\mathrm{HA}_{4}$ & Blend w5 & Blend 16 & Blend 47 & Blend 月ด & Blend $\mathbf{H} 9$ & Blend $\$ 10$ \\
\hline \multirow{4}{*}{$1000 \mathrm{lbs}$} & Tablet Volunie (c.mm) & 0.015788 & 0.017577 & - & 0.017201 & - & 0.017621 & 0.017466 & 0.164720 & 0.017632 & - \\
\hline & Tab. Surlace Area(Sq.In.) & 0.354504 & 0.373589 & - & 0.369583 & - & 0.374060 & 0.372411 & 0.361808 & 0.374178 & $\therefore$ \\
\hline & Porosity (\%) & 24 & 49.6 & - & 44.8 & - & 53.8 & 41.4 & 40.3 & 51.6 & - \\
\hline & $\operatorname{Ln}(1 / \mathrm{E})$ & 1.43 & 0.7 & & 0.8 & - & 0.62 & 0.88 & 0.91 & 0.66 & - \\
\hline \multirow[t]{4}{*}{$2000 \mathrm{lths}$} & Toblet Volume & 0.014484 & 0.014871 & - & 0.014959 & 0.015600 & 0.016141 & 0.015776 & 0.150360 & 0.015147 & 0.015710 \\
\hline & Tab. Surface Area(Sq.In.) & 0.340602 & 0.344725 & - & 0.345668 & 0.352501 & 0.358274 & 0.354386 & 0.346493 & 0.347671 & 0.353679 \\
\hline & \begin{tabular}{|l|} 
Porosity \\
\end{tabular} & 18 & 41.2 & - & 36.3 & 58.2 & 48.7 & 35.6 & 34.6 & 43.5 & 51.3 \\
\hline & $\operatorname{Ln}(1 / \mathrm{E})$ & 1.71 & 0.89 & & 1.01 & 0.54 & 0.72 & 1.03 & 1.06 & 0.83 & 0.67 \\
\hline \multirow[t]{4}{*}{$3000 \mathrm{lbs}$} & Trablet Volume & 0.013788 & 0.013932 & - & - & 0.015059 & 0.015191 & 0.014528 & 0.014274 & 0.014053 & - \\
\hline & Tab. Surface Area(Sq.In.) & 0.333180 & 0.334712 & - & $=$ & 0.346728 & 0.348142 & 0.341073 & 0.338364 & 0.336007 & - \\
\hline & \begin{tabular}{|l|} 
Porosity \\
\end{tabular} & 14.2 & 37.7 & - & - & 56.9 & 45.5 & 29.8 & 30.9 & 39.1 & - \\
\hline & $\operatorname{Ln}(1 / E)$ & 1.95 & 0.98 & & - & 0.56 & 0.79 & 1.21 & 1.17 & 0.94 & - \\
\hline \multirow[t]{4}{*}{$4000 \mathrm{lbs}$} & Tablet Volume & 0.013612 & 0.013280 & 0.014241 & 0.013479 & 0.014816 & 0.014915 & 0.014042 & 0.013678 & 0.013590 & 0.014882 \\
\hline & Trb. Surface Area(Sq.In, & 0.331295 & 0.327761 & 0.338010 & 0.329881 & 0.344136 & 0.345197 & 0.335890 & 0.332002 & 0.331059 & 0.344843 \\
\hline & \begin{tabular}{|l|} 
Porosity \\
\end{tabular} & 11.6 & 34.8 & 51.7 & 29.8 & 55.9 & 44.8 & 27.4 & 28.1 & 36.6 & 48.2 \\
\hline & $\operatorname{Ln}(1 / E)$ & 2.15 & 1.05 & 0.66 & 1.21 & 0.58 & 0.8 & 1.29 & 1.27 & 1.00 & 0.73 \\
\hline \multirow[t]{4}{*}{$5000 \mathrm{Jbs}$} & Tablet Volume & 0.013247 & 0.013082 & - & - & 0.014484 & 0.014650 & 0.013755 & 0.013424 & 0.013336 & 0.014904 \\
\hline & Tab. Surface Area(Sq.Jn.) & 0.327407 & 0.325640 & - & - & 0.340602 & 0.342369 & 0.332827 & 0.329292 & 0.328350 & 0.345079 \\
\hline & Porosity & 9.5 & 33.6 & - & - & 54.8 & 43.6 & 26.1 & 26.5 & 35.4 & 48 \\
\hline & $\operatorname{Ln}(1 / \mathrm{E})$ & 2.36 & 1.09 & - & - & 0.6 & 0.83 & 1.34 & 1.33 & 1.04 & 0.73 \\
\hline \multirow[t]{4}{*}{$6000 \mathrm{lbs}$} & Tablet Volume & 0.012982 & 0.012993 & 0.014274 & 0.012927 & 0.014407 & 0.014495 & 0.013590 & 0.013170 & 0.013170 & 0.014749 \\
\hline & Tsb. Surface Area(Sq.In.) & 0.324580 & 0.324698 & 0.338364 & 0.323991 & 0.339777 & 0.340720 & 0.331059 & 0.326583 & 0.326583 & 0.343429 \\
\hline & Porosity & 7.6 & 32.9 & 50.8 & 26.3 & 54.6 & 43.2 & 25 & 24.8 & 35 & 47.8 \\
\hline & $\operatorname{Ln}(1 / E)$ & 2.57 & 1.11 & 0.68 & 134 & 0.61 & 0.84 & 1.39 & 1.39 & 1.05 & 0.74 \\
\hline \multirow{4}{*}{$\begin{array}{l}8500 \text { lbs } \\
\text { (Max For }\end{array}$} & Tablet Volume & 0.013391 & 0.012828 & 0.014617 & 0.012717 & 0.014142 & 0.014374 & 0.013369 & 0.012971 & 0.013071 & 0.014562 \\
\hline & Tub. Surface Area(Sq.ln.) & 0.328939 & 0.322931 & 0.324016 & 0.321752 & 0.336950 & 0.339424 & 0.328703 & 0.324462 & 0.325522 & 0.341427 \\
\hline & Porosity & - & 32.1 & 51.5 & 24.8 & 539 & 42.7 & 23.7 & 24.2 & 33.6 & 47.1 \\
\hline & $\operatorname{Ln}(1 / E)$ & - & 1.14 & 0.66 & 1.29 & 0.62 & 0.85 & 1.44 & 1.42 & 1.09 & 0.75 \\
\hline
\end{tabular}




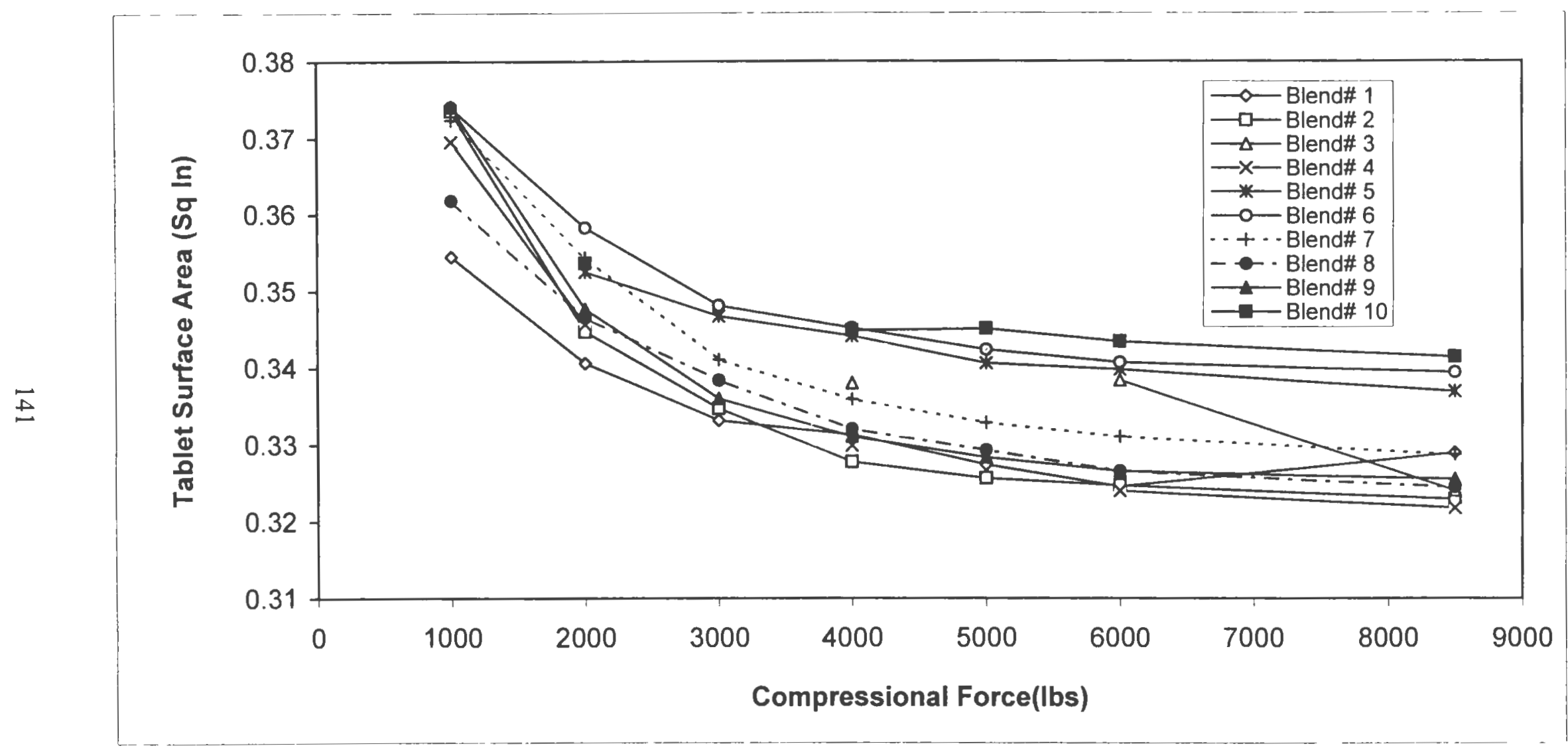

Figure 39. Effect of Compression Force on Tablet Surface Area 


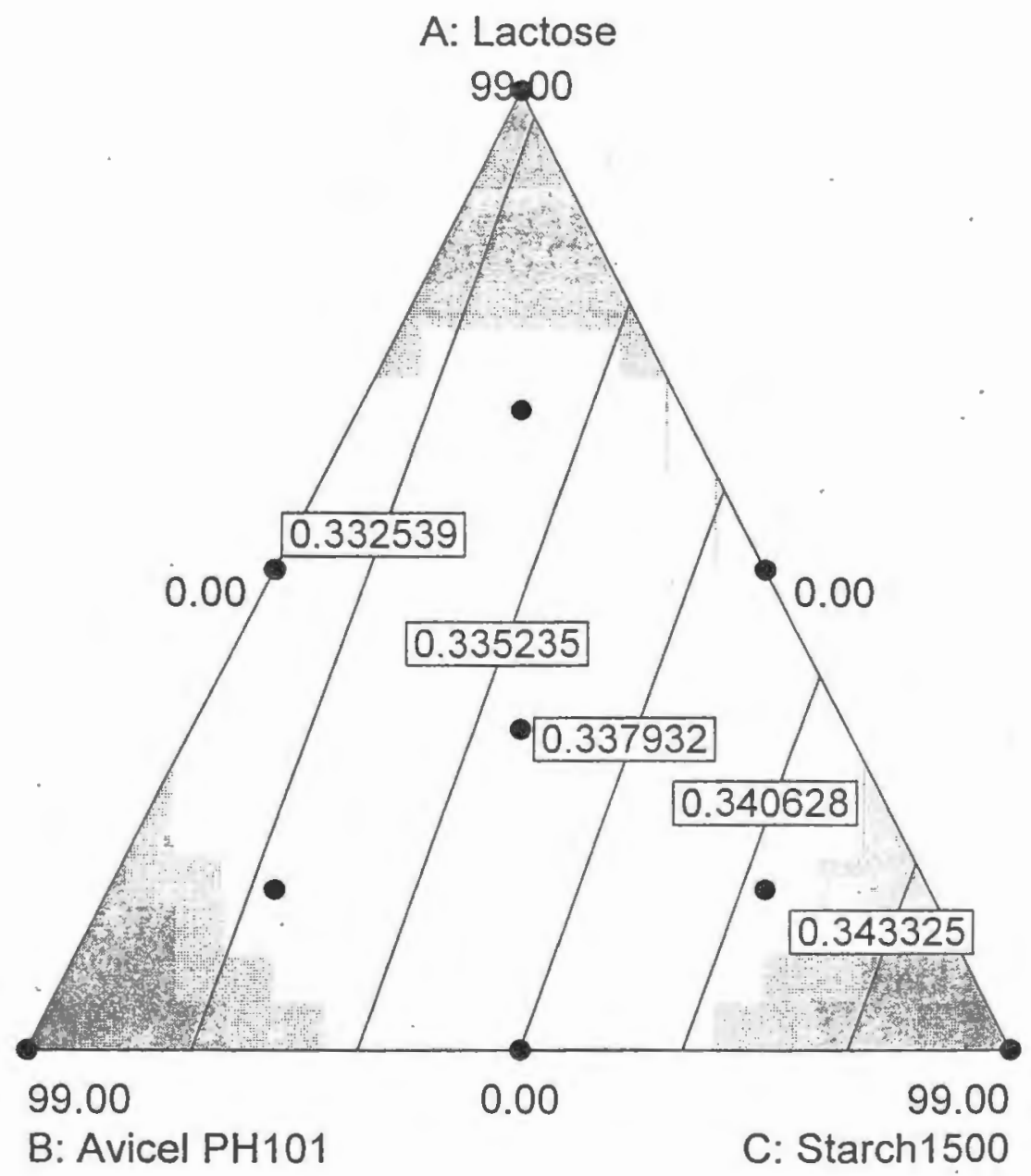

Figure 40. Effect of Formulation Composition on Tablet Surface Area at 4000 Ibs of Compression Force 
reduces the tablet surface area; and increase in the $\operatorname{Starch}^{\circledR} 1500$ concentration results in tablet that has low surface area. These trends can be explained based on the compaction mechanism of respective excipients. Avicel ${ }^{\circledR}$ PH101 displays excellent compressibility values indicating larger amounts of material can be compressed into smaller volumes. Conversely, $\operatorname{Starch}^{\circledR} 1500$ displays poor compressibility characteristics and hence larger amount of material results in larger tablets which in turn will have high surface areas.

Particulate solids may be characterized by two parameters: compressibility, that is, the material's ability to undergo volume reduction under pressure; and compactibility, that is, the material's ability to yield a compact of adequate deformation resistance when compressed. Figure 41 and Table 21 provide the reduction of tablet volume as a function of applied force. All the blends display high tablet volume in the initial stages and a continuous reduction as the applied force increases until a plateau value is reached. The volume of fixed amount of powder blend in die is reduced by decreases in the inter- and intra-particulate pore space. The process of volume reduction is generally divided onto different stages: die filling, rearrangement of particles, deformation by elastic changes, permanent deformation by plastic flow, or particle failure by brittle fracturing (8). As expected, the volume data displayed trends similar to those observed with the tablet surface area values. Blends containing Starch ${ }^{\circledR} 1500$ produced tablets with high volumes whereas the blends containing Avicel ${ }^{\circledR}$ PH101 produced tablets with low volumes. 


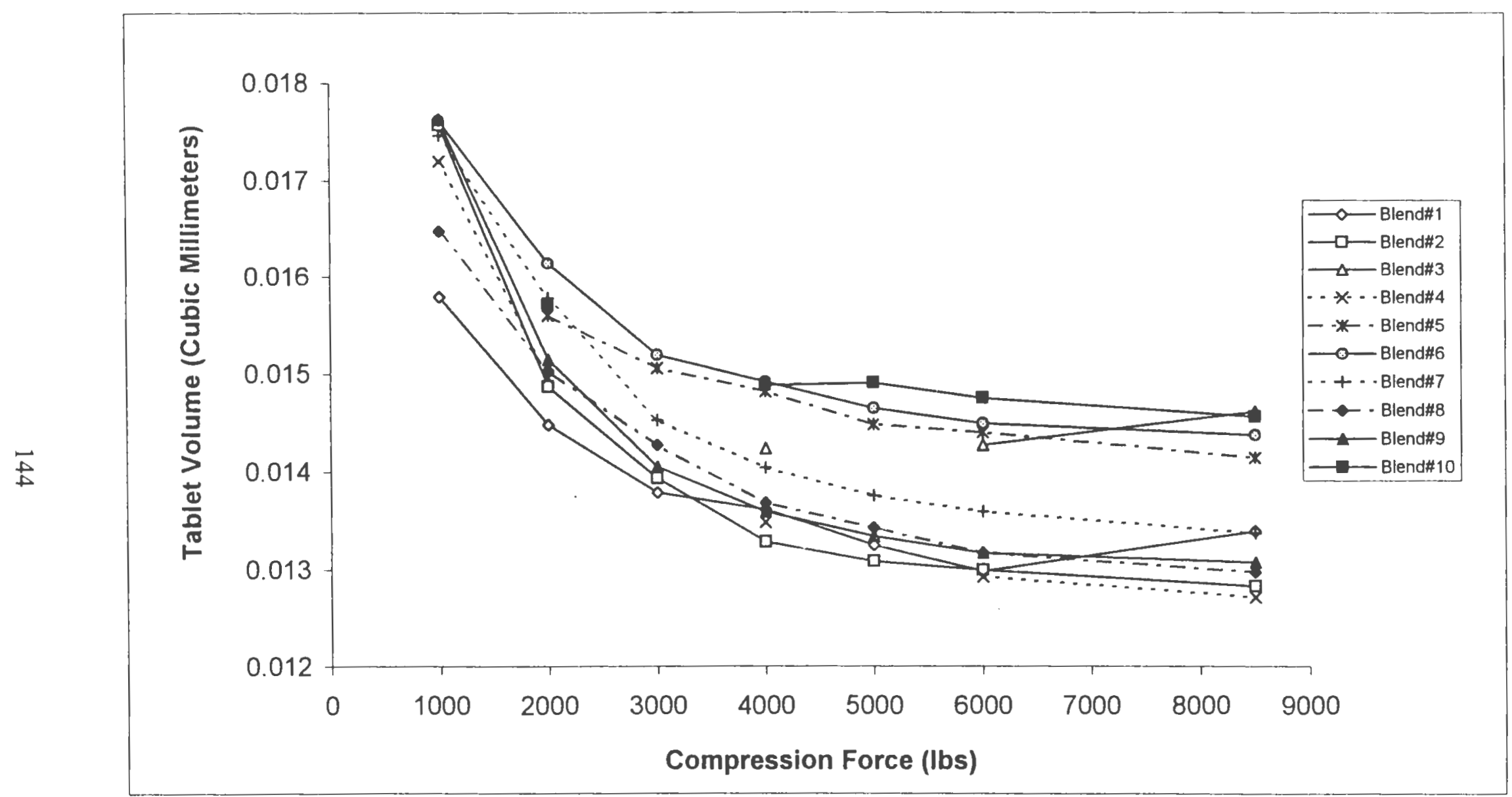

Figure 41. Effect of Compression Force on Tablet Volume 
This is attributed to the excellent ability of Avicel ${ }^{\circledR}$ PH101 to undergo high volume reduction with applied force as compared to $\operatorname{Starch}^{\circledast} 1500$, which behaves differently during compaction.

Tablet porosity is the entrapped air in the compacts and provides critical information how a mixture behaves under pressure. Figure 42 and Table 21 provides the porosity values for tablets prepared from the various blends as a function of compression force. Among the ten blends, Blend\#5 which contains $49.5 \%$ of lactose anhydrous and $49.5 \%$ of Starch 1500 displayed the highest values for porosity. For Blend\#5, increase in compression force from $1000 \mathrm{lbs}$ to $8500 \mathrm{lbs}$ did not affect the high porosity values significantly. Higher porosity values indicate that blends cannot deform well to make compacts. The high porosity values are associated with the amount of Starch 1500 present in the formulation. The blends containing Avicel ${ }^{\circledR}$ PH101 has high porosity values initially, but as the applied force increases, the porosity values drop significantly. $99 \%$ lactose anhydrous blend provided tablets with lowest amount of porosity. Figure 43 shows the effect of formulation composition on tablet porosity of blends compressed at $4000 \mathrm{lbs}$ of applied force. As graph indicates that as the concentration of $\operatorname{Starch}^{\otimes} 1500$ increases, the porosity values seem to increase.

Numerous mathematical models describing the change of relative density in a powder column as a function of the applied pressure have been derived and adopted from other fields of industry for pharmaceutical compression processes $(9-14,17)$. 


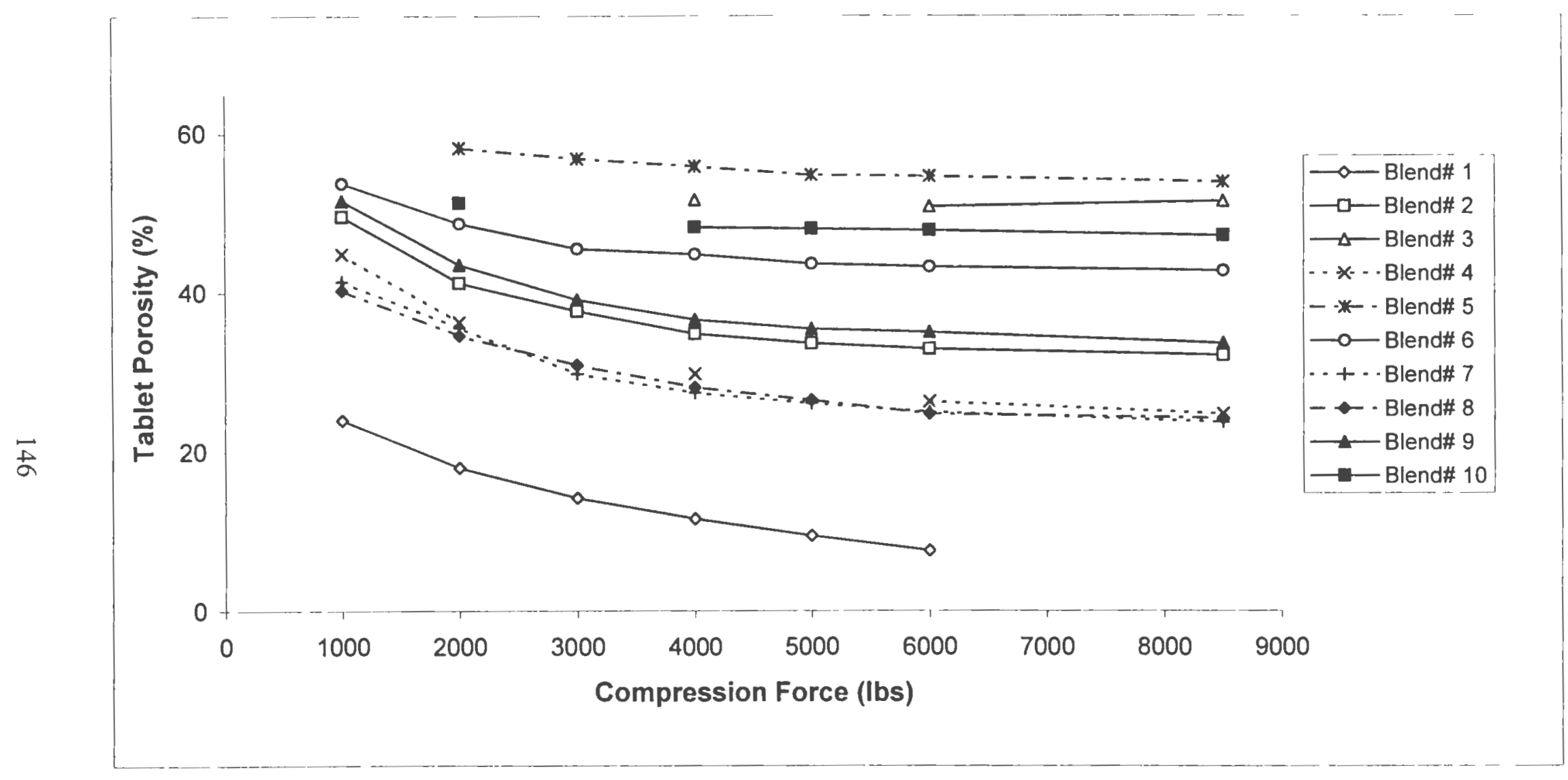

Figure 42. Effect of Compression Force on Tablet Porosity 


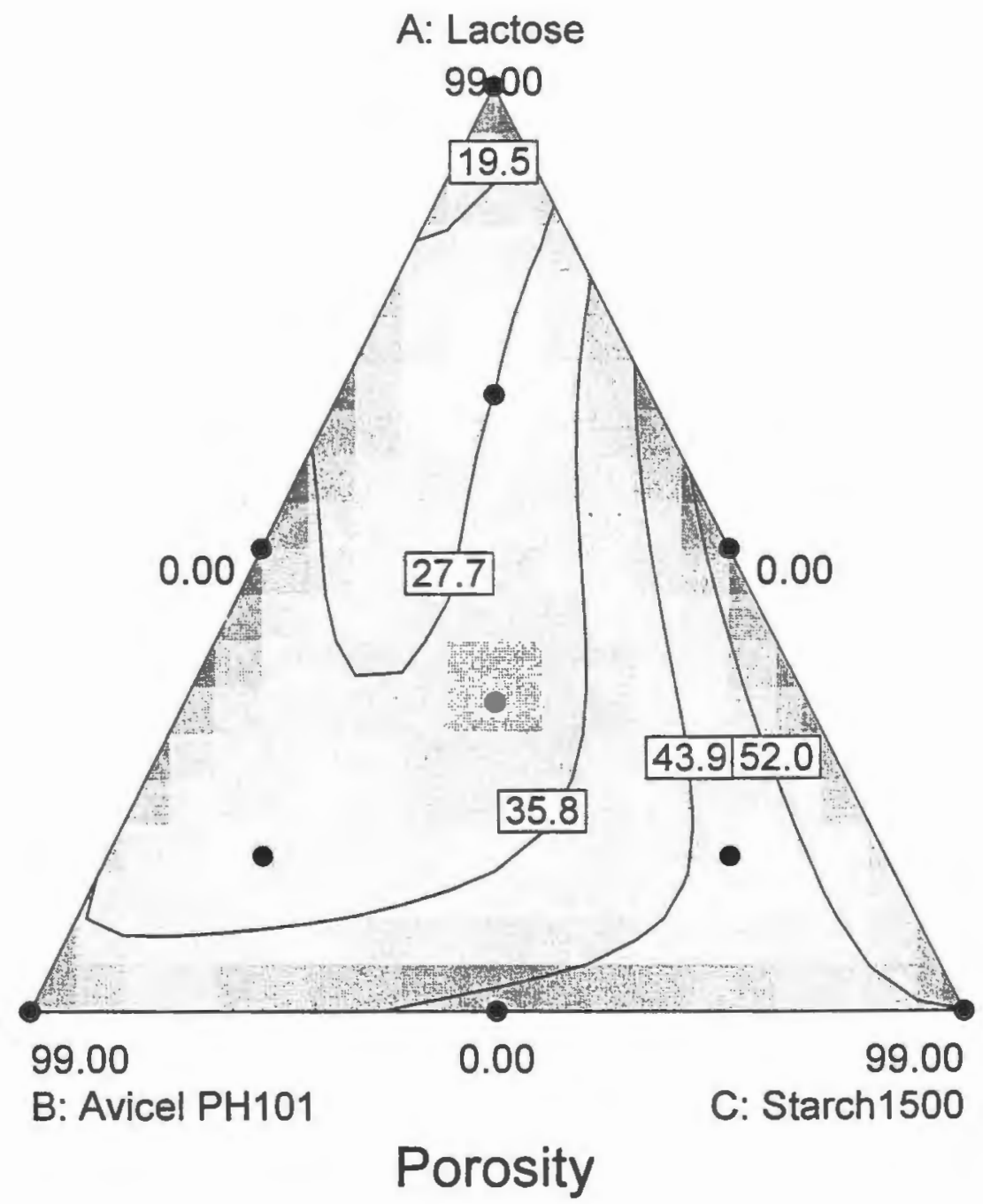

Figure 43. Effect of Formulation Composition on Tablet Porosity at 4000 Ibs of Compression Force 
Heckel equation is widely used to study the densification behavior of materials with applied pressure. Three types of volume reduction mechanisms of pharmaceutical powders have been distinguished by using the Heckel equation (17). The types are referred as $\mathrm{A}, \mathrm{B}$ and $\mathrm{C}$ (Figure 44). In type $\mathrm{A}$, size fractions had different initial packing fractions and the plots remain parallel as the compression pressure was increased. In type B, the plots were slightly curved at the initial stages of compaction and later became coincidental. In type C, the plots had an initial steep linear part after which they became coincidental with only trivial volume reduction. Generally, type A behavior was related to the densification by plastic flow, preceded by particle rearrangement. In type $\mathrm{B}$, powder densification occurs by fragmentation of the particles. Type $\mathrm{C}$ densification occurs by plastic flow but no initial particle rearrangement is observed.

The effects of experimental variables on Heckel plots have been studied quite intensively. Rue and Rees (11) and York (12) have published about the limitations of Heckel plots used for predicting the compaction mechanisms. Rue and Rees (11) pointed out that the predominant compaction mechanism may change with the particle size. They also reported that an increased volume reduction was observed increased compression time indicating deformation of microfine cellulose by plastic flow. In contrast, no increase in volume reduction as a function of contact time was observed for dicalcium phosphate, this being characteristic of brittle materials. The authors proposed measuring the area under the Heckel plot to quantify the amount of plastic deformation. York (12) reviewed several studies where densification behavior of crystalline lactose was evaluated and he pointed out that the general form of the 

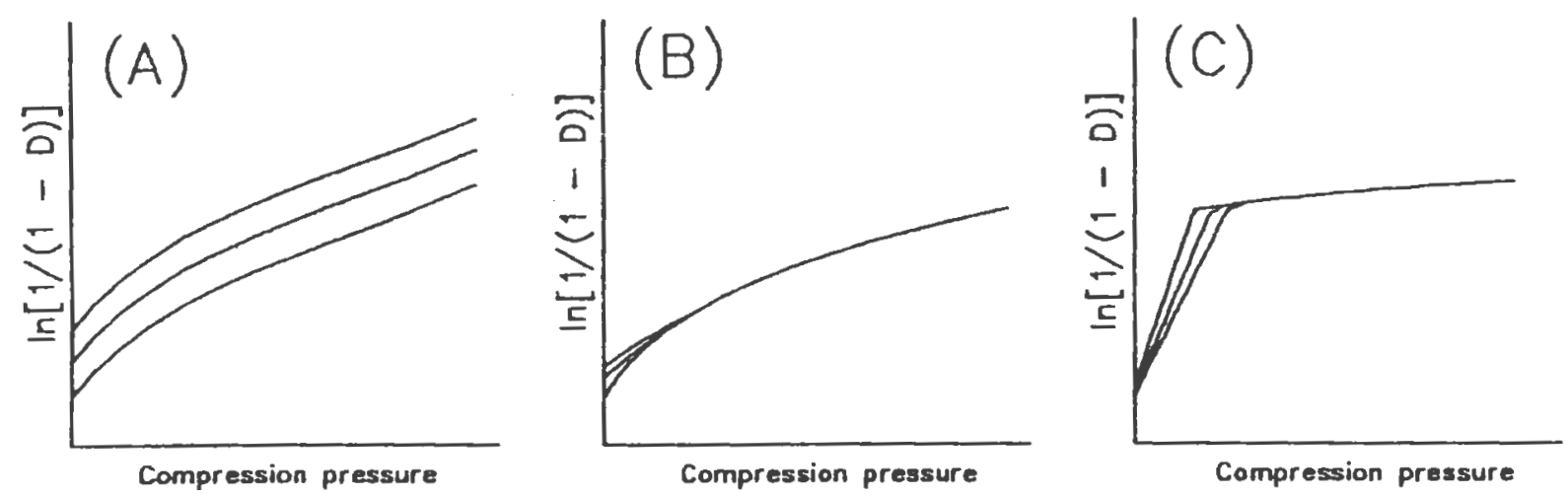

Figure 44. Different Types of Compression Behavior Distinguished by the Heckel Equation 
Heckel plots was similar in all cases though the numerical values describing the compression process were dependent on experimental variables. York (12) has listed several variables such as the state and type of lubrication, rate of compaction, mode of die filling, contact time, dimensions of tools and techniques used to measure compact dimensions, all which are necessary to take into account in tableting studies.

Duberg and Nystrom (13) have used the initial curvature of Heckel plots as an indication of particle fragmentation. Also the correlation coefficient describing the linearity of the Heckel plots have been used for the same purpose. Thus, nonlinear plots may indicate fragmentation, and linear plots the deformation by plastic flow. Also poor packing of powder due to cohesiveness, small particle size and irregular particle shape may lead to initial curvature in a Heckel plot. In most cases, however, the rearrangement of the relatively regular particles occurs already at low pressures. Thus measurements of the nonlinearity could be a useful tool for categorizing pharmaceutical materials. This is especially true if fragmentation of microcrystalline particles or aggregates of primary particles are concerned, since they are intensively fragmented to smaller particles already at low compression pressures and this results in considerable volume reduction. At higher pressures the volume reduction becomes more difficult, and is expressed by nonlinear Heckel plots. On the other hand, the densification due to plastic flow and elastic deformation of particles, and the volume reduction of a powder column proceed steadily, since according to Heckel function the porosity reduction occurs exponentially.

Most of the reports on porosity-pressure functions are derived from single component powders. There are hardly any reports concerning the compression 
behavior of multi-component powder mixtures $(6,9)$. Solid dosage forms are always multi-component systems containing typically, filler/binder, disintegrant and lubricant. Hence, the current study was designed to evaluate the densification behaviors of multicomponent powder mixtures using simplex experimental design. The compaction parameters generated using instrumented Piccola rotary tablet for ten powder blends were summarized in Tables 15 to 20 . Table 21 provides the summary of tablet volume, surface area, porosity and $\operatorname{Ln}(1 / \mathrm{E})$ values at compression forces varying from $1000 \mathrm{lbs}$ to approximately $8500 \mathrm{lbs}$. Figure 45 shows Heckel plots determined using Heckel equation and compaction parameters.

The ability of powder materials to form tablets or compacts depends on their deformation and bonding characteristics. Materials are usually classified as either brittle or plastic, depending on their predominant deformation behavior. Plastic materials are basically viscoelastic, which is apparent from their sensitivity to changes in strain rate. The consolidation is affected by the speed of compaction. Elastic deformation at higher tableting speeds leads to additional stress relaxation of tablets.

The individual components, namely, lactose anhydrous, Avicel ${ }^{\circledR}$ PH101 and Starch ${ }^{\circledast} 1500$ have been well researched when used alone (8). Lactose consolidates primarily by fragmentation, but directly compressible lactose contains some amorphous material which is capable of plastic flow (58). The anhydrous lactose used in the current study, consists of agglomerated, extremely fine crystals, produced by roller-drying of a solution of pharmaceutical grade $\alpha$-lactose monohydrate followed by subsequent comminution and sieving. It contains about $85 \%$ of $\beta$-lactose and about $15 \%$ anhydrous $\alpha$-lactose. 


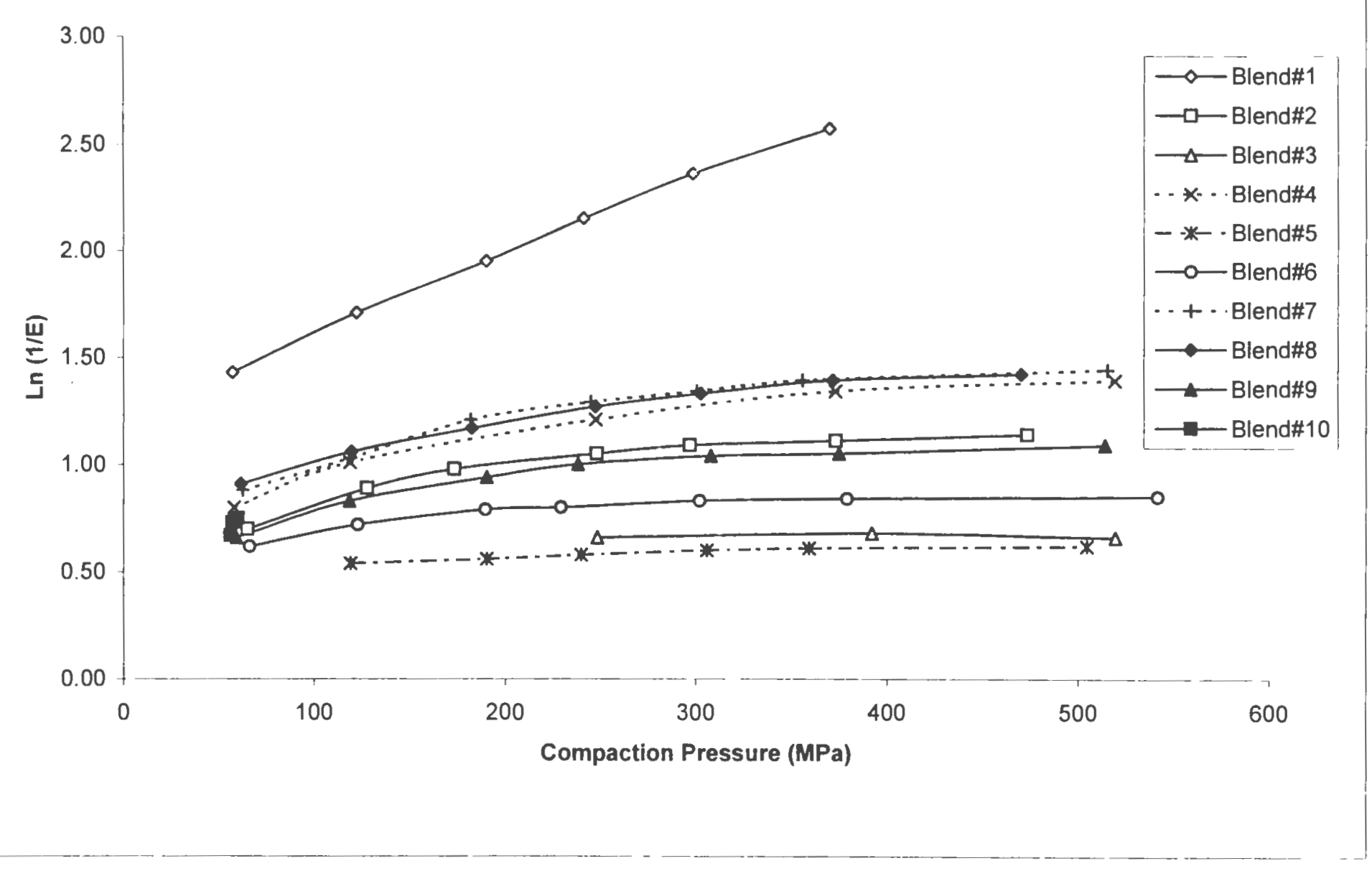

Figure 45. Heckel Plots for Statistically Designed Mixtures 
During compaction, microcrystalline cellulose is thought to undergo stress relief deformation by several mechanisms. David and Augusburger (1) reported that microcrystalline cellulose consolidates by two mechanisms: fragmentation and plastic deformation. At low compression forces, stress relief is dominated by a slight elastic phase. This has been explained by its hollow microfibrillar structure. At higher force, there is either further deformation or permanent deformation by nonspecific plastic flow. Following stress relaxation studies, David and Augusburger (1) suggested that plastic flow is an important factor affecting the compressibility of microcrystalline cellulose. Plastic deformation is facilitated by the presence of slip planes, dislocations, and the small size of the individual microcrystals. The plasticity of microcrystalline cellulose increases with increasing compressing force, which is accompanied by a decrease in viscoelasticity. When microcrystalline cellulose tablets are prepared by wet granulation, there is less plastic deformation in comparison with tablets prepared by direct compression. Force versus displacement plots on diametric compression to fracture indicates that Avicel shows stress relief by time-dependent yielding. The yield pressure increases with punch velocity, because of a reduction in the amount of plastic deformation caused by the time-dependent nature of plastic flow. This increase in mean yield pressure at increasing compression speeds is reflected by the high strain rate sensitivity value for microcrystalline cellulose. Armstrong and Palfrey $(35,36)$ show that the reduction in crushing strength at increasing compression speed is caused by an increased porosity of the compacted powder bed. 
Strong binding properties of microcrystalline cellulose are caused by hydrogen bonds between hydrogen groups on the plastically deformed, and adjacent cellulose particles. The hydrogen bonds on the extremely large surface area are brought into close contact during plastic deformation. This is the reason for the extremely good compactability of microcrystalline cellulose, better than that of any other directly compressible filler-binder. The microcrystalline cellulose (Avicel ${ }^{\circledR}$ PH101) has a very low brittle fracture index and a very high bonding index, two properties that make it an excellent tableting excipient. The low brittle fracture index can successfully mask the brittle properties of drugs, while the low brittle fracture index will overcome the poor bonding of the active compound. The compactability of microcrystalline cellulose depends on its moisture content. During plastic deformation, the moisture within the pores should act as an internal lubricant and facilitate slippage and flow within the individual microcrytsals. The presence of an optimum amount of water will prevent elastic recovery by forming bonds through hydrogen bond bridges $(8,53,54)$. The compactibility of microcrystalline cellulose decreases with a reduction of its moisture content. The strongest compacts are produced when the microcrystalline cellulose contains $7.3 \%$ moisture. The capping tendency of microcrystalline cellulose is reduced by increasing the moisture content. This is attributed to the strengthening of interparticle binding forces and the reduction of elastic recovery by lowering the yield point (8).

Density-stress and stress-relaxation studies show that $\operatorname{Starch}^{\circledR} 1500$ exhibits extensive, yet slow, plastic deformation during compression. Changes in contact time during compaction, therefore, have a marked effect on tablet properties (8). Starch ${ }^{\circledR}$ 
1500 has a slower initial relaxation than anhydrous lactose, but after prolonged time periods the total relaxation of $\operatorname{Starch}^{\boxplus} 1500$ is much greater than that of anhydrous lactose. As compared with other plastically deforming materials, the strength of Starch 1500 tablets is low. This effect may be because plastic deformation is too slow to produce adequate interparticle binding during rapid compression. In addition, during compaction at high strain rate, a large proportion of the total deformation will be elastic (8). When elastic and plastic deformation and interparticles binding occur during compression and when elastic recovery occurs on decompression and ejection, interparticle bonds are not formed rapidly enough to prevent brittle fracture reducing tablet strength and possibly causing capping.

Because of its plastic behavior under pressure, $\operatorname{Starch}^{\circledR} 1500$ is extremely sensitive to mixing with lubricants (37-42). This behavior is confirmed with the results obtained in this study. Among, the ten mixtures, 99\% $\operatorname{Starch}^{\circledast} 1500$ blend provided low tablet hardness and high tablet friability values. Since $\operatorname{Starch}^{\circledR} 1500$ is an important component in tablet formulation because of its disintegrant properties and better flow characteristics, the limitations seen above can be offset by choosing appropriate amount of other components (Avicel ${ }^{\boxplus}$ PH0101 and lactose anhydrous) based on trends observed in this study and desired tablet characteristics.

Based on shape of Heckel plots (Figure 45) and comparing with theoretical curves (Figure 44), we can understand how each blend is behaving during compression process. Since each blend is a multi-component mixture, it is difficult to precisely estimate what type of mechanism each blend is following for deformation during compression. However, since all three major components, Lactose Anhydrous, 
Avicel ${ }^{\mathbb{E}}$ PH101, Starch ${ }^{\circledR} 1500$ behave differently as described above, the blends seem to follow the same mechanism as its major component. Similar trends can be seen for all other compression and tablet parameters.

In summary, compaction parameters were generated for statistically designed powder mixtures containing Lactose Anhydrous, Avicel ${ }^{\circledR}$ PH101, Starch ${ }^{\circledR} 1500$ and Magnesium Stearate. The powder blends were evaluated and then compressed into tablets at an applied force of $1000 \mathrm{lbs}, 2000 \mathrm{lbs}, 3000 \mathrm{lbs}, 4000 \mathrm{lbs}, 5000 \mathrm{lbs}, 6000 \mathrm{lbs}$ and maximum achievable force on tableting machine $(\sim 8500 \mathrm{lbs})$. The tablets were characterized. The compression force-time curves and ejection force-time curves were studied and all critical compression parameters were summarized. Critical parameters such as tablet volume, surface area, true density, porosity and $\operatorname{Ln}(1 / \mathrm{E})$ values were computed and heckle plots were generated. In order to determine the effect of formulation composition on a specific property, response surface contour plots were generated to study the trends. 


\section{CONCLUSIONS}

In the current investigation, experimentally designed blends comprising Lactose Anhydrous, Avicel ${ }^{\circledast}$ PH101, Starch ${ }^{\circledast} 1500$ and Magnesium Stearate were evaluated using an instrumented tablet press. Simplex design was utilized to mimic the actual formulation requirements and ten different blends were prepared using a high shear mixer. The powder mixtures were compressed at $1000 \mathrm{lbs}, 2000 \mathrm{lbs}, 3000$ lbs, $4000 \mathrm{lbs}, 5000 \mathrm{lbs}, 6000 \mathrm{lbs}$ and maximum achievable force on tableting machine ( $>8500 \mathrm{lbs})$. The compression force-time curves and ejection force-time curves were evaluated and critical compression parameters such as porosity and $\ln (1 / \mathrm{E})$ values and Heckel plots were determined to understand the compression behavior of the experimental blends. The compression parameters generated in this study, provide valuable insights into how multi-component mixtures behave under pressure.

The key findings can be summarized as : 1) Maximum weight variation was observed for blends containing $99 \%$ Starch $^{\circledR} 1500$ and minimum variation was observed for blends containing Lactose Anhydrous and Avicel ${ }^{\circledR}$ PH101 at $49.5 \%$ level. 2) $99 \%$ Avicel $^{\circledR}$ PH101 provided the highest tablet hardness values $(7.3-23.7 \mathrm{Kp})$ as compared to all other mixtures. $99 \% \operatorname{Starch}^{\circledast} 1500$ provided the lowest tablet hardness values (0-0.3 Kp). 99\% Lactose Anhydrous provided an intermediate hardness profile (1.9-14.2 Kp). As the level of Avicel ${ }^{\circledast}$ PH101 in the blend increases, so does the hardness profile for tablets.

3) Starch $^{\circledast} 1500$ imparted more thickness to the tablets followed by Avicel ${ }^{\circledast}$ PH101 and Lactose Anhydrous. 
4) Maximum disintegration times were observed for tablets prepared from blend containing Avicel ${ }^{\circledR}$ PH101 and Lactose Anhydrous at $49.5 \%$ level.

5) Maximum dwell time of $107 \mathrm{msec}$ was observed for $99 \%$ Lactose Anhydrous at maximum achievable force $(\sim 8500 \mathrm{lbs})$ and a minimum dwell time of $51 \mathrm{msec}$ was observed for the same blend at 1000 lbs of applied force.

6) Maximum total area of compression pulse was observed for $99 \%$ Avicel $^{\circledR} \mathrm{PH} 101$.

7) The highest amount of ejection force $(98.8 \mathrm{lbs})$ was required for tablets prepared from $99 \%$ Anhydrous Lactose blend.

8) Tablet surface area and volume are dependent upon the amount of $\operatorname{Starch}^{\circledR} 1500$ present in the blend.

9) Tablets from the blend containing 49.5\% Anhydrous Lactose and $49.5 \%$ Starch $^{\circledR}$ 1500 displayed maximum amount percentage of porosity. It indicates that the blend can not deform well to make compacts. Presence of Starch 1500 also resulted in higher porosity values. Tablets containing Avicel ${ }^{\circledR}$ PH101 displayed high porosity values initially (at $1000 \mathrm{lbs}$ ) but the porosity was reduced significantly as the applied force was increased.

10) Heckel plots were generated to elucidate the deformation mechanism of various blends.

The current findings will help formulation scientist to design and develop a robust tablet dosage form that meets the predetermined quality attributes and will be free of typical tableting problems such as hardness variation and weight variations. 
Finally, at present only very few investigations comprising multi-component mixtures were available in literature for compaction process and more studies will definitely shed more light on the complex process of compaction especially with the advent of so many new polymeric materials. 


\section{REFERENCES}

1. David, S. T. and Augusburger, L. L. Plastic flow during compression of directly compressible fillers and its effects on tablet strength. Journal of Pharmaceutical Sciences, 66:155-159 (1977).

2. Schmidt, P. C. Tableting characteristics of sorbitol. Pharmaceutical Technology, 7 (11):65-72 (1983).

3. Bolhuis, G. K.; Zuurman, K. Tableting properties of experimental and commercially available lactose granulations for direct compression. Drug Development and Industrial Pharmacy, 21 (18): 2057-2071 (1995).

4. Zuurman, K., Riepma, K. A., Bolhuis, G.K., Vromans, H. and Lerk, C.F. The relationship between bulk density and compactibility of lactose granulations. International Journal of Pharmaceutics, 102: 1-9 (1994).

5. Schmidt, P. C. and Vogel, P. J. Force-time curves of a modern rotary tablet machine: II. Influence of compression force and tableting speed on the deformation mechanisms of pharmaceutical substances. Drug Development and Industrial Pharmacy, 19 (15): 1917-1930 (1993).

6. Celik, M. The past, present and future of tableting technology. Drug Development and Industrial Pharmacy, 22 (1): 1-10 (1996).

7. Wong, L. W. and Pilpel, N. The effect of shape of fine particles on the formulation of ordered mixtures. Journal of Pharmacy and Pharmacology, 40: 567-568 (1988).

8. Bolhuis, G. K. and Chowan, Z. T. Materials for direct compaction, In Pharmaceutical Powder Compaction Technology, Alderborn,G. and Nystrom C. (Eds.), Marcel Dekker, Inc., New York, 419-500 (1996). 
9. Paronen, P. and Ilkka, J. Pressure-porosity functions. In Pharmaceutical Powder Compaction Technology, Alderborn,G. and Nystrom C. (Eds.), Marcel Dekker, Inc., New York, 55-75 (1996).

10. Kawakita, K. and Ludde, K. H. Some considerations on powder compression equations. Powder Technology, 4 (2): 61-68 (1971).

11. Rue, J. and Rees, J. E. Limitations of the Heckel relation for predicting powder compaction mechanisms. Journal of Pharmacy and Pharmacology, 30: 642-643 (1978).

12. York, P. A consideration of experimental variables in the analysis of powder compaction behaviour. Journal of Pharmacy and Pharmacology, 31(4): 244-246 (1979).

13. Duberg, M. and Nystrom, C. Studies on direct compression of tablets. VI. Evaluation of methods for the estimation of particle fragmentation during compaction. Acta Pharmaceutica Suec, 19 (6): 421-436 (1982).

14. Schmidt, P. C. and Vogel, P. J. Force-time curves of a modern rotary tablet machine: I. Evaluation techniques and characterization of deformation behavior of pharmaceutical substances. Drug Development and Industrial Pharmacy, 20 (5): 921-934 (1994).

15. Celik, M. and Okutgen, E. Feasibility study for the development of a prospective compaction functionality test and the establishment of a compaction data bank. Drug Development and Industrial Pharmacy, 19 (17-18): 2309-2334 (1993).

16. Shangraw, R. F. and Demarest, D. A. Survey of current industrial practices in the formulation and manufacture of tablets and capsules. Pharmaceutical Technology, 17 (1): 32-44 (1993). 
17. Heckel, R. W. Density-pressure relationships in powder compaction. Trans Metallurgy Society, AIME, 221:671-675 (1961).

18. Scheffe, H. The simplex-centroid design for experiments with mixtures. Journal of Royal Statistical Society, B25: 235-263 (1963).

19. Scheffe, H. Experiments with mixtures. Journal of Royal Statistical Society, B20: 344-360 (1958).

20. Gorman, J. W. and Hinman, J. E. Simplex lattice designs for multicomponent systems. Technometrics, 4: 463-487 (1962).

21. Statgraphics ${ }^{\circledR}$ Plus for Windows, Version 2.0, Manugistics, Inc., Rockville, Maryland, USA.

22. Design-Expert ${ }^{\circledR}$, Version 6.0, Stat-Ease, Inc., MN, USA.

23. Carr, R. L. Classifying flow properties of solids. Chemical Engineering, 72: 69 (1965).

24. Carr, R. L. Evaluating flow properties of solids. Chemical Engineering, 72: 163168 (1965).

25. Johnson, M. C. R. The effect of particle size upon mixture homogeneity. Pharmaceutica Acta Helvetiae, 50 (3): 60-63 (1975).

26. Williams, J. C. and Khan, M. I. The mixing and segregation of particulate solids of different particle size. The Chemical Engineer, January, 19-25 (1973).

27. Chowhan, Z. T. Segregation of particulate solids-Part I. Pharmaceutical Technology, 19: 56-70 (1995). 
28. Chowhan, Z. T. Segregation of particulate solids-Part II Pharmaceutical Technology, 19: 80-94 (1995).

29. Andres, C., Ndiaye, A., Thomas, C., Tromelin, A., Chaillot, B. and Pourcelot, Y. Influence of the parameters molecular structure and granularity on the compactibility of a powder. Drug Development and Industrial Pharmacy, 21(16): 1875-1885 (1995).

30. Pilpel, S. and Esezobo, S. Effects of applied load and particle size on the plastoelasticity and tablet strength of some directly compressible powders. Journal of Pharmacy and Pharmacology, 39: 303 - 304 (1987).

31. Katikaneni, P. R., Upadrashta, S. M., Rowlings, C. E., Neau, S. H. and Hileman G. A. Consolidation of ethylcellulose: effect of particle size, press speed, and lubricants. International Journal of Pharmaceutics, 117: 13-21 (1995).

32. Amidon, G. E and Houghton, M. E. The effect of moisture on the mechanical and powder flow properties of microcrystalline cellulose. Pharmaceutical Research, 12: $923-929$ (1995).

33. Shotton, E. J. and Harb, N. The effect of humidity and temperature on the cohesion of powders. Journal of Pharmacy and Pharmacology, 18: 175-178 (1966).

34. Nokhodchi, A., Rubinstein, M. H., Larhrib, H. and Guyot, J. C. The effect of moisture content on the energies involved in the compaction of ibuprofen International Journal of Pharmaceutics, 120: 13-20 (1995).

35. Armstrong, N. A. Considerations of compression speed in tablet manufacture. Pharmaceutical Technology, 14 (9): 106-116 (1990). 
36. Armstrong, N. A. and Palfrey, L. P. The effect of machine speed on the consolidation of four directly compressible tablet diluents. Journal of Pharmacy and Pharmacology, 41: 149 - 151 (1989).

37. Delacourte, A., Guyot, J. C., Colombo, P. and Catellani, P. L. Effectiveness of lubricants and lubrication mechanism in tablet technology. Drug Development and Industrial Pharmacy, 21 (19): $2187-2199$ (1995).

38. Johansson, M. E. Investigations of mixing time dependence of the lubricating properties of granular and powdered magnesium stearate. Acta Pharmaceutica Suec 22: 343-350 (1985).

39. Ragnarsson, G., Holzer, A. W., and Sjogren, J. The influence of mixing time and colloidal silica on the lubricating properties of magnesium stearate. International Journal of Pharmaceutics. 3: 127-131 (1979).

40. Khan, K. A., Musikabhumma, P. and Rubinstein, M. H. The effect of mixing time of magnesium stearate on the tabletting properties of dried microcrystalline cellulose. Pharmaceutica Acta Helvetiae, 58: 109-111 (1983).

41. Rizk, S., Guyot, J.C., Duru, C. and Gaudy, D. Influence of lubricant properties on compression behavior and drug dissolution rate of scleroglucan hydrophilic matrix. International Journal of Pharmaceutics, 126: 57-63(1995).

42. Velasco, V., Munoz-Ruiz, A., Mondero, C. and Jimenez-Castellanos, R. Forcedisplacement parameters of maltodextrins after the addition of lubricants International Journal of Pharmaceutics, 152: 111-120 (1997).

43. Garcia, T., Elsheimer, B., Tarczynski, F. Examination of components of variance for a production scale, low dose powder blend and resulting tablets. Drug Development and Industrial Pharmacy, 21 (18): 2035-2045 (1995). 
44. Jetzer, W., Leuenberger, and Sucker, H. Compressibility and compactability of powder mixtures. Pharmaceutical Technology 7(11): 33-48 (1983).

45. York, P. and Pilpel, N. The tensile strength and compression behavior of lactose, four fatty acids, and their mixtures in relation to tableting. Journal of Pharmacy and Pharmacology, 25 (Supplement):1P-11P (1973).

46. Karehill, P.G., Glazer, M. and Nystrom C. Studies on direct compression of tablets. XXXIII. The importance of surface roughness for the compactibility of some directly compressible materials with different bonding and volume reduction properties. International Journal of Pharmaceutics, 64: 35-43 (1990).

47. Hersey, J. A., Rees, J. E. and Cole, E. T. Density changes in lactose tablets. Journal of Pharmaceutical Sciences, 62: 2060 (1973).

48. Asano, T., Tsubuku, S., Sugawara, S., Miyajima, M., Sato, H., Yuasa, H. and Kanaya, Y. Changes in volume and compression energy upon compression of calcium silicate tablets. Drug Development and Industrial Pharmacy, 23 (7): 679685 (1997).

49. Juppo, A. M., Kervinen, L., Yliruusi, J. and Eristofferson, E. Compression of lactose, glucose, and mannitol granules. Journal of Pharmacy and Pharmacology, 47: 543-549 (1995).

50. Bodmeier, R. Tableting of coated pellets. European Journal of Pharmaceutics and Biopharmaceutics, 43: 1-8 (1997).

51. Torrado, J. J. and Augsburger, L. L. Effect of different excipients on the tableting of coated particles. International Journal of Pharmaceutics, 106: 149-155 (1994). 
52. Ferrari, F., Bertoni, M., Bonferoni, M. C., Rossi, S., Caramella, C. and Nystrom, C. Investigation on bonding and disintegration properties of pharmaceutical materials. International Journal of Pharmaceutics 136: 71 - 79 (1996).

53. Luangtana-Anan, M. and Fell, J. T. Bonding mechanisms in tableting. International Journal of Pharmaceutics, 60: 197-202 (1990).

54. Hiestand, E. N. Powders: Particle-particle interactions. Journal of Pharmaceutical Sciences, 55 (12):1325-1344 (1966).

55. Pilpel, N.; Igwilo, C. I. and Malamataris, S. Effects of molecular coatings on the compression and tableting of some pharmaceutical powders. International Journal of Pharmaceutics, 68: 157-166 (1991).

56. Konkel, P. and Mielck, J. B. A compaction study of directly compressible vitamin preparations for the development of a chewable tablet: Part I" Pharmaceutical Technology. 16 (3): 138-146 (1992).

57. Doldan, C., Souto, C., Concheiro, A., Martinez-Pacheco, R. and Gomez-Amoza, J. L. Dicalcium phosphate dihydrate and anhydrous dicalcium phosphate for direct compression: A comparative study. International Journal of Pharmaceutics, 124: 69-74(1995).

58. Hsu, S. H.; Tsai, T. R.; Chuo, W. H. and Cham, T. M. Evaluation of Era-tab as a direct compression excipient. Drug Development and Industrial Pharmacy, 23 (7): $711-716$ (1997).

59. Udeala, O. K., Chukwu, A."Compaction behavior of Musol: A new direct compression vehicle. Drug Development and Industrial Pharmacy, 15 (4): 533 548 (1989). 
60. Zuurman, K., Riepma, K.A.; Bolhuis, G.K., Vromans, H. and Lerk, C. F. The relationship between bulk density and compactibilty of lactose granulations. International Journal of Pharmaceutics, 102: 1-9 (1994).

61. Wikberg, M. and Alderborn, G. Compression characteristics of granulated materials. III. The relationship between air permeability and mechanical strength of tablets of some lactose granulations. International Journal of Pharmaceutics, 63: 23-27 (1990). 
MANUSCRIPT III

\section{EFFECT OF FORMULATION COMPONENTS AND MANUFACTURING PROCESS ON THE ELECTROSTATIC BEHAVIOR OF PHARMACEUTICAL POWDERS}




\begin{abstract}
The unit processes involved in preparation of pharmaceutical solid dosage forms include sieving, milling, mixing and compression. All these processes involve use of large amounts of shear forces and may result in generation of electrostatic charges on the powders. In turn the induced charges on the powders may adversely affect powder flow and packing behavior, fill uniformity, dose uniformity and drug-carrier particle separation on actuation. The mechanism of development of electrical charges on powders and their behavior is complex and remains largely unexplored. The current study is designed to investigate the significance of static charges generated on pharmaceutical powders during the processing of solid dosage forms. The objectives of this study are to determine the effect of formulation components (lubricants/glidants) and process parameters (mixing time, mixer type and batch size) on the electrostatic charges generated during the blending of pharmaceutical materials. The effect of high shear mixing on the electrical properties of pharmaceutical materials including pregelatinized starch (Starch 1500), microcrystalline cellulose (Avicel ${ }^{\circledR}$ PH101) and a cimetidine containing formulation was determined. Various lubricants/glidants such as magnesium stearate, stearic acid, colloidal silicon dioxide (Cab-O-Sil M5) and sodium stearyl fumarate $\left(\right.$ Pruv $\left.{ }^{\circledR}\right)$ were evaluated on triboelectrification of electronegative and electropositive materials. When evaluated individually, cimetidine displayed electropositive charge whereas all the other excipients displayed electronegative charges. Cab-O-Sil M5 was found to be the most electronegative whereas stearic acid was found to be the least electronegative among the excipients examined. Based on the results obtained in this study, when Starch
\end{abstract}


1500 was blended with $1 \%$ lubricant/glidant in a Collette Gral 10 High Shear Mixer, the lubricants/glidants can be arranged as follows in decreasing order of their ability to reduce the static charges produced during the blending process: magnesium stearate $>$ Pruv $^{\circledR}>$ stearic acid $>$ Cab-O-Sil M5. For Avicel ${ }^{\circledR}$ PH101 blends, the antistatic effect of the same agents can be arranged in decreasing order as: magnesium stearate > stearic acid $>$ Pruv $^{\circledR}>$ Cab-O-Sil M5. The antistatic effect was reduced when the mixing time with lubricants increased from 1 minute to 3 minutes. The antistatic effect of lubricants/glidants was dependent on the electrical charge behavior of the materials studied. The mixer design and type played an important role in determining the electrostatic charges of powder blends in pharmaceutical processing. Powders blended in Colletie Gral 10 High Shaar Mixer produced more electrostatic charges as compared to those blended in a Kitchen Aid Planetary Mixer. The triboelectrification of the blend in a high shear mixer decreased with an increase in the batch size from 0.5 $\mathrm{kg}$ to $2.5 \mathrm{~kg}$.

Key words: triboelectrification; electrical charge; pharmaceutical powder; high shear mixing; lubricant; glidant; antistatic effect; microcrystalline cellulose; pregelatinized starch; cimetidine; magnesium stearate; stearic acid; colloidal silicon dioxide; sodium stearyl fumarate. 


\section{INTRODUCTION}

Pharmaceutical powders tend to acquire electrical charges during processing operations such as milling, mixing, micronization, sieving, compaction, spray drying and congealing, coating, transfer of material from one place to another and packaging (1). The induced charges on powders may cause problems with the efficient operation of processing equipment, uniform mixing of formulation components, flowability of powder blends in high speed machines, drug content uniformity, and accurate delivery of powders from drug delivery systems, fire hazards, and explosion hazards and may affect the quality of dosage forms. Although the accumulation of electrical charge on solid and solid-liquid systems is one of the earliest physical phenomena known, the significance of these electrical charges on powders in pharmaceutical processing remains largely unexplored (2-3). Drug substances and pharmaceutical excipients can be classified as electropositive, electronegative or neutral depending on the charge behavior on powder particles. Table 1 provides the examples of commonly used pharmaceutical materials and their electrical behavior.

'Static electrification' by definition includes all processes that produce segregation of positive and negative electrical charges by mechanical actions operating through contact, impact, or friction between two surfaces, or by rupture or by separation of solid and liquid surfaces (1-3). 'Static charge' results from contact of 'true surfaces' and not from friction. Such a net static charge may be electropositive or electronegative and is derived from a complex bipolar system. 
Table 1. Electrical Behavior of Selected Pharmaceutical Excipients

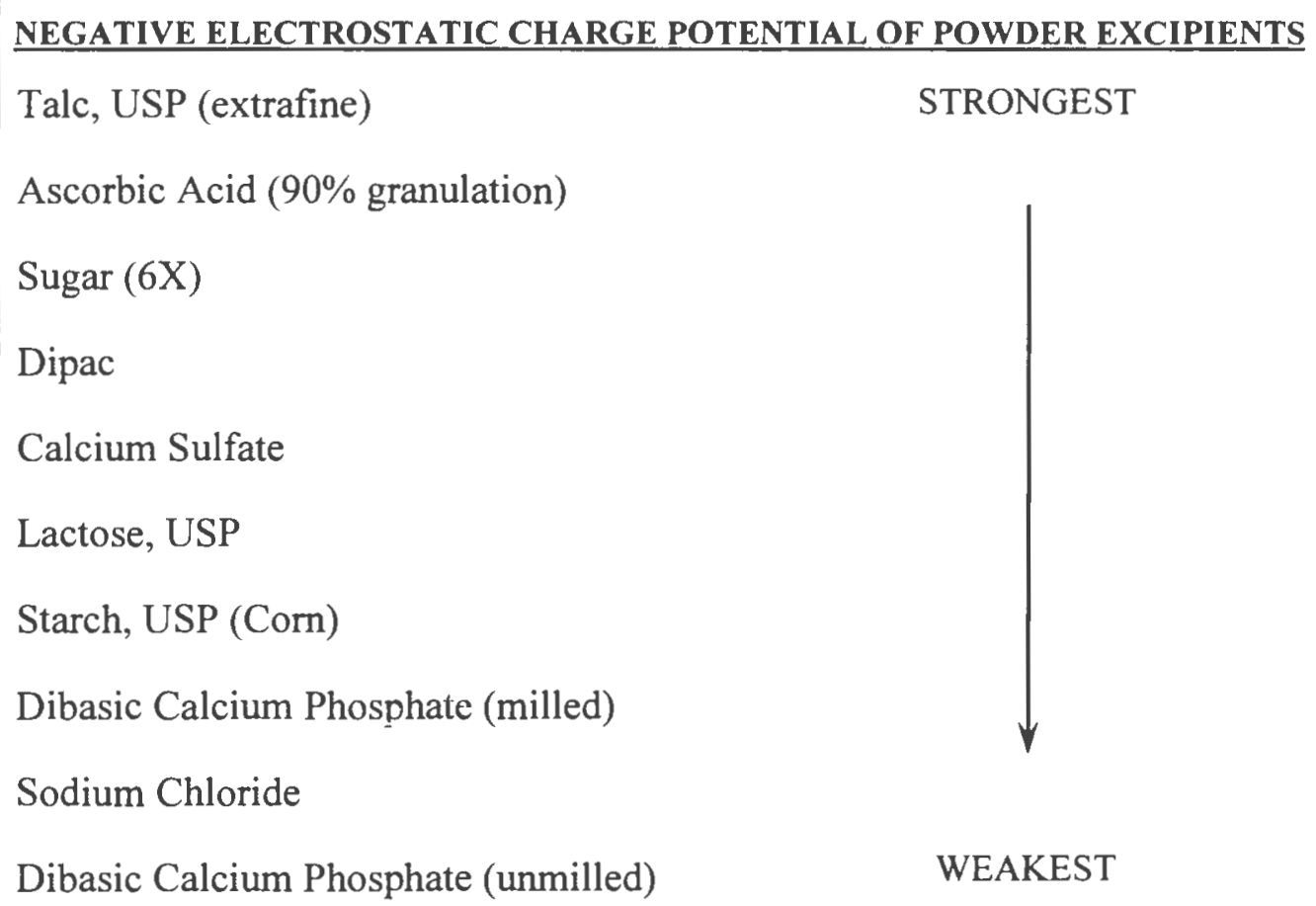


The transfer of charge that takes place when two materials collide or are rubbed together is called triboelectrification (2). Triboelectrification is similar to, though not the same as, contact electrification, which occurs when two materials are brought together and then separated, resulting in a transfer of charge between the two materials. Triboelectrification is a more complicated form of contact electrification in which there is also transverse motion. Triboelectrification causes a transfer of charge leading to a buildup of static charge. Static electricity is the result and triboelectrification is the cause. There are two approaches that can be used for quantifying and measuring triboelectric phenomena. The first approach is to measure the results of static accumulation i.e. the buildup of charge due to many charge transfers on powder particles. The majority of the research into this phenomenon has been performed using this approach. The second approach is to measure the charge transfer directly as it takes place (4-5). The advantage of second approach is that it is more accurate and can be used as a tool to monitor the flow of solids during material transfer.

In pharmaceutical operations, the triboelectrification or contact charging is influenced by several factors such as particle size and shape, and the electrical properties of the formulation components, surface properties of particles, nature of the last contact surface, contact area and frequency, surface purity, and atmospheric conditions (6-9). Triboelectrification remains a challenge, as some materials are sensitive to electrostatic charging at atmospheric conditions, while other materials are not. Also, triboelectrification can be completely characterized only if the true area of contact is known (1). The true area of contact depends on the surface roughness as 
well as contact pressure. The process of triboelectrification is a complex phenomenon and is not yet fully understood in pharmaceutical processing. Most pharmaceutical powders are organic crystals, which behave as insulators under ambient conditions. These systems are complex and less well defined when compared to conductors and however, similar theoretical considerations can be extrapolated to explain the electrostatic behavior of pharmaceutical systems (10). The work function of a substance is defined as the difference in the energy state between the outermost electrons or Fermi level, and a reference source. When two dissimilar substances come into contact, transfer of electrons occurs as to equalize the Fermi level energies. A contact potential or electrostatic charge is produced, and this is the difference between the work functions. It is this adhesion energy, with electric force contributions from London- Van der Waals and surface tension interactions, as well as Coulomb interactions, which must be overcome in order to allow free movement of powder particles.

During dry powder handling operations, particles make frequent contact with different surfaces, such as surface of other particles, metallic surfaces of the handling equipment and surfaces of the processing equipment (1). The process of contact electrification thus charges the powder particles with either positive or negative charge. The dynamic behavior of charged particles depends largely on the charges present on the powder particles. On contact with surfaces in the neighborhood, charged particles adhere by a combination of electrostatic and Van der Waal forces. Once a particle is charged during handling, the charge is transferred at the particle contact point and will redistribute itself over the surface electrostatic forces. The rate 
at which this redistribution proceeds depends upon the electrical relaxation time of the particle material. Charged particles set up electrostatic fields, which influence particle trajectories and powder dynamics. Such charged particles are subject to extreme attractive forces and may adhere strongly to surfaces. This powder adhesion can be very problematic in processing and cleaning operations. The practical significance of electrostatic charge measurements is more critical for aerosol formulations intended for nasal and inhalation dosage forms. The charges on the powders affect powder flow and packing behavior, fill uniformity, dose uniformity and drug-carrier particle separation on actuation. Addition of antistatic agents is one approach that can be used to overcome these problems in the pharmaceutical industry. Another approach is selection of each excipient in the formulation based on the electrical properties of individual components so that final formulation can display neutral charge during processing.

Although it has been recognized that triboelectrification can be a serious problem in handling of pharmaceutical powders, only a few reports have been published so far. The significance of electrostatic charges in pharmaceutical formulation development and process development remains largely unexplored. The purpose of this investigation was to enhance the understanding of triboelectrification process during blending of pharmaceutical materials for solid dosage forms. The objectives of this study were: 1) to evaluate the electrostatic nature of various pharmaceutical powders, 2) to determine the mixing time effect on triboelectrification process in a high shear mixer, 3) to understand the effect of mixer type and batch size 
on static charging of pharmaceutical materials and 4) to compare the antistatic effect of different lubricants/glidants on electronegative and electropositive materials. 


\section{METHODOLOGY}

Materials: The materials used in this study were cimetidine, USP (Agvar Chemicals, USA), microcrystalline cellulose, NF (Avicel ${ }^{\circledR}$ PH101) (FMC Inc., USA), pregelatinized starch, NF (Starch 1500) (Colorcon Inc., USA), anhydrous lactose, NF (Sheffield Products, USA), magnesium stearate, NF (Mallinckrodt Co., USA), sodium stearyl fumarate, NF (Pruv ${ }^{\circledR}$ ) (Mendell, USA), stearic acid, NF (Witco Corp., USA) and colloidal silicon dioxide, NF (Cab-O-Sil M5) (Cabot Corp., USA).

The equipment used includes Collette Grallo High Shear Mixer (Collette, USA), Kitchen Aid Planetary Mixer (Kitchen Aid, USA) and Faraday Cup connected to NanoCoulomb Meter (Monroe Electronics, USA).

\section{Methods}

Preparation of Powder Blends: Selected pharmaceutical materials namely, microcrystalline cellulose (Avicel ${ }^{\circledR} \mathrm{PH101}$ ), pregelatinized starch (Starch 1500) and a cimetidine formulation containing active, Avicel ${ }^{\circledR}$ PH101, Starch 1500 and anhydrous lactose in the ratio of 69:10:10:10 were evaluated for electrostatic behavior during blending process in a high shear mixer. Lubricants/glidants such as magnesium stearate, sodium stearyl fumarate, NF (Pruv $\left.{ }^{\circledR}\right)$, stearic acid, and colloidal silicon dioxide, NF (Cab-O-Sil M5) were added to the pre-blends to evaluate their antistatic effect. The selected material(s) were screened through a 30-mesh hand screen and were mixed in a Collette Gral 10 High Shear Mixer for 10 minutes at a mixer arm speed of $660 \mathrm{rpm}$ and a chopper speed of $3000 \mathrm{rpm}$. Lubricant/glidant at $1 \% \mathrm{w} / \mathrm{w}$ level was added to the pre-blend and the mixing was continued for an additional 3 
minutes. The batch size of $0.5 \mathrm{~kg}$ was used for all the experiments in order to evaluate the antistatic effect of various lubricants/glidants. The electrostatic charges on powder blends were measured after $0,5,10,11,12$ and 13 minutes of mixing.

Mixer load will also affect the blending efficiency during preparation of powder mixtures. In order to determine the effect of batch size on electrostatic charging of powders in a high shear mixer, Starch 1500 at batch sizes of $0.5 \mathrm{~kg}$ and 2.5 $\mathrm{kg}$ was blended in a Collette Gral 10 High Shear Mixer. The charge developed on powder was monitored after $0,5,10,15$ and 20 minutes of mixing.

In a blending operation, mixing efficiency is dependent on the design and type of mixing vessel used for processing. In order to determine the effect of mixer type on triboelectric charging, Starch 1500 was blended in a Collette Gral 10 High Shear Mixer (capacity - 7 liters) and in a Kitchen Aid Planetary Mixer (capacity- 2.5 liters) keeping the batch size constant $(0.5 \mathrm{~kg})$. The charge developed on powder was monitored after $0,5,10,15$ and 20 minutes of mixing.

Measurement of Electrostatic Charges: Electrostatic charges on powder particles were measured using the Faraday Cup connected to an electrometer (11). The experimental set up is shown in Figure 1. The Faraday Cup consists of 6-inch can inserted in another can and the two cans were insulated from one another with a teflon block. The inner can which is a static charge detector was connected to an electrometer, NanoCoulomb Electrometer (Model:253, Monroe Electronics, Inc., USA) via a coaxial cable. The electrometer is capable of measuring charges in the range of $2 \times 10^{-12}-2 \times 10^{-7}$ Coulombs. At predetermined intervals, the powder samples 
were taken using a stainless steel scoop from the mixer and a teflon coated stainless steel spoon was used to pour sample into the Faraday Cup. Sufficient sample was poured into the Faraday Cup such that the bottom surface of the Cup is covered with the powder. The total charge (C) present on powder particles following a constant flow from a teflon coated stainless steel spoon into Faraday Cup was measured on the electrometer. The mean charge per mass of powder was calculated from six replicate measurements. The mean specific charge values were presented as nanoCoulombs/g or $\mathrm{nC} / \mathrm{g}\left(10^{-9} \mathrm{C} / \mathrm{g}\right)$. The same procedure was followed for all powder samples collected at different experimental conditions. The last contact surface for samples used for electrostatic measurements from all blends and individual components was kept the same as teflon coated stainless steel surface. All the measurements were taken in a controlled environment with a relative humidity of $30-35 \%$ and temperature of $20-23^{\circ} \mathrm{C}$. 


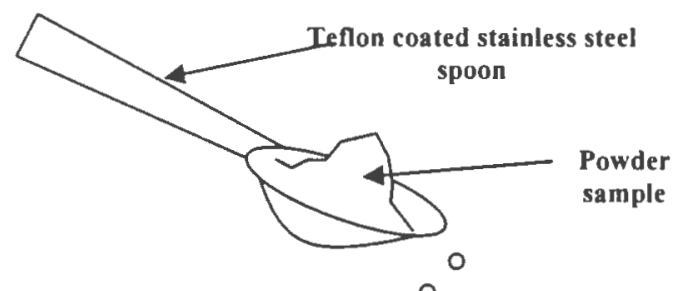

0

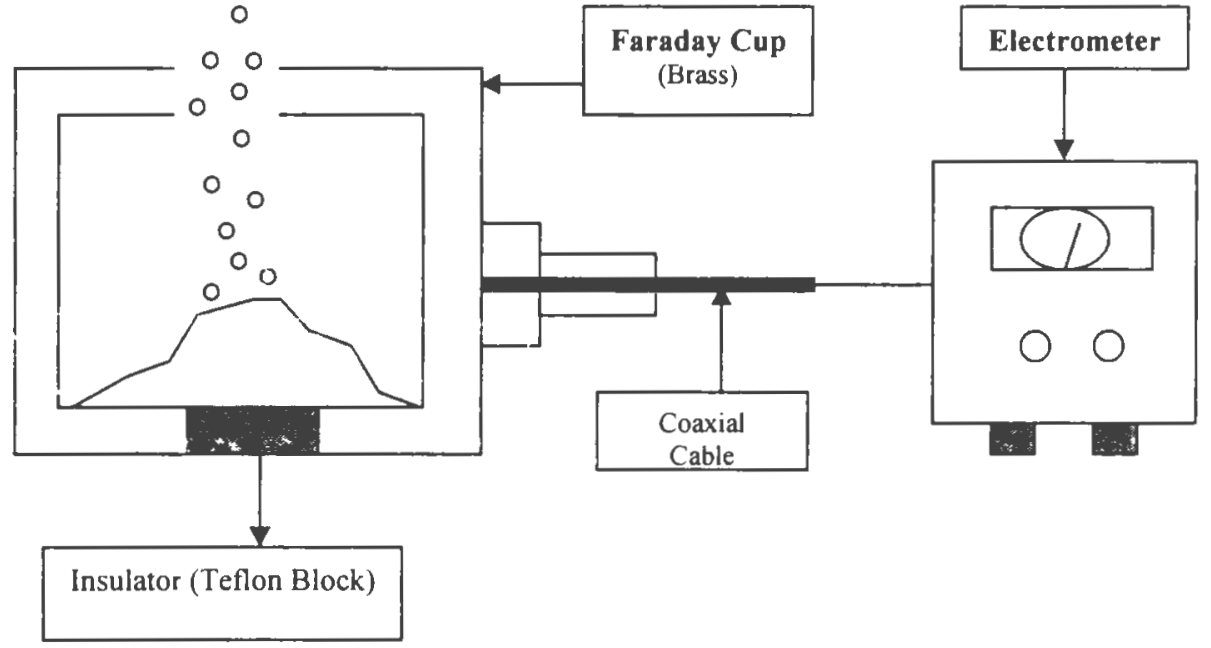

Figure 1. Experimental Set-Up for Measurement of Electrostatic Charges on Pharmaceutical Powders 


\section{RESULTS AND DISCUSSION}

Typical processing of pharmaceutical dosage forms involves different stages such as sieving, milling, mixing, and transfer of powder blend from hopper to the die, and compaction (3). All these stages involve close interaction of particles of various formulation components along with those of active material(s). Since triboelectrification is a surface contact phenomenon and pharmaceutical powders tend to acquire electrical charges during various stages involved in the preparation of dosage forms, electrostatic forces associated with dry powders have been identified as playing a significant role in cohesion/adhesion (12-14). The accumulated static charge on the surface of powder particles contributes to 'demixing'. This may cause flow and segregation problems which are detrimental to the content uniformity of the formulation as well as deteriorates powder flow and compaction properties. The induced charge on powders also causes problems in the efficient operation of processing equipment, flowability of powder blends from hopper to die table in high speed machines and affects the quality of dosage forms.

In order to investigate the effect of triboelectrification during the mixing process of pharmaceutical materials, the commonly used excipients: microcrystalline cellulose (Avicel ${ }^{\circledast}$ PH101) - filler/diluent, pregelatinized starch (Starch 1500) disintegrant, and a cimetidine tablet formulation containing active, Avicel ${ }^{\circledR}$ PH101, Starch 1500 , lactose anhydrous and lubricant/glidant were evaluated using a high shear mixer.

The individual components used in the study were evaluated for electrical properties using a Faraday Cup connected to an electrometer and the results are 
summarized in Table 2. The specific charge $(\mathrm{nC} / \mathrm{g})$ was calculated for each material and the results represent the mean and standard deviation of six replicate readings. Table 2 shows that different charging tendencies exist for different materials. The data indicates that all the excipients evaluated in this study displayed negative charges except the drug substance, cimetidine, USP which showed a positive charge. Among the excipients studied, Cab-O-Sil M5 displayed the highest electronegative charge ($53.488 \mathrm{nC} / \mathrm{g}$ ) as compared to stearic acid, which showed the least amount of electronegative charge $(-0.115 \mathrm{nC} / \mathrm{g})$. 
Table 2. Electrostatic Properties of Individual Pharmaceutical Materials

\begin{tabular}{|c|c|c|c|}
\hline \multirow[b]{2}{*}{ MATERIAL } & \multicolumn{3}{|c|}{ MEAN (SD), n=6 } \\
\hline & $\begin{array}{c}\text { Charge } \\
\text { (nC) }\end{array}$ & $\begin{array}{c}\text { Sample Weight } \\
\text { (g) }\end{array}$ & $\begin{array}{c}\text { Specific Charge } \\
(\mathrm{nC} / \mathrm{g})\end{array}$ \\
\hline Cimetidine, USP & $+0.80(0.24)$ & $0.571(0.076)$ & $+1.379(0.250)$ \\
\hline $\begin{array}{l}\text { Microcrystalline } \\
\text { Cellulose, NF (Avicel }{ }^{\circledast} \\
\text { PH 101) }\end{array}$ & $-0.58(0.11)$ & $0.448(0.045)$ & $-1.305(0.300)$ \\
\hline $\begin{array}{l}\text { Pregelatinized Starch, NF } \\
\left(\text { Starch }^{\circledR} 1500\right)\end{array}$ & $-0.45(0.19)$ & $0.824(0.119)$ & $-0.550(0.224)$ \\
\hline Lactose Anhydrous, NF & $-0.65(0.08)$ & $0.507(0.059)$ & $-1.293(0.134)$ \\
\hline Magnesium Stearate, NF & $-0.26(0.02)$ & $0.397(0.020)$ & $-0.649(0.068)$ \\
\hline Stearic Acid, NF & $-0.14(0.02)$ & $1.216(0.252)$ & $-0.115(0.013)$ \\
\hline $\begin{array}{l}\text { Sodium Stearyl Fumarate, } \\
\left.\text { NF (Pruv }{ }^{\circledR}\right)\end{array}$ & $-0.20(0.07)$ & $0.384(0.059)$ & $-0.537(0.201)$ \\
\hline $\begin{array}{l}\text { Colloidal Silicon Dioxide, } \\
\text { NF }\left(\text { Cab-O-Sil M5 }{ }^{\circledR}\right)\end{array}$ & $-7.69(0.52)$ & $0.144(0.007)$ & $-53.488(4.038)$ \\
\hline
\end{tabular}




\section{Effect of Lubricants/Glidants on Triboelectrification of Starch 1500:}

Figures 2, 3, 4, and 5 and Table 3 demonstrate the effect of mixing time and addition of lubricant/glidant on triboelectrification of Starch 1500 in a Collette Gral 10 High Shear Mixer. Magnesium stearate, sodium stearyl fumarate (Pruv ${ }^{\circledR}$ ), stearic acid, and colloidal silicon dioxide (Cab-O-Sil M5) were evaluated for their antistatic effect on triboelectrification of Starch 1500. As shown in Figure 2, the electronegative charge on Starch 1500 increased with mixing time for up to 10 minutes and when $1 \%$ w/w magnesium stearate was added, the charge on Starch 1500 powder was converted from electronegative to electropositive. After one minute of mixing with magnesium stearate, the charge on powder particles was converted from $-0.807 \mathrm{nC} / \mathrm{g}$ to +0.575 $\mathrm{nC} / \mathrm{g}$ (Table 3). A net charge of $+0.498 \mathrm{nC} / \mathrm{g}$ and $-0.057 \mathrm{nC} / \mathrm{g}$ was found on the powder blend after 2 minutes and 3 minutes of lubricant mixing respectively. As the data indicates in Figure 2 and Table 3, the addition of magnesium stearate neutralized the negative charges present on Starch 1500 particles after one minute of lubricant mixing. When the mixing was continued further, the positive charge on powder blend was reduced and eventually a negative charge was developed again. This reduction in charge may be due to demixing of powder blend (15-17). Thus use of one minute of lubricant mixing time is recommended for magnesium stearate as the antistatic effect was observed to be optimum.

As demonstrated in Figure 3 and Table 3, when 1\% w/w Pruv ${ }^{\circledR}$ was added to Starch 1500 after 10 minutes of pre-blend mixing, the electronegative charge present on powder particles was converted to electropositive. After one minute of mixing with Pruv $^{\circledR}$, the charge on powder particles was reduced from $-1.422 \mathrm{nC} / \mathrm{g}$ to $-0.561 \mathrm{nC} / \mathrm{g}$. 
Table 3. Effect of Lubricant/Glidant on Triboelectrification of Starch 1500

\begin{tabular}{|c|c|c|c|c|}
\hline CUMULATIVE & \multicolumn{4}{|c|}{ SPECIFIC CHARGE (nC/g) } \\
\hline $\begin{array}{c}\text { MIXING TIME } \\
\text { (min.) }\end{array}$ & $\begin{array}{c}\text { MEAN (SD) } \\
n=6\end{array}$ & $\begin{array}{c}\text { MEAN (SD) } \\
n=6\end{array}$ & $\begin{array}{c}\text { MEAN (SD) } \\
n=6\end{array}$ & $\begin{array}{c}\text { MEAN (SD) } \\
n=6\end{array}$ \\
\hline 0 & $\begin{array}{l}-0.245 \\
(0.031)\end{array}$ & $\begin{array}{c}-0.82 \\
(0.092)\end{array}$ & $\begin{array}{l}-0.515 \\
(0.088)\end{array}$ & $\begin{array}{l}-0.198 \\
(0.039)\end{array}$ \\
\hline 5 & $\begin{array}{l}-0.666 \\
(0.093)\end{array}$ & $\begin{array}{l}-0.974 \\
(0.100)\end{array}$ & $\begin{array}{l}-0.816 \\
(0.084)\end{array}$ & $\begin{array}{l}-0.284 \\
(0.059)\end{array}$ \\
\hline 10 & $\begin{array}{l}-0.807 \\
(0.070)\end{array}$ & $\begin{array}{l}-1.422 \\
(0.202)\end{array}$ & $\begin{array}{l}-0.930 \\
(0.185)\end{array}$ & $\begin{array}{c}-0.32 \\
(0.039)\end{array}$ \\
\hline $\begin{array}{c}\text { Addition of } 1 \% \\
\text { Lubricant } \\
\text { Glidant }\end{array}$ & $\begin{array}{c}\text { Addition of } 1 \% \\
\text { Magnesium } \\
\text { Stearate, NF }\end{array}$ & $\begin{array}{c}\text { Addition of } \\
1 \% \text { Pruv }\end{array}$ & $\begin{array}{l}\text { Addition of } 1 \% \\
\text { Stearic Acid, NF }\end{array}$ & $\begin{array}{c}\text { Addition of } \\
1 \% \text { Cab-O-Sil } \\
\text { M5 }\end{array}$ \\
\hline 11 & $\begin{array}{l}+0.575 \\
(0.103)\end{array}$ & $\begin{array}{l}-0.561 \\
(0.077)\end{array}$ & $\begin{array}{l}-0.319 \\
(0.045)\end{array}$ & $\begin{array}{l}-2.093 \\
(0.247)\end{array}$ \\
\hline 12 & $\begin{array}{l}+0.498 \\
(0.110)\end{array}$ & $\begin{array}{l}+0.096 \\
(0.030)\end{array}$ & $\begin{array}{l}-0.218 \\
(0.032)\end{array}$ & $\begin{array}{l}-1.732 \\
(0.115)\end{array}$ \\
\hline 13 & $\begin{array}{l}-0.057 \\
(0.124)\end{array}$ & $\begin{array}{l}-0.278 \\
(0.043)\end{array}$ & $\begin{array}{l}-0.131 \\
(0.020)\end{array}$ & $\begin{array}{l}-1.729 \\
(0.236)\end{array}$ \\
\hline
\end{tabular}




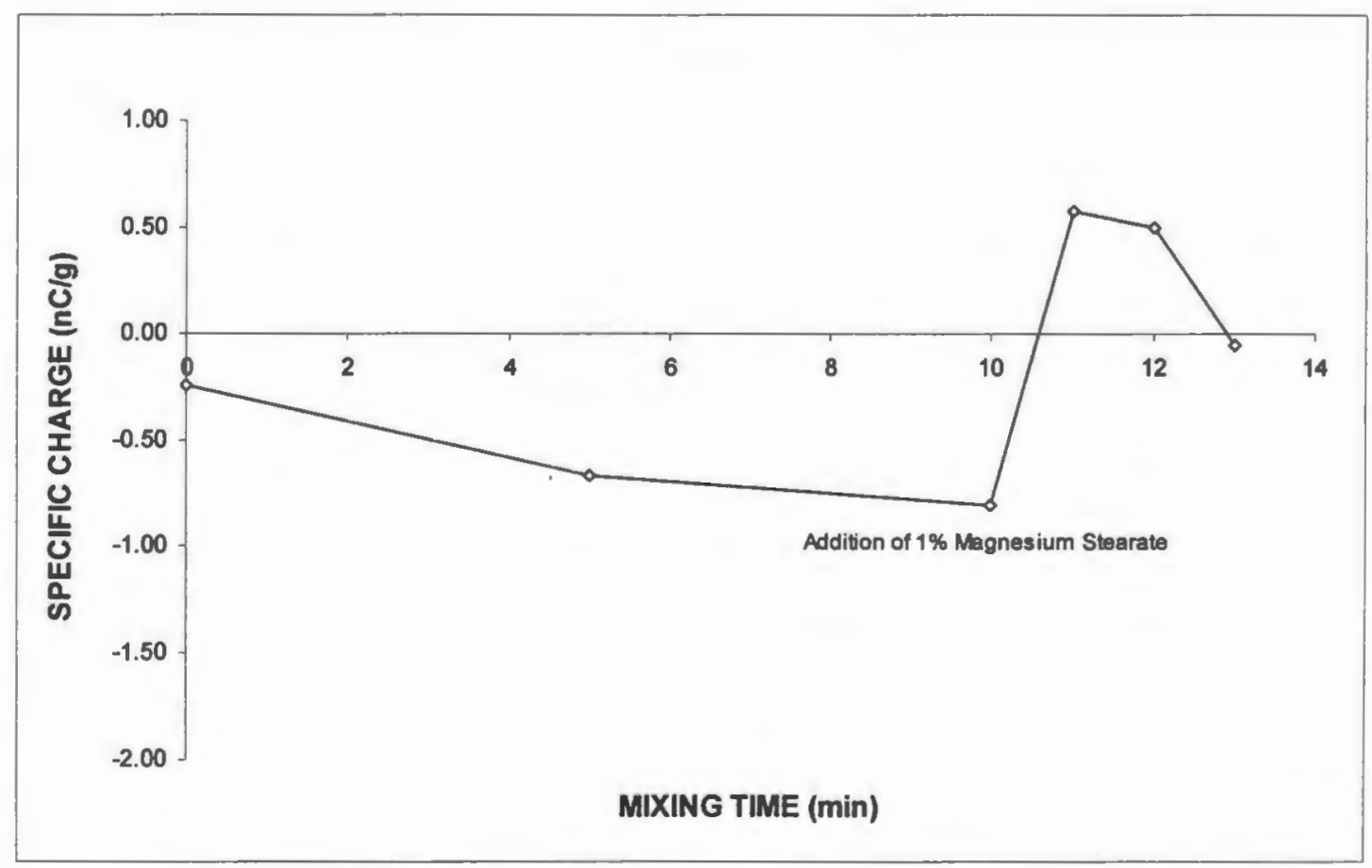

Figure 2. Effect of Magnesium Stearate on Triboelectrification of Starch 1500 in Collette Gral 10 High Shear Mixer 


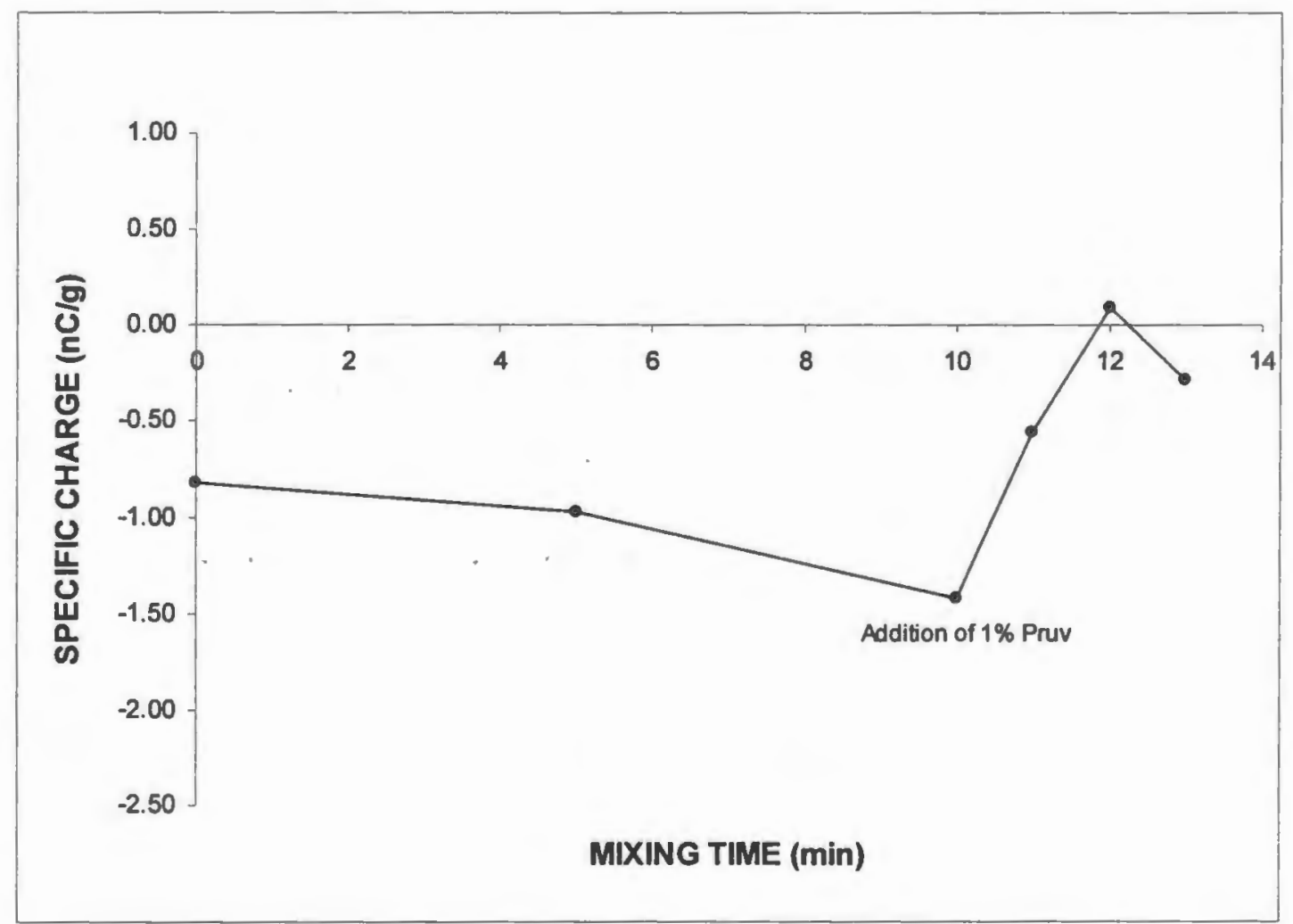

Figure 3. Effect of Pruv on Triboelectrification of Starch 1500 in Collette Gral 10 High Shear Mixer 
The negative charge was further neutralized to $+0.096 \mathrm{nC} / \mathrm{g}$ after 2 minutes of lubricant mixing. The positive charge was converted to negative $(-0.278 \mathrm{nC} / \mathrm{g})$ after 3 minutes of lubricant mixing. Thus, addition of Pruv seems to reduce the negative charges generated on Starch 1500 due to high shear mixing and the optimum effect was observed after two minutes of lubricant mixing. When the mixing was continued further, there was a re-development of electronegative charge on powder particles probably due to demixing of the blend after 3 minutes of lubricant mixing. Lubricants have a tendency to cause demixing with prolonged mixing times. (15-17).

In Figure 4 and Table 3, the charges generated on Starch 1500 due to high shear mixing and the effect of stearic acid on these triboelectric charges was shown. When $1 \% \mathrm{w} / \mathrm{w}$ of stearic acid was added after 10 minutes of mixing in high shear mixer, the negative charge present on Starch 1500 powder was reduced from -0.930 $\mathrm{nC} / \mathrm{g}$ to $-0.319 \mathrm{nC} / \mathrm{g}$ after 1 minute of lubricant mixing. When the mixing was continued for two additional minutes, the negative charge on powder particles was further reduced to $-0.131 \mathrm{nC} / \mathrm{g}$. Thus, addition of stearic acid decreased the electronegative charges generated on Starch 1500 during high shear mixing and the reduction in negative charge increased with lubricant mixing time.

Figure 5 and Table 3 display the effect of Cab-O-Sil M5 on the triboelectrification process. When $1 \% \mathrm{w} / \mathrm{w}$ of $\mathrm{Cab}-\mathrm{O}-\mathrm{Sil} \mathrm{M} 5$ was added to Starch 1500 after 10 minutes of high shear mixing, the negative charges present on the particles were increased from $-0.327 \mathrm{nC} / \mathrm{g}$ to $-2.093 \mathrm{nC} / \mathrm{g}$ after one minute of glidant mixing. The negative charges were reduced slightly when the mixing was continued further for two additional minutes. 


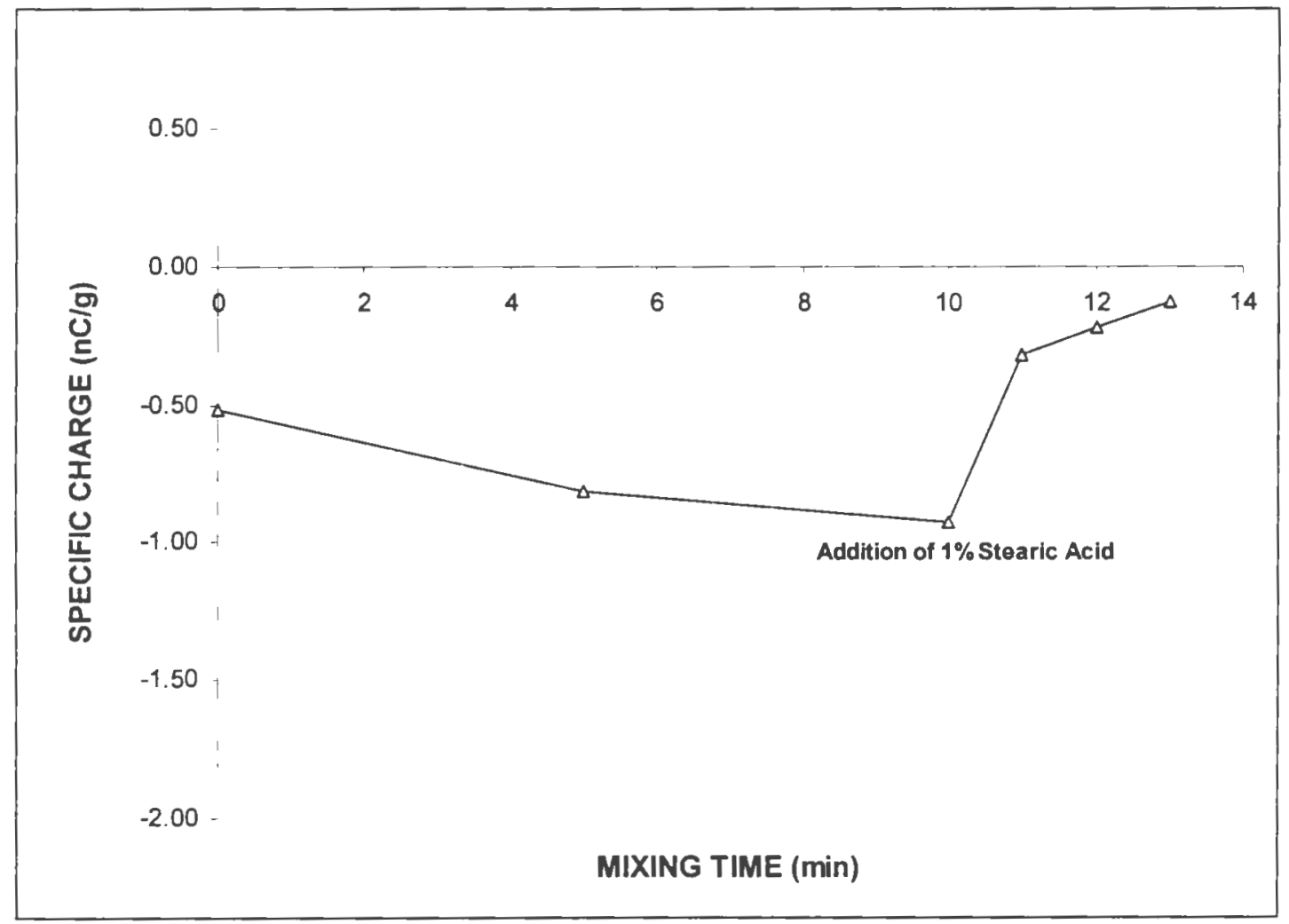

Figure 4. Effect of Stearic Acid on Triboelectrification of Starch 1500 in Collette Gral 10 High Shear Mixer 


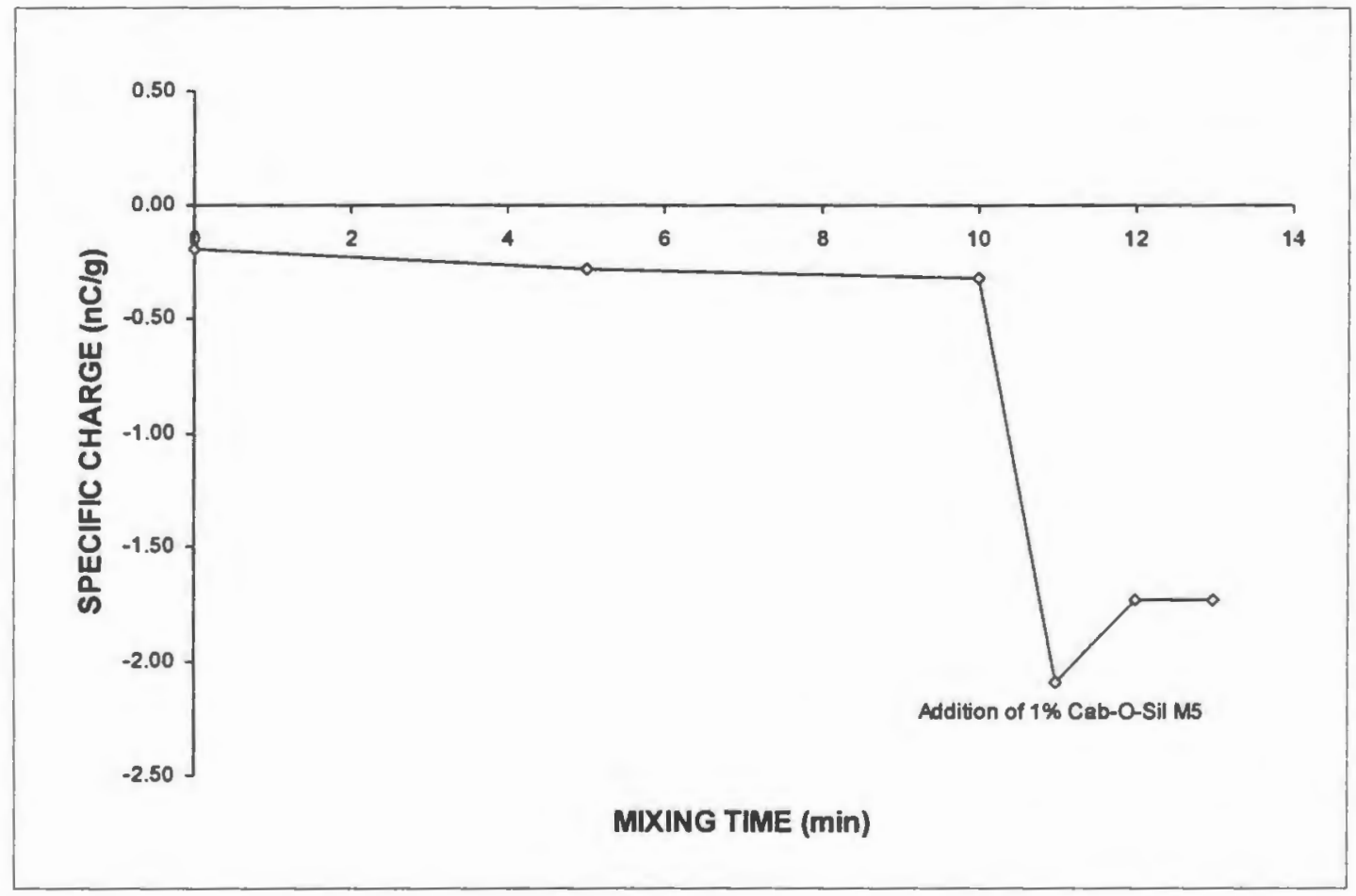

Figure 5. Effect of Cab-O-Sil M5 on Triboelectrification of Starch 1500 in Collette Gral 10 High Shear Mixer 
Thus, addition of Cab-O-Sil M5 to Starch 1500 significantly increased the electronegative charges present on the powder blend. Increased mixing with $\mathrm{Cab}-\mathrm{O}-$ Sil $\mathrm{M}^{(}{ }^{\circledR}$ had a marginal effect on the net negative charges present on the powder blend.

Starch 1500 particles displayed electronegative behavior initially when the last contact with the powder sample was the teflon coated stainless steel surface. The electronegative charge present on Starch 1500 increased with mixing time in Collette Gral 10 High Shear Mixer when compared to the initial charge. The addition of magnesium stearate and Pruv ${ }^{\circledR}$ neutralized the negative charges generated during mixing process. Stearic acid reduced the negative charges generated on Starch 1500 after initial mixing but the effect was not as significant as either magnesium stearate or Pruv ${ }^{\circledR}$. Addition of Cab-O-Sil M5 as glidant increased the net negative charges present on the powder particles as compared to the initial charge present on the particles. Based on the antistatic effect on Starch 1500, the lubricants/glidants can be arranged in the following order: magnesium stearate $>$ Pruv $^{\circledR}>$ stearic acid $>$ Cab-OSil M5.The maximum antistatic effect was observed for magnesium stearate and Pruv $^{\circledR}$ after one minute of lubricant mixing. Increase in mixing time seems to reduce the antistatic effect of these lubricants. The mixing time seems to have marginal effect when the additive was either stearic acid or Cab-O-Sil M5. 


\section{Effect of Lubricants/Glidants on Triboelectrification of Avicel ${ }^{\circledR}$ PH101:}

Avicel ${ }^{\circledR}$ PH101 is commonly used as a filler in solid dosage forms. It displays high compressibility but poor flow properties due to a fine particle size distribution. In the current study, the antistatic effect of magnesium stearate, sodium stearyl fumarate $\left(\right.$ Pruv $^{(B)}$ ), stearic acid, and colloidal silicon dioxide (Cab-O-Sil M5) was evaluated on the triboelectrification of Avicel ${ }^{\circledR}$ PH101 during a high shear mixing process. The results are summarized in Table 4 and data plotted as a function of mixing time in Figures 6, 7, 8, and 9. The graphs display the effect of mixing time on triboelectrification of Avicel ${ }^{\circledR}$ PH101 and the effect of lubricant/glidant on electrical nature of Avicel $^{\circledR}$ PH101 during high shear mixing.

As shown in Figure 6 and Table 4, the electronegative charge on Avicel ${ }^{\circledR}$ PH101 increased with mixing time up to 10 ininutes and when $1 \% \mathrm{w} / \mathrm{w}$ magnesium stearate was added to the blend, the negative charge present on powder was significantly neutralized. After one minute of mixing with magnesium stearate, the charge on powder particles was reduced from $-1.920 \mathrm{nC} / \mathrm{g}$ to $-0.992 \mathrm{nC} / \mathrm{g}$ (Table 4 ). After 2 minutes of mixing, a net positive charge of $+0.124 \mathrm{nC} / \mathrm{g}$ was observed. When mixing was continued for one more minute, then there was a redevelopment of negative charge $(-0.260 \mathrm{nC} / \mathrm{g})$ on powder particles indicating demixing of blend. As the data indicates in Figure 6, the addition of magnesium stearate neutralized the negative charges generated on Avicel $^{\circledR}$ PH101 particles due to triboelectrification during mixing process. Magnesium stearate acts as lubricant by forming a thin film on the primary particles. Thus the particle size distributions of individual components in a formulation play significant role in electrical behavior of final blends (18-19). 
Table 4. Effect of Lubricant/Glidant on Triboelectrification of Avicel ${ }^{\circledR}$ PH101

\begin{tabular}{|c|c|c|c|c|}
\hline \multirow[b]{2}{*}{$\begin{array}{c}\text { CUMULATIVE } \\
\text { MIXING TIME } \\
\text { (min) }\end{array}$} & \multicolumn{4}{|c|}{ SPECIFIC CHARGE (nC/g) } \\
\hline & $\begin{array}{c}\text { MEAN } \\
\text { (SD) } \\
n=6\end{array}$ & $\begin{array}{c}\text { MEAN } \\
\text { (SD) } \\
n=6\end{array}$ & $\begin{array}{c}\text { MEAN } \\
\begin{array}{c}\text { (SD) } \\
n=6\end{array}\end{array}$ & $\begin{array}{c}\text { MEAN } \\
\begin{array}{c}\text { (SD) } \\
n=6\end{array}\end{array}$ \\
\hline 0 & $\begin{array}{l}-0.883 \\
(0.190)\end{array}$ & $\begin{array}{l}-1.165 \\
(0.173)\end{array}$ & $\begin{array}{l}-1.056 \\
(0.157)\end{array}$ & $\begin{array}{l}-1.096 \\
(0.253)\end{array}$ \\
\hline 5 & $\begin{array}{l}-1.284 \\
(0.131)\end{array}$ & $\begin{array}{l}-1.242 \\
(0.205)\end{array}$ & $\begin{array}{l}-1.324 \\
(0.214)\end{array}$ & $\begin{array}{l}-1.408 \\
(0.180)\end{array}$ \\
\hline 10 & $\begin{array}{l}-1.920 \\
(0.312)\end{array}$ & $\begin{array}{l}-1.398 \\
(0.145)\end{array}$ & $\begin{array}{l}-1.385 \\
(0.210)\end{array}$ & $\begin{array}{l}-2.017 \\
(0.367)\end{array}$ \\
\hline $\begin{array}{c}\text { Addition of } 1 \% \\
\text { Lubricant/Glidant }\end{array}$ & $\begin{array}{c}\text { Addition of } 1 \% \\
\text { Magnesium } \\
\text { Stearate, NF }\end{array}$ & $\begin{array}{c}\text { Addition of } \\
1 \% \text { Pruv }\end{array}$ & $\begin{array}{l}\text { Addition of } 1 \% \\
\text { Stearic Acid, NF }\end{array}$ & $\begin{array}{c}\text { Addition of } \\
1 \% \text { Cab-O-Sil } \\
\text { M5 }\end{array}$ \\
\hline 11 & $\begin{array}{l}-0.992 \\
(0.167)\end{array}$ & $\begin{array}{l}-1.077 \\
(0.191)\end{array}$ & $\begin{array}{l}-0.496 \\
(0.065)\end{array}$ & $\begin{array}{l}-4.886 \\
(0.737)\end{array}$ \\
\hline 12 & $\begin{array}{l}+0.124 \\
(1.233)\end{array}$ & $\begin{array}{l}-0.659 \\
(0.093)\end{array}$ & $\begin{array}{l}+0.323 \\
(0.180)\end{array}$ & $\begin{array}{l}-4.051 \\
(0.635)\end{array}$ \\
\hline 13 & $\begin{array}{l}-0.260 \\
(1.002)\end{array}$ & $\begin{array}{l}-0.505 \\
(0.087)\end{array}$ & $\begin{array}{l}-0.196 \\
(0.030)\end{array}$ & $\begin{array}{l}-3.103 \\
(0.430)\end{array}$ \\
\hline
\end{tabular}




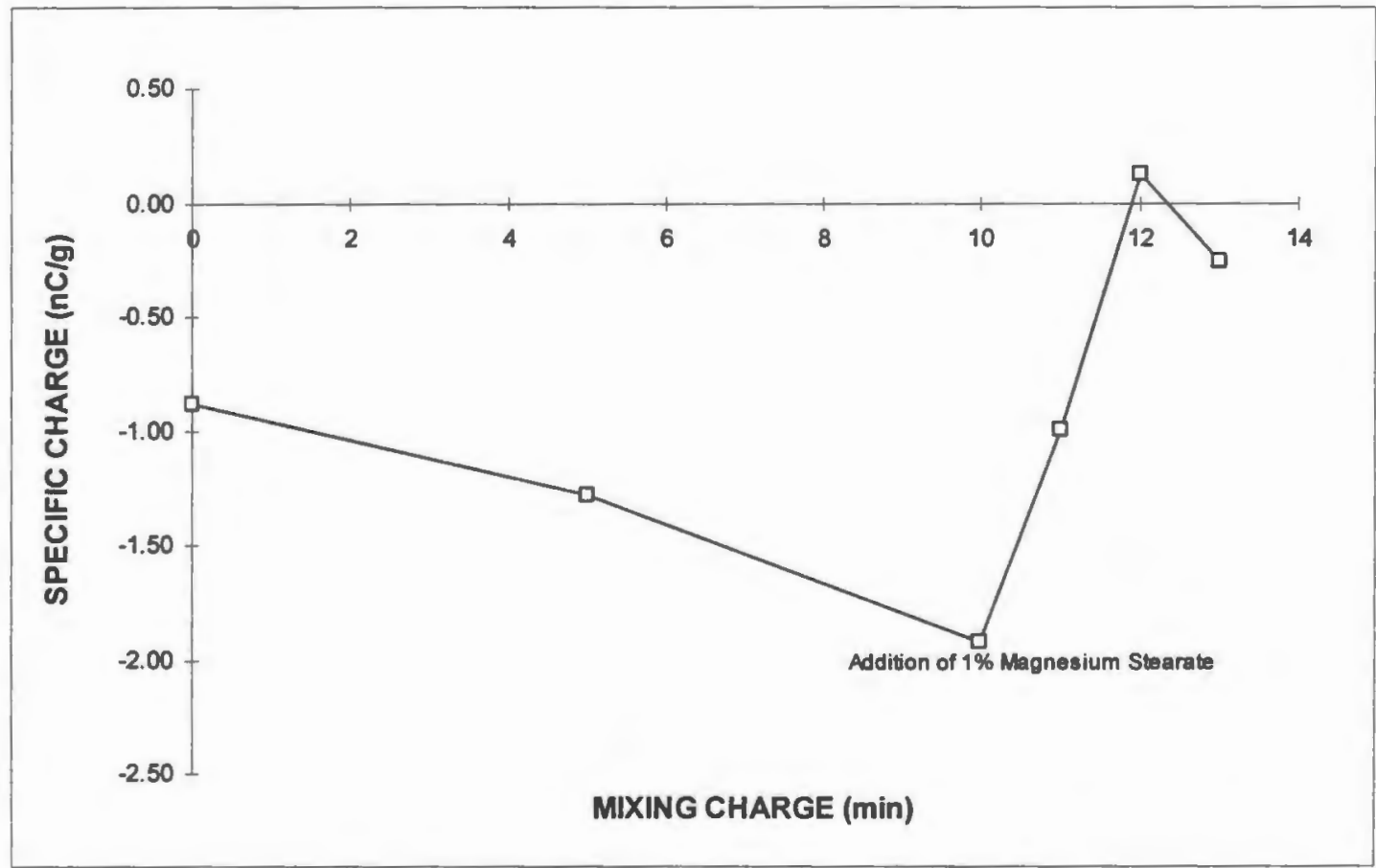

Figure 6. Effect of Magnesium Stearate on Triboelectrification of Avicel ${ }^{\otimes}$ PH101 in Collette Gral 10 High Shear Mixer 
Since Avicel ${ }^{\circledast}$ PH101 consists of fine particles, it took longer time for antistatic agent to neutralize the charges present on Avicel $^{\circledR} \mathrm{PH} 101$ as compared to that was observed for Starch 1500. The maximum antistatic effect of magnesium stearate on Avicel ${ }^{\circledR}$ PH101 was seen after two minutes of mixing. When the mixing was continued further, the antistatic effect seems to diminish probably due to demixing of powder blend (15-17).

As demonstrated in Figure 7, when $1 \%$ w/w Pruv ${ }^{\circledR}$ was added to Avicel ${ }^{\circledR}$ PH101 after 10 minutes of high shear mixing, the electronegative charge present on powder particles was reduced from $-1.398 \mathrm{nC} / \mathrm{g}$ to $-1.077 \mathrm{nC} / \mathrm{g}$ after 1 minute of mixing with Pruv ${ }^{\otimes}$ (Table 4). The negative charge was further reduced to $-0.659 \mathrm{nC} / \mathrm{g}$ and $-0.505 \mathrm{nC} / \mathrm{g}$ after 2 minutes and 3 minutes of lubricant mixing, respectively. Thus, addition of Pruv ${ }^{\circledR}$ seerns to reduce the negative charges generated on Avicel ${ }^{\circledR}$ PH101 due to high shear mixing. The antistatic effect of Pruv ${ }^{\circledR}$ on Avicel ${ }^{\circledR}$ PH101 increased with an increase in the mixing time.

Figure 8 shows the effect of stearic acid on the triboelectric charges generated on Avicel ${ }^{\circledR}$ PH101 due to high shear mixing. When $1 \% \mathrm{w} / \mathrm{w}$ of stearic acid was added after 10 minutes of mixing, the negative charge present on Avicel $^{\circledR} \mathrm{PH} 101$ powder was reduced from $-1.385 \mathrm{nC} / \mathrm{g}$ to $-0.496 \mathrm{nC} / \mathrm{g}$ after 1 minute of lubricant mixing (Table 4). When the mixing was continued further for another minute, then the electronegative charges present on powder particles were converted to electropositive (from -0.496 $\mathrm{nC} / \mathrm{g}$ to $+0.323 \mathrm{nC} / \mathrm{g}$ ). The negative charges reappear after 3 minutes of lubricant mixing. 


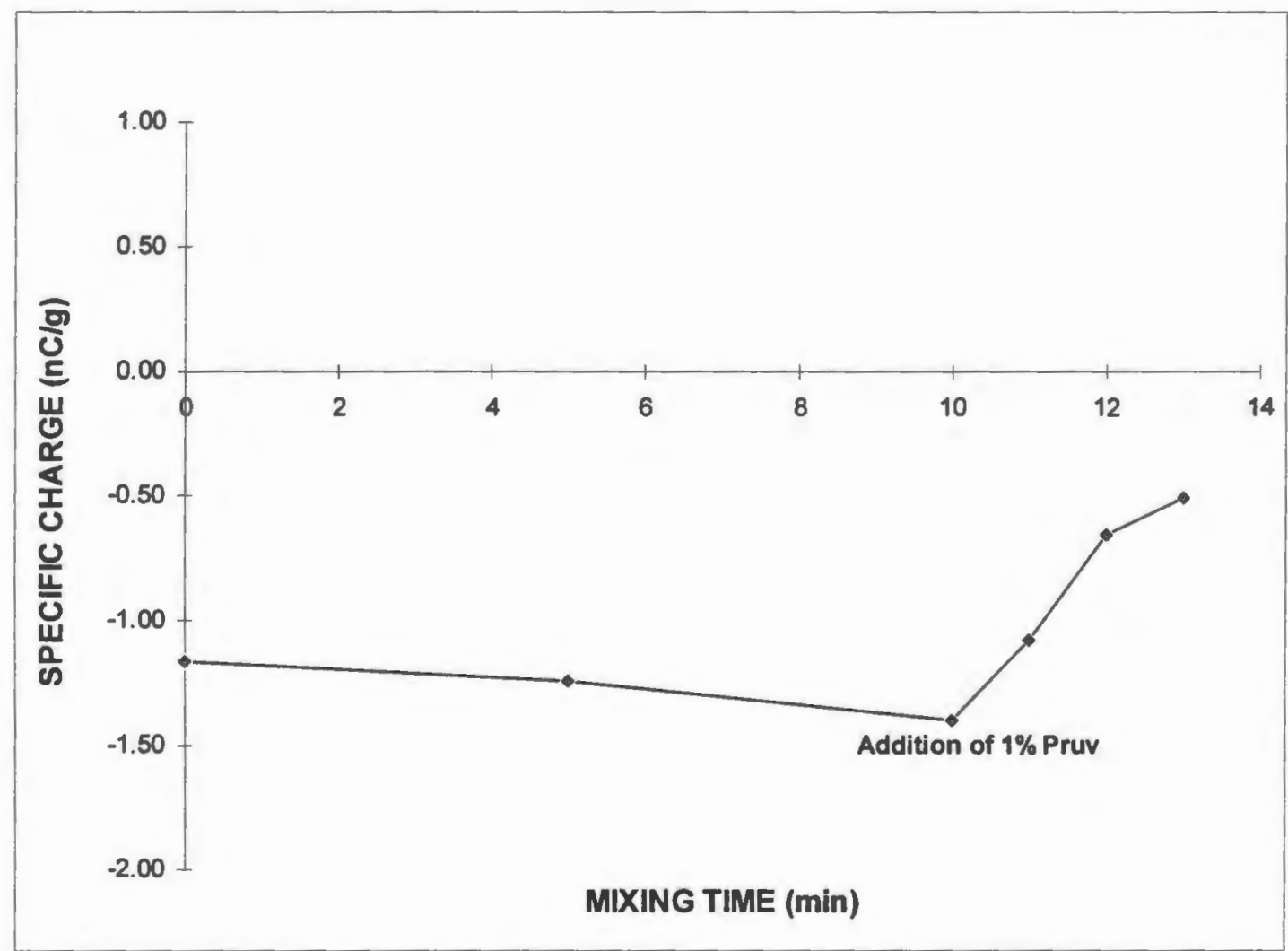

Figure 7. Effect of Pruv on Triboelectrification of Avicel ${ }^{\circledR}$ PH101 in Collette Gral 10 High Shear Mixer 


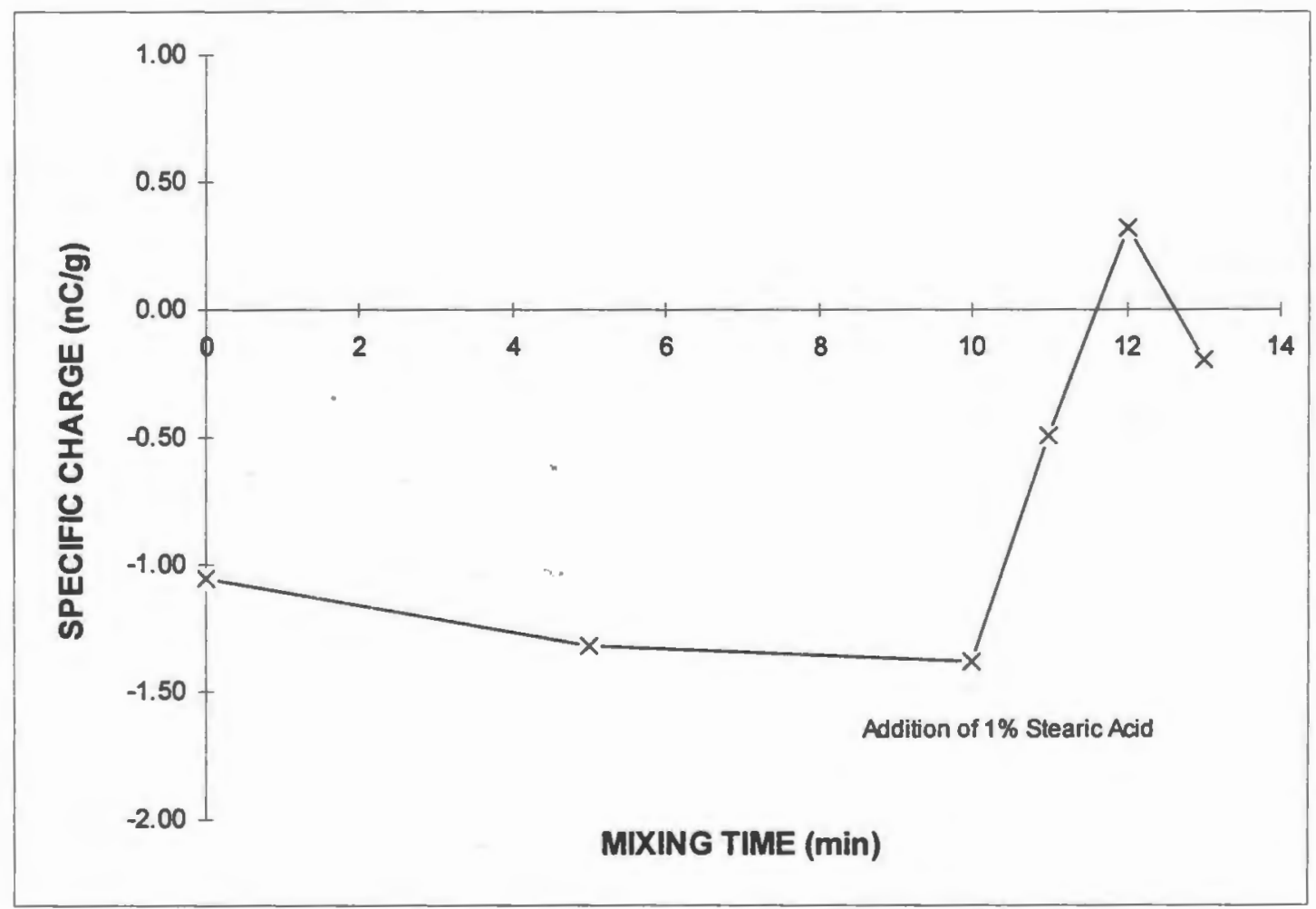

Figure 8. Effect of Stearic Acid on Triboelectrification of Avicel ${ }^{\otimes}$ PH101in Collette Gral 10 High Shear Mixer 
Thus, addition of stearic acid decreased the electronegative nature of Avicel ${ }^{\circledR}$ PH101 and the reduction in negative charge increased with lubricant mixing time for up to two minutes.

Figure 9 demonstrates the electrical charges present on Avicel $^{\circledR}$ PH101 as a function of mixing time and the effect of Cab-O-Sil M5 on the triboelectrification process. When $1 \% \mathrm{w} / \mathrm{w}$ of Cab-O-Sil M5 was added to Avicel ${ }^{\circledR}$ PH101 after 10 minutes of high shear mixing, the negative charges present on the particles were significantly increased from $-2.017 \mathrm{nC} / \mathrm{g}$ to $-4.886 \mathrm{nC} / \mathrm{g}$ after one minute of mixing (Table 4). The negative charges were reduced to $-4.051 \mathrm{nC} / \mathrm{g}$ and to $-3.103 \mathrm{nC} / \mathrm{g}$ when the mixing was continued for 2 and 3 minutes respectively. Thus, addition of Cab-O-Sil M5 as glidant to Avicel ${ }^{\boxplus}$ PH101 significantly increased the amount of electronegative charges present on the powder blend. Increased mixing with Cab-OSil M5 had a reducing effect on the overall negative charges present on the powder blend. However, addition of Cab-O-Sil M5 has resulted in increasing the net electronegative charges present on Avicel $^{\circledR} \mathrm{PH} 101$ powder.

Avicel ${ }^{\circledR}$ PH101 displayed electronegative behavior initially when the last contact with powder sample was a teflon coated stainless steel surface. The electronegative charge present on Avicel $^{\circledR}$ PH101 increased with mixing time (up to 10 minutes) in Collette Gral 10 High Shear Mixer when compared to the initial charge. The addition of magnesium stearate, Pruv ${ }^{\circledR}$ and stearic acid resulted in reduction of the negative charges generated during mixing process. Addition of Cab-O-Sil M5 as glidant increased the net negative charges present on the powder particles as compared to the initial charge present on the particle. Additional mixing however reduced the 


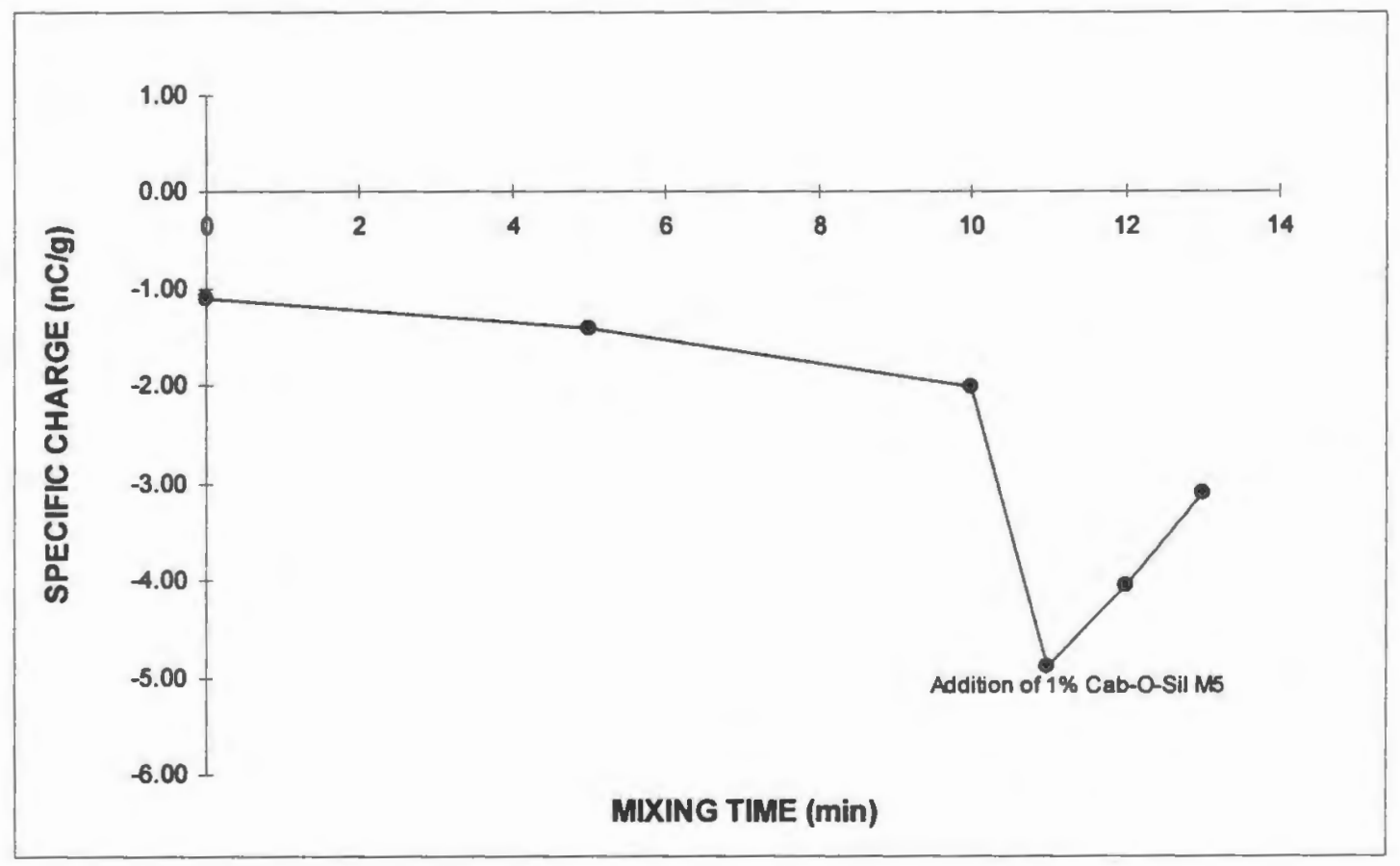

Figure 9. Effect of Cab-O-Sil M5 on Triboelectrification of Avicel ${ }^{\otimes} \mathrm{PH} 101$ in Collette Gral 10 High Shear Mixer 
negative charges marginally. The antistatic agents can be arranged in the following order based on their decreasing order of effectiveness to reduce electrostatic charges: magnesium stearate $>$ stearic acid $>$ Pruv $^{\circledR}>$ Cab-O-Sil M5. The maximum antistatic effect was observed for magnesium stearate and stearic acid after two minutes of lubricant mixing. Increase in mixing time seems to increase the antistatic effect of Pruv $^{\circledR}$ and Cab-O-Sil M5. The mixing time had an adverse effect when the additive was either stearic acid or magnesium stearate (15-17). 


\section{Effect of Lubricants/Glidants on Triboelectrification of Cimetidine Formulation:}

A typical tablet formulation contains active ingredient, filler, binder, disintegrant and lubricant/glidant. In this study an attempt was made to determine the electrostatic charges present on cimetidine tablet formulation as a function of mixing time in a high shear mixer and also evaluate the effect of antistatic agents. A cimetidine formulation was prepared consisting of $69 \%$ cimetidine, USP, $10 \%$ Avicel $^{\circledR}$ PH101, 10\% Starch 1500, 10\% lactose anhydrous and 1\% lubricant or glidant. When evaluated independently the drug displayed electropositive charge and all the excipients used in formulation showed electronegative charge (Table 2). Figure 10 and Table 5 indicate that the pre-blend displayed an electropositive charge of +1.269 $\mathrm{nC} / \mathrm{g}$ prior to mixing. After 5 and 10 minutes of mixing, the charges on blend were reduced to $+0.884 \mathrm{nC} / \mathrm{g}$ and $+0.917 \mathrm{nC} / \mathrm{g}$, respectively. Magnesium stearate was added at $1 \% \mathrm{w} / \mathrm{w}$ to the pre-blend after 10 minutes of mixing in order to evaluate its antistatic effect (Table 5 and Figure 10). After mixing for 1 minute with magnesium stearate, the electrostatic charge on the pre-blend was reduced from $+0.917 \mathrm{nC} / \mathrm{g}$ to $+0.834 \mathrm{nC} / \mathrm{g}$. A net charge of $+0.695 \mathrm{nC} / \mathrm{g}$ and $+0.908 \mathrm{nC} / \mathrm{g}$ were recorded for blend after 2 and 3 minutes of lubricant mixing. Thus the addition of magnesium stearate showed an antistatic effect by reducing the net electropositive charges present on cimetidine formulation. The maximum antistatic effect was observed after two minutes of lubricant mixing.

In another experiment, Cab-O-Sil M5, a commonly used glidant was added to cimetidine composition after 10 minutes of high shear mixing. The results were presented in Table 5 and Figure 11. After mixing for 1 minute with Cab-O-Sil M5 the 
Table 5. Effect of Lubricant/Glidant on Triboelectrification of Cimetidine Formulation

\begin{tabular}{|c|c|c|}
\hline \multirow[b]{2}{*}{$\begin{array}{l}\text { CUMULATIVE } \\
\text { MIXING TIME } \\
\text { (min.) }\end{array}$} & \multicolumn{2}{|c|}{ SPECIFIC CHARGE (nC/g) } \\
\hline & $\begin{array}{c}\text { MEAN } \\
\text { (SD) } \\
n=6\end{array}$ & $\begin{array}{c}\text { MEAN } \\
\text { (SD) } \\
n=6\end{array}$ \\
\hline 0 & $\begin{array}{l}+1.269 \\
(0.521)\end{array}$ & $\begin{array}{l}+1.229 \\
(0.348)\end{array}$ \\
\hline 5 & $\begin{array}{l}+0.884 \\
(0.188)\end{array}$ & $\begin{array}{l}+1.173 \\
(0.284)\end{array}$ \\
\hline 10 & $\begin{array}{l}+0.917 \\
(0.205)\end{array}$ & $\begin{array}{l}+1.607 \\
(0.348)\end{array}$ \\
\hline $\begin{array}{c}\text { Addition of } 1 \% \\
\text { Lubricant/Glidant }\end{array}$ & $\begin{array}{c}\text { Addition of } 1 \% \text { Magnesium } \\
\text { Stearate, } N F\end{array}$ & $\begin{array}{c}\text { Addition of } 1 \% \mathrm{Cab}-\mathrm{O}- \\
\text { Sil } \mathrm{M} 5\end{array}$ \\
\hline 11 & $\begin{array}{l}+0.834 \\
(0.281)\end{array}$ & $\begin{array}{l}-0.040 \\
(0.183)\end{array}$ \\
\hline 12 & $\begin{array}{l}+0.695 \\
(0.131)\end{array}$ & $\begin{array}{l}-0.756 \\
(0.259)\end{array}$ \\
\hline 13 & $\begin{array}{l}+0.908 \\
(0.211)\end{array}$ & $\begin{array}{l}-0.020 \\
(0.169)\end{array}$ \\
\hline
\end{tabular}




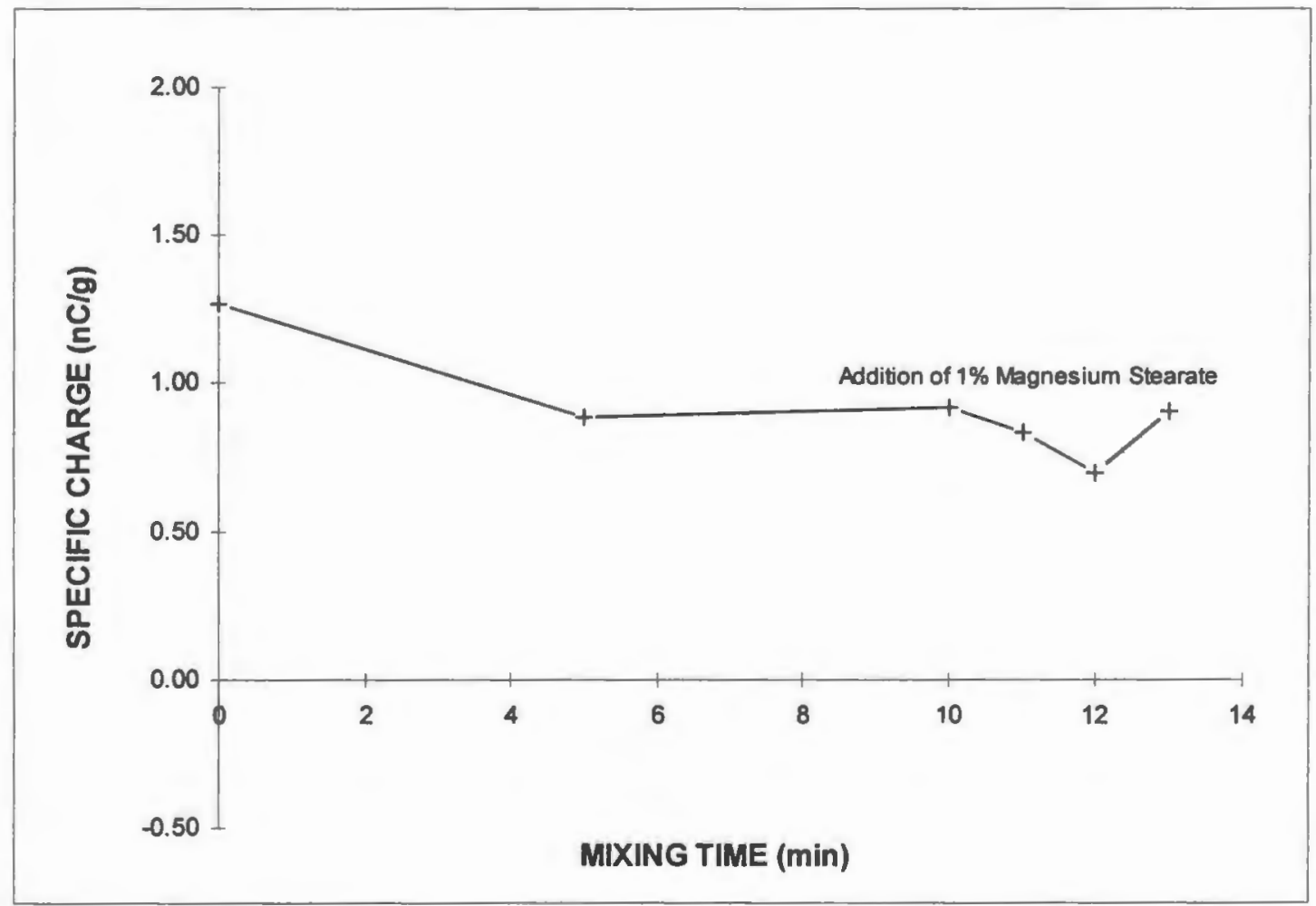

Figure 10. Effect of Magnesium Stearate on Triboelectrification of Cimetidine Formulation in Collette Gral 10 High Shear Mixer 


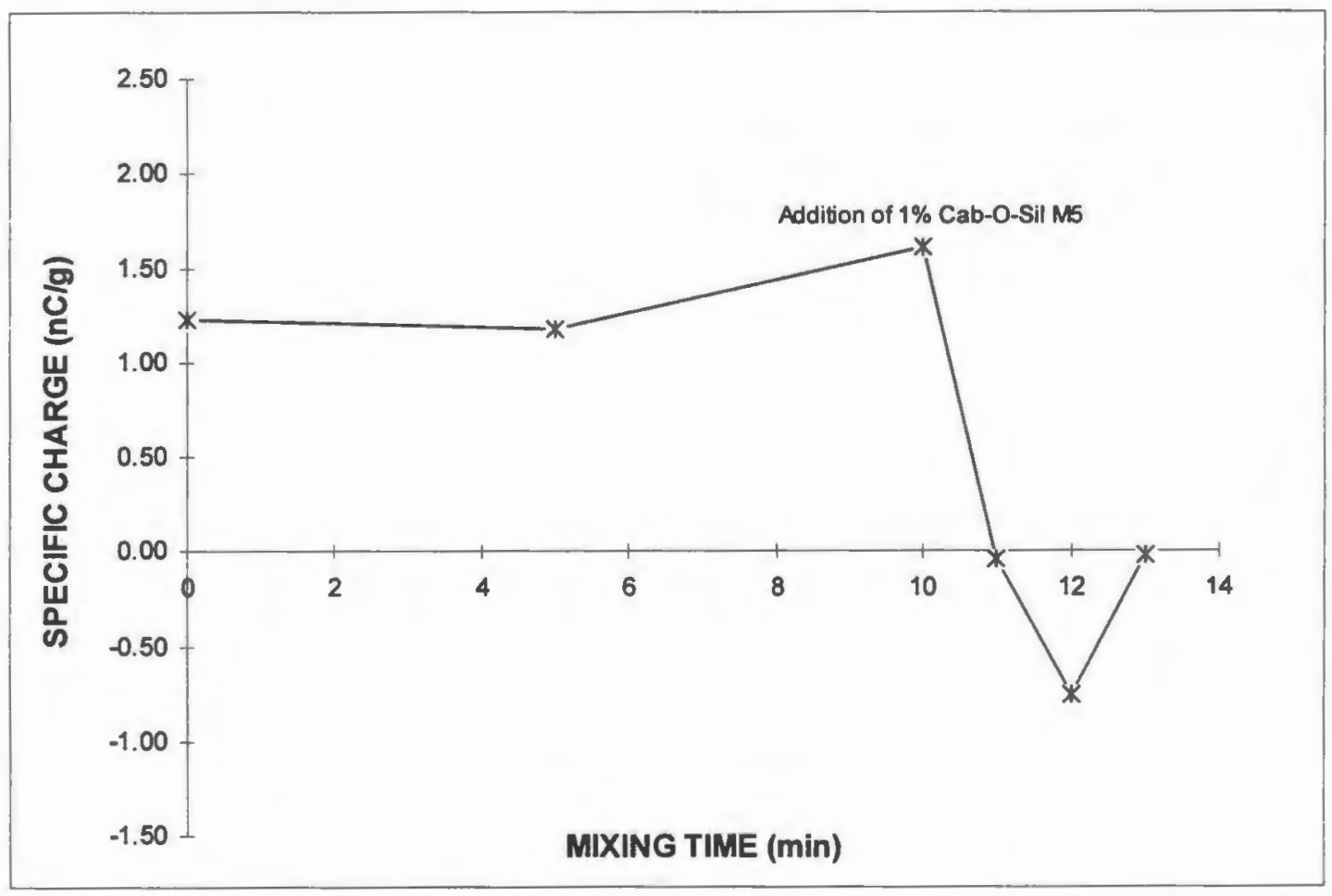

Figure 11. Effect of Cab-O-Sil M5 on Triboelectrification of Cimetidine Formulation in Collette Gral 10 High Shear Mixer 
charge on cimetidine blend has been reduced from $+1.607 \mathrm{nC} / \mathrm{g}$ to $-0.040 \mathrm{nC} / \mathrm{g}$. The charge was further reduced to $-0.756 \mathrm{nC} / \mathrm{g}$ after mixing for an additional minute. When the mixing was continued for a total of 3 minutes with the glidant, a net charge of $-0.020 \mathrm{nC} / \mathrm{g}$ was observed on cimetidine blend. Thus, when compared with magnesium stearate, Cab-O-Sil M5 had a more substantial antistatic effect on the positive charges present on the cimetidine blend. The addition of Cab-O-Sil M5 neutralized the electropositive nature of cimetidine formulation after one minute of mixing. The antistatic effect seems to be optimum with two minutes of mixing.

There are many factors that contribute to the interaction of solids $(12-14,18$ 22). The interaction between two particles is dependent upon the surface to interfacial energy change that occurs when the solids come into contact. The surface energy of a solid rarely is homogenous. Therefore, the energy change at the true areas of contact will not be a single function of the true area of contact but will vary with the nature of the exact portions of the two solid surfaces in contact. The area of true contact between individual particles is dependent on the particle shape, size, distribution, roughness, the compressive force at the interface, the shear to which the sample has been subjected, and the mechanical properties of the particles. Most organic solids are insulators. Unless their surface is made conducting by additives such as lubricants/glidants, the solid particles will charge on contact. The resulting electrostatic attractions may be large thereby affecting the powder flow and compression operations. 
Staniforth et al. (23-26) have demonstrated that contact and frictional electrification can be used to develop surface charges on drug and excipient powders. These surface charges can be optimized to facilitate the formation of ordered mixes and to minimize their segregation tendency. The last contact surface for charge measurement is critical as glass, plastic and brass behave differently for the same material. It has been demonstrated that dry powders with similar charges are less stable than those with dissimilar charges. Further drug-excipient blends with like charges are less stable than those with opposite charges. Stability in this case implies a tendency to segregate on standing.

The results obtained in the current study clearly indicate that the lubricants have a higher anti-static effect on the negatively charged materials where as glidant has a high anti-static effect on positively charged powders indicating that it is possible to select formulation components so that final formulation is not prone to high static charging.

Gold and Palermo (27) provides an interesting comparison of mechanisms proposed for of tablet lubricants and antistatic agents. In manufacture of tablets, the primary function of lubricants is to reduce the friction between the tablet-die wall interface during tablet formation and ejection. The reduction in friction occurs by mechanism of fluid and boundary lubrication. In fluid lubrication, the two surfaces are separated by a finite layer of fluid lubricant. Boundary lubrication results from the adherence of polar portions of molecules with long carbon chains to the metal surfaces. Lubricants may also function to improve the flow characteristics of powder blends and to prevent sticking to the punch faces. 
Antistatic agents function by reducing friction or by increasing conductance or by both mechanisms. A material added to reduce friction may not be an efficient agent for mitigating static accumulation, as the generation of static charges is thought to arise from contact rather than friction. Surfaces may be made electrically conductive by utilizing antistatic agents which have polar or hygroscopic properties. 


\section{Effect of Mixer Type on Triboelectrification of Starch 1500:}

The design and size of a mixing vessel has significant impact on generation of electrostatic charges on powders as they affect the shearing forces that are applied on particles (31-32). Generally, in blending of pharmaceutical materials, two types of mixers are used in order to obtain homogeneous mixtures. These include high shear mixers such as Collette Gral and low shear mixers such as V-blenders. The high shear mixers are preferred due to their high process efficiencies as compared to the low shear mixers. In the current study, two types of high shear mixers were evaluated for their effect on triboelectrification process on Starch 1500. The two mixers evaluated were: the Collette Gral 10 High Shear Mixer with a capacity of 7 liters and the Kitchen Aid Planetary Mixer with a capacity of 2.5 liters. A batch size of $0.5 \mathrm{~kg}$ was used for both mixers. For Collette Gral 10 High Shear Mixer, the speed settings for mixer blade and chopper were set at $660 \mathrm{rpm}$ and $3000 \mathrm{rpm}$ respectively. For the Kitchen Aid Planetary Mixer, the mixer blade was set at $94 \mathrm{rpm}$. The Starch 1500 powder was mixed for a total period of 20 minutes in both mixers. Figure 12 and Table 6 show the effect of mixer type on triboelectrification of Starch 1500 as a function of mixing time. In both the mixers, Starch 1500 displayed electronegative behavior prior to initiation of mixing process. As mixing progressed, in both mixers, the electronegative charges present on Starch 1500 powder particles increased as a function of mixing time. In the Kitchen Aid Planetary Mixer, the negative charges were increased from $-0.615 \mathrm{nC} / \mathrm{g}$ to $-0.945 \mathrm{nC} / \mathrm{g}$ after 20 minutes of mixing (Table 6). In the Collette Gral $10 \mathrm{High}$ Shear Mixer, the negative charges present on Starch 1500 were increased from -0.186 $\mathrm{nC} / \mathrm{g}$ to $-1.023 \mathrm{nC} / \mathrm{g}$ after 20 minutes of mixing. As the data indicates, the Collette 
Table 6. Effect of Mixer Type on Triboelectrification of Starch 1500

\begin{tabular}{|c|c|c|}
\hline \multirow[t]{2}{*}{$\begin{array}{c}\text { CUMULATIVE } \\
\text { MIXING TIME } \\
\text { (min.) }\end{array}$} & \multicolumn{2}{|c|}{ 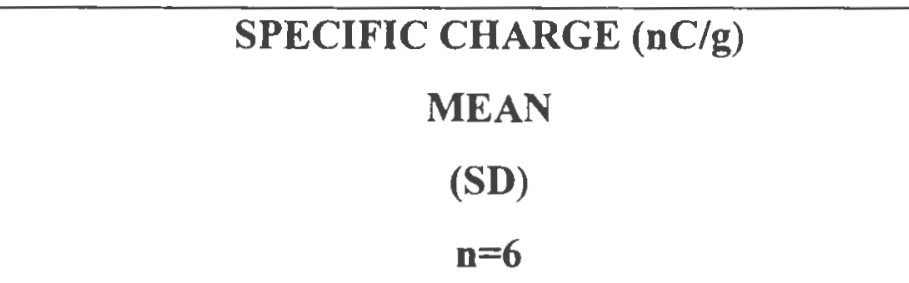 } \\
\hline & $\begin{array}{c}\text { Kitchen Aid Planetary } \\
\text { Mixer }\end{array}$ & $\begin{array}{c}\text { Collette Gral } 10 \text { High } \\
\text { Shear Mixer }\end{array}$ \\
\hline 0 & $\begin{array}{l}-0.615 \\
(0.046)\end{array}$ & $\begin{array}{l}-0.186 \\
(0.025)\end{array}$ \\
\hline 5 & $\begin{array}{l}-0.682 \\
(0.033)\end{array}$ & $\begin{array}{l}-0.261 \\
(0.047)\end{array}$ \\
\hline 10 & $\begin{array}{l}-0.742 \\
(0.099)\end{array}$ & $\begin{array}{l}-0.749 \\
(0.112)\end{array}$ \\
\hline 15 & $\begin{array}{l}-0.845 \\
(0.146)\end{array}$ & $\begin{array}{l}-0.954 \\
(0.131)\end{array}$ \\
\hline 20 & $\begin{array}{l}-0.945 \\
(0.149)\end{array}$ & $\begin{array}{l}-1.023 \\
(0.124)\end{array}$ \\
\hline
\end{tabular}




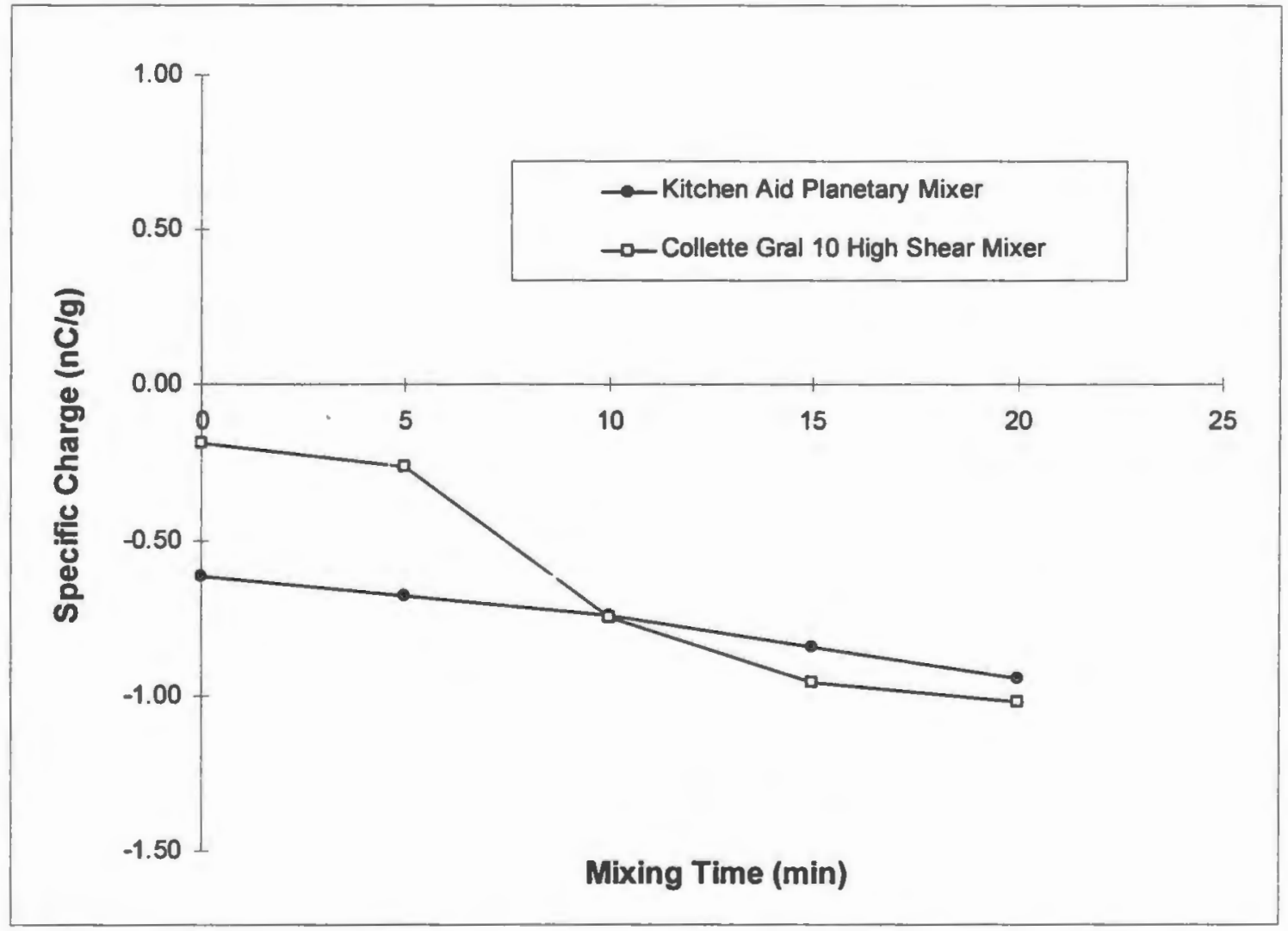

Figure 12. Effect of Mixer Type on Triboelectrification of Starch 1500 
Gral 10 High Shear Mixer had a more substantial effect on the electronegative nature of Starch 1500 as compared to the Kitchen Aid Planetary Mixer. This is attributed to the higher effective shear and higher efficiency of the Collette Gral 10 High Shear Mixer as compared to the Kitchen Aid Planetary Mixer (Figure 12). The design of Collette Gral 10 High Shear Mixer i.e. presence of two mixing blades as compared to one present in Kitchen Aid Planetary Mixer and the larger size of the mixer also contributed to increased particle-particle interactions resulting in generation of high electrostatic charges. 


\section{Effect of Batch Size on Triboelectrification of Starch 1500:}

Batch size is a critical parameter in pharmaceutical processing as it affects directly the efficiency of mixing operation (31-32). In order to evaluate the batch size effect on triboelectrification of Starch 1500 in Collette Gral 10 High Shear Mixer, batch sizes of $0.5 \mathrm{~kg}$ and $2.5 \mathrm{~kg}$ were investigated. For both batch sizes, the same speed settings of mixer $(660 \mathrm{rpm})$ and chopper $(3000 \mathrm{rpm})$ were used and the batches were mixed for a total of 20 minutes. As shown in Figure 13 and Table 7, the initial charge found on Starch 1500 for both batches was electronegative. The charge for 0.5 $\mathrm{kg}$ batch increased from $-0.186 \mathrm{nC} / \mathrm{g}$ to $-1.023 \mathrm{nC} / \mathrm{g}$ after 20 minutes of mixing. For $2.5 \mathrm{~kg}$ batch, the negative charge was found to increase from $-0.806 \mathrm{nC} / \mathrm{g}$ to -1.273 $\mathrm{nC} / \mathrm{g}$ after 20 minutes of mixing. For both batch sizes, the negative charges seem to increase as a function of mixing time. The triboelectrification observed for $0.5 \mathrm{~kg}$ batch seems to be more profound as compared to the one seen for $2.5 \mathrm{~kg}$ batch. This can be explained based on the fact that under same processing conditions, the $0.5 \mathrm{~kg}$ batch received more shearing energy relative to mass of powder present in the mixer as compared to the $2.5 \mathrm{~kg}$ batch. The $0.5 \mathrm{~kg}$ batch was fluidized more in the mixer vessel due to large available area as compared to the bigger batch $(2.5 \mathrm{~kg})$. The high frequent particle movement of powders could be the reason for the higher triboelectric effect that was seen with the small batch size as compared to the large batch size. Thus the triboelectrification of Starch 1500 due to high shear mixing decreased with an increase in the batch size from $0.5 \mathrm{~kg}$ to $2.5 \mathrm{~kg}$. 
Table 7. Effect of Batch Size on Triboelectrification of Starch 1500 in Collette Gral 10 High Shear Mixer

\begin{tabular}{|c|c|c|}
\hline \multirow{2}{*}{$\begin{array}{c}\text { CUMULATIVE } \\
\text { MIXING TIME }\end{array}$} & \multicolumn{2}{|c|}{ MEAN } \\
(SD) \\
$\mathbf{n}=\mathbf{6}$ \\
\hline \multirow{2}{*}{0} & \multicolumn{2}{|c|}{ BPECIFIC CHARGE (nC/g) } \\
\cline { 2 - 3 } & Batch Size: $\mathbf{0 . 5}$ Kg & -0.806 \\
& -0.186 & $(0.077)$ \\
\hline \multirow{2}{*}{5} & $(0.025)$ & -0.875 \\
& -0.261 & $(0.130)$ \\
\hline \multirow{2}{*}{10} & $(0.047)$ & -1.088 \\
& -0.749 & $(0.133)$ \\
\hline \multirow{2}{*}{15} & $(0.112)$ & -1.177 \\
& -0.954 & $(0.134)$ \\
\hline \multirow{2}{*}{20} & $(0.131)$ & -1.273 \\
& -1.023 & $(0.125)$ \\
\hline
\end{tabular}




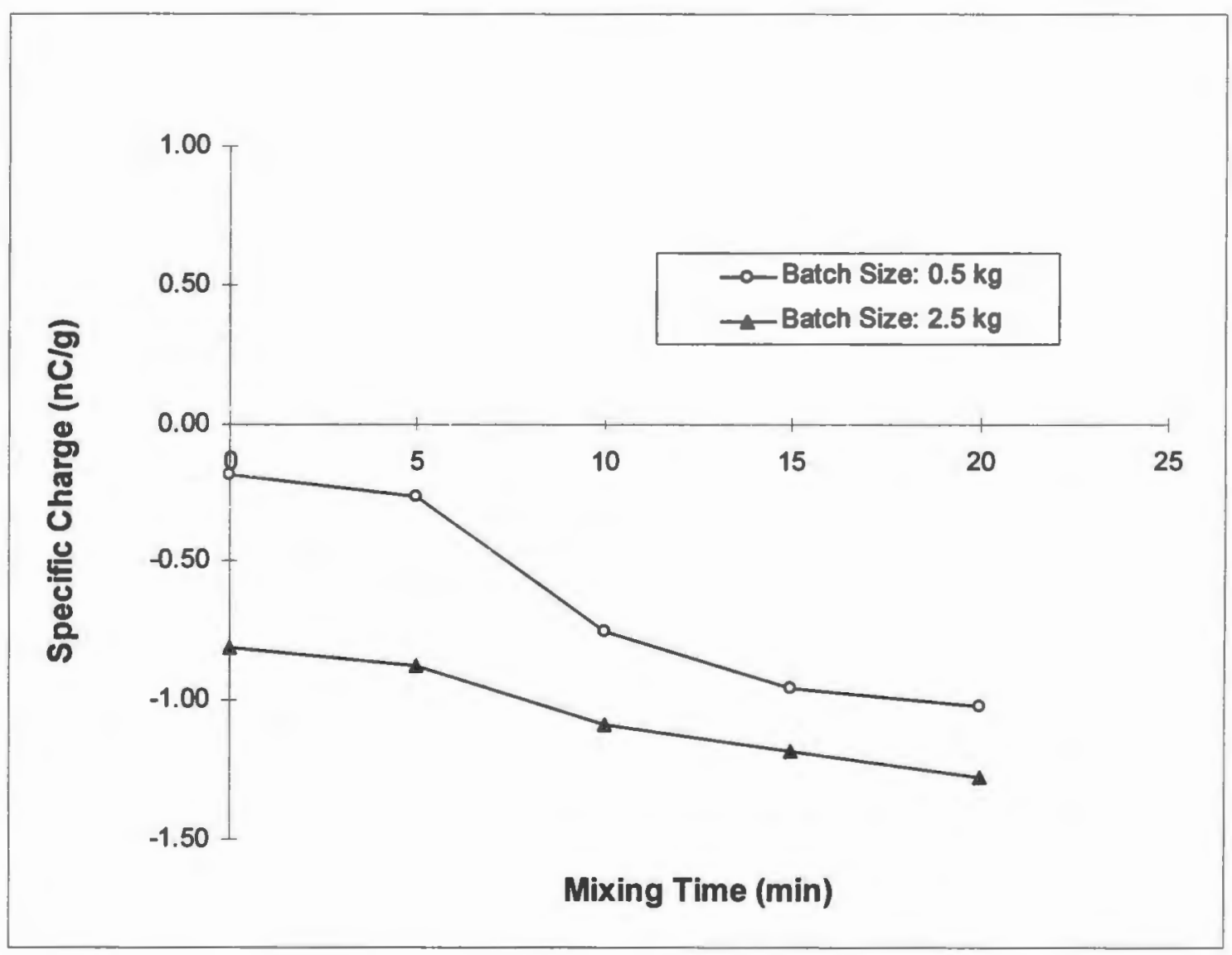

Figure 13. Effect of Batch Size on Triboelectrification of Starch 1500 in Collette Gral 10 High Shear Mixer 
These preliminary findings showed significant differences in charging propensity among drug and different excipient materials that have relevance in formulation, manufacture and use. The results also illustrate the complexities and difficulties when conducting charging experiments with different materials. As data in Tables 2-7 indicate that there is a high degree of variation associated with electrostatic measurements. These variations can be explained based on: complex and bi-polar nature of triboelectrification process, chemical nature of test material, particle size and shape, surface properties of test material, nature of last contact surface, contact area and frequency, surface purity, relaxation nature, mode of charge decay, atmospheric conditions such as humidity, temperature, sampling plan, sample handling and instrumental variation (6-9). The limitation of these measurements is the reliance on the final net specific charge value (28-30). It will be useful to measure charge continuously during triboelectrification process (2).

Though there is high variation in static measurements, the charging tendencies in the materials investigated clearly provide useful information that can be utilized in selecting formulation components. It has been demonstrated in this study that by measurement of static charges present on drugs/excipients during developmental stage, triboelectrification can be used to obtain stable blends that have low segregation tendencies. Results also indicated that choice of process equipment such as type of mixer, processing conditions such as mixing time and batch size play significant role in electrostatic charging. 


\section{CONCLUSIONS}

When evaluated individually, cimetidine displayed electropositive charge whereas all other excipients displayed electronegative charges. Cab-O-Sil M5 was found to be the most electronegative whereas stearic acid was found to be the least electronegative among excipients studied. The dry mixing of Avicel ${ }^{\circledR}$ PH101 and Starch 1500 in a Collette Gral 10 High Shear Mixer caused an increase in the electronegative charges probably due to the frictional and shearing forces, modified particle behavior such as particle size reduction and increased particle-particle interactions. Four excipients namely, magnesium stearate, sodium stearyl fumarate $\left(\right.$ Pruv $\left.^{\circledR}\right)$, stearic acid and colloidal silicon dioxide (Cab-O-Sil M5) were evaluated for antistatic effects.

Addition of magnesium stearate to Starch 1500 and Avicel ${ }^{\circledR}$ PH101 after 10 minutes of high shear mixing resulted in neutralization of electrostatic charges present on the powder particles. Pruv neutralized the negative electrostatic charges more on Starch 1500 particles as compared to Avicel ${ }^{\circledR} \mathrm{PH} 101$. The antistatic effect of stearic acid is more profound on Avicel ${ }^{\circledR}$ PH101 as compared to Starch 1500. Addition of Cab-O-Sil M5 caused an increase in the electronegative charges of both Avicel ${ }^{\circledast}$ PH101 and Starch 1500. As the mixing time with lubricants/glidants increased from 1 minute to 3 minutes, the antistatic effect seems to reduce. Based on this study, when Avicel ${ }^{\circledR}$ PH101 was blended with $1 \%$ lubricant/glidant in a Collette Gral 10 High Shear Mixer, the additives can be arranged as follows in the decreasing order of their ability to reduce the static charges produced during the blending process: magnesium 
stearate $>$ Pruv $^{\circledR}>$ stearic acid $>$ Cab-O-Sil M5. When Starch 1500 was blended with $1 \%$ lubricant/glidant in a Collette Gral 10 High Shear Mixer, the antistatic effectiveness of additives can be arranged in the decreasing order as: magnesium stearate $>$ stearic acid $>$ Pruv ${ }^{\circledR}>$ Cab-O-Sil M5 .

The cimetidine tablet formulation containing electropositive active ingredient (cimetidine, USP) and four electronegative excipients: Avicel ${ }^{\circledR}$ PH101, Starch 1500, anhydrous lactose and lubricant/glidant in the ratio of 69:10:10:10:1 was evaluated for electrostatic measurements. Mixing for 10 minutes a high shear mixer without lubricant/glidant did not neutralize the charges present on powder particles. But addition of 1\% Cab-O-Sil M5 significantly reduced the positive charges present on the cimetidine blend and neutralized the charges after two minutes of mixing. Magnesium Stearate showed marginal reduction of electropositive charges present on the cimetidine powder blend.

The mixer design and size play critical role in determining the homogeneity of blends in pharmaceutical processing. In the current study, two types of mixers: Collette Gral 10 High Shear Mixer (capacity-7 liters) and Kitchen Aid Planetary Mixer (capacity-2.5 liters) were evaluated for triboelectrification of Starch 1500. Mixing of Starch 1500 in the Collette Gral 10 High Shear Mixer resulted in generation of more electronegative charges as compared to the mixing in the Kitchen Aid Planetary Mixer. This is attributed to the higher effective shear and higher efficiency of the Collette Gral 10 High Shear Mixer as compared to the Kitchen Aid Planetary Mixer. In both cases, the increased mixing time resulted in increased electrostatic charges. 
In order to evaluate the batch size effect on electrostatic charging of Starch 1500 in a high shear mixer, two batch sizes of $0.5 \mathrm{~kg}$ and $2.5 \mathrm{~kg}$ were investigated. The triboelectrification of Starch 1500 due to high shear mixing decreased with an increase in the batch size from $0.5 \mathrm{~kg}$ to $2.5 \mathrm{~kg}$. The larger and more frequent particle movement of powders could be the reason for high triboelectric effect that was seen with the small batch size as compared to the large batch size.

These preliminary findings showed that significant differences in charging propensities existed among drug and different excipient materials. The charging tendencies in the materials investigated clearly provide useful information that can utilized in selecting formulation components prior to development. By measuring static charges present on diugs/excipients during developmental stage, formulation scientist can utilize triboelectrification process to obtain powder blends that have low segregation.

Since there are numerous factors that may affect the triboelectrification process and further investigations are warranted to fully understand its mechanism. Results from this study will enable further detailed investigations of triboelectrification of powders to be undertaken which will definitely aid the formulation scientists in formulating a stable and desired product. 


\section{REFERENCES}

1. Bailey, A. G. Electrostatic phenomena during powder handling. Powder Technology, 37: 71-85 (1984).

2. Dechene, R. L. and Averdieck, W. J. Triboelectricity: A parameter for solids flow measurement. Powder and Bulk Engineering, 11-13, June 1987.

3. Lachman. L. and Lin. S. N., Electrostatic characteristics of pharmaceutical solids and packaging materials I: Design of testing equipment and preliminary findings. Journal of Pharmaceutical Sciences, 57 (3): 504-510 (1968).

4. Gajewski, J. Charge measurement of dust particles in motion. Part II. Journal of Electrostatics, 15: 67-69 (1984).

5. Kittaka, Masui and Murata. A method for measuring the charging tendency of powders in pneumatic conveyance through metal pipes. Journal of Electrostatics, 6 (1979).

6. Bailey, A. G. Charging of solids and powders. Journal of Electrostatics, 30: 167180 (1993).

7. Kulvanich, P. and Stewart, P. J. Influence of relative humidity on adhesive properties of a model interactive system. Journal of Pharmacy and Pharmacology, 40: 453-458 (1988).

8. Kulvanich, P. and Stewart, P. J. An evaluation of the air stream Faraday cage in the electrostatic charge measurement of interactive drug systems. International Journal of Pharmaceutics, 36: 243-252 (1987). 
9. Jashnani, R. N., Byron, P. R. and Dalby, R. N. Tetsing of dry powder aerosol formulations in different environmental conditions. International Journal of Pharmaceutics, 113: 125-130 (1995).

10. Peart, J., Staniforth, J. N. and Meakin, B. J. Electrostatic charge interactions in pharmaceutical dry powder aerosols. Instrumental Physics Conference Series, No. 143: $271-274$ (1995).

11. Secker, E. and Chubb, J. N. Instrumentation for electrostatic measurements Journal of Electrostatics, 16: 1-19 (1984).

12. Hiestand, E. N. Powders: Particle-particle interactions. Journal of Pharmaceutical Sciences, 55(12):1325-1344 (1966).

13. Hartley, P. A., Parfitt, G. D., and Pollack, L. B. The role of the Van der Waals force in the agglomeration of powders containing submicron particles. Powder Technology, 42: 35-46 (1985).

14. Buckton, G. The estimation and application of surface energy data for powdered systems. Drug Development and Industrial Pharmacy, 18: 1149-1167 (1992).

15. Johansson, M. E. Investigations of mixing time dependence of the lubricating properties of granular and powdered magnesium stearate. Acta Pharmaceutica Suec 22: 343-350 (1985).

16. Ragnarsson, G., Holzer, A. W., and Sjogren, J. The influence of mixing time and colloidal silica on the lubricating properties of magnesium stearate. International Journal of Pharmaceutics, 3: 127-131 (1979).

17. Khan, K. A., Musikabhumma, P. and Rubinstein, M. H. The effect of mixing time of magnesium stearate on the tabletting properties of dried microcrystalline cellulose. Pharmaceutica Acta Helvetiae, 58: 109-111 (1983). 
18. Johnson, M. C. R. The effect of particle size upon mixture homogeneity. Pharmaceutica Acta Helvetiae, 50 (3): 60-63 (1975).

19. Williams, J. C. and Khan, M. I. The mixing and segregation of particulate solids of different particle size. The Chemical Engineer, January, 19-25 (1973).

20. Otsuka, A., Iida, K., Danjo, K. and Sunada, H. Measurement of adhesive force between particles. III. Effect of particle shape and surface asperity. Chemical Pharmaceutical Bulletin, 36: 741-749 (1988).

21. Wong, L. W. and Pilpel, N. The effect of shape of fine particles on the formulation of ordered mixtures. Journal of Pharmacy and Pharmacology, 40: 567-568 (1988).

22. Shotton, E. J. and Harb, N. The effect of humidity and temperature on the cohesion of powders. Journal of Pharmacy and Pharmacology, 18: 175-178 (1966).

23. Staniforth, J. N. and Rees, J. E. Electrostatic charge interactions in ordered powder mixes. Journal of Pharmacy and Pharmacology, 34: $69-76$ (1982).

24. Staniforth, J. N. and Rees, J. E. Powder mixing by triboelectrification. Powder Technology, 30: 255-256 (1981).

25. Staniforth, J. N. and Rees, J. E. Effect of vibration time, frequency and acceleration on drug content uniformity. Journal of Pharmacy and Pharmacology, 34: 700-706 (1981).

26. Staniforth, J. N. The effect of frictional charges on flow properties of direct compression tableting excipients. International Journal of Pharmaceutics, 11: 109-117 (1982).

27. Gold, G. and Palermo, B. T. Hopper flow characteristics of tabletting material II. Tablet lubricants. Journal of Pharmaceutical Sciences, 54 (10): 1517-1519 (1965). 
28. Carter, P. A., Rowley, G., Fletcher, E. J. and Stylianopoulos, V. Measurement of electrostatic charge decay in pharmaceutical powders and polymer materials used in dry powder inhaler devices. Drug Development and Industrial Pharmacy, 24 (11): 1083-1088 (1998).

29. Carter, P. A., Rowley, G., Fletcher, E. J. and Hill, E. A. An experimental investigation of triboelectrification in cohesive and non-cohesive pharmaceutical powders. Drug Development and Industrial Pharmacy, 18 (14): 1505-1526 (1992).

30. Lopez, J. M. and Peleg, M. Linearization of electrostatic charge and charge decay curves of powders. Ibid., 42: 217-223 (1985).

31. Hersey, J. A., Cook, P., Smyth, M., Bishop, E. A. and Clarke, E. A. Homogeneity of multicomponent powder mixtures. Journal of Pharmaceutical Sciences, 63(3): 408-411 (1974).

32. Fuller, W. O. Mixing up a batch: Batch mixer types and selection tips. Powder and Bulk Engineering, January, 48-66 (1998). 


\section{BIBLIOGRAPHY}

Abouzied, A. Z. M. and Fuerstenau, D. W. Effect of mixing aids on the transport behavior of particulate solids. Powder Technology, 23: 261-271 (1979).

Amidon, G. E and Houghton, M. E. The effect of moisture on the mechanical and powder flow properties of microcrystalline cellulose. Pharmaceutical Research, 12: 923-929 (1995).

Amidon, G. E. and Houghton, M. E. Powder flow testing in preformulation and formulation development. Pharmaceutical Manufacturing, July, 21-31 (1985).

Amidon, G. E. Physical and mechanical property characterization of powders. In Brittain, H.G. (Ed.), Physical Characterization of Pharmaceutical Solids, Marcel Dekker, Inc., New York. $281-319$ (1995).

Andres, C., Ndiaye, A., Thomas, C., Tromelin, A., Chaillot, B. and Pourcelot, Y. Influence of the parameters molecular structure and granularity on the compactibility of a powder. Drug Development and Industrial Pharmacy, 21(16): 1875-1885 (1995).

Armstrong, N. A. and Palfrey, L. P. The effect of machine speed on the consolidation of four directly compressible tablet diluents. Journal of Pharmacy and Pharmacology, 41: 149 - 151 (1989).

Armstrong, N. A. Considerations of compression speed in tablet manufacture. Pharmaceutical Technology, 14 (9): 106-116 (1990).

Asano, T., Tsubuku, S., Sugawara, S., Miyajima, M., Sato, H., Yuasa, H. and Kanaya, Y. Changes in volume and compression energy upon compression of calcium silicate tablets. Drug Development and Industrial Pharmacy, 23 (7): 679685 (1997). 
Bailey, A. G. Charging of solids and powders. Journal of Electrostatics, 30: 167180 (1993).

Bailey, A. G. Electrostatic phenomena during powder handling. Powder Technology, 37: 71-85 (1984).

Bodmeier, R. Tableting of coated pellets. European Journal of Pharmaceutics and Biopharmaceutics, 43: 1-8 (1997).

Bolhuis, G. K. and Chowan, Z. T. Materials for direct compaction, In Pharmaceutical Powder Compaction Technology, Alderborn,G. and Nystrom C. (Eds.), Marcel Dekker, Inc., New York, 419-500 (1996).

Bolhuis, G. K.; Zuurman, K. Tableting properties of experimental and commercially available lactose granulations for direct compression. Drug Development and Industrial Pharmary, 21 (18): 2057-2071 (1995).

Buckton, G. The estimation and application of surface energy data for powdered systems. Drug Development and Industriai Pharmacy, 18: 1149-1167 (1992).

Buslik, D. A proposed universal homogeneity and mixing index. Powder Technology, 7: 111-116 (1973).

Carr, R. L. Classifying flow properties of solids. Chemical Engineering, 72: 69 (1965).

Carr, R. L. Evaluating flow properties of solids. Chemical Engineering, 72: 163168 (1965).

Carr, R. L. Particle behavior storage and flow. British Journal of Chemical Engineering, 15: 1541 (1970).

Carson J. W. and Marinelli, J. Characterize bulk solids to ensure smooth flow. Chemical Engineering, April, 78-90 (1994). 
Carter, P. A., Rowley, G., Fletcher, E. J. and Hill, E. A. An experimental investigation of triboelectrification in cohesive and non-cohesive pharmaceutical powders. Drug Development and Industrial Pharmacy, 18 (14): 1505-1526 (1992).

Carter, P. A., Rowley, G., Fletcher, E. J. and Stylianopoulos, V. Measurement of electrostatic charge decay in pharmaceutical powders and polymer materials used in dry powder inhaler devices. Drug Development and Industrial Pharmacy, 24 (11): 1083-1088 (1998).

Celik, M. and Okutgen, E. Feasibility study for the development of a prospective compaction functionality test and the establishment of a compaction data bank. Drug Development and Industrial Pharmacy, 19 (17-18): 2309-2334 (1993).

Celik, M. The past, present and future of tableting technology. Drug Development and Industrial Pharmacy, 22 (1): 1-10 (1996).

Chowhan, Z. T. and Chi, L. Drug-excipient interactions resulting from powder mixing III: Solid state properties and their effect on drug dissolution. Journal of Pharmaceutical Sciences, 75(6): 534-541 (1986).

Chowhan, Z. T. Segregation of particulate solids-Part I. Pharmaceutical Technology, 19: 56-70 (1995).

Chowhan, Z. T. Segregation of particulate solids-Part II Pharmaceutical Technology, 19: 80-94 (1995).

Cooke, M. H., Stephens, D. J. and Bridgwater, J. Powder mixing- A literature survey. Powder Technology, 15: 1-20 (1976).

David, S. T. and Augusburger, L. L. Plastic flow during compression of directly compressible fillers and its effects on tablet strength. Journal of Pharmaceutical Sciences, 66:155-159 (1977). 
de Villiers, M. M. Description of the kinetics of the deagglomeration of drug particle agglomerates during powder mixing. International Journal of Pharmaceutics, 151:1-6 (1997).

Dechene, R. L. and Averdieck, W. J. Triboelectricity: A parameter for solids flow measurement. Powder and Bulk Engineering, 11-13, June 1987.

Delacourte, A., Guyot, J. C., Colombo, P. and Catellani, P. L. Effectiveness of lubricants and lubrication mechanism in tablet technology. Drug Development and Industrial Pharmacy, 21 (19): 2187-2199 (1995).

Design-Expert ${ }^{\circledR}$, Version 6.0, Stat-Ease, Inc., MN, USA.

Doldan, C., Souto, C., Concheiro, A., Martinez-Pacheco, R. and Gomez-Amoza, J. L. Dicalcium phosphate dihydrate and anhydrous dicalcium phosphate for direct compression: A comparative study. International Journal of Pharmaceutics, 124: 69-74(1995).

Duberg, M. and Nystrom, C. Studies on direct compression of tablets. VI. Evaluation of methods for the estimation of particle fragmentation during compaction. Acta Pharmaceutica Suec, 19 (6): 421-436 (1982).

Ferrari, F., Bertoni, M., Bonferoni, M. C., Rossi, S., Caramella, C. and Nystrom, C. Investigation on bonding and disintegration properties of pharmaceutical materials. International Journal of Pharmaceutics 136: 71 - 79 (1996).

Fuller, W. O. Mixing up a batch: Batch mixer types and selection tips. Powder and Bulk Engineering, January, 48-66 (1998).

Gajewski, J. Charge measurement of dust particles in motion. Part II. Journal of Electrostatics, 15: 67-69 (1984).

Garcia, T., Elsheimer, B., Tarczynski, F. Examination of components of variance for a production scale, low dose powder blend and resulting tablets. Drug Development and Industrial Pharmacy, 21 (18): 2035-2045 (1995). 
Gold, G. and Palermo, B. T. Hopper flow characteristics of tabletting material II. Tablet lubricants. Journal of Pharmaceutical Sciences, 54 (10): 1517-1519 (1965).

Gorman, J. W. and Hinman, J. E. Simplex lattice designs for multicomponent systems. Technometrics, 4: 463-487 (1962).

Hartley, P. A., Parfitt, G. D., and Pollack, L. B. The role of the Van der Waals force in the agglomeration of powders containing submicron particles. Powder Technology, 42: 35-46 (1985).

Heckel, R. W. Density-pressure relationships in powder compaction. Trans Metallurgy Society, AIME, 221:671-675 (1961).

Hersey, J. A., Cook, P., Smyth, M., Bishop, E. A. and Clarke, E. A. Homogeneity of multicomponent powder mixtures. Journal of Pharmaceutical Sciences, 63(3): 408-411 (1974).

Hersey, J. A., Rees, J. E. and Cole, E. T. Density changes in lactose tablets. Journal of Pharmaceutical Sciences, 62: 2060 (1973).

Hiestand, E. N. Powders: Particle-particle interactions. Journal of Pharmaceutical Sciences, 55(12): 1325-1344 (1966).

Hsu, S. H.; Tsai, T. R.; Chuo, W. H. and Cham, T. M. Evaluation of Era-tab as a direct compression excipient. Drug Development and Industrial Pharmacy, 23 (7): $711-716$ (1997).

Jashnani, R. N., Byron, P. R. and Dalby, R. N. Tetsing of dry powder aerosol formulations in different environmental conditions. International Journal of Pharmaceutics, 113: 125-130 (1995).

Jetzer, W., Leuenberger, and Sucker, H. Compressibility and compactability of powder mixtures. Pharmaceutical Technology 7(11): 33-48 (1983). 
Johanson, J. R. Predicting segregation of bimodal particle mixtures using the flow properties of bulk solids. Pharmaceutical Technology, 20: 46-57 (1996).

Johansson, M. E. Investigations of mixing time dependence of the lubricating properties of granular and powdered magnesium stearate. Acta Pharmaceutica Suec 22: 343-350 (1985).

Johnson, M. C. R. The effect of particle size upon mixture homogeneity. Pharmaceutica Acta Helvetiae, 50 (3): 60-63 (1975).

Juppo, A. M., Kervinen, L., Yliruusi, J. and Eristofferson, E. Compression of lactose, glucose, and mannitol granules. Journal of Pharmacy and Pharmacology, 47: 543-549 (1995).

Karehill, P.G., Glazer, M. and Nystrom C. Studies on direct compression of tablets. XXXIII. The importance of surface roughness for the compactibility of some directly compressible materials with different bonding and volume reduction properties. International Journal of Fharmaceutics, 64: 35-43 (1990).

Katikaneni, P. R., Upadrashta, S. M., Rowlings, C. E., Neau, S. H. and Hileman G. A. Consolidation of ethylcellulose: effect of particle size, press speed, and lubricants. International Journal of Pharmaceutics, 117: 13-21 (1995).

Kawakita, K. and Ludde, K. H. Some considerations on powder compression equations. Powder Technology, 4 (2): 61-68 (1971).

Khan, K. A., Musikabhumma, P. and Rubinstein, M. H. The effect of mixing time of magnesium stearate on the tabletting properties of dried microcrystalline cellulose. Pharmaceutica Acta Helvetiae, 58: 109-111 (1983).

Kittaka, Masui and Murata. A method for measuring the charging tendency of powders in pneumatic conveyance through metal pipes. Journal of Electrostatics, 6 (1979). 
Konkel, P. and Mielck, J. B. A compaction study of directly compressible vitamin preparations for the development of a chewable tablet: Part I" Pharmaceutical Technology. 16 (3): 138-146 (1992).

Kulvanich, P. and Stewart, P. J. An evaluation of the air stream Faraday cage in the electrostatic charge measurement of interactive drug systems. International Journal of Pharmaceutics, 36: 243-252 (1987).

Kulvanich, P. and Stewart, P. J. Influence of relative humidity on adhesive properties of a model interactive system. Journal of Pharmacy and Pharmacology, 40: $453-458$ (1988).

Kumar, V., Sunder, N. and Potdar, A. Critical factors in developing pharmaceutical formulations - An overview, Part I. Pharmaceutical Technology, 16: 94-102 (1992).

Kumar, V., Sunder, N. and Potdar, A. Critical factors in developing pharmaceutical formulations - An overview, Part II. Pharmaceutical Technology, 16: 86-92 (1992).

Lachman. L. and Lin. S. N., Electrostatic characteristics of pharmaceutical solids and packaging materials I: Design of testing equipment and preliminary findings. Journal of Pharmaceutical Sciences, 57 (3): 504-510 (1968).

Lopez, J. M. and Peleg, M. Linearization of electrostatic charge and charge decay curves of powders. Ibid., 42: 217-223 (1985).

Luangtana-Anan, M. and Fell, J. T. Bonding mechanisms in tableting. International Journal of Pharmaceutics, 60: 197-202 (1990).

Nokhodchi, A., Rubinstein, M. H., Larhrib, H. and Guyot, J. C. The effect of moisture content on the energies involved in the compaction of ibuprofen International Journal of Pharmaceutics, 120: 13-20 (1995). 
Otsuka, A., Iida, K., Danjo, K. and Sunada, H. Measurement of adhesive force between particles. IIl. Effect of particle shape and surface asperity. Chemical Pharmaceutical Bulletin, 36: $741-749$ (1988).

Paronen, P. and Ilkka, J. Pressure-porosity functions. In Pharmaceutical Powder Compaction Technology, Alderborn,G. and Nystrom C. (Eds.), Marcel Dekker, Inc., New York, 55-75 (1996).

Peart, J., Staniforth, J. N. and Meakin, B. J. Electrostatic charge interactions in pharmaceutical dry powder aerosols. Instrumental Physics Conference Series, No. 143: $271-274$ (1995).

Pilpel, N.; Igwilo, C. I. and Malamataris, S. Effects of molecular coatings on the compression and tableting of some pharmaceutical powders. International Journal of Pharmaceutics, 68: 157-166 (1991).

Pilpel, S. and Esezobo, S. Effects of applied load and particle size on the plastoelasticity and tablet strength of some directly compressible powders. Journal of Pharmacy and Pharmacology, 39: 303 - 304 (1987).

Ragnarsson, G., Holzer, A. W., and Sjogren, J. The influence of mixing time and colloidal silica on the lubricating properties of magnesium stearate. International Journal of Pharmaceutics, 3: 127-131 (1979).

Ragnarsson, G., Holzer, A. W., and Sjogren, J. The influence of mixing time and colloidal silica on the lubricating properties of magnesium stearate. International Journal of Pharmaceutics, 3: 127-131 (1979).

Rizk, S., Guyot, J.C., Duru, C. and Gaudy, D. Influence of lubricant properties on compression behavior and drug dissolution rate of scleroglucan hydrophilic matrix. International Journal of Pharmaceutics, 126: 57-63(1995).

Rue, J. and Rees, J. E. Limitations of the Heckel relation for predicting powder compaction mechanisms. Journal of Pharmacy and Pharmacology, 30: 642-643 (1978). 
Scheffe, H. Experiments with mixtures. Journal of Royal Statistical Society, B20: 344-360 (1958).

Scheffe, H. The simplex-centroid design for experiments with mixtures. Journal of Royal Statistical Society, B25: 235-263 (1963).

Schmidt, P. C. and Vogel, P. J. Force-time curves of a modern rotary tablet machine: II. Influence of compression force and tableting speed on the deformation mechanisms of pharmaceutical substances. Drug Development and Industrial Pharmacy, 19 (15): $1917-1930$ (1993).

Schmidt, P. C. and Vogel, P. J. Force-time curves of a modern rotary tablet machine: I. Evaluation techniques and characterization of deformation behavior of pharmaceutical substances. Drug Development and Industrial Pharmacy, 20 (5): 921-934 (1994).

Schmidt, P. C. Tableting characteristics of sorbitol. Pharmaceutical Technology, 7 (11):65-72 (1983).

Schwartz, J. B. and O'Connor, R. E. Optimization techniques in pharmaceutical formulation and processing. In Banker, G.S. and Rhodes, C.T. (Eds.), Modern Pharmaceutics, $3^{\text {rd }}$ Edition, Marcel Dekker, Inc., New York, 727-772 (1996).

Secker, E. and Chubb, J. N. Instrumentation for electrostatic measurements Journal of Electrostatics, 16: 1-19 (1984).

Shangraw, R. F. and Demarest, D. A. Survey of current industrial practices in the formulation and manufacture of tablets and capsules. Pharmaceutical Technology, 17 (1): 32-44 (1993).

Sheskey, P. J. and Dasbach, T. P. Evaluation of various polymers as dry binders in the preparation of an immediate release tablet formulation by roller compaction. Pharmaceutical Technology, 19: 98-112 (1995). 
Shotton, E. J. and Harb, N. The effect of humidity and temperature on the cohesion of powders. Journal of Pharmacy and Pharmacology, 18: 175-178 (1966).

Sindel, U., Schweiger, A. and Zimmermann, I. Determination of the optimum mixing time for a mixture of lactose and colloidal silicon dioxide. Journal of Pharmaceutical Sciences, 87 (4): 524-526 (1998).

Spendley, W., Hext, G. R. and Hinsworth, F. R. Sequential application of simplex designs in optimization and evolutionary operation. Technometrics, 4: 441-461 (1962).

Stamm, A. Process and dosage form controls: Formulation factors. Drug Development and Industrial Pharmacy, 15: $965-974$ (1989).

Staniforth, J. N. and Rees, J. E. Effect of vibration time, frequency and acceleration on drug content uniformity. Journal of Pharmacy and Pharmacology, 34: 700-706 (1981).

Staniforth, J. N. and Rees, J. E. Electrostatic charge interactions in ordered powder mixes. Journal of Pharmacy and Pharmacology, 34: 69-76 (1982).

Staniforth, J. N. and Rees, J. E. Powder mixing by triboelectrification. Powder Technology, 30: 255-256 (1981).

Staniforth, J. N. The effect of frictional charges on flow properties of direct compression tableting excipients. International Journal of Pharmaceutics, 11: 109-117 (1982).

Staniforth, P. T. and Berry, R. E. R. A general flowability index for powders, Powder Technology, 8: 243 (1973).

Statgraphics ${ }^{\circledR}$ Plus for Windows, Version 2.0, Manugistics, Inc., Rockville, Maryland, USA. 
Stetsko, G. Statistical experimental design and its application to pharmaceutical development problems. Drug Development and Industrial Pharmacy, 12: 11091123 (1986).

Torrado, J. J. and Augsburger, L. L. Effect of different excipients on the tableting of coated particles. International Journal of Pharmaceutics, 106: 149-155 (1994).

Udeala, O. K., Chukwu, A."Compaction behavior of Musol: A new direct compression vehicle. Drug Development and Industrial Pharmacy, 15 (4): 533548 (1989).

Vachon, M. G. and Chulia, D. The use of particle characteristics to elucidate mix homogeneity in binary powder blends. Drug Development and Industrial Pharmacy, 24(10): 961-971 (1998).

Velasco, M. V., Munoz-Ruiz, A., Monedero, M. C. and Jimenez-Castellanos, M. R. Study of flowability of powders. Effect of the addition of lubricants. Drug Development and Industrial Pharmacy. 21(20): 2385-2391 (1995).

Velasco, V., Munoz-Ruiz, A., Mondero, C. and Jimenez-Castellanos, R. Forcedisplacement parameters of maltodextrins after the addition of lubricants International Journal of Pharmaceutics, 152: 111-120 (1997).

Waters, A. J. Solving flow problems: How to select a bin retrofit. Powder and Bulk Engineering, November, 45-55 (1997).

Wikberg, M. and Alderborn, G. Compression characteristics of granulated materials. III. The relationship between air permeability and mechanical strength of tablets of some lactose granulations. International Journal of Pharmaceutics, 63: 23-27 (1990).

Williams, J. C. and Khan, M. I. The mixing and segregation of particulate solids of different particle size. The Chemical Engineer, January, 19-25 (1973). 
Wong, L. W. and Pilpel, N. The effect of shape of fine particles on the formulation of ordered mixtures. Journal of Pharmacy and Pharmacology, 40: 567-568 (1988).

York, P. A consideration of experimental variables in the analysis of powder compaction behaviour. Journal of Pharmacy and Pharmacology, 31(4): 244-246 (1979).

York, P. and Pilpel, N. The tensile strength and compression behavior of lactose, four fatty acids, and their mixtures in relation to tableting. Journal of Pharmacy and Pharmacology, 25 (Supplement):1 P-11P (1973).

Zuurman, G. K. Bolhuis and H. Vromans. Effect of binder on the relationship between bulk density and compactibility of lactose granulations. International Journal of Pharmaceutics, 119: 65-69 (1995).

Zuurman, K., Riepma. K. A., Bolhuis, G.K., Vromans, H. and Lerk, C.F. The relationship between bulk density and compactibility of lactose granulations. International Journal of Pharmaceutics, 102: 1-9 (1994). 